\title{
EVOLUCIÓN BAJO DOMESTICACIÓN Y CAMBIOS EN CARACTERES FUNCIONALES Y ESTRUCTURALES DE FRUTOS Y SEMILLAS DE CUCURBITA MAXIMA SUBSP. MAXIMA
}

Lic. Analía Beatriz Luján Martínez

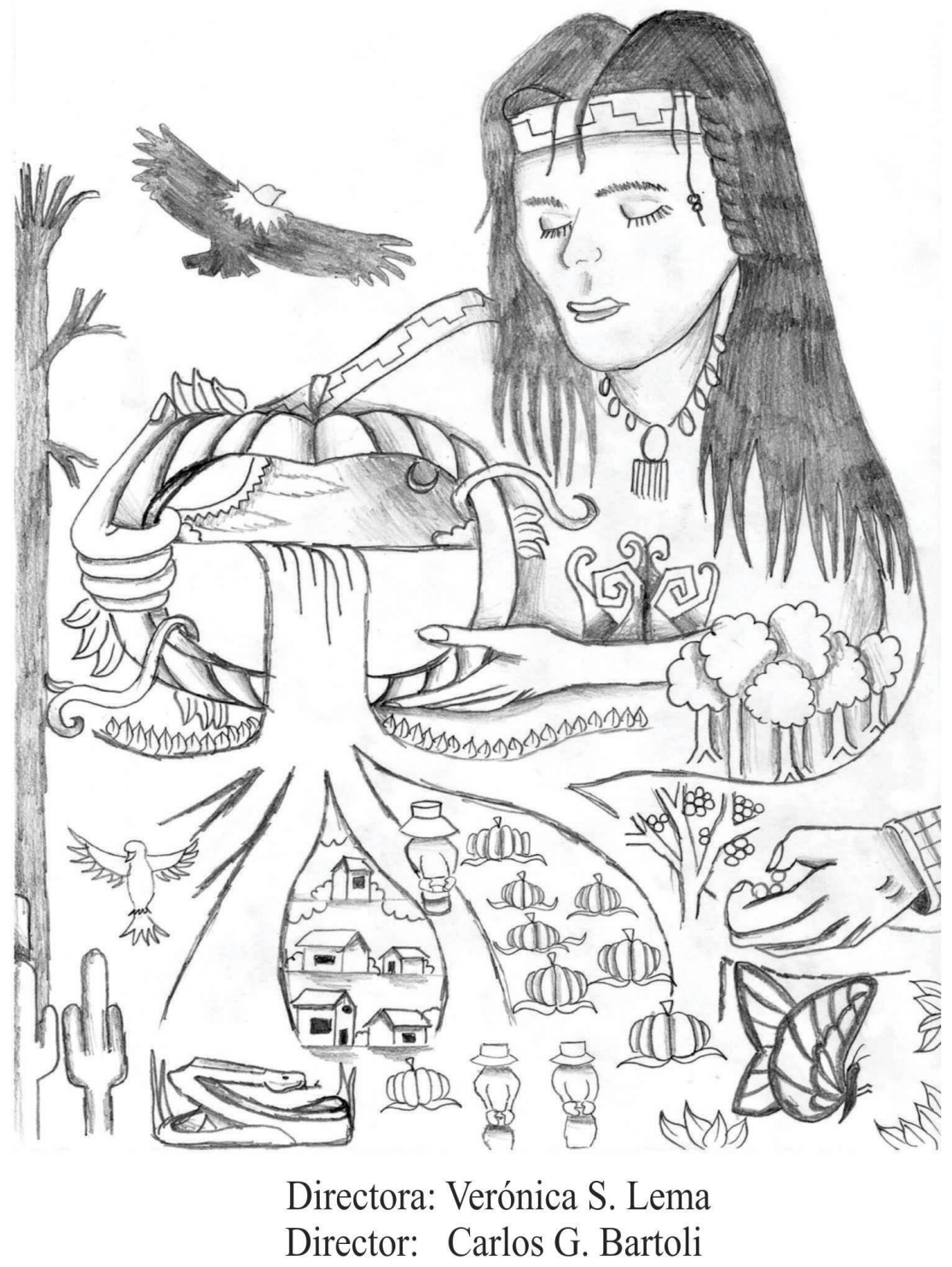

Tesis para optar el grado académico de Doctora en Ciencias Naturales

(FCNyM UNLP) 2016 


\section{EVOLUCIÓN BAJO DOMESTICACIÓN Y CAMBIOS EN CARACTERES FUNCIONALES Y ESTRUCTURALES DE FRUTOS Y SEMILLAS DE CUCURBITA MAXIMA SUBSP. MAXIMA}

Lic. Analía Beatriz Luján Martínez

Directora: Verónica S. Lema

Director: Carlos G. Bartoli

Tesis para optar el grado académico de

Doctora en Ciencias Naturales

(FCNyM UNLP) 
2016

\author{
A Clara y Maxi, porque \\ son el sostén de mis días. \\ A mis padres, $y$ al resto \\ de mi familia
}




\section{AGRADECIMIENTOS}

En primer lugar les quiero agradecer a mis directores: a Verónica Lema (Vero) y a Carlos Bartoli (Tolo) por las charlas en las que compartieron conmigo sus conocimientos, por su compromiso, por la enseñanza diaria y por haber confiado en mí para llevar adelante esta tesis.

Al Ing. Agr. Fernando López Anido quien colaboró desde el primer momento con la realización de los cruces experimentales y la generación del material vegetal.

Al Dr. Roberto Benech-Arnold y al personal del IFEVA por las mediciones de ABA.

Al Lic. Diego Gobbo por su asesoramiento informático.

Al Dr. Iván Perez por su ayuda desde la parte estadística.

A mis compañeros del INFIVE (becarios, técnicos y cuerpo docente) con los que siempre he podido contar para resolver mis dudas.

A mis compañeros del laboratorio 129 anexo del Museo de Ciencias Naturales de la UNLP por todos estos años de compañía y trabajo juntos!

Al laboratorio de Etnobotánica y Botánica Aplicada (LEBA) de la UNLP por haberme facilitado instrumental de laboratorio cada vez que lo necesité.

A mis amigas: Ma. Inés Troncozo, Laura Ciampagna, Leticia Ruso y Natalia Petrucci, porque cada una de ellas aportó en un poquito para el desarrollo de esta tesis.

A mi familia y amigos quienes siempre se preocuparon y se alegraron con cada logro.

A la Universidad Nacional de la Plata por la financiación de la Beca de Doctorado.

Y sobre todo a la Dra. Aylén Capparelli por permitirme ser parte de su equipo de trabajo, por su ayuda y preocupación no sólo en lo profesional sino también en lo humano. 


\section{Índice General}

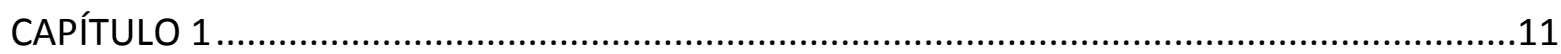

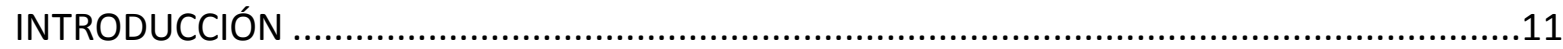

FUNDAMENTACIÓN, OBJETIVOS ESPECÍFICOS E HIPÓTESIS DE INVESTIGACIÓN ...............11

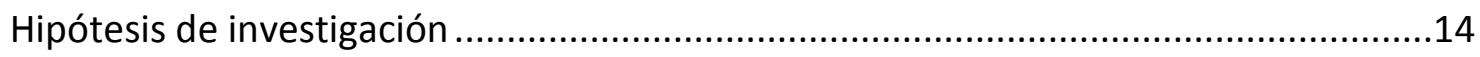

Metodología general utilizada.................................................................................14

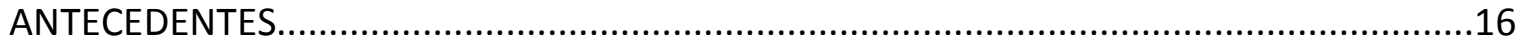

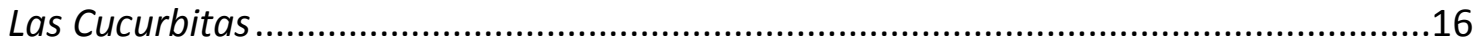

Categorías y conceptos empleados en esta tesis ..........................................................18

Aproximaciones al estudio de la domesticación vegetal .............................................19

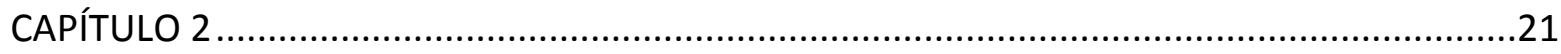

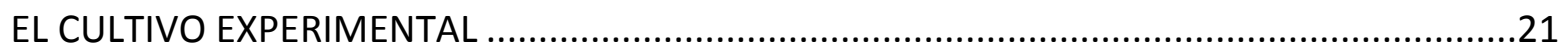

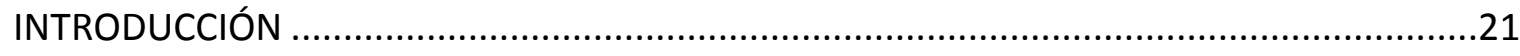

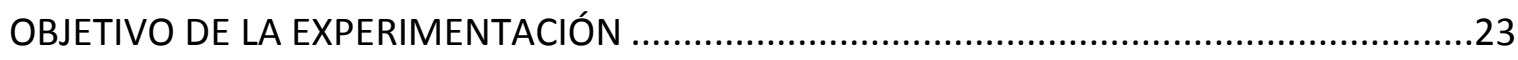

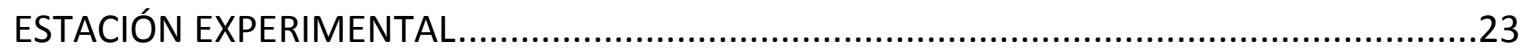

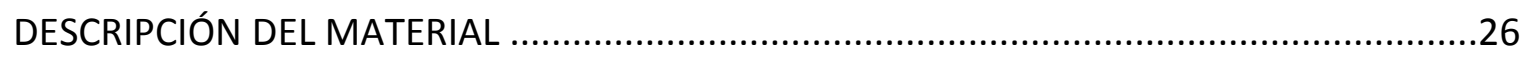

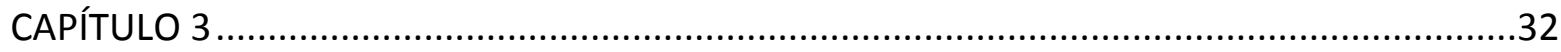

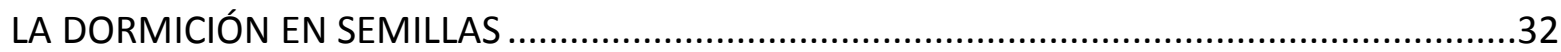

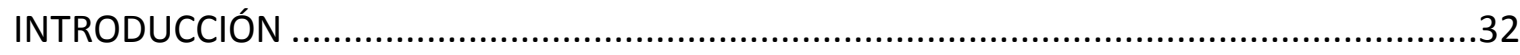

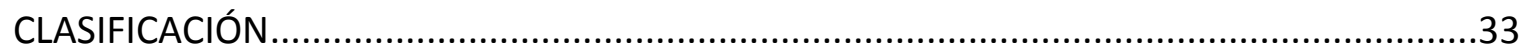

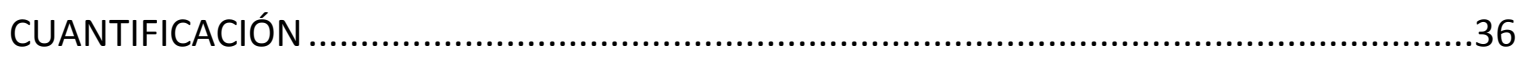

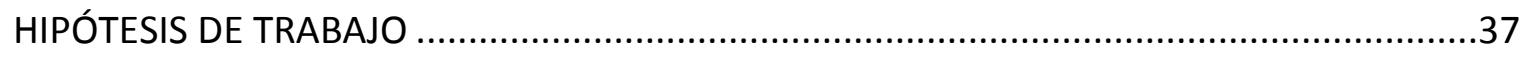

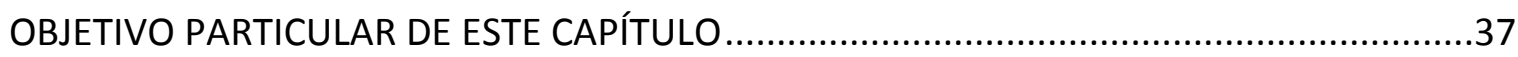

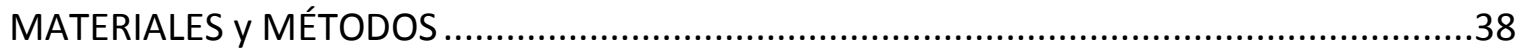

1) Metodología específica para la determinación de las condiciones ambientales ......39

2) Metodología específica para la determinación de factores internos: ........................40

RESULTADOS:

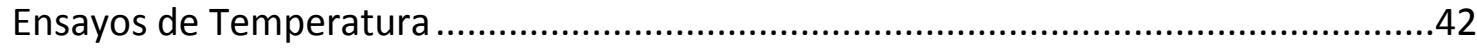

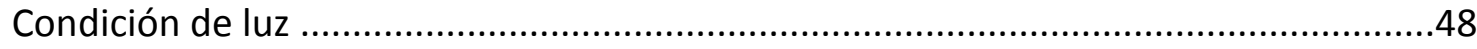

Escarificación mecánica..........................................................................................48

Difusión de agua ...................................................................................................5

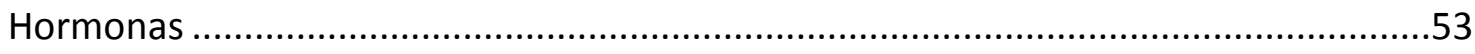

DISCUSIÓN Y CONCLUSIONES GENERALES DEL CAPÍTULO_...........................................5 


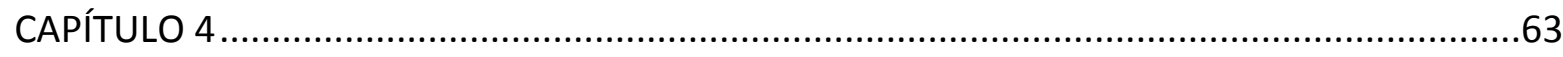

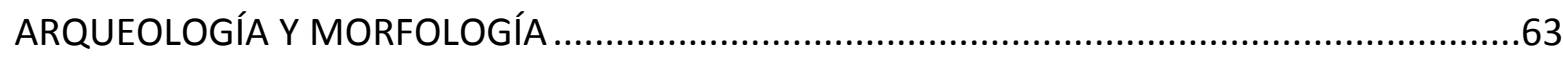

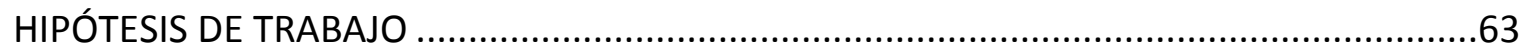

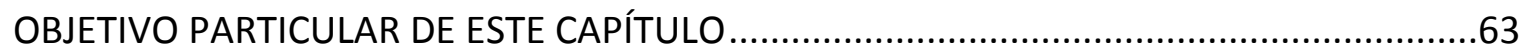

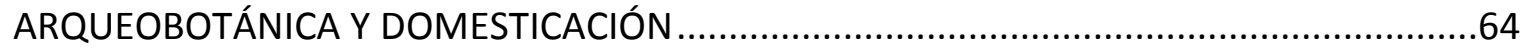

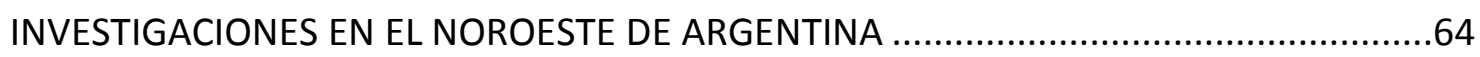

ARQUEOBOTÁNICA Y DOMESTICACIÓN DE CUCURBITAS .........................................65

RESTOS ARQUEOBOTÁNICOS Y SITIOS ANALIZADOS EN ESTA TESIS .........................67

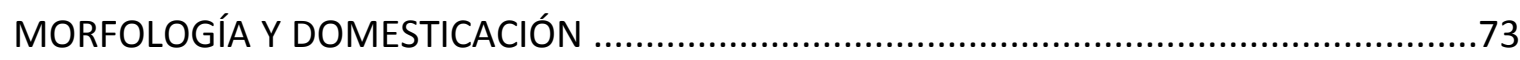

1. MORFOLOGÍA Y BIOMETRÍA DE SEMILLAS, PEDÚNCULOS Y PERICARPIOS ..........76

2. ANATOMÍA Y BIOMETRÍA DE CUBIERTAS SEMINALES .....................................95

DISCUSIÓN Y CONCLUSIONES GENERALES DEL CAPÍTULO............................................ 108

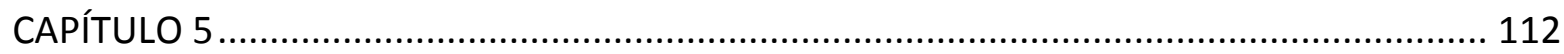

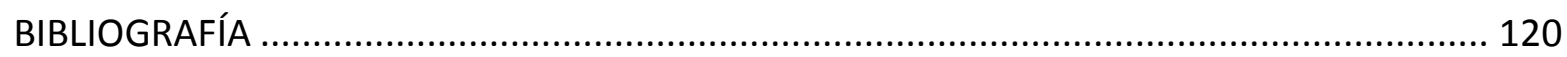

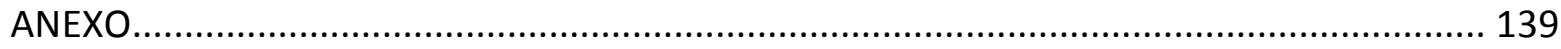




\section{RESUMEN}

El objetivo general de esta tesis consistió en determinar las modificaciones fisiológicas, morfológicas y anatómicas que tuvieron lugar en semillas y frutos de Cucurbita maxima Duch. ex Lam. subsp. andreana (Naudin) Filov. a lo largo del proceso de domesticación que dio origen a Cucurbita maxima subsp. maxima Duch. ex Lam y sus diversos cultivares, atendiendo principalmente a cambios en la dormición ligados a procesos naturales y culturales (entiéndase, bioculturales) de selección a lo largo de la historia prehispánica del Área Andina Centro-Meridional. Esto se llevó a cabo mediante un abordaje interdisciplinario que incluyó cultivos y cruces experimentales a campo, ensayos fisiológicos y estudios biométricos (morfológicos y anatómicos) en ejemplares actuales de referencia y arqueobotánicos de diversos sitios ubicados en el actual territorio peruano y del noroeste de Argentina, correspondientes a momentos posteriores a la domesticación de la subsp. maxima, desde Arcaicos a Tardíos.

Los resultados obtenidos muestran que a lo largo del proceso de domesticación se generaron cambios a nivel fisiológico y morfológico. Los fisiológicos fueron evidenciados por la reducción gradual de la dormición desde las formas silvestres hacia las formas domesticadas, condición que se encontró está regulada hormonalmente por la testa seminal a través de cambios en el contenido y sensibilidad al ácido abscísico (ABA).

Los estudios biométricos mostraron en general un aumento en el tamaño de las semillas desde las formas arcaicas a las más tardías (mediante análisis de la media geométrica), con un aporte menos preciso resultante del análisis de la forma y el coeficiente de variación. Asimismo se detectaron cambios en la forma y la presencia de ejemplares híbridos a todo lo largo de la secuencia con distinta representatividad.

A nivel anatómico el estudio de los distintos tejidos que componen la testa seminal de las semillas permitió aproximarnos a la variedad de situaciones pasadas. El análisis de la hipodermis y aerénquima fueron los más adecuados para correlacionar las semillas de distintas épocas con los grupos funcionales agrupados tras los ensayos fisiológicos. 
En el caso de la localidad arqueológica de Pampa Grande (Salta, Argentina), el estudio de los pedúnculos indicó la presencia de ejemplares híbridos y una tendencia al aumento del diámetro basal de los mismos entre este tipo de ejemplares y los domesticados. El análisis realizado sobre pericarpios no aportó mayor información respecto de la existente para este conjunto de restos.

Todas estas aproximaciones permitieron determinar la presencia de hibridaciones y flujo génico desde periodos tempranos hasta tardíos, lo cual habría sido un mecanismo que generaría micro trayectorias evolutivas a lo largo de la historia macro de domesticación de C. maxima subsp. maxima a lo largo del tiempo, en el Área Andina Meridional. 


\begin{abstract}
\end{abstract}
The aim of this thesis consisted in determining the physiological, morphological and anatomical modifications that occurred in seeds and fruits of Cucurbita maxima Duch. ex Lam. subsp. andreana (Naudin) Filov. throughout the process of domestication and gave rise to Cucurbita. maxima subsp. maxima Duch. ex Lam and its several cultivars. Special attention was drawn to changes in dormancy associated to natural and cultural processes (in the sense of biocultural relations) of selection throughout prehispanic history of Central Meridional Andean area. To fulfill the task, a multidisciplinary approach was carried out, which included crops and field experimental crosses, physiological trials and biometrical tests (morphological and anatomical) in reference and archaeobotanical samples from several sites located in the actual Peruvian territory as well as the northwest of Argentina. They belonged to a moment posterior to domestication of subsp. maxima, from archaic to late periods.

In order to emulate possible crossbreeding in the past, experimental crops and controlled crosses between the two subspecies and among their hybrids were made (F1, F2), thus representing a considerable variability of genotypes/phenotypes that underwent physiological (for seeds) and biometrical trials (for seeds and fruits).

The results obtained show that throughout the process of domestication, physiological and morphological changes were generated. The former were made clear in the gradual reduction of dormancy from wild to domesticated forms, a condition that proved to be hormonally regulated by the seed coat by means of changes in the content and sensibility to abscisic acid (ABA).

Biometrical studies led to the conclusion that there was an increase in the size of seeds from archaic to late periods (through the analysis of geometric measure) but a less precise contribution derived from the analysis of shape and variation coefficient. Likewise, some changes in shape and in the representativity of hybrid specimens throughout the archaeological sequence were detected.

The study at an anatomical level of different tissues that compose the seed coat allowed us to approach to the variety of past situations. The analysis of hypodermis and aerenchyma were 
the most suitable to correlate seeds from different periods to functional groups gathered after physiological trials.

As regards the archaeological site Pampa Grande (Salta, Argentina), the study of peduncles was an indicator of the presence of hybrid samples and a tendency to basal diameter rise among this type of samples and the domesticated ones. The analysis performed to pericarps did not provide further information to the existing data for this group of remains.

In sum, the approaches developed in this thesis allow us to determine the presence of hybridizations and gene flow since early periods to late ones, which could have been a mechanism generating evolutive micro trajectories throughout the macro history of domestication of C. maxima subsp. maxima in Andean Meridional area. 


\section{CAPÍTULO 1}

\section{INTRODUCCIÓN}

El objetivo general del presente trabajo de tesis doctoral consiste en determinar las modificaciones fisiológicas, morfológicas y anatómicas que tuvieron lugar en semillas y frutos de Cucurbita maxima Duch. ex Lam subsp. andreana (Naudin) Filov. a lo largo del proceso de domesticación que dio origen a Cucurbita maxima subsp. maxima Duch. ex Lam y sus diversos cultivares, atendiendo principalmente a cambios en la dormición ligados a procesos naturales y culturales (entiéndase, bioculturales) de selección a lo largo de la historia prehispánica del Área Andina Centro-Meridional. Para ello se recurrió en primer lugar a la realización de cruces experimentales entre las dos subespecies mencionadas. El material obtenido de estos cruces, así como sus parentales fue objeto de estudio del abordaje fisiológico, en el cual se tuvieron en cuenta variables relacionadas a la germinación y dormición (ver objetivo específico 1). Luego se realizó la caracterización de las modificaciones morfológicas y anatómicas de distintos órganos y tejidos de Cucurbita a través del análisis cualitativo y biométrico (ver objetivos específicos 2 y 3) de material tanto arqueológico como actual (material obtenido de los cruces experimentales, sus parentales y otros materiales de referencia). Por último, la integración de los resultados obtenidos en los capítulos previos (ver objetivo específico 4) se desarrolla en paralelo a la discusión de la presente tesis.

\section{FUNDAMENTACIÓN, OBJETIVOS ESPECÍFICOS E HIPÓTESIS DE INVESTIGACIÓN}

Esta tesis surge de los resultados obtenidos por la Dra. Lema en su trabajo de tesis doctoral sobre procesos de manejo y domesticación vegetal en ejemplares arqueológicos de $C$. 
maxima procedentes de sitios principalmente ubicados en el Noroeste de Argentina (NOA) y centro-sur de Perú (Lema, 2009a). Los análisis sobre macrorrestos desecados que dicha investigadora llevó a cabo se hicieron mediante el empleo de medidas lineales macroscópicas (largo y ancho para semillas, espesor de pericarpios y diámetro basal para pedúnculos) y estudios anatómicos cualitativos y cuantitativos en pericarpios y cubiertas seminales. Mediante esta aproximación, Lema identifica ejemplares de la subsp. maxima y de la subsp. andreana junto a otros que presentaban caracteres morfológicos, anatómicos y biométricos intermedios entre ambas subespecies. Dado que estos tres grupos se presentaban en contextos contemporáneos, la investigadora plantea la posibilidad de que las formas intermedias respondan a ejemplares híbridos sujetos a distintas prácticas de manejo en complejos silvestre-maleza-domesticados y no a ejemplares transicionales entre la forma silvestre y domesticada (Lema 2009a, 2015). Estos complejos de formas que también ocurren en poblaciones actuales de otras especies del género se caracterizan por presentar flujo génico, hibridación y/o introgresión (Nee, 1990, Wilson et al., 1994, Ellstrand et al., 1999, Montes Hernández y Eguiarte, 2002). Estos mecanismos están comenzando a ser considerados de manera más sistemática en varios casos de domesticación de taxa distintos, en diferentes lugares y épocas (Fuller, 2012, Aguirre-Dugua y González-Rodríguez, 2016, Allaby et al., 2016; Casas et al., 2016; Vibrans, 2016). Mediante estos mecanismos se da lugar a cambios en la morfología y la fisiología de los organismos que no sólo le sirven para adaptarse a condiciones ambientales diversas, sino que también otorgan resistencia a las enfermedades y/o favorecen el mejoramiento agronómico (Hernández Leal et al., 2013).

Estos mecanismos han favorecido la evolución de las especies y en este caso, tras la domesticación sirvieron como estrategias para generar nuevas variedades y/o cultivares. El flujo génico es un mecanismo de relevancia que genera micro procesos evolutivos con consecuencias a largo plazo, sea en la generación de nuevas formas (especies domesticadas, cultivares, malezas) o la extinción de otras como, por ejemplo, antecesores silvestres (Ellstrand et al., 1999, Wilson et al., 1994, Arriola, 2005), inclusive puede contrarrestar fuerzas tales como la selección o mutación (Montes Hernández y Eguiarte, 2002). El flujo génico post domesticación entre antecesores o parientes silvestres o malezoides y formas domesticadas se ha detectado por medios diversos en plantas tales como el maíz, considerándose a dicho mecanismo como responsable en gran parte de su diversidad actual (Matsuoka et al., 2002). Las 
hibridaciones e introgresiones entre especies intra o interespecíficas se dan en la naturaleza de manera espontánea, sin embargo a veces puede ser una estrategia de los pobladores locales que ante la heterogeneidad del ambiente, provoquen estas relaciones para la mejor adaptación de poblaciones bajo cultivo. Esto último es una estrategia de manejo que en el ámbito andino resulta crucial al caracterizarse las sociedades locales -prehispánicas y actuales- por el empleo de varios pisos ecológicos y microambientes dentro de los mismos (algo que también ha sido mencionado para el manejo de otros miembros del género en similar situación de diferencias altitudinales tales como en México, Lira Saade et al., 2016). Observaciones como las precedentes han llevado a considerar a la introgresión como un mecanismo que permitió la recuperación de diversidad tras la domesticación (Hufford et al., 2012).

Explorar la posibilidad de la presencia de formas híbridas de C. maxima en el registro arqueológico y ahondar en los procesos y mecanismos de domesticación pasados en este taxon llevó al planteo de esta tesis. En este sentido, se entendió que era necesario abordar el tema mediante una aproximación interdisciplinaria que considerara no sólo la evidencia arqueológica, sino también los aportes de la biología y la fisiología en el entendimiento de los cambios bajo domesticación. Fue así que un rasgo particular que no pudo ser cabalmente explicado por Lema en su tesis, esto es, los procesos que llevaron a cambios en la biometría y anatomía de las cubiertas seminales entre la subsp. andreana y maxima llevó a considerar que los mismos pudieran ser el resultado de cambios en la dormición, tal como ha sido planteado para otros taxa como parte del denominado "síndrome adaptativo de la domesticación" (Smith, 2006a). Teniendo en cuenta esto, junto a la hipótesis planteada por Lema de que se podría estar ante la presencia de formas híbridas y que era necesario ampliar las colecciones de referencia para el estudio de los ejemplares arqueológicos, se planteó la realización de cultivos experimentales a campo de ambas subespecies de $C$. maxima y la obtención de distintos cruces entre los mismos. Todo lo antes dicho llevó a considerar el objetivo general a través de una serie de objetivos específicos.

1. Determinar las condiciones ambientales para la germinación de semillas de C. maxima subsp. maxima, C. maxima subsp. andreana, poblaciones híbridas de ambas subespecies y retrocruzas, y a partir de ello caracterizar la dormición de las semillas (ver capítulo 3). 
2. Caracterizar la morfología y anatomía de la testa seminal, pericarpio, semillas y pedúnculos de frutos de poblaciones híbridos de ambas subespecies y retrocruzas, identificando caracteres diagnósticos de cada conjunto, evaluando su relación con el tipo de dormición caracterizado en el objetivo específico 1 (ver capítulo 4).

3. Utilizar los caracteres morfoanatómicos diagnósticos previamente obtenidos para reconocer poblaciones silvestres, domesticadas e híbridos en restos arqueobotánicos de sitios arqueológicos del actual territorio peruano centro meridional y del NOA, correspondientes a distintos momentos cronológicos (del Arcaico al Tardío) (ver capítulo 4).

4. Reconstruir el proceso de domesticación de C. maxima subsp. maxima junto a la generación de cultivares en el Área Andina Centro-Meridional, evaluando las presiones de selección naturales y culturales que llevaron a modificar caracteres fisiológicos, anatómicos y morfológicos, atendiendo en particular a los cambios en la dormición (ver capítulo 5).

A partir del objetivo general, fundamentos y objetivos específicos se desprendieron dos hipótesis de investigación.

\section{Hipótesis de investigación}

1) "La pérdida de la dormición de las semillas de Cucurbita maxima es consecuencia de modificaciones fisiológicas y/o micro-morfológicas ocurridas durante el proceso de domesticación" (responde al objetivo específico 1, abordada en capítulo 3).

2) "Es posible evaluar el tipo de dormición en el pasado a través del estudio de correlatos morfológicos de caracteres fisiológicos tanto en Cucurbita maxima subsp. maxima como en Cucurbita maxima subsp. andreana, sus híbridos respectivos y diversos cruzamientos" (responde a los objetivos específicos 2, 3 y 4 abordada en el capítulo 4 y 5).

\section{Metodología general utilizada}


A fin de dar respuesta a los objetivos específicos de investigación y contrastar las hipótesis previamente planteadas se implementaron metodologías diversas y acordes a los abordajes experimentales, fisiológicos, morfológicos y anatómicos propuestos para el estudio de material actual y arqueobotánico. Las mismas se explicitan detalladamente en sus capítulos correspondientes, no obstante se brinda aquí un resumen general de las actividades que se llevaron a cabo.

Dentro de la aproximación experimental de cultivos a campo (capítulo 2), se puso énfasis en la generación de plantas de crecimiento controlado, en la polinización artificial y en la realización de hibridaciones y recombinaciones con el fin de generar distintos tipos de híbridos y retrocruzas, así como también la reproducción de accesiones parentales, que sirvieran como material base para los estudios fisiológicos y morfo-anatómicos. Para el abordaje fisiológico (capítulo 3) se realizaron ensayos de laboratorio a fin de caracterizar las condiciones de germinación y dormición en semillas actuales (obtenidas de la experimentación a campo), controlando factores externos (temperatura, disponibilidad de agua y régimen lumínico) internos (morfología de la testa seminal) y reguladores de crecimiento.

Para el abordaje morfo-anatómico (capítulo 4) se realizaron: 1) mediciones del tamaño y la forma de semillas, 2) estudios biométricos macroscópicos en pedúnculos y pericarpios y 3) estudios biométricos anatómicos sobre cubiertas seminales. Estos tres análisis se realizaron sobre ejemplares obtenidos tras los cultivos experimentales y caracterizados fisiológicamente, a fin de comparar los resultados con iguales indicadores en ejemplares arqueológicos.

Los ejemplares arqueológicos analizados en esta tesis (capítulo 4) son macrorrestos desecados provenientes de sitios del NOA y del Área Andina Central y Meridional de Perú. En este apartado se nombra de manera sintetizada cada uno de los sitios, junto a su cronología, siendo presentados con mayor detalle en el capítulo 4.

El material arqueobotánico proviene de nueve sitios arqueológicos: los correspondientes al período Arcaico (ca. 3000-2000 años AP) son: Bandurria, Cerro Lampay y Pampa de los Perros, todos del centro-sur de Perú. Los correspondientes al período Formativo (ca. 20001200 AP) son: Los Viscos, situado en la provincia de Catamarca (NOA) y SSalLap 20 o Puente del Diablo y la localidad arqueológica de Pampa Grande, ambos en la provincia de 
Salta (NOA), mientras que los del período Tardío o de Desarrollos Regionales (ca. 1200800 AP) son los sitios Las Champas, Bebé de La Troya y Lorohuasi, todos ubicados en territorio catamarqueño.

\section{ANTECEDENTES}

\section{Las Cucurbitas}

Las cucurbitáceas son una familia que consta de unos 118 géneros y 825 especies (Jeffrey, 1990, Bisognin, 2002). Se trata de una familia tropical, sus miembros se han adaptado bien a climas templados con baja incidencia de heladas, aunque se han desarrollado cultivares con tolerancia a bajas temperaturas y con capacidad para crecer rápidamente en suelos fríos (Whitaker, 1974). Son plantas herbáceas, con zarcillos y tallos angulosos, sus hojas son alternas, pecioladas, de lámina simple o compuesta y base generalmente cordada. Las flores solitarias o en inflorescencias cimosas, diclinas, pentámeras, epíginas y actinomorfas poseen un androceo formado por 5 estambres libres o unidos por sus filamentos o por sus anteras, los granos de polen son grandes y de morfología variada. El gineceo es 2-5carpelar, de estilos libres o unidos y estigma entero, lobulado o dividido en ramas. El fruto característico es de tipo pepo y las semillas son grandes y aplanadas (Parodi, 1988, Pozner, 2012).

Dentro de esta familia los géneros Cucurbita (zapallos o calabazas), Cucumis (melones y pepinos) y Citrullus (sandías) tienen valor económico por su importancia alimenticia y ornamental. Se suelen utilizar las flores, tallos, hojas, frutos y semillas. Los frutos se suelen comer en estado maduros o inmaduros y las semillas son ricas en proteínas y aceites (Mapes y Basurto, 2016).

El género americano Cucurbita L. incluye, según Lira Saade y colaboradores (2009), entre 15 y 20 especies, las cuales tradicionalmente, por las características ecológicas de sus hábitats y por la duración de su ciclo de vida, tradicionalmente han sido divididas en dos grandes grupos: las especies xerofíticas, con raíces tuberiformes perennes de almacenamiento y las especies de hábitats más o menos mesofíticos, anuales o perennes de 
vida corta y cuyas raíces son fibrosas. Dentro de este último grupo se incluyen los taxa domesticados, que presentan extraordinaria variación morfológica, principalmente a nivel de los frutos y las semillas (Lira Saade et al., 2009).

El género posee especies propias del hemisferio norte como C. argyrosperma y C. pepo subsp. pepo y subsp. ovifera, estas dos últimas domesticadas en dicha región (Lira Saade et al., 2016). Dentro de las especies domesticadas en Sudamérica se reconocen a C. moschata (Duch. ex Lam.) Duch. ex Poir, la cual no tolera bajas temperaturas y C. maxima subsp. maxima la cual -si bien es sensible a las heladas- es la más tolerante a bajas temperaturas y la más austral del género (Lira Saade, 1995). A diferencia de las anteriores C. ficifolia Bouché posee una amplia distribución desde Norte de México a Sudamérica y su historia evolutiva y área de domesticación está aún bajo debate (Lira Saade et al., 2016).

Dentro de las formas espontáneas en Sudamérica se reconocen dos taxa C. maxima subsp. andreana, y C. ecuadorensis Cutler y Whitaker. La primera se trata de una hierba anual muy variable en tamaño con tallos rastreros, distribuida en el centro-este de Argentina y Uruguay, habitando terrenos modificados (Ashworth, 1997, Ashworth y Galetto, 1999, Nee, 1990). Es conocida con el nombre de "Yeruá" en Entre Ríos y Uruguay, "Cháncara" en San Luis y Córdoba y "Zapallo amargo" en Buenos Aires y Santa Fe (Ashworth y Galetto, 1999). Los frutos son variables, usualmente ovoides y de fuerte sabor amargo por la presencia de la cucurbitacina que los caracteriza (Millán, 1945, Martínez Crovetto, 1974, Ashworth y Galetto, 1999) (ver más detalles sobre estos aspectos en capítulo 4). En cuanto a sus relaciones evolutivas, gran cantidad de autores (Whitaker y Bemis, 1964, Nee, 1990, Decker-Walters y Walters, 2000, Sanjur et al., 2002) coinciden en que la subsp. andreana es el antecesor de la subsp. maxima, y que puede ser originaria del territorio argentino (Millán, 1945, Whitaker y Bemis, 1964, Nee, 1990), aunque la evidencia arqueológica no lo demuestre aún de manera irrefutable (Lema 2009a, 2014).

La segunda $C$. ecuadorensis Cutler y Whitaker, es una especie que se distribuye en el noroeste de Sudamérica y a diferencia de la subsp. andreana, no tiene sabor amargo. Según Nee (1990) es una forma semidomesticada, mientras que Piperno y Pearsall (1998) consideran que es una forma domesticada, asilvestrada posteriormente.

En lo que respecta a antecedentes sobre dormición de ambas subespecies de C. maxima, la misma es una propiedad que no ha sido estudiada ni reportada por los curadores de las listas 
de genes de las especies de Cucurbitas (http://cuke.hort.ncsu.edu/cgc/cgcgenes/genelists.html), ni se poseen reportes que den cuenta de aproximaciones que procuren su caracterización.

\section{Categorías y conceptos empleados en esta tesis}

La domesticación es entendida como un proceso continuo de evolución acelerada de poblaciones vegetales, mediada por la selección cultural (Ford, 1985, Harlan, 1992). La misma constituye uno de los mejores exponentes de cómo las prácticas humanas y los mecanismos naturales se articulan conformando unidades dialécticas bioculturales (Balée, 1998, Lema, 2009a; 2010).

Etimológicamente la palabra domesticar significa "traer al domus" (casa) e implica procesos que llevan al desarrollo de modificaciones que pueden producirse a nivel morfológico, fisiológico, genético y/o ecológico de las poblaciones vegetales con el fin de adaptarlas a ambientes disturbados por las poblaciones humanas (Harlan, 1992). Otros procesos de domesticación implican la escala de paisaje, con diversos grados de intervención en el mismo (Hallam, 1989, Clement et al., 2015) y no serán objeto de esta tesis. Siguiendo a De Wet y Harlan (1975), Harlan (1992) y Hillman y Davies (1990), entenderemos a las plantas silvestres como aquellas que prosperan por fuera de ambientes disturbados y que no pueden invadir de forma exitosa los mismos. Los mismos autores consideran a las plantas domesticadas como aquellas que prosperan en ambientes disturbados por acción antrópica y requieren de la acción humana para su dispersión, reproducción y mantenimiento a lo largo del tiempo. Entre ambos extremos se ubican las malezas que, prosperando en ambientes disturbados por presencia, o no, de actividades humanas, no requieren de los seres humanos para su reproducción exitosa (De Wet y Harlan, 1975). La coexistencia de estas tres categorías genera los denominados "complejo silvestre-maleza-domesticado" mencionados al inicio de este capítulo (Beebe et al., 1997, Zizumbo-Villarreal et al., 2005). Asimismo, y producto de los cruzamientos entre las tres categorías antes mencionadas, al igual que de procesos de asilvestramiento, cultivo sin domesticación, entre otros, existen formas con rasgos intermedios denominados y/o considerados de diversa manera (plantas semi-domesticadas, cultivadas no domesticadas, 
incluso malezas), dada la dificultad de ubicarlas en un compartimento estanco (Hillman y Davies, 1990, Beebe et al., 1997, Clement, 1999).

En lo que respecta a prácticas de manejo, se entiende que, además de la recolección y la siembra o cultivo sensu stricto (Lema, 2009a), existen otras prácticas de manejo. Respecto a estas últimas seguimos la propuesta de Casas (2001) que reconoce las siguientes: tolerancia, protección, erradicación y fomento o inducción, las cuales se pueden considerar como cultivo sensu lato (Lema, 2009a). Respecto a las categorías de asociaciones de plantas antes mencionadas cabe aclarar que la recolección puede darse en plantas silvestres y malezas y el cultivo (en sus dos acepciones) en plantas silvestres, malezas y domesticadas con distinto grado de intensidad (Harlan, 1992, Hillman y Davies, 1990, Casas, 2001, Lema, 2009a).

\section{Aproximaciones al estudio de la domesticación vegetal}

De acuerdo a los estudios realizados en los géneros Triticum y Hordeum de origen euroasiático, sus procesos de domesticación habrían comenzado en el 9500 AC aproximadamente (Fuller, 2012), en tanto en el continente americano el proceso cuenta con una antigüedad cercana a los 10.000 años AP (Lira Saade et al., 2016). En lo que respecta al registro particular del género Cucurbita, el mismo se abordará en detalle en el capítulo 4. Durante mucho tiempo la arqueología consideró a este tema como preámbulo de la agricultura y como indicador de la transición de cazadores-recolectores a agricultores (Guillen, 2010, Staller, 2006), sin embargo el mismo es un proceso que existe incluso actualmente (Harlan, 1992, Casas, 2001) y por lo tanto puede analizarse más allá de los límites de la transición antes mencionada, tal como haremos en esta tesis.

La reconstrucción desde el registro arqueológico de procesos vinculados a la domesticación

y manejo de poblaciones vegetales no suele ser una tarea sencilla y requiere atender a indicadores diversos. Los arqueobotánicos han ahondado en herramientas analíticas para abordar estos estudios, la reconstrucción de los cambios de la forma y del tamaño de diversos órganos vegetales (raíces, tallos, frutos, semillas, entre otros) e incluso de tejidos y contenidos subcelulares (almidones, cristales) es la principal línea de evidencia empleada 
para hablar de domesticación y manejo en el pasado (Pochettino y Scattolin, 1991, Babot, 2011, Aguirre, 2012, entre otros, ver referencias y antecedentes en capítulo 4). Un indicador fisiológico por excelencia es la dormición, presente en semillas de especies de tipo silvestres (sobre todo aquéllas adaptadas a climas de estacionalidad marcada) ya que permite una adecuada germinación y crecimiento de las plantas de acuerdo a las estaciones del año y condiciones climáticas particulares, pero que actualmente se considera indeseable en especies de utilización agronómica (ver capítulo 3). Es por ello que se asume que durante el proceso de domesticación de diversas especies vegetales se ha ejercido una fuerte presión de selección en contra de la dormición, provocando su reducción o eliminación (De Wet y Harlan, 1975, Hillman y Davies, 1990, Smith, 2006a, Jones, 2009). Trabajos previos indican que la reducción de la dormición está frecuentemente relacionada a cambios en el espesor de los tejidos de la cubierta seminal (Hilhorst, 2007, Smith, 2006b). Por lo tanto caracterizar la dormición de semillas y explorar los mecanismos implicados en su pérdida resulta de gran importancia para la comprensión de los cambios ocurridos durante la evolución bajo domesticación de un taxon, ya que -se asume- favoreció el desarrollo de poblaciones vegetales con germinación y maduración sincrónica, a diferencia de la variabilidad presentada por las poblaciones que le dieron origen (Hillman y Davis, 1990, Willcox, 1999).

El cultivo experimental y la replicación de los procesos biológicos han sido abordados en investigaciones arqueológicas y arqueobotánicas desarrolladas en Europa y Asia (Hillman y Davies, 1990, Anderson, 1999, Jones, 1992), pero poseen escasos antecedentes en Suramérica (Doebley, 2004), es por ello que esta tesis aporta un antecedente a este respecto el cual abordamos en el capítulo siguiente. 


\section{CAPÍTULO 2}

\section{EL CULTIVO EXPERIMENTAL}

En este capítulo se presentará el cultivo a campo, la manera en que se realizaron los cruces genéticos entre las dos subespecies y los conceptos necesarios a tener en cuenta para interpretar la información mencionada en los capítulos siguientes.

\section{INTRODUCCIÓN}

La observación y la selección que el Hombre realizó sobre las plantas se ha desarrollado desde los albores de la domesticación y el cultivo. Dentro de la historia de la ciencia occidental, el control artificial sobre la floración y la polinización, como aspecto de la manipulación y el mejoramiento de las plantas constituyó, junto a los cultivos y cruzamientos experimentales, las puertas de entrada para la construcción del conocimiento de la genética clásica (www.Agrobanco.com.pe.UNLM/AGROBANCO).

Este párrafo es un resumen de la información obtenida de la página antes citada, la cual es una recopilación de los trabajos que se mencionan a continuación, pudiéndose encontrar los mismos en dicha página. Incontables trabajos e investigadores han aportado para la construcción de este conocimiento, el primero de ellos fue Camerarius en 1694, quien determina la sexualidad de las flores, seguido por Kröelreuter en 1766, que describe el polen y el proceso de polinización. Posteriormente los influyentes e innovadores experimentos de Gregor Mendel en 1866 con sus cruces controlados en guisantes, redescubiertos en 1900 por De Vries, Correns y Tschermak y -sin alejarnos demasiado en el tiempo- las hibridaciones realizadas en maíz (Beal, 1880), en cebada (Harlan, 1937) e inclusive en Cucurbitas (Contardi, 1939). Este último autor fue quien comenzó a 
experimentar con distintos tipos de zapallos para conocer la transferencia del principio amargo característico de las formas silvestres.

Fue así que con el avance de la experimentación, la genética y la biología en general se contó con nuevas herramientas para comprender los procesos biológicos: Técnicas tales como el análisis de mutantes, el aislamiento de $\mathrm{ADN}$, análisis bioquímicos y cruzamientos controlados entre variantes fenotípicas son algunas de las estrategias desarrolladas en esta área (Griffiths et al., 2000).

En este trabajo de tesis doctoral se hará uso de la última de esas técnicas mencionadas -que consiste en la selección de organismos de acuerdo a sus características fenotípicas, realización de hibridaciones y recombinación- para caracterizar la variabilidad de las posibles formas que surgieron durante el proceso de domesticación.

Antes de comenzar a detallar la metodología utilizada para llevar a cabo los cruzamientos experimentales es apropiado definir una serie de términos para la comprensión de este capítulo y los siguientes.

Genotipo: el termino genotipo, fue acuñado por el botánico holandés Wilhelm Johannsen, en 1903 y hace referencia a toda la información genética que posee un organismo en particular. Es la totalidad de genes que componen a un organismo.

Cruce genético: consiste en la reproducción entre individuos de líneas o genotipos diferentes, con la intención de obtener una descendencia intermedia. Se simboliza con la letra X.

La nomenclatura utilizada para indicar un cruce genético puede ser: $\underline{(\mathrm{SxD})}$ cruce entre la subsp. silvestre/espontánea (como parental pistilado) y la subsp. domesticada (como parental estaminado) o (DxS) cruce entre la subsp. domesticada (como parental pistilado) y la subsp. silvestre/espontánea (como parental estaminado).

Híbrido: ejemplar resultante de la cruza entre dos individuos de líneas o genotipos diferentes.

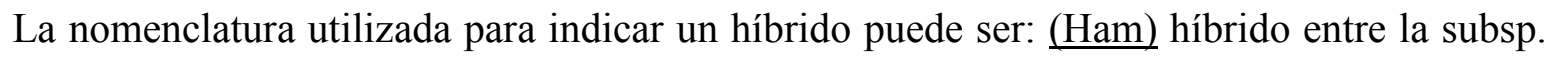
silvestre/espontánea (como parental pistilado) y la subsp. domesticada (como parental estaminado) o bien ( la subsp. silvestre/espontánea (como parental estaminado). 
Generación 1, Filial 1 (F1): son los individuos resultantes del cruzamiento de dos parentales diferentes. En este caso entre las dos subespecies de Cucurbita maxima.

A partir de los individuos de la Filial 1, se obtiene la segunda generación o F2, pudiendo sus miembros originarse de la siguiente manera:

-Cruce de un descendiente híbrido de primera generación (F1) con uno de los ejemplares cuyo genotipo es idéntico al del propio híbrido (Srb, 1971).

-Retrocruza o cruzamiento retrogrado: refiere al cruce entre un híbrido con un ejemplar cuyo genotipo es el mismo del de uno de sus parentales (Srb, 1971).

\section{OBJETIVO DE LA EXPERIMENTACIÓN}

El objetivo de los ensayos experimentales fue generar la mayor variabilidad de genotipos posibles, resultantes todos de los cruces genéticos realizados entre Cucurbita maxima subespecie maxima Duch. ex Lam y Cucurbita maxima Duch.ex Lam subespecie andreana (Naudin) Filov. y los híbridos generados entre ambas, con el fin de simular las posibles cruzas producidas en el pasado.

\section{ESTACIÓN EXPERIMENTAL}

El cultivo fue realizado en la Campo Experimental José Félix Villarino de la Facultad de Cs. Agrarias de la Universidad Nacional de Rosario (UNR), Zavalla, provincia de Santa Fe,

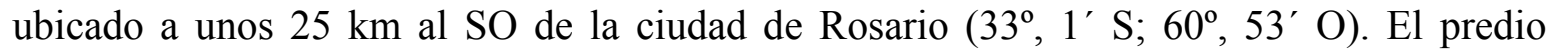
cuenta con una superficie de 350 ha. aproximadamente, de las cuales se utilizaron $2,1 \mathrm{~m}^{2}$ por planta, utilizando al menos ocho plantas por genotipo. Inicialmente se trabajó con seis genotipos parentales, número que se fue incrementando en las sucesivas generaciones (F1 y F2). Todas las tareas ya sean de sembrado, control, trillado y limpieza de los frutos estuvieron a cargo del Ing. Agr. Fernando López Anido, Profesor Adjunto de dicha unidad académica y especialista en genética. 
El crecimiento de las plantas se realizó durante las temporadas 2011 hasta el 2016. Antes de realizar la siembra, los plantines crecieron en bandejas de germinación de 72 celdas con sustrato comercial bajo condiciones controladas (Fig. 1-1). Durante los meses de octubrenoviembre las plantas fueron transplantadas en surcos separados por una distancia de 2,1 metros entre surcos y a 1 metro entre plantas dentro del surco (Fig. 1-2). Se utilizó riego por goteo, con cintas de riego de 600 micrones, con goteros cada $35 \mathrm{~cm}$ y sólo se regó en forma complementaria cuando no llueve por varios días (Fig. 1-3).

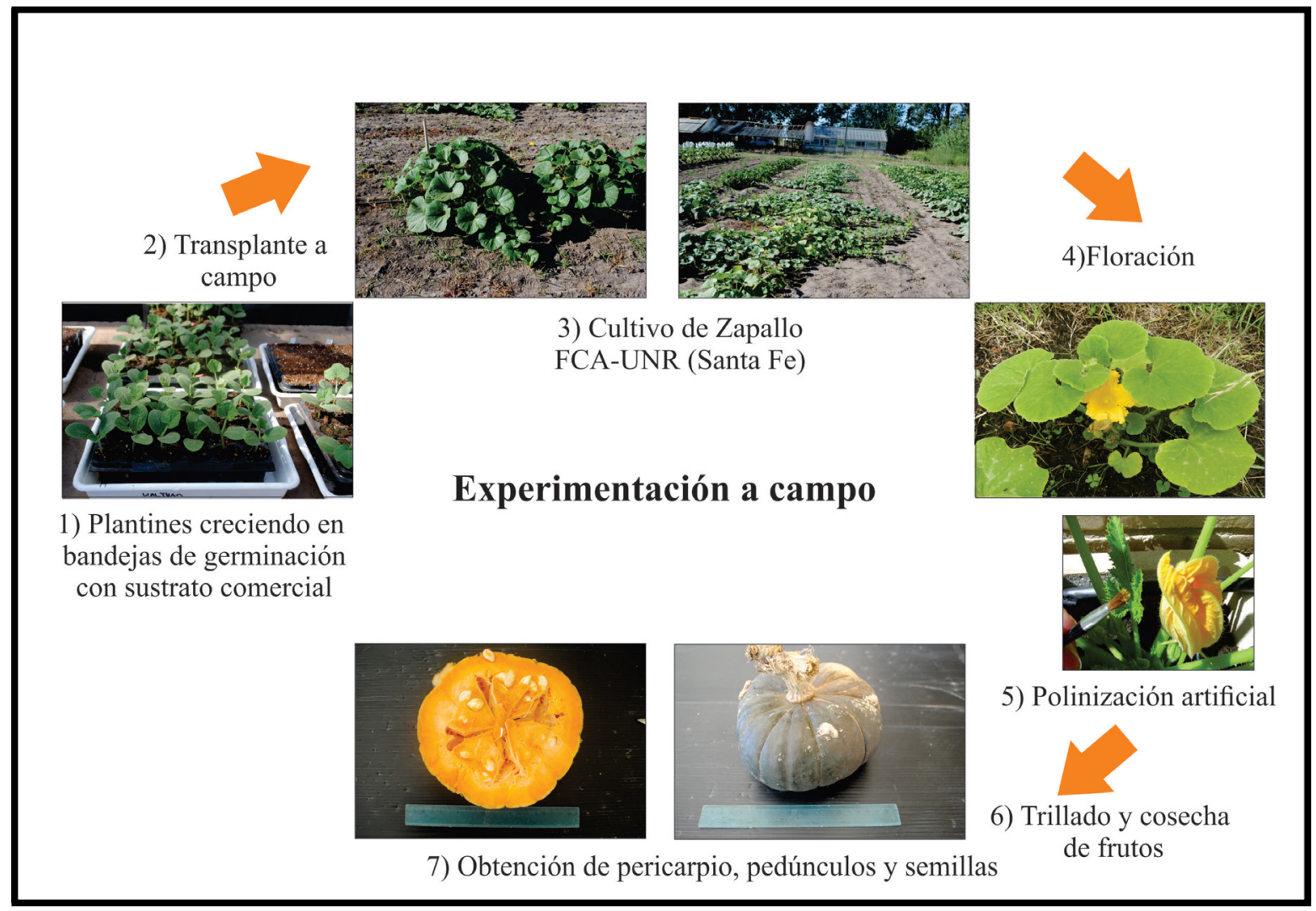

\section{FIGURA 1: ciclo que representa la experimentación a campo}

Al comenzar la floración (Fig. 1-4), ésta es continua por un par de semanas, abriendo cada día flores pistiladas y estaminadas. La antesis de cada flor comienza a la madrugada y termina antes del mediodía, luego de lo cual la flor estaminada se absiciona naturalmente y la pistilada, si fue polinizada, desencadena el comienzo del desarrollo de fruto y semilla. Para intervenir en la polinización, la tarde previa hay que asegurar con bandas elásticas las flores que abrirán al día siguiente; éstas se reconocen ya con la corola cerrada de color amarillo-naranja; esto es fundamental ya que el saqueo de polen por parte de insectos 
polinizadores comienza muy temprano al día siguiente. A la flor estaminada se le saca la corola y el pedicelo junto con los estigmas soldados, los cuales hacen de pincel natural para llevar polen al estigma de la flor pistilada (Fig.1-5). Es decir, el polen de una planta de carácter espontánea/silvestre se deposita en el estigma de una planta con características domesticadas y viceversa. Se cierra luego la flor para evitar la entrada de algún agente polinizador extraño y se identifica el cruzamiento con una etiqueta plástica (Fig.2).

Teniendo en cuenta que el fruto deriva del gineceo y de las demás partes florales que puedan asociarse con él, constituyendo el ovario modificado de la planta madre (Essau, 1976), los frutos de la primer generación o F1 no son híbridos. Esto se aplica también a los pericarpios dado que cuando el ovario se transforma en fruto la pared del ovario se convierte en la pared del fruto o pericarpio. De igual manera, pedúnculos y cubiertas seminales tampoco son híbridos en F1, sólo el embrión de la semilla es el único heterocigoto. Sin embargo, esta generación es imprescindible para luego obtener la F2. Es a partir de esta segunda generación que podernos decir que tanto la planta, el fruto en su conjunto y las semillas son verdaderos híbridos ya que la planta madre de la cual derivan es híbrida.

Dada esta aclaración, una vez realizada la polinización y en condiciones óptimas los frutos crecieron y permanecieron en las plantas hasta el momento de su maduración. El período de cosecha se completó a fines del mes de marzo de cada temporada respectivamente y después del secado se procedió a la trilla (separación de semillas del resto de tejidos) de los frutos (Fig. 1-6). Luego de la trilla las semillas, pedúnculos y pericarpios llegan a la ciudad de La Plata en sobres de papel madera, con el código de identificación de cada genotipo y cruzamiento (Fig.1-7). 


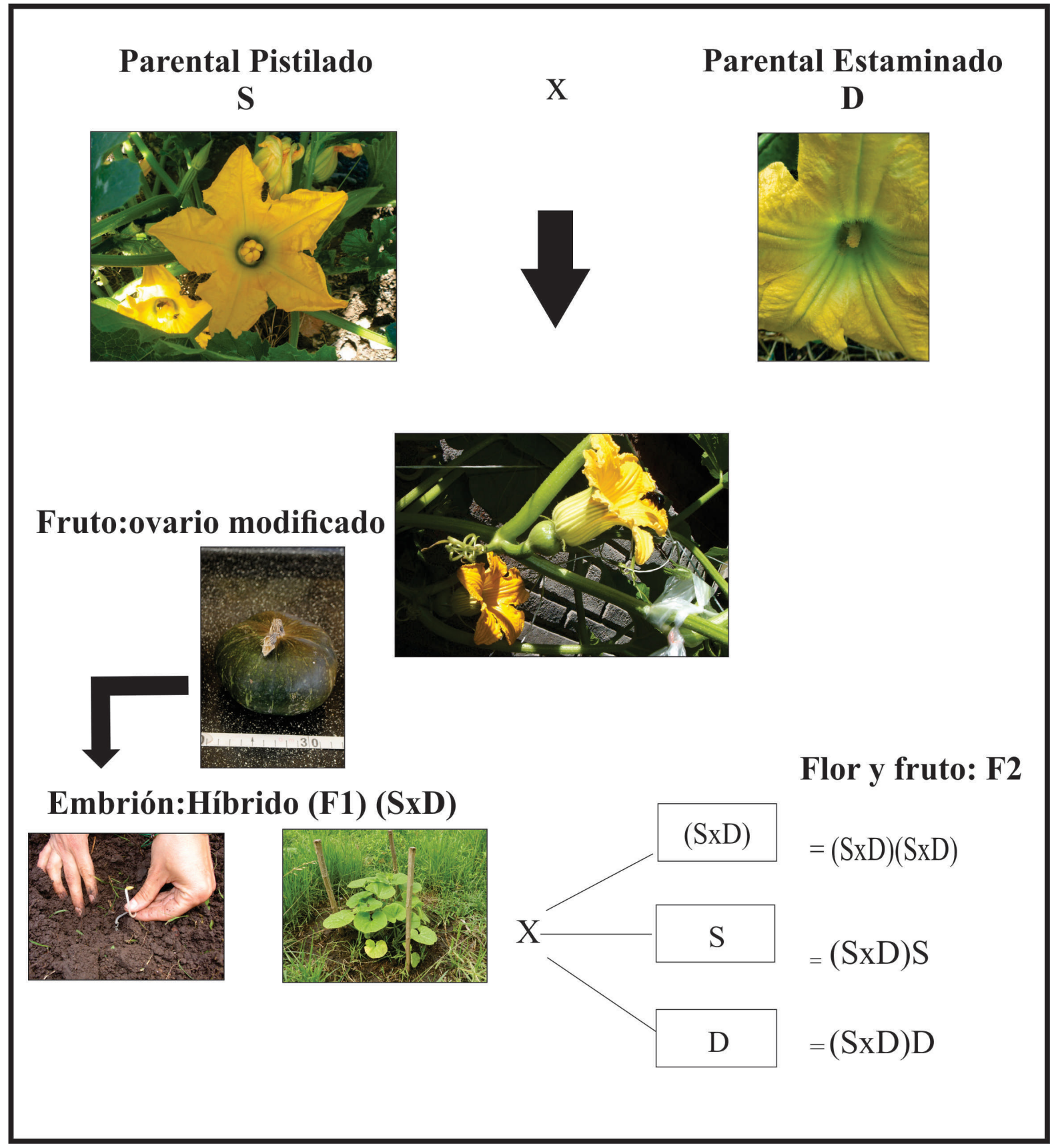

FIGURA 2: se indica a modo de ejemplo, la realización de un cruce controlado. Utilizando en este caso a la forma silvestre/espontánea (S) como parental pistilado y a la forma domesticada (D) como parental estaminado.

DESCRIPCIÓN DEL MATERIAL 
Se utilizaron tres accesiones de la subespecie espontánea/silvestre y tres accesiones de la subespecie domesticada con distinto origen cada una de ellas. A partir de estos parentales se obtuvo la Filial 1 con un número total de diecisiete genotipos y a partir de ésta, la Filial 2 con un número total de treinta y cinco genotipos seleccionados (Tablas 1,2). Los códigos utilizados son los definidos por la UNR. Este material fue el seleccionado para los tres tipos de análisis: semillas, (para los análisis fisiológicos, morfológicos y anatómicos), pedúnculos y pericarpios (para análisis morfológicos). 


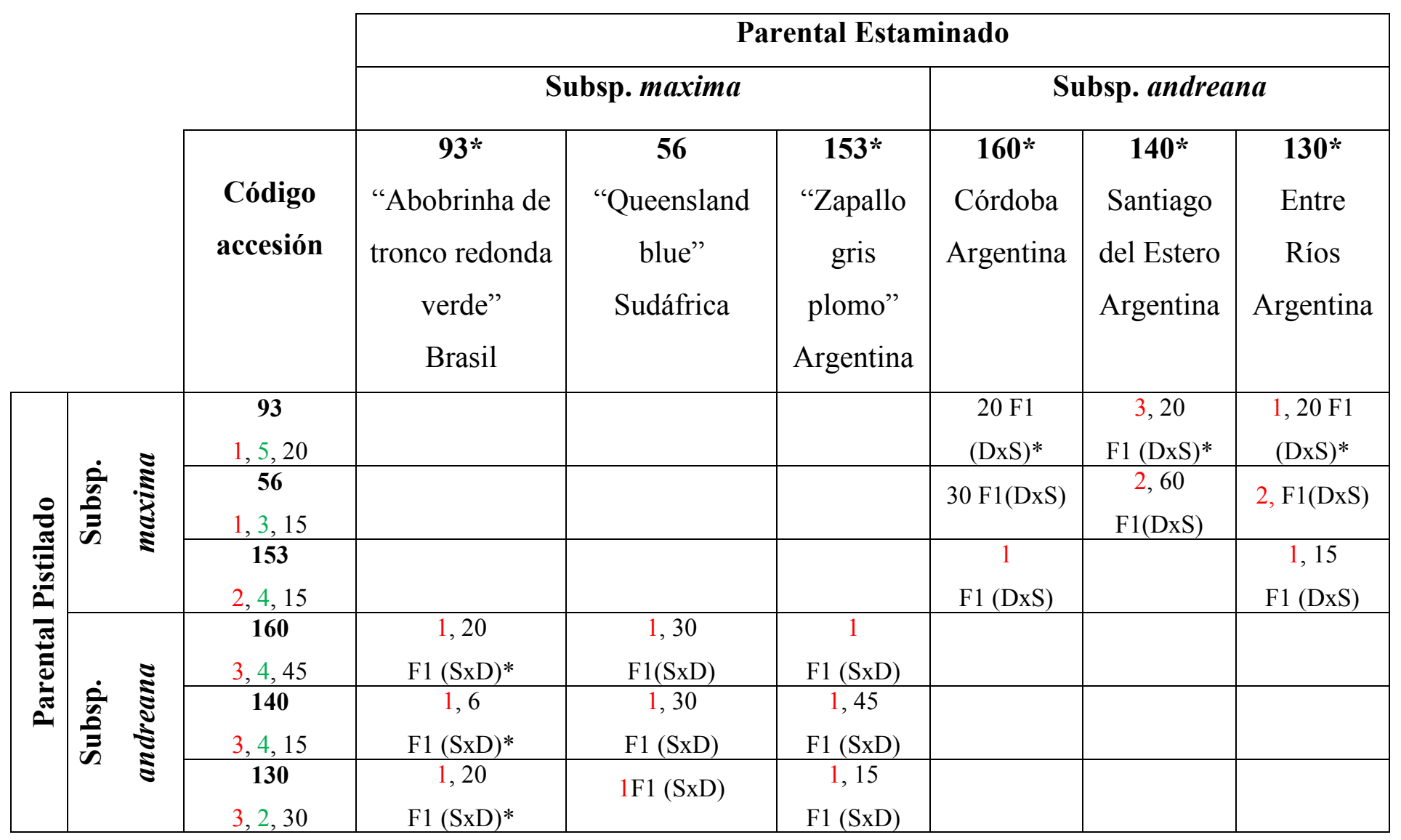

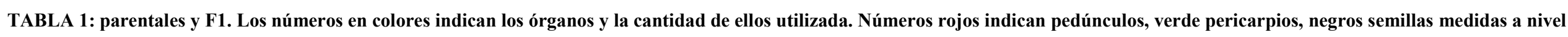

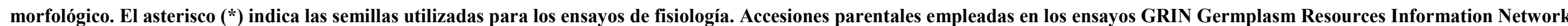
(http://www.ars-grin.gov) EEUU/ Feltrin Sementes http://www.sementesfeltrin.com.br/produtos-categoria-abobrinha. IPK Leibniz Institute of Plant Genetics and Crop Plant Research, Gatersleben, Alemania http://www.ipk-gatersleben.de/Internet. Semillas CAPS (Compañía Argentina Productora de Semillas) http://www.semillascaps.com.ar/ 


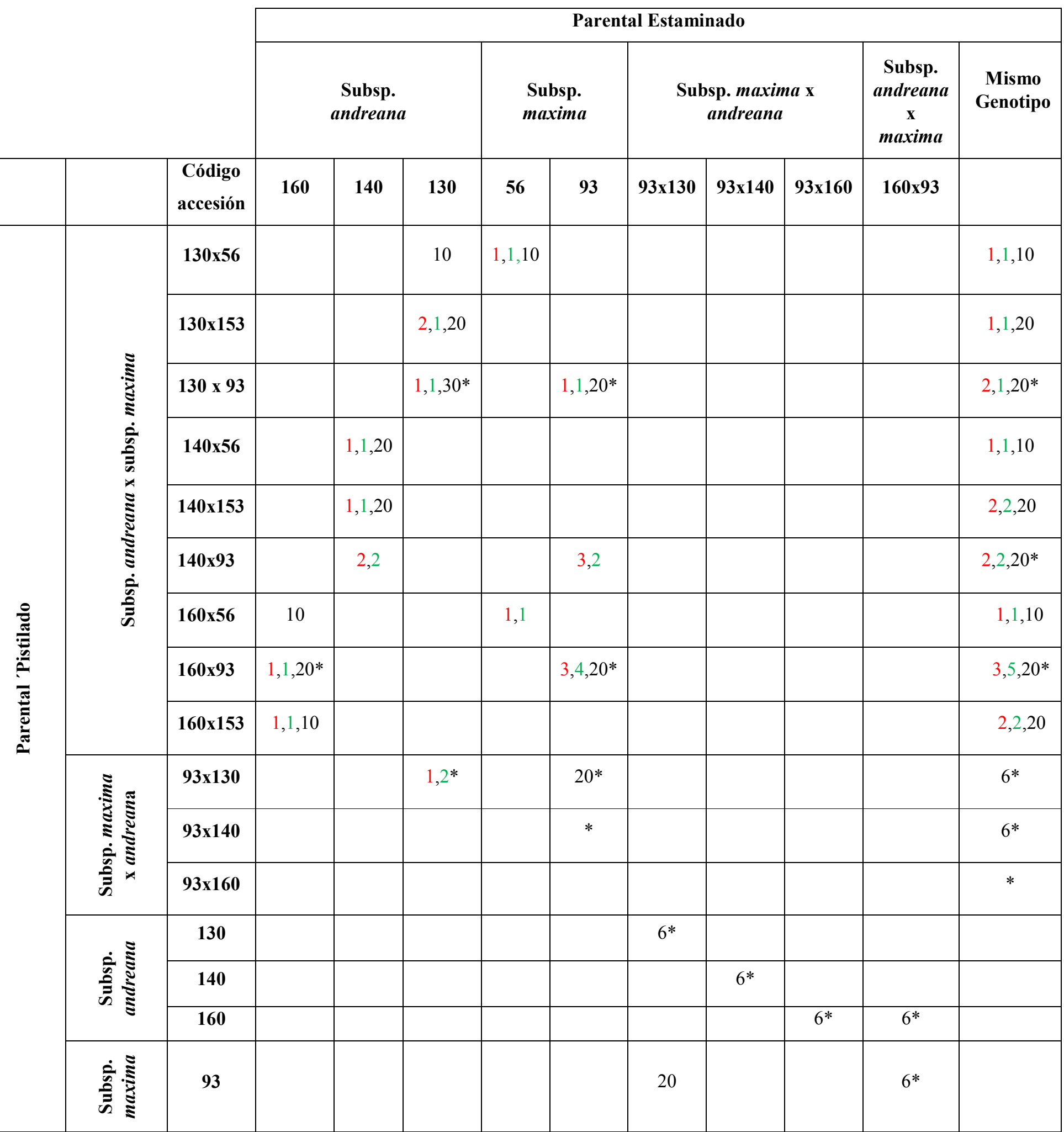

TABLA 2: F2. Los números en colores indican los órganos y la cantidad de ellos utilizada.

Números rojos indican pedúnculos, verde pericarpios, negros semillas medidas a nivel morfológico. El asterisco (*) indica las semillas utilizadas para los ensayos de fisiología. 


\begin{tabular}{|c|c|c|c|c|}
\hline Genotipos & $\begin{array}{c}\text { Código } \\
\text { GF }\end{array}$ & $\begin{array}{c}\mathrm{N}^{\circ} \mathrm{de} \\
\text { semillas } \\
\text { medidas }\end{array}$ & $\begin{array}{c}\mathbf{N}^{\circ} \text { de cortes } \\
\text { por semilla }\end{array}$ & $\begin{array}{c}\mathrm{N}^{\circ} \mathrm{de} \\
\text { mediciones }\end{array}$ \\
\hline 130 & GF 1 & 15 & 10 & 150 \\
\hline 140 & GF 4 & 15 & 10 & 150 \\
\hline 160 & GF 1 & 15 & 10 & 150 \\
\hline 93 & GF 4 & 15 & 10 & 150 \\
\hline$(93 \times 130)$ & GF 4 & 5 & 6 & 30 \\
\hline$(130 \times 93)$ & GF 3 & 5 & 6 & 30 \\
\hline$(93 \times 140)$ & GF 4 & 5 & 6 & 30 \\
\hline$(140 \times 93)$ & GF 4 & 5 & 6 & 30 \\
\hline$(93 \times 160)$ & GF 4 & 5 & 6 & 30 \\
\hline$(160 \times 93)$ & GF 3 & 5 & 6 & 30 \\
\hline$(93 \times 140)(93 \times 140)$ & GF 4 & 5 & 6 & 30 \\
\hline$(93 \times 160)(93 \times 160)$ & GF 4 & 5 & 6 & 30 \\
\hline $140(93 \times 140)$ & GF 4 & 5 & 6 & 30 \\
\hline$(130 \times 93) 93$ & GF 4 & 5 & 6 & 30 \\
\hline$(160 \times 93) 93$ & GF 4 & 5 & 6 & 30 \\
\hline$(93 \times 130)(93 \times 130)$ & GF 3 & 5 & 6 & 30 \\
\hline$(160 \times 93)(160 \times 93)$ & GF 3 & 5 & 6 & 30 \\
\hline$(140 \times 93)(140 \times 93)$ & GF 3 & 5 & 6 & 30 \\
\hline$(130 \times 93)(130 \times 93)$ & GF 3 & 5 & 6 & 30 \\
\hline$(93 \times 130) 93$ & GF 3 & 5 & 6 & 30 \\
\hline $160(160 \times 93)$ & GF 3 & 5 & 6 & 30 \\
\hline $93(160 \times 93)$ & GF 3 & 5 & 6 & 30 \\
\hline$(130 \times 93) 130$ & GF 2 & 5 & 6 & 30 \\
\hline
\end{tabular}




\begin{tabular}{|c|c|c|c|c|}
\hline $160(93 \times 160)$ & GF 2 & 5 & 6 & 30 \\
\hline$(160 \times 93) 160$ & GF 2 & 5 & 6 & 30 \\
\hline $130(93 \times 130)$ & GF 1 & 5 & 6 & 30 \\
\hline
\end{tabular}

TABLA 3: genotipos que fueron medidos a nivel anatómico. Se indica la cantidad de semillas medidas anatómicamente, el número de cortes hecho por cada semilla y la cantidad de mediciones. El código GF hace referencia a los grupos funcionales (Ver capítulo 3).

Con el objetivo de asegurar el número de semillas se mantuvieron plantas de las formas parentales en el Instituto de Fisiología Vegetal (INFIVE) de UNLP durante los años 2014, 2015 y 2016. Debido al reducido espacio, sólo se pudo contar con una parcela de $6 \mathrm{~m} \mathrm{x} 6 \mathrm{~m}$ aproximadamente, que albergó unas 25 plantas en cada temporada. Al igual que en la estación experimental de Santa Fe, éstas crecieron en invernáculo y luego de preparar el suelo fueron trasplantadas. 


\section{CAPÍTULO 3}

\section{LA DORMICIÓN EN SEMILLAS}

En este capítulo se estudiará el control ejercido por factores fisiológicos y ambientales sobre la dormición de las semillas de las dos subespecies de C. maxima (C. maxima subsp. maxima y C. maxima subsp. andreana) y de sus híbridos.

\section{INTRODUCCIÓN}

El término dormición, dormancia o también llamada latencia es definido como el cese temporario en el crecimiento de una planta entera o en alguno de sus órganos (semillas, yemas, tubérculos) (Hilhorst et al., 2010). Para el caso de las semillas la dormición, es el bloqueo de la germinación en un período de tiempo específico y bajo cualquier combinación de factores físicos y ambientales favorables (Baskin y Baskin, 2004, Finch Savage y Leubner Meztger, 2006).

Desde el aspecto ecológico esta condición es una ventaja adaptativa que reduce la competencia entre individuos de la misma población permitiendo la germinación a distintos tiempos y la exploración de las diferentes condiciones ambientales por parte de las futuras plántulas (Benech-Arnold et al., 2000), pero para los cultivos agrícolas la dormancia es una característica indeseable que retrasa la germinación (Bewley, 1997).

La dormición ha sido abordada por distintas áreas de las ciencias naturales dado a que constituye un parámetro de gran utilidad para responder a los problemas vinculados con la germinación de las plantas: Para los estudios agronómicos -área que reúne la mayor cantidad de trabajos- sirve como una aproximación para conocer la dinámica poblacional de especies forrajeras (Kruk et al., 2006, Cardozo et al.,2007, Galussi, 2010, Crecovich, 2012, Benech et 
al., 2000), de especies arbóreas forestales y alimenticias (Killian, 2012) o de malezas de cultivos (Puriceli et al., 2005, Chantre, 2010, Duarte-Vera et al., 2015). A nivel fisiológico y experimental los trabajos que indagan sobre el adecuado balance hormonal y los factores que regulan la dormición son algunos de los temas más desarrollados (Benech, 2000, Vigliocco et al., 2010, Montechiarini et al., 2010, Tapia, 2013). Desde el área molecular también se la ha tratado el tema, contribuyendo en este caso a determinar cómo la expresión de los genes regulan esta propiedad (Hedden, 2000, Ali-rachedi, 2004, Holdsworth et al., 2008, Cantoro, 2010).

Estos trabajos son sólo algunos ejemplos de entre los tantos que han sido reportados en la bibliografía y que no sólo contribuyen a aumentar el conocimiento de esta condición en diversas disciplinas, sino que también han servido como herramienta para otras áreas de investigación como la arqueología. En este último caso a diferencia de las anteriores, como ciencia social, ha estudiado a la dormición y a su reducción como indicador del proceso de domesticación. Tal como se adelantó en la introducción de esta tesis este carácter es observable en las formas silvestres y/o en malezas y se ha ido eliminando/reduciendo a lo largo del proceso de domesticación y en vinculación a las prácticas de manejo en general (Ver capítulo 1) (Hillman y Davis, 1990, Willcox, 1999, Smith, 2006 a, Jones 2009).

\section{CLASIFICACIÓN}

La dormición puede ser clasificada en cinco clases: fisiológica, morfológica, morfofisiológica, física y una última categoría resultante de la combinación entre la dormición fisiológica y la física. Sin profundizar demasiado en cómo es cada una de ellas, podemos caracterizarlas del siguiente modo (Finch Savage y Leubner Meztger, 2006).

-Dormición fisiológica: es la más difundida de las formas de dormición en semillas de gimnospermas y angiospermas tanto en bancos de semillas, en cultivos, como en laboratorios. Se diferencia en dos niveles de dormición, no profunda y profunda, según las semillas respondan o no respectivamente a tratamientos con reguladores de crecimiento como por ejemplo las giberelinas (GAs). 
-Dormición morfológica: es evidente en semillas con embriones diferenciados pero subdesarrollados (en término de tamaño). En este caso hablamos de embriones no dormidos pero que les falta crecer para poder germinar.

-Dormición morfofisiológica: se da en semillas con embriones subdesarrollados, pero que están dormidas por lo tanto esas semillas requieren un tratamiento para romper la dormición. -Dormición física: es causada por la impermeabilidad al agua o a inhibidores provocada por las capas de células o tejidos de la cubierta.

-Dormición física morfológica: es evidente en semillas con cubiertas impermeables combinada con una dormición fisiológica del embrión.

Otro tipo de clasificación de acuerdo a la capacidad germinativa y a la dispersión de las semillas incluye:

-Dormición primaria: es aquella que presentan las semillas cuando se dispersan de la planta madre en un estado latente. Aquí, la latencia se inicia durante el desarrollo. Se encuentra controlada genéticamente, aunque también influyen aspectos fisiológicos (estado hormonal de la semilla, flujo de hormonas desde la planta madre) y factores ambientales (factores edáficos, temperatura y luz) (Bewley y Black, 1994).

-Dormición secundaria o inducida: se produce en semillas maduras ya caídas de la planta madre y que antes no estaban en estado durmiente. Esta dormición se puede inducir cuando las semillas se encuentran bajo condiciones que son desfavorables para la germinación (anoxia, intensidad luminosa) (Bewley y Black, 1994, Hilhorst, 1995, Matilla, 2000, Kucera et al., 2005, Finch-Savage y Leubner Meztger, 2006).

\section{INDUCCIÓN Y MANTENIMIENTO DE LA DORMICIÓN: REGULACIÓN HORMONAL}

El ácido abscísico (ABA) y las (GAs) son las principales hormonas intervinientes en la regulación de la dormición (Kucera et al., 2005). Es por ello que la dormición es controlada por el equilibrio entre la biosíntesis y el catabolismo de ABA y GAs (Wang et al., 1995, Debeaujon y Koornneef, 2000; Ali-Rachedi et al., 2004 Cadman et al., 2006, Holdsworth et al., 2008).

El ABA es un compuesto perteneciente a la familia de los terpenos que se encuentra tanto en la cubierta seminal como en el embrión. Esta diferente localización implica una diferente 
funcionalidad: por un lado, la evidencia experimental sugiere que el ABA contenido en el embrión es requerido para la maduración e inducción del estado de dormición ( Karsen et al., 1983, Hilhorst, 1995, Finch-Savage y Leubner Meztger, 2006, Holdsworth, et al., 2008), "mientras que el ABA producido por los tejidos maternos como el aplicado exógenamente, no es efectivo para inducir la dormición sino para mantenerla" (Huarte, 2013: 25) sugiriéndose además que la síntesis y acumulación de ABA está relacionada con la adquisición (tolerancia) de la semilla frente a situaciones de desecación y otros tipos de estreses (Jordán y Casaretto, 2006, Nambara et al., 2010).

A diferencia del ABA, las GAs que son también de la familia de los terpenos, promueven la germinación, removilización y degradación de reservas ablandando tejidos para la expansión del embrión (Ali-Rachedi et al., 2004, Kucera et al., 2005). Otra de la hormonas involucradas en la terminación de la dormición y que atenúa los niveles de ABA es el etileno, que actúa como un regulador positivo activando la germinación en semillas (Kucera et al., 2005, Jordán y Casaretto, 2006).

\section{INDUCCIÓN Y MANTENIMIENTO DE LA DORMICIÓN: REGULACIÓN AMBIENTAL}

La temperatura, el régimen lumínico y la disponibilidad de agua son factores ambientales que regulan el balance hormonal ABA/GAs (Roberts y Ellis, 1988, Bewley y Black, 1994, Benech et al., 2000). Dependiendo de la especie y del ambiente en que se encuentren, las temperaturas altas, bajas o una alternancia entre las mismas, pueden activar la expresión de los genes que participan de esta relación, inclinando este balance a favor de alguna de estas hormonas y por ende favoreciendo la germinación o la dormición (Benech-Arnold et al., 1990, Batla y Benech Arnold., 2005, Puriceli et al., 2005, Finch Savage-Leubner-Metzger, 2006).

Respecto al régimen lumínico, cambios en la relación rojo/rojo lejano pueden modificar la expresión de la dormición de las semillas. El cambio en la sensibilidad de la luz es mediado por los fitocromos. Éstos son cromoproteínas que dentro del espectro de luz absorben la luz roja (Pr) para luego modificar su conformación hacia la forma de fitocromo capaz de absorber luz del rojo lejano (Pfr) (por ejemplo, debajo del canopeo). La luz del rojo lejano es 
la que puede liberar a las semillas de la dormición (Bewley, 1997, Casal y Sanchez, 1998, Benech-Arnold et al., 2000, Batlla et al., 2004).

Respecto de la cantidad de agua disponible en el suelo se ha determinado que ésta es un factor que puede alterar la velocidad de germinación y modificar los niveles de dormición de la población (Batlla y Benech-Arnold, 2005). Tal como ha sido determinado para distintas especies el gradiente de potenciales agua entre el suelo y la semilla podría condicionar la expresión de la dormición (Brandford 2005, Batlla y Benech-Arnold, 2005).

\section{CUANTIFICACIÓN}

La dormición tal como expresó Finkelstein y colaboradores (2008) no se la ve pero se la reconoce y se la cuantifica midiéndola siempre indirectamente como un retraso en la germinación. De acuerdo al rango de amplitud de condiciones ambientales, citadas anteriormente, que permiten la germinación de una semilla se plantean "niveles de dormición" es decir si la semilla germina bajo un amplio rango de temperatura y no necesita de ningún otro factor del ambiente como por ejemplo fluctuación de la temperatura se dice que tiene un bajo nivel de dormición. Mientras que cuando la germinación se produce bajo un rango estrecho de temperatura $u$ algún otro factor del ambiente se dice que el nivel de dormición es alto. Si no se produce germinación bajo ninguna temperatura, fluctuación o intensidad luminosa se dice que el estado de dormición es absoluto. Lo importante es poder determinar que este diferente grado de dormición que presentan las semillas dentro de una misma población permita la distribución de la germinación en el tiempo con la consecuente exploración de las diferentes condiciones ambientales por parte de las futuras plántulas generadas (Benech-Arnold et al., 2000).

Así como existen factores fisiológicos y ambientales que inducen y/o modifican el estado de dormición, existen también métodos para la liberación de esta condición y que las semillas puedan germinar de manera adecuada. Estos tratamientos son muy aplicados en las especies de interés agronómico, pudiendo nombrar entre ellos:

-Estratificación: se establece a través de la permanencia de las semillas a bajas temperaturas $\left(0\right.$ a $\left.10^{\circ} \mathrm{C}\right)$ por varios días ó semanas.

-Alternancia de temperaturas: fluctuaciones diarias entre bajas y altas $\mathrm{T}^{\circ}$. 
-Exposición a luz con una alta relación rojo/rojo lejano.

-Utilización de reguladores de crecimiento (GAs, etileno) y nutrientes (nitratos).

-Postmaduración: almacenamiento en seco a temperaturas altas por varias semanas o meses.

-Escarificación: abrasión mecánica del tegumento.

-Escarificación química: remojo con ácidos $\mathrm{HCL}$ o $\mathrm{H}_{2} \mathrm{SO}_{4}$ para debilitar las cubiertas impermeables.

\section{HIPÓTESIS DE TRABAJO}

"La pérdida de la dormición de las semillas de Cucurbita maxima es consecuencia de modificaciones fisiológicas y/o micro-morfológicas ocurridas durante el proceso de domesticación".

\section{OBJETIVO PARTICULAR DE ESTE CAPÍTULO}

-Determinar las condiciones ambientales para la germinación de semillas de C. maxima subsp. maxima, C. maxima subsp. andreana, poblaciones híbridas de ambas subespecies y retrocruzas, y a partir de ello caracterizar la dormición de las semillas.

Para poder responder a dicho objetivo se realizaron ensayos de laboratorio bajo condiciones controladas seleccionando una serie de factores para conocer tanto la capacidad de germinación como la presencia o no de dormición en semillas obtenidas de frutos maduros recién cosechados.

$\underline{\text { Dentro de los factores ambientales o externos se evaluaron: }}$

1) Régimen de temperaturas

2) Disponibilidad lumínica

Dentro de los factores internos se evaluaron:

1) Difusión de agua hasta los embriones 
2) Papel de la cubierta seminal (i.e. crecimiento de embriones aislados)

3) Participación de reguladores de crecimiento vegetal: ácido abscísico (ABA) y (GAs).

\section{MATERIALES y MÉTODOS}

Se trabajó con cinco accesiones parentales: dos de la subespecie maxima (93 y 153) y tres de la subespecie andreana $(130,140,160)$. En cuanto a los híbridos y retrocruzas se trabajó con seis accesiones de la generación F1 y dieciocho genotipos correspondientes a la segunda generación (Ver tablas 1 y 2 del cap. 2). Es importante aclarar que debido a razones de tiempo, espacio y sobre todo a la posibilidad de realizar los cruces, no siempre se contó con todos los genotipos para todos los ensayos, razón por la cual se fueron seleccionando las accesiones y cruzamientos que mejor nos permitieran caracterizar la dormición de Cucurbita maxima.

Las semillas fueron colocadas en placas de Petri de plástico de 8,7 cm aproximadamente de diámetro interno y recubiertas con papel aluminio para aislarlas de cualquier agente que pudiera interferir con el tratamiento aplicado, trabajando siempre a humedad constante.

Cada ensayo tuvo una duración de 7 a 10 días contando con un registro diario (Fernández y Johnston, 1986) -(excepto el ensayo de efecto de la luz)- se utilizó esta cantidad de días puesto que las semillas con baja dormición germinaban aproximadamente a las 48 horas del inicio de cada ensayo. Se realizaron como mínimo un número de tres experimentos independientes y tres replicas por ensayo puesto que después de cada cosecha durante cinco años desde el 2012 al 2015 se verificaba el estado y el porcentaje de germinación de las semillas. Cada ensayo consistió en colocar 10 semillas y/o embriones en placas de Petri sobre papel de filtro humedecido con agua desionizada o con el compuesto químico o regulador necesario $(5 \mathrm{ml})$ según el tipo de análisis.

Todo el material vegetal y de laboratorio fue desinfectado con alcohol al $70 \%$ durante unos segundos y luego se enjuagó con lavandina comercial 50\% unos cinco minutos, finalizando el tratamiento con abundante agua antes de poner el material a germinar. Posteriormente se aseguró la viabilidad de las semillas mediante la reacción de coloración de actividad de deshidrogenasas con 1, 2, 3 trifenil tetrazolio (TZ). Esta práctica consistió en colocar sólo un par de semillas en placas de Petri en remojo y luego cortarlas a la mitad para facilitar la 
entrada de la solución acuosa de $\mathrm{TZ}$ al 0,2 \% a los tejidos del embrión, se dejaron las semillas en ese líquido en un lugar oscuro, durante 24 horas (FAO, 1991). A través de este método las células vivas se tiñen de rojo, por medio de la reducción del TZ produciendo formazano e indicando así su "estado vivo" como resultado de la actividad de enzimas que participan de la respiración.

Esta metodología general se utilizó para todos los ensayos. A partir de este apartado se detallará la metodología seguida para cada uno de los ensayos realizados. Los datos fueron analizados a través de un análisis de varianza (ANOVA) de una ó dos vías y en caso de encontrar diferencias se utilizó la prueba de comparaciones Tukey a través del software estadístico InfoStat (2001) Manual del usuario, Version 1. Universidad Nacional de Córdoba.

\section{1) Metodología específica para la determinación de las condiciones ambientales}

Ensayos de temperatura: debido a que la dormicion se puede expresar de manera diferencial a distintas temperaturas de incubacion se utilizó un amplio rango que va desde los $16^{\circ}$ a los $28^{\circ} \mathrm{C}$ contando para ello con la utilización de estufas de germinación y cámaras de crecimiento a temperatura constante.

Las semillas fueron colocadas en las placas de Petri, como se detalló anteriormente y se dejaron siete días a 16,22 y $28{ }^{\circ} \mathrm{C}$ con un seguimiento diario que sirvió para registrar la emergencia y medición de radícula, aparición de hongos, cambio de papel de filtro y agregado de agua destilada.

A partir de estas pruebas se determinó:

Porcentaje de germinación (\%): se contabilizó el número total de semillas germinadas al finalizar cada tratamiento expresando su número en porcentaje

Tiempo de germinación: se contabilizó el número de semillas germinadas a medida que avanzaba el tiempo, a lo largo de los siete días que duró el ensayo

Crecimiento radicular (cm/día): se midió la velocidad de crecimiento diario de la radícula hasta el momento en que término cada tratamiento utilizando la siguiente fórmula: [(LRF)(LRI)]/ [LRI]/diferencia de días entre mediciones.

LRF: Largo de radícula final 
LRI: Largo de radícula inicial al $3^{\text {er }}$ día de ensayo (se toma el tercer día por ser "en promedio" el día en que la radícula se pudo medir cómodamente).

Preacondicionamiento previo a una temperatura inferior: en este caso se realizó el cambio de $4 / 28.0{ }^{\circ} \mathrm{C}$, de $16 / 28.0{ }^{\circ} \mathrm{C}$ y de $22 / 28.0{ }^{\circ} \mathrm{C}$. Los genotipos seleccionados fueron: 93, 130, 140, 160, (93x130), (160x93), (160x93)160, (160x93)93, (160x93)(160x93).

Este ensayo se planteó a distintos tiempos, de la siguiente manera:

*Se trataron las semillas con temperaturas de 4,16 y $22{ }^{\circ} \mathrm{C}$ durante un período de 160 horas y luego a $28^{\circ} \mathrm{C}$ durante 120 horas más en estufa de germinación.

* Se trataron las semillas con temperatura de 4,16 y $22{ }^{\circ} \mathrm{C}$ durante un período de 48 horas y luego a $28^{\circ} \mathrm{C}$ durante 120 horas más en estufa de germinación.

Régimen lumínico: el primer ensayo estuvo destinado a determinar si era necesario el requerimiento lumínico para la germinación, es decir conocer el fotoblastismo de las semillas. Se trabajó con dos accesiones las 93 y 130 en presencia y en ausencia de luz a una temperatura constante de $28^{\circ} \mathrm{C}$. Las placas con semillas que no recibieron luz fueron recubiertas con papel de aluminio y no se abrieron hasta el momento en que se dio por finalizado el tratamiento. Mientras que los que recibieron luz no fueron recubiertas con papel de aluminio recibiendo luz contínua.

El segundo ensayo se realizó con el objetivo de determinar si pequeños pulsos de luz eran útiles para la germinación. En este caso se trabajó con los genotipos 93, 130, (93x130), (130x93) y 130(93x130). Las placas estuvieron expuestas a pulsos de luz de tres horas diarias a una intensidad de $120 \mu \mathrm{mol}$ de fotones $\mathrm{m}^{-2} \mathrm{seg}^{-1}$ (PPFD), pasado este tiempo fueron retiradas y colocadas en oscuridad el resto de las horas del día. Esta alternancia fue realizada durante tres días consecutivos y luego no se alternó más dejando las semillas en ausencia de luz durante siete días.

\section{2) Metodología específica para la determinación de factores internos:}

Escarificación mecánica: se despojó de manera completa la cubierta seminal de las semillas con cortante metálico, tratando de no dañar al embrión con la finalidad de comprobar si ante la ausencia de testa se producía o no germinación. 
Una vez extraída la cubierta se utilizaron los embriones desnudos para caracterizar el poder germinativo. El material vegetal utilizado corresponde a los genotipos: domesticado 93, a las tres formas silvestres y/o espontáneas (130, 140, 160), y a dos F1 (93x130), (130x93).

Ensayos de difusión de agua. Difusión a través de las cubiertas seminales: se colocaron semillas de los genotipos parentales 93 y 130 a $28{ }^{\circ} \mathrm{C}$ en estufa de germinación y se utilizó una tinción con safranina como marcador para monitorear el ingreso de agua a través de los tejidos que componen la cubierta hasta la llegada al embrión. La safranina (1gr) se disolvió en alcohol al 50\% y se agregó agua destilada $(1 / 100 \mathrm{ml})$.

Se añadieron $5 \mathrm{ml}$ de la solución colorante a cada grupo de semillas y luego a las 24 y $48 \mathrm{hs}$ de imbibición se realizaron cortes transversales y se observaron al microscopio óptico a 100 y 200X.

Determinación de la relación peso seco-peso fresco (CHR): para evidenciar la posible entrada de agua en la semilla, acción que se refleja ante los cambios de peso, se tomó el peso de las semillas antes de la imbibición, a las 24 y 48 horas luego de haber comenzado el ensayo. Las semillas fueron dejadas en estufa de germinación a $28{ }^{\circ} \mathrm{C}$ y se evaluaron sus diferencias a lo largo del tiempo (24-0, 48-24 hs). Para este ensayo se analizaron diez semillas correspondientes a las accesiones 93, 130 y 160.

Determinación del sitio de absorción de agua: para identificar el posible sitio de entrada de agua en las semillas se obstruyó la región micropilar con cera parafina, se registró el peso antes de la imbibición, a las 24, 48 y 72 horas, dejando a las mismas en estufa de germinación a $28^{\circ} \mathrm{C}$ y evaluando sus diferencias a lo largo del tiempo (24-0,48-24,72-48 hs). Para este ensayo se utilizaron diez semillas correspondientes a las accesiones 93 y 160.

\section{Reguladores de crecimiento vegetal ABA y GAs}

Para los ensayos de ABA se utilizaron tres concentraciones diferentes $(0,0,0,1,1,0$ y 10,0 uM). El ABA se disolvió en un volumen pequeño de alcohol y luego se agregó agua (no a volumen), se colocó a baño maría hasta que se volatilizó todo el alcohol y se completó el volumen de agua hasta alcanzar la concentración mayor. Para este ensayo el material utilizado corresponde a la forma domesticada 93, a la accesión de andreana (130) y a dos formas híbridas, correspondientes a la primer generación F1 (93x130), (130x93). 
Además de la concentración de este regulador posteriormente se adicionó como variable la temperatura, trabajando a 16,22 y $28^{\circ} \mathrm{C}$. En este caso el material vegetal corresponde a los genotipos 93, 130 y sus cruces F1. También se pudo cuantificar el contenido endógeno de $\mathrm{ABA}$ en semillas, embriones y testas seminales de la forma silvestre y la forma domesticada embebidas a temperaturas constantes de 16 y $28{ }^{\circ} \mathrm{C}$. Se tomaron muestras de estas estructuras cada 12 horas aproximadamente durante las primeras 72 horas. Una vez tomadas las muestras se recubrieron con papel de aluminio y se conservaron en $\mathrm{N}_{2}$ líquido a $-80^{\circ} \mathrm{C}$ hasta el momento de su cuantificación. La cuantificación estuvo a cargo de personal técnico del grupo de investigación dirigido por el Dr R Benech-Arnold (IFEVA, Universidad de Buenos Aires) quienes se ocuparon de liofilizar, moler, pesar y almacenar las semillas a -18 ${ }^{\circ} \mathrm{C}$ para su medición. La determinación se realizó mediante radio-inmunoensayo, realizando una curva estándar que relacionó concentraciones conocidas de $(+)$ ABA de 125, 250, 500, 1000 y 2000 pg/ $50 \mu \mathrm{L}$. Los resultados presentados corresponden a los valores medios de tres repeticiones (Huarte, 2013).

Otros reguladores hormonales utilizados para caracterizar la dormición fueron:

GAs: se embebieron las semillas de los genotipos 93 y 130 en dos concentraciones diferentes de GAs $(0,0$ y 100,0 $\mu \mathrm{M})$ dejándolas luego en estufa de germinación a $28^{\circ}$ durante siete días. Para determinar la contribución de la síntesis de novo de GAs durante la germinación se utilizó $100 \mathrm{mg} / \mathrm{l}$ paclobutrazol, que es un compuesto que inhibe específicamente la síntesis de estas hormonas. Complementariamente se embebieron embriones de los genotipos 93 y 130 en dos concentraciones diferentes $(0,0$ y $100,0 \mu \mathrm{M}$ GAs $)$ en combinación o no con paclobutrazol dejándolos luego en estufa de germinación a $28^{\circ} \mathrm{C}$ durante siete días.

\section{RESULTADOS:}

Antes de presentar los resultados de cada tipo de ensayo cabe aclarar que, siguiendo a Fernández y Johnston (1986), una semilla se consideró germinada cuando la radícula mostró un tamaño mayor a los $2 \mathrm{~mm}$.

\section{Ensayos de Temperatura}

$\underline{\text { Porcentaje de germinación }}$ 
Los ensayos demostraron que los distintos genotipos presentan una germinación diferencial en el rango de temperaturas utilizadas, siendo $28{ }^{\circ} \mathrm{C}$ la temperatura a la cual se observó la mayor germinación (Fig. 1A). El análisis estadístico (ANOVA) demostró que los genotipos se diferencian de acuerdo al porcentaje de germinación y el análisis a posteriori (Tukey) determinó que es posible realizar agrupamientos entre los genotipos en base a su \% de germinación observándose a $28{ }^{\circ} \mathrm{C}$ comportamientos similares entre muchos de ellos. Para evitar confusión dado el solapamiento de los genotipos no se colocó la significancia estadística, sin embargo se puede indicar que la misma mostró cuatro agrupamientos. Un pequeño grupo que incluye los genotipos que tienen entre 0 y $10 \%$ de germinación, un segundo grupo que incluía los genotipos que germinaban hasta un $60 \%$ de germinación, un tercer grupo que comprende los genotipos que germinan entre el 60 y el $80 \%$ de germinación, y un último agrupamiento con más del $80 \%$ de germinación (Ver final del capítulo).

En general el patrón de comportamiento que han mostrado las distintas formas es la siguiente: mientras que la subespecie maxima presentó un 100 \% de germinación (Fig. 1B a), las accesiones de andreana mostraron diferencias: la accesión 130 no presentó germinación (Fig. 1B b), la accesión 140 lo hizo con niveles de germinación tan altos como los de maxima (Fig. 1B c) y la accesión 160 sólo germinó en un 10 \% (Fig. 1B d). En el caso de los cruces F1, pudo observarse que el patrón de crecimiento se asemeja principalmente al del parental pistilado (femenino) ya sea éste el característico de la subespecie maxima o el de la subespecie andreana. En todos los F2 se observó germinación y una tendencia de comportamiento similar a la de la subespecie maxima (93). Este primer resultado permitió caracterizar el comportamiento de los genotipos a esa temperatura y asimismo seleccionar el material vegetal para los siguientes ensayos priorizando analizar la línea que permita caracterizar la historia de la dormición por sobre las accesiones que mostraron baja dormición en estas condiciones favorables.

A $22{ }^{\circ} \mathrm{C}$ de temperatura se observó germinación de las accesiones correspondientes a los parentales 93, 160, los F1 resultantes del cruce de ambos y los híbridos (93×130), (160x93)93 (Fig. 2). A $16^{\circ} \mathrm{C}$ los genotipos que mostraron germinación fueron 93, (93x130), (93x160), (160x93) (Fig. 3). 


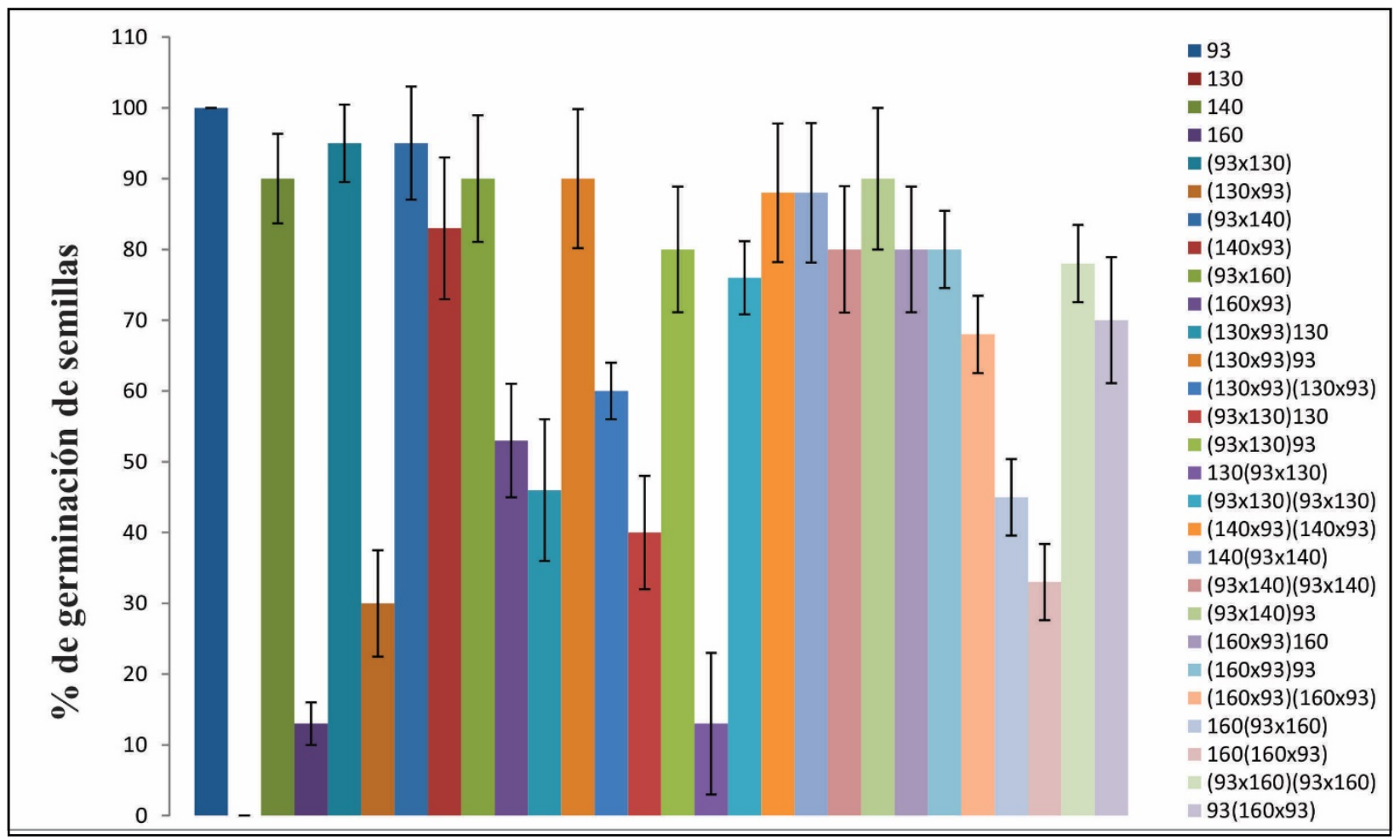

FIGURA 1A: germinación de semillas de diversos genotipos de Cucurbita a $28^{\circ} \mathrm{C}$. Se observa una gran variación en el \% de germinación de los distintos genotipos, presentando desde, $0-100 \%$ de germinación (ANOVA, Tukey $\alpha \leq 0,05$ ). Las barras de error corresponden al desvío estándar.

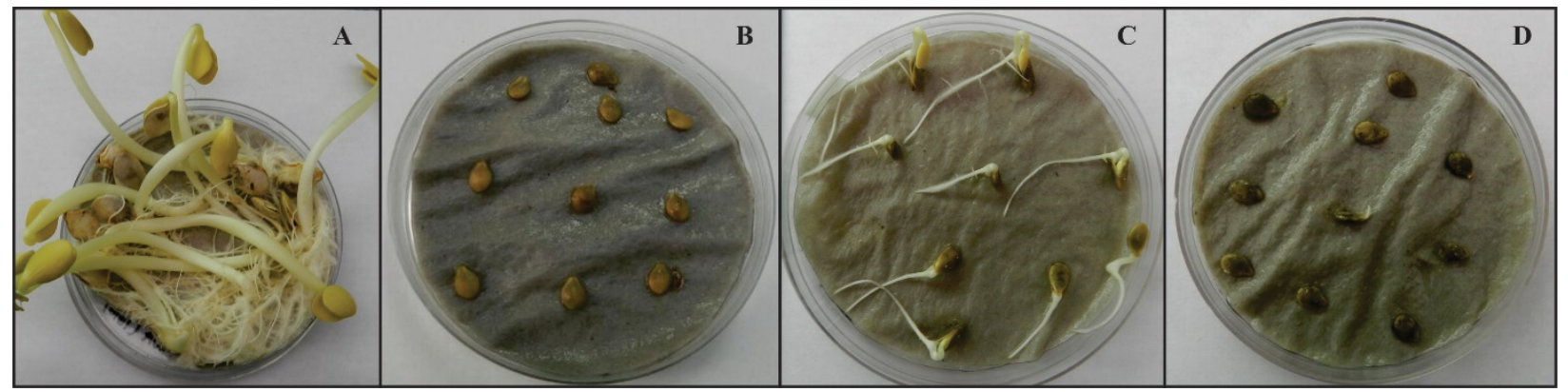

FIGURA 1B: genotipos parentales a $28^{\circ} \mathrm{C}$ : A) $C$. maxima subsp. maxima (93) B) $C$. maxima subsp. andreana (130) C) C. maxima subsp. andreana (140) D) C. maxima subsp. andreana (160) fotos correspondiente al día 4 para C) y D), fotos correspondiente al día 7 para A) y B). 


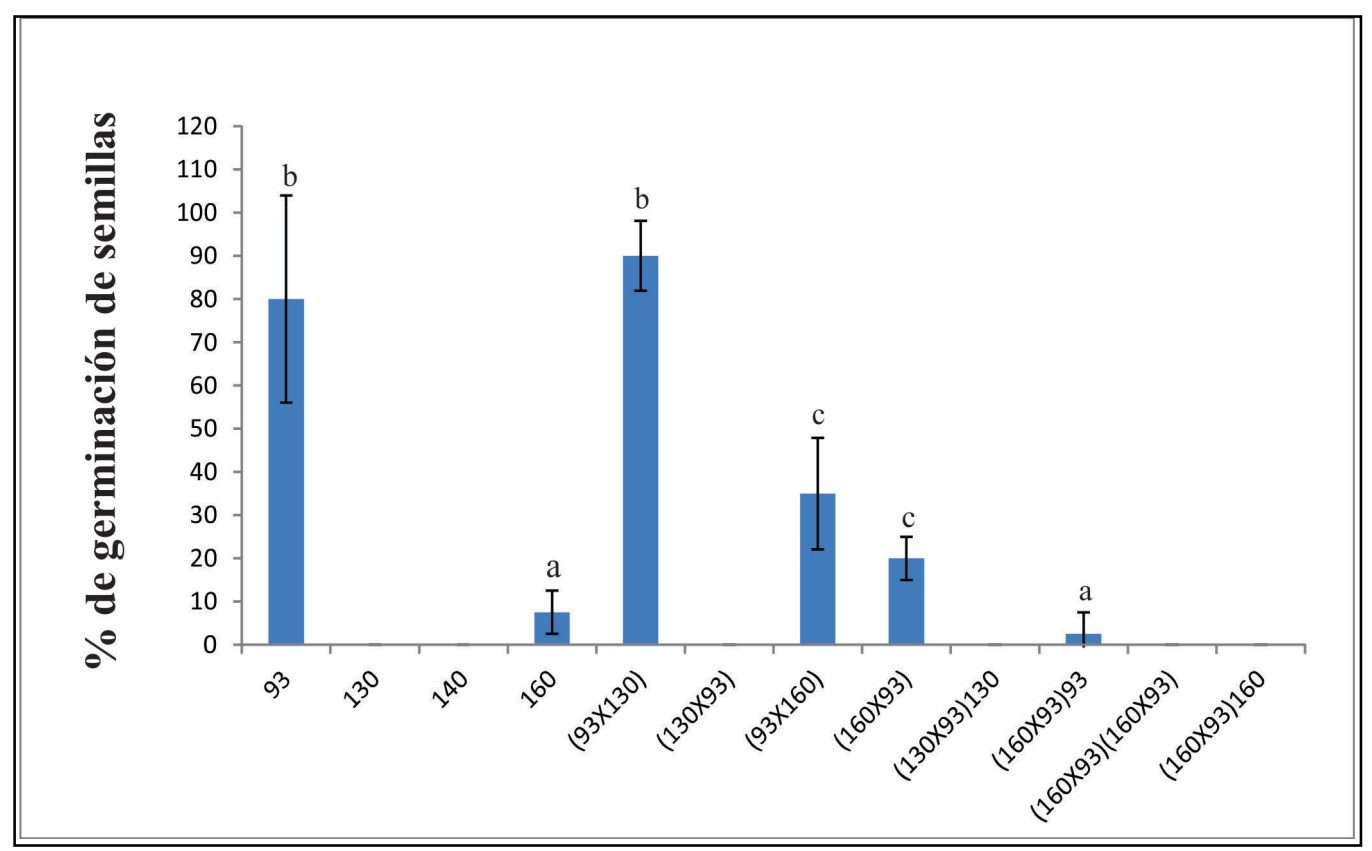

FIGURA 2: germinación de semillas de diversos genotipos de Cucurbita a $22^{\circ}$. Los genotipos con mismas letras no presentan diferencias significativas. Los genotipos sin letras no presentaron germinación (ANOVA, Tukey $\alpha \leq 0,05$ ). Las barras de error corresponden al desvío estándar.

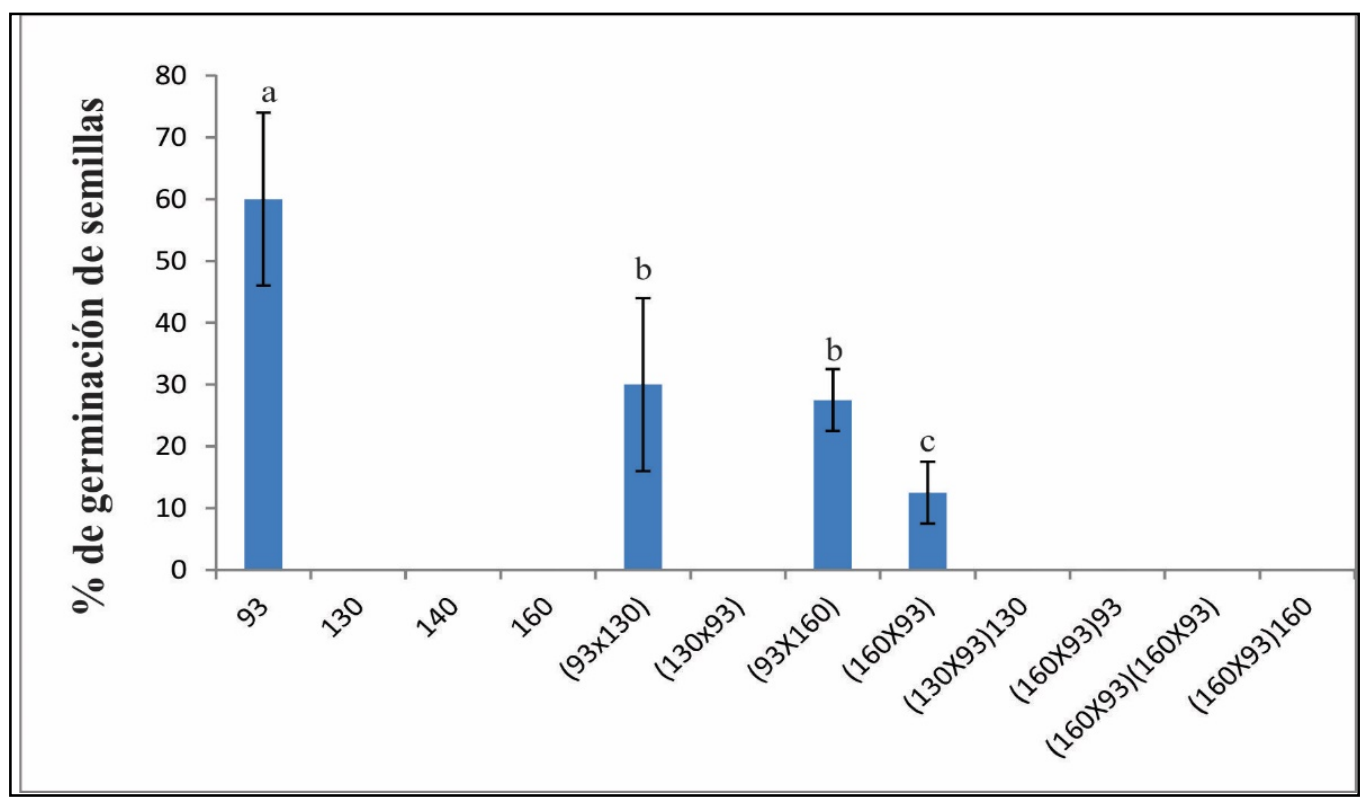

FIGURA 3: germinación de semillas de diversos genotipos de Cucurbita a $16^{\circ}$. Los genotipos con mismas letras no presentan diferencias significativas. Los genotipos sin letras no presentaron germinación (ANOVA, Tukey $\alpha \leq 0,05$ ). Las barras de error corresponden al desvío estándar. 
Las subespecies se diferencian no sólo en su \% de germinación sino también en la velocidad en que germinan. La Figura 4 muestra que el genotipo 93 y sus F1 $(93 \times 130)$ y $(93 \times 140)$ germinan en un $100 \%$ a las 48 horas y además que el resto de las accesiones alcanzan su mayor porcentaje de germinación pasado este tiempo.

Es de destacar el comportamiento diferencial de las subsp. andreana puesto que la accesión 140 alcanza más del 80 \% de germinación después de las 72 horas y la accesión 160 (en bajo número) germinó pasadas las 96 hs. El resto de los híbridos F1 comparten el patrón de velocidad de la forma parental pistilada correspondiente y germinan en mayor número después de las 96 horas. En tanto los F2 presentan velocidad intermedia (Fig. 4).

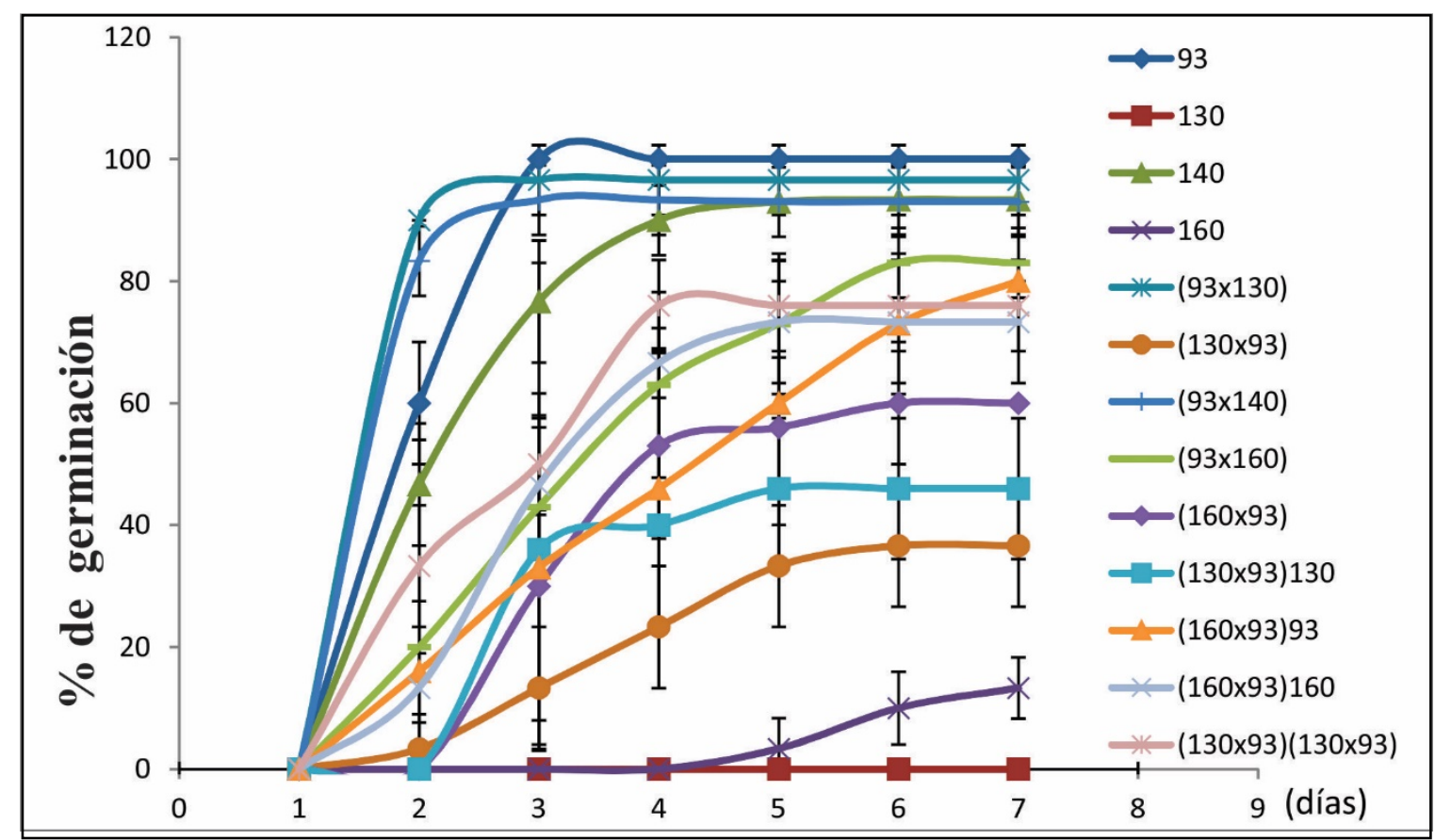

FIGURA 4: cinética de crecimiento de los distintos genotipos de Cucurbita a lo largo de los ensayos, incubación a $28^{\circ} \mathrm{C}$. Las barras de error corresponden al desvío estándar.

\section{$\underline{\text { Crecimiento radícular o vigor }}$}

La longitud radicular relativa demostró que existen diferencias en las tasas de crecimiento diario de los genotipos. La accesión 93 supera marcadamente el tamaño del resto de las accesiones y alcanza un promedio de $2 \mathrm{~cm}$ de crecimiento por día. La siguen luego sus 
híbridos $(93 \times 140)$ y $(93 \times 160)$ aunque sus tasas de $(\mathrm{cm} /$ día $)$ son mucho menores. Estos tres genotipos además se caracterizan por tener a simple vista radículas morfológicamente más gruesas y con más cantidad de pelos absorbentes. Nuevamente las accesiones de andreana se diferenciaron entre sí, la accesión 140 tiene una velocidad de crecimiento significativamente mayor que la accesión 160, sin embargo en lo que sí se asemejan es que ambas accesiones desarrollan radículas finas, de aspecto delicado y con pocos o sin pelos absorbentes. El resto de los híbridos tienen un crecimiento bastante similar, aunque estadísticamente se los puede diferenciar (Fig.5).

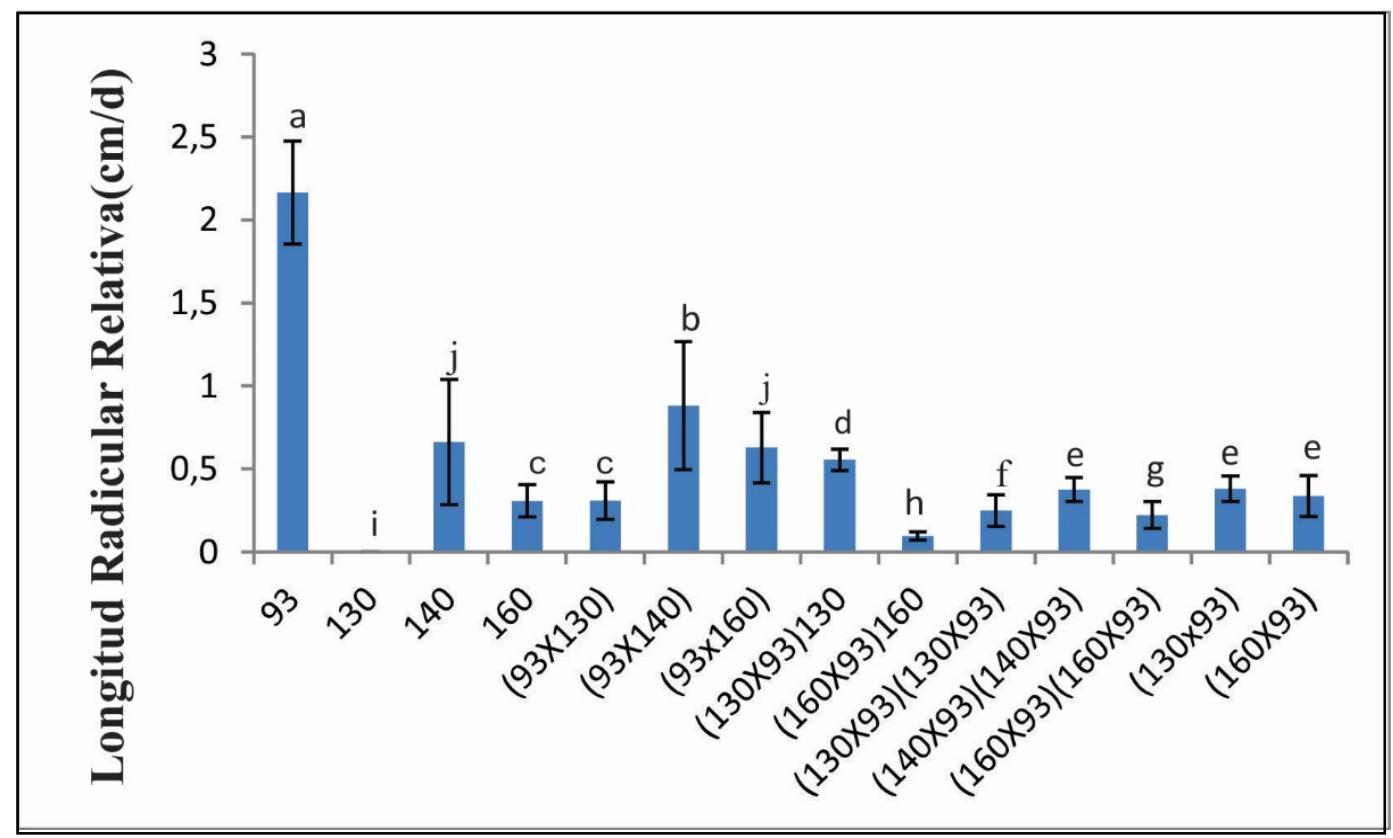

FIGURA 5: longitud radícular relativa (\%) de las semillas medidas a una incubación de $28{ }^{\circ} \mathrm{C}$. Los genotipos con mismas letras no presentan diferencias significativas (ANOVA, Tukey $\alpha \leq 0,05$ ). Las barras de error corresponden al desvío estándar.

\section{$\underline{\text { Preacondicionamiento a bajas temperaturas }}$}

El preacondicionamiento a bajas temperaturas no fue un recurso útil para romper la dormición del genotipo 130, pero sí favoreció la germinación de las accesiones 140 y 160 , las cuales a temperaturas aplicadas de manera constante y menores a $28^{\circ} \mathrm{C}$ no germinaron $\mathrm{o}$ lo hicieron sólo en un 10\% (Ver Fig. 2 y 3). Es de destacar que el intercambio estimuló aún más la germinación de los genotipos 93, sus híbridos F1 y los F2 y que el efecto fue independiente de las horas de exposición a las bajas temperaturas, ya que los dos ensayos arrojaron el mismo resultado (ver metodología y Fig.6). 


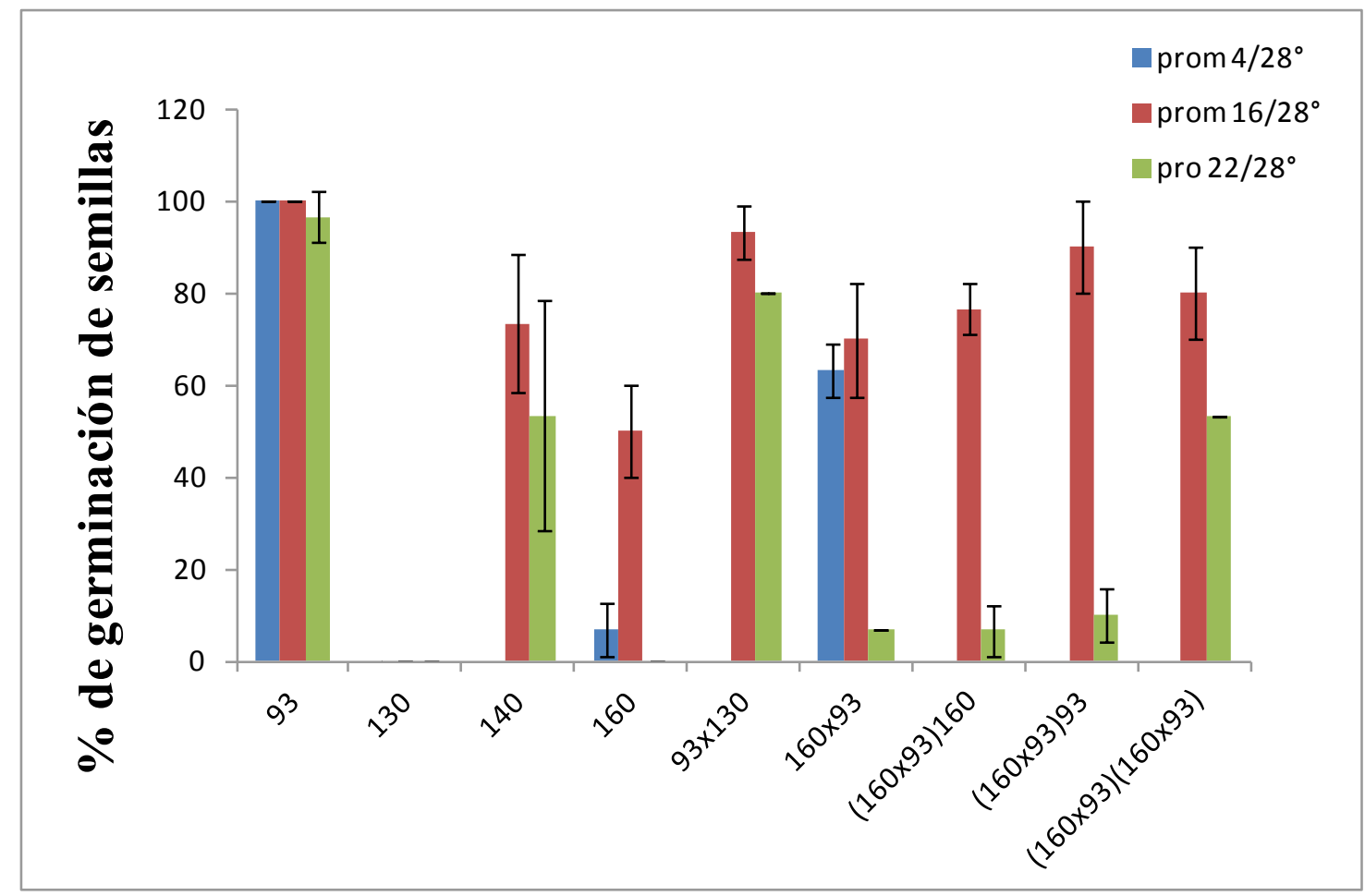

FIGURA 6: preacondicionamiento a bajas temperaturas sobre genotipos parentales e híbridos de la primera y segunda generación de Cucurbita. Se realizaron tres cambios de temperatura diferente para cada genotipo. Las barras de error corresponden al desvío estándar.

\section{Condición de luz}

Los ensayos realizados para determinar si la luz era un factor desencadenante de germinación, establecieron que la accesión 130 no germina ni en ausencia ni en presencia de luz mientras que la 93 germinó aún en ausencia de este factor. Los pequeños intervalos de luz tampoco resultaron efectivos para romper y liberar al genotipo 130 de su estado de dormición y en este último caso el resto de los híbridos y el genotipo 93 no mostraron un comportamiento diferente del que tuvieron en ausencia de luz, creciendo de igual manera. (Datos no representados en forma gráfica)

\section{Escarificación mecánica}


Al retirar las cubiertas seminales y dejar a los embriones aislados para evaluar su potencial de germinación, se observó que todos los embriones germinaron sin dificultad. A diferencia de lo que sucede con las semillas, los embriones de las accesiones de andreana germinaron sin restricción presentando entre un 80 y $90 \%$ de germinación. Por su parte el genotipo 93 y sus híbridos crecieron todos por igual, presentando 100\% de germinación (Fig. 7).

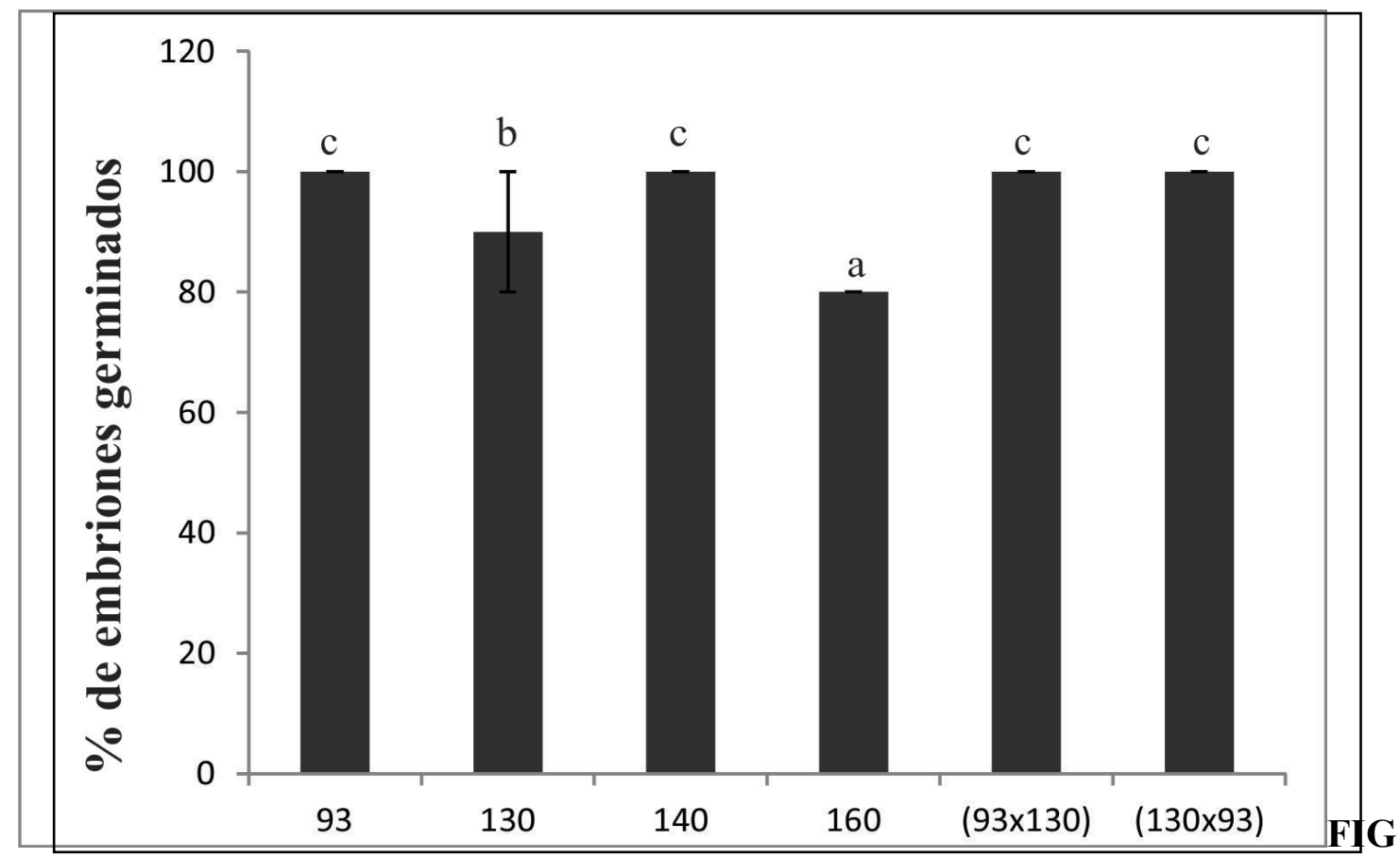

URA 7: germinación de embriones de diversos genotipos de Cucurbita incubados a $28^{\circ} \mathrm{C}$. Los genotipos con mismas letras no presentan diferencias significativas (ANOVA, Tukey $\alpha \leq 0,05)$. Las barras de error corresponden al desvío estándar.

\section{$\underline{\text { Tiempo de germinación }}$}

La curva de germinación demuestra que todos los embriones germinan en su máximo porcentaje a lo largo de los ensayos. Al igual que para las semillas los embriones de las accesiones 93, (93x130) y 140 alcanzan un alto porcentaje de germinación (100\%), pero alrededor de las 24 horas de comenzado el ensayo. El otro híbrido (130x93) también alcanza su máximo, pero tardando 24 horas más en completar ese número, lo que indica que todos tienen un gran potencial de crecimiento. Las dos accesiones restantes de andreana estabilizan su germinación alrededor de las 48 horas de comenzado el ensayo (Fig. 8). 


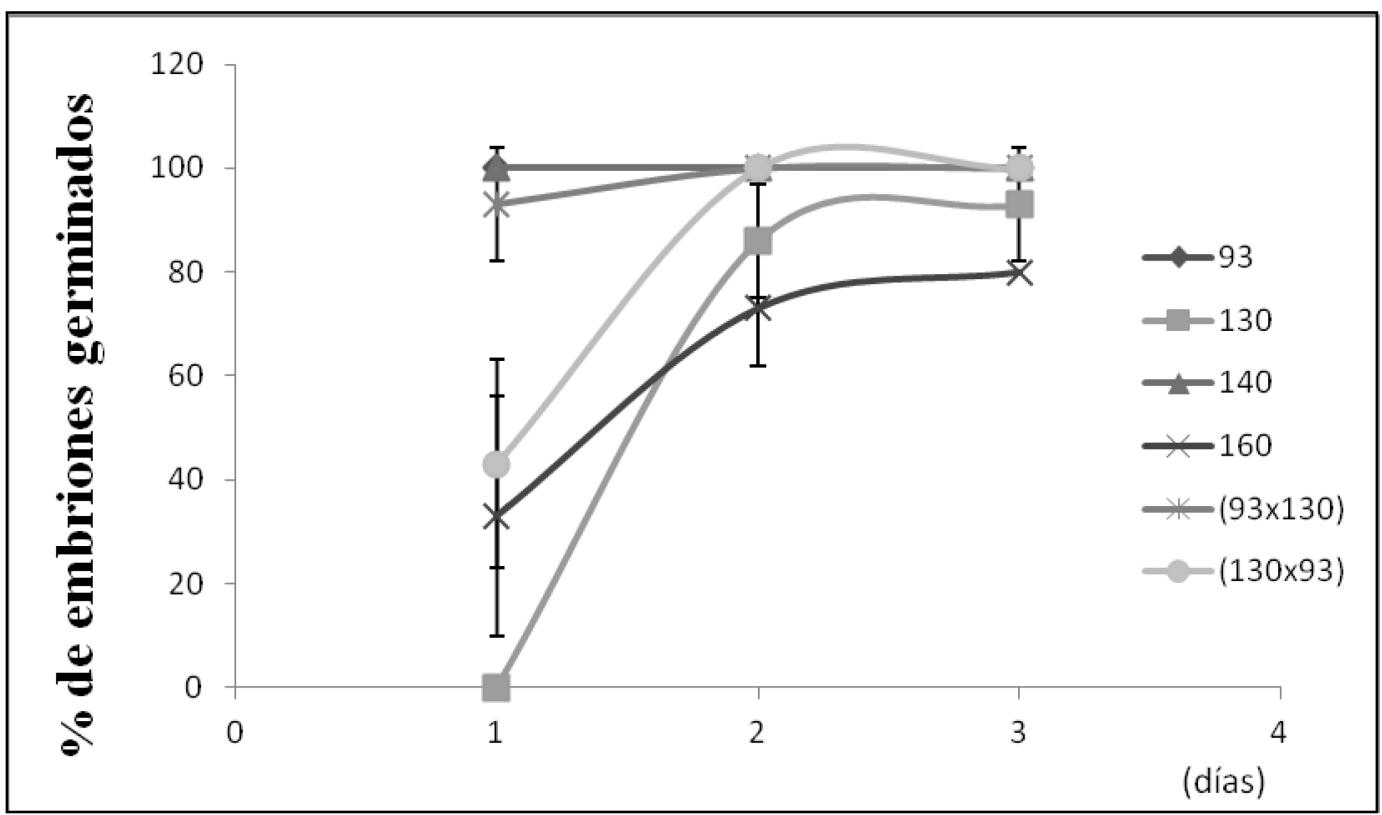

FIGURA 8: cinética de germinación de los distintos embriones de Cucurbita a lo largo de los ensayos incubados a $28^{\circ} \mathrm{C}$. La accesión 93 y 140 se encuentran solapadas pues muestran un 100 \% de germinación desde el día 1. Las barras de error corresponden al desvío estándar.

\section{Difusión de agua}

Los ensayos de imbibición permitieron determinar que en ninguna de las subespecies estudiadas existen restricciones o dificultades para que el agua se ponga en contacto con el embrión, aunque lo que sí se observó fue una difusión diferencial del agua al atravesar los tejidos que componen la testa.

A las 24 hs de haber comenzado la imbibición se observa que en la subsp. andreana el agua teñida con el indicador llegó a colorear la hipodermis y apenas el tejido esclerenquimático, mientras que en la subsp. maxima para ese mismo tiempo se observó una coloración completa de las esclereidas. Pasadas las 48 hs la subsp. andreana se iguala con su contraparte domesticada, lo que deja en evidencia el retraso en el pasaje de agua hacia el embrión (Fig. 9). 

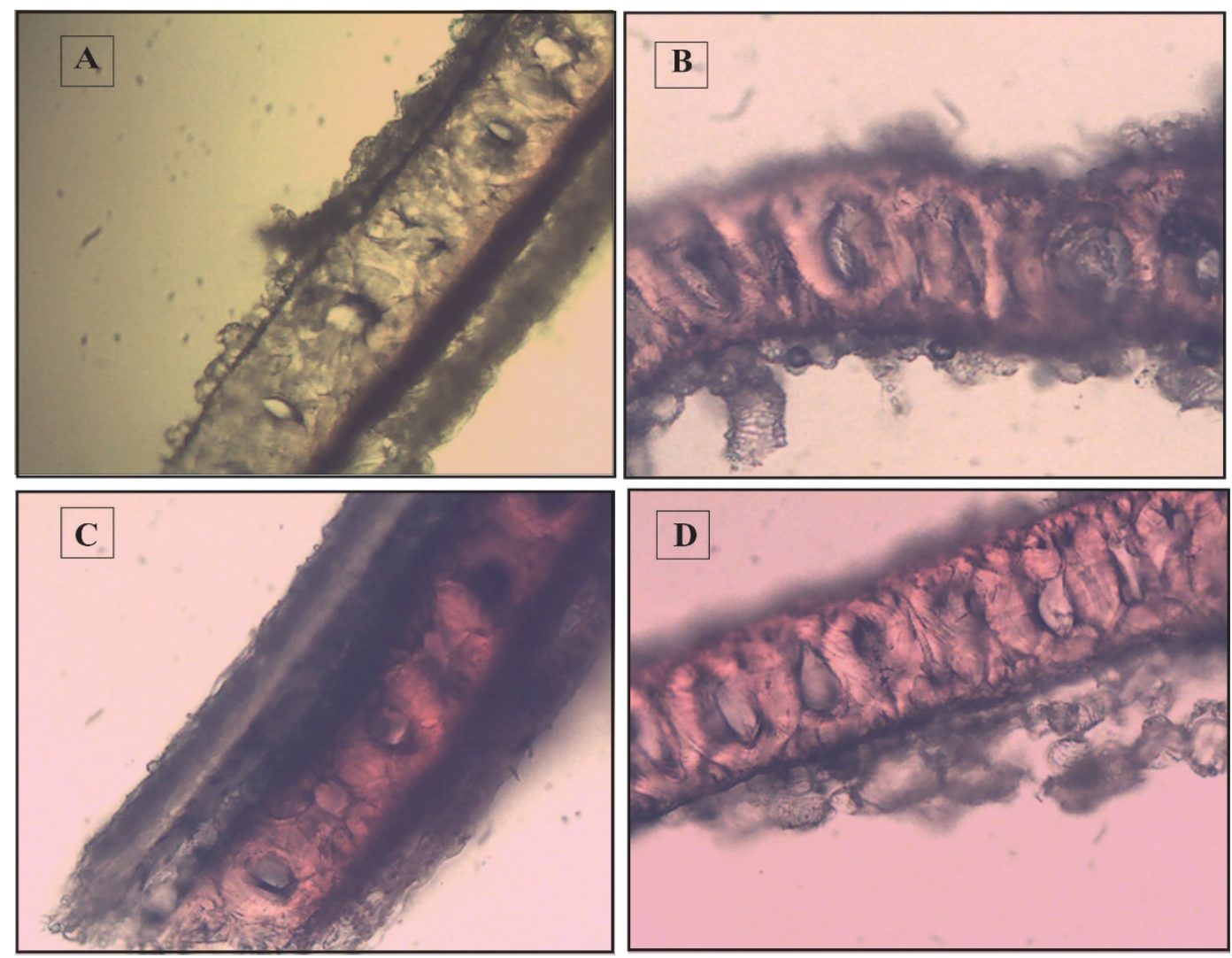

FIGURA 9: difusión de agua a través de los tejidos: A) accesión 130 a las 24 horas de imbibición, B) accesión 93 a las 24 horas de imbibición, C) accesión 130 a las 48 horas de imbibición, D) accesión 93 a las 48 horas de imbibición. Las barras de error corresponden al desvío estándar.

\section{$\underline{\text { Relación Peso seco/Peso Fresco (CHR) }}$}

El cambio de peso tras la imbibición indicó que la mayor cantidad de agua es absorbida durante las primeras $24 \mathrm{hs}$, habiendo diferencias significativas entre las accesiones. Pasadas las primeras 24 horas la absorción de agua disminuyó y las tres accesiones presentaron un cambio de peso homogéneo (entre un 5 y $10 \%$ respecto del total absorbido a las 24 hs) (Fig. $10)$. 


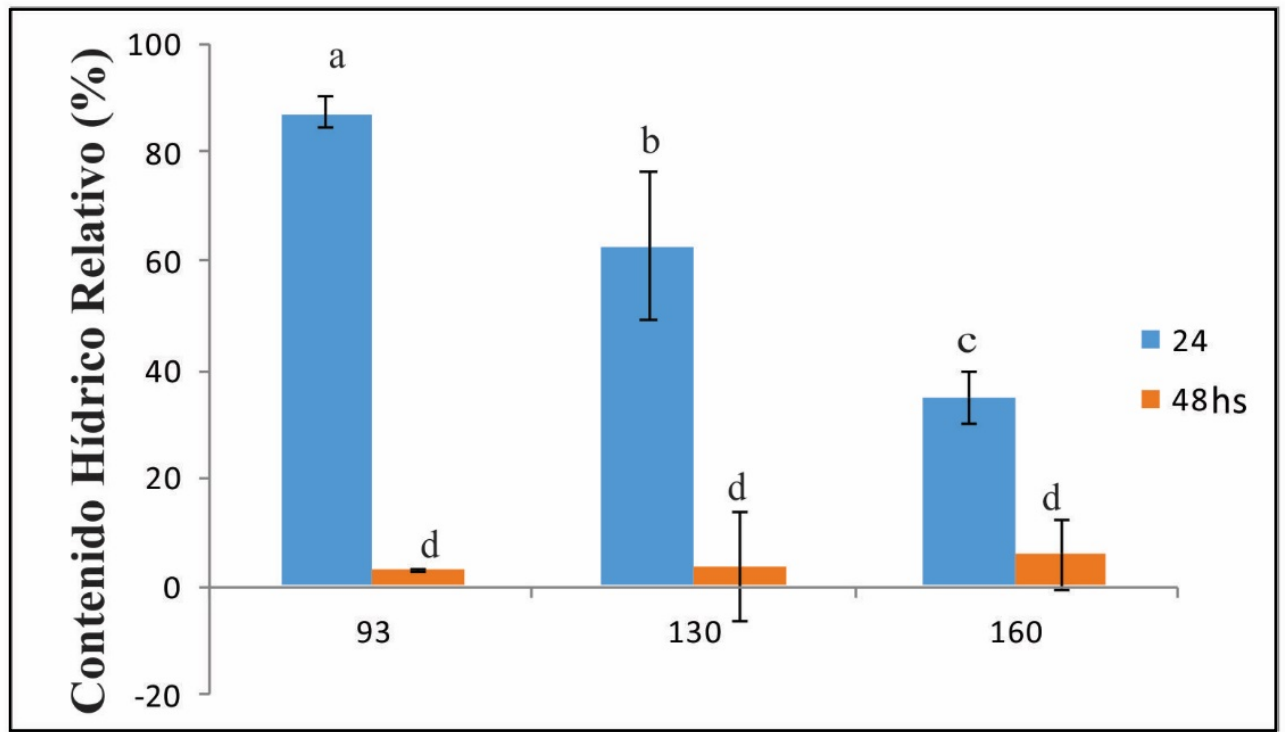

FIGURA 10: contenido hídrico relativo de las accesiones 93,130 y 160 a $28^{\circ} \mathrm{C}$ tras 48 hs de imbibición. Las letras arriba de las barras indican comportamientos similares (ANOVA, Test de Tukey $\alpha=0,05$ ). Las barras de error corresponden al desvío estándar.

\section{Obstrucción micropilar}

La obstrucción de la micrópila no fue un limitante para la entrada de agua en la semilla ya que pudo comprobarse que, al bloquear la micrópila de las semillas con cera parafina, éstas igualmente modificaron su peso, de manera que se puede establecer que las semillas absorben agua a través de toda la cubierta seminal. Lo que sí provocó la obstrucción fue un retraso en la germinación de, al menos, 24 hs en la subespecie maxima. En las semillas control (sin parafina) la germinación se dio a las 48 hs aproximadamente (ver Fig. 3) y en este caso al obturar la micrópila se prolongó la germinación hasta pasadas las 72 hs (Fig. 11). 


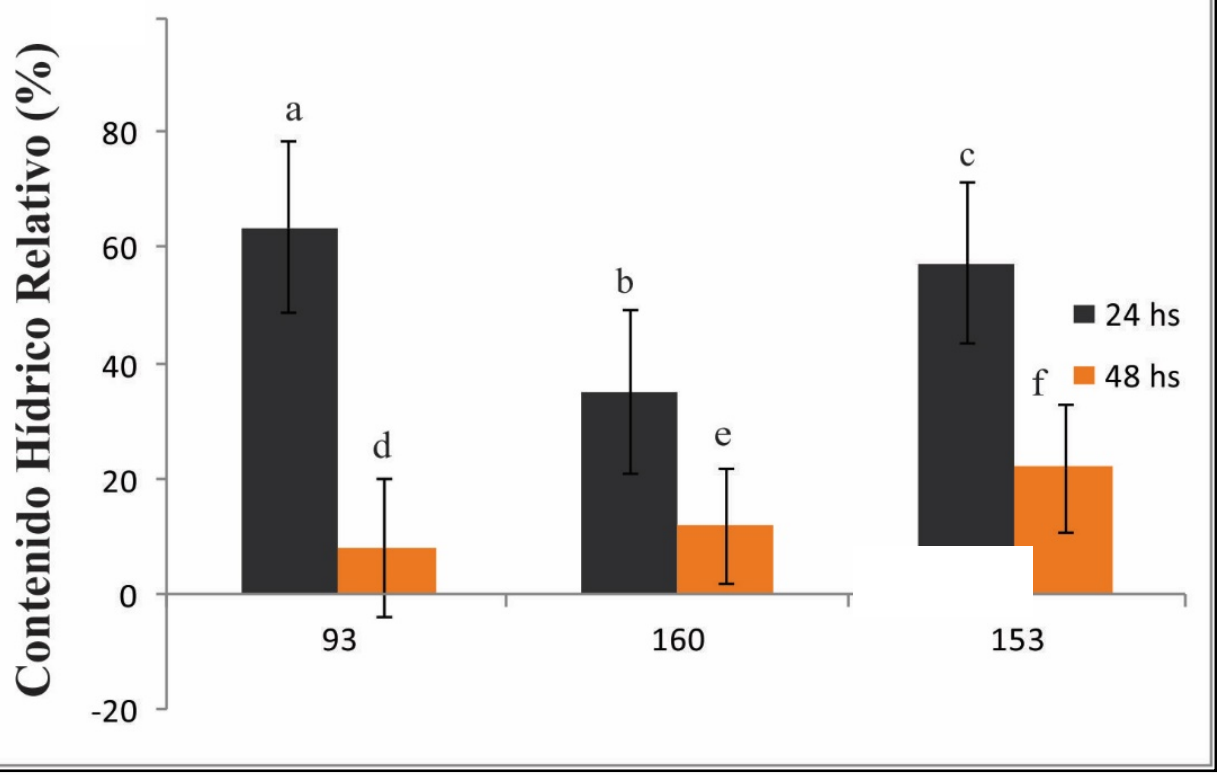

FIGURA 11: contenido hídrico relativo obturando micrópila de las accesiones 93, 160 y 153 a $28^{\circ} \mathrm{C}$ tras 48 horas de imbibición. Las letras arriba de las barras indican comportamientos similares (ANOVA, Test de Tukey $\alpha=0,05$ ). Las barras de error corresponden al desvío estándar.

\section{Hormonas}

Los resultados obtenidos indican que la aplicación exógena de ABA en embriones a temperatura constante $\left(28^{\circ} \mathrm{C}\right)$ y en su mayor concentración $(10 \mu \mathrm{M})$ inhibe totalmente la germinación de todos los embriones de los distintos genotipos ( $0 \%$ de germinación). A medida que el agregado de la concentración de esta hormona disminuyó se observó un porcentaje cada vez mayor de germinación. Las accesiones de la subespecie andreana son particularmente más sensibles a este inhibidor y en el caso de los F1 se mantuvo un comportamiento similar al de los parentales pistilados (Fig. 12). En el caso de los F2 la sensibilidad se vio disminuida y los genotipos mostraron mayor porcentaje de germinación. 

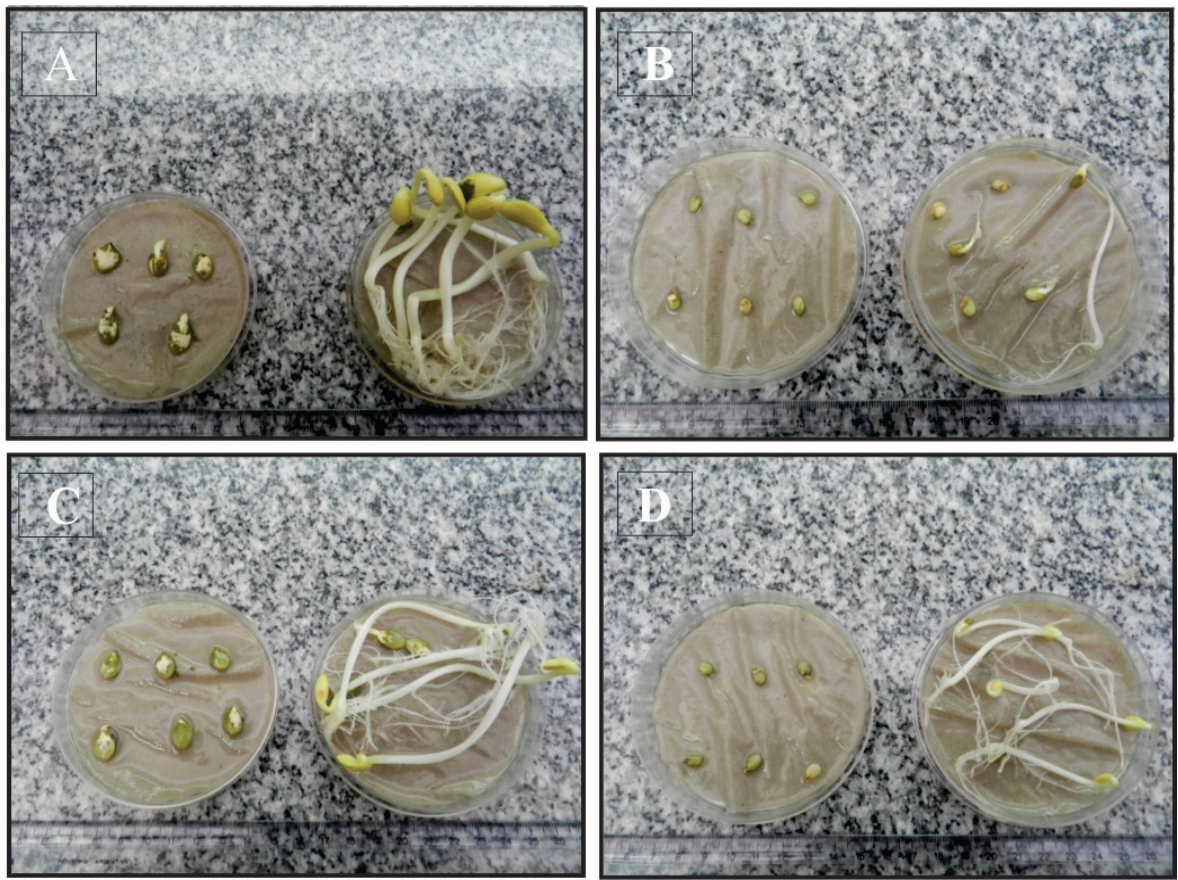

FIGURA 12: germinaci

nbriones parentales e I '

ıcubados en distintas concentraciones de $\mathbf{A B}$.

A: izq) Genotipo 93

ler) $(0,1 \mu \mathrm{m}) \mathrm{B}$ : izq)

Genotipo $130 \mathrm{izq})(10 \mu \mathrm{m})$, der) $(0,1 \mu \mathrm{m}) \mathrm{C}$ : izq) Genotipo 93x130 (10 $\mu \mathrm{m})$, der) (0,1 $\mu \mathrm{m})$ D: izq) Genotipo $130 \times 93(10 \mu \mathrm{m})$ y der $)(0,1 \mu \mathrm{m})$.

Al incubar los embriones bajo concentraciones diferenciales de ABA y de temperatura se observó que existe una interacción entre estos dos factores: la inducción de la dormición en embriones es más acentuada a bajas temperaturas, lo que significa que el ABA ejerce un mayor efecto sobre la germinación y de manera más pronunciada en la forma silvestre. Con el aumento de la temperatura de (16 a $\left.28^{\circ}\right)$ su efecto se fue reduciendo llegando a verificar germinación para todos los genotipos aún con las máximas concentraciones de ABA $(10 \mu \mathrm{M})$, mientras que a menores temperaturas no se observó germinación a dicha concentración (Fig.13). 

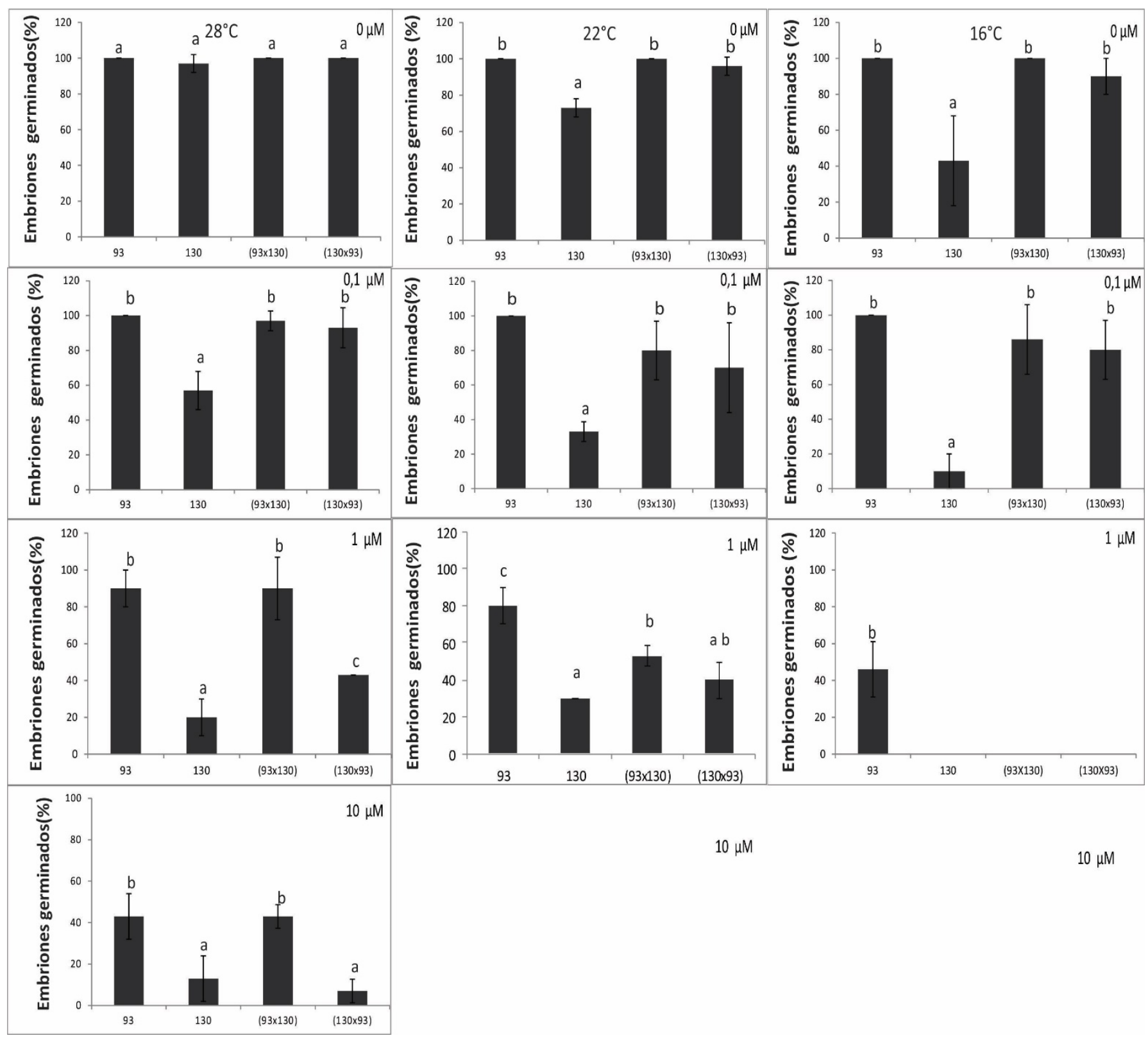

$10 \mu \mathrm{M}$

FIGURA 13: germinación de embriones de Cucurbita incubados a distintas temperaturas y a distintas concentraciones de ABA. A de 16 y $22^{\circ} \mathrm{C}$ y con $10 \mu \mathrm{M}$ de concentración no hubo germinación (cuadrante vacio). Los genotipos con mismas letras no presentan diferencias significativas (ANOVA, Tukey $\alpha \leq 0,05$ ). Las barras de error corresponden al desvío estándar.

$\underline{\text { Concentración de ABA en semillas }}$

Se observó que el genotipo 130 posee un valor inicial del contenido de pg ABA /mg peso 
seco en su cubierta seminal mayor que las del genotipo 93 esto es 406,3 pg ABA/mg peso seco en la forma silvestre frente a 155,7 en la forma domesticada. A su vez el contenido de ABA de toda la semilla es mayor en el genotipo 130. En ambas subespecies el comportamiento de los niveles de esta hormona fue similar a las dos temperaturas utilizadas, ya que presentaron una disminución abrupta a las 12 horas, estabilizando sus niveles a las 24 hs, para luego ir disminuyendo de manera más paulatina a las ambas temperaturas (Fig.14).

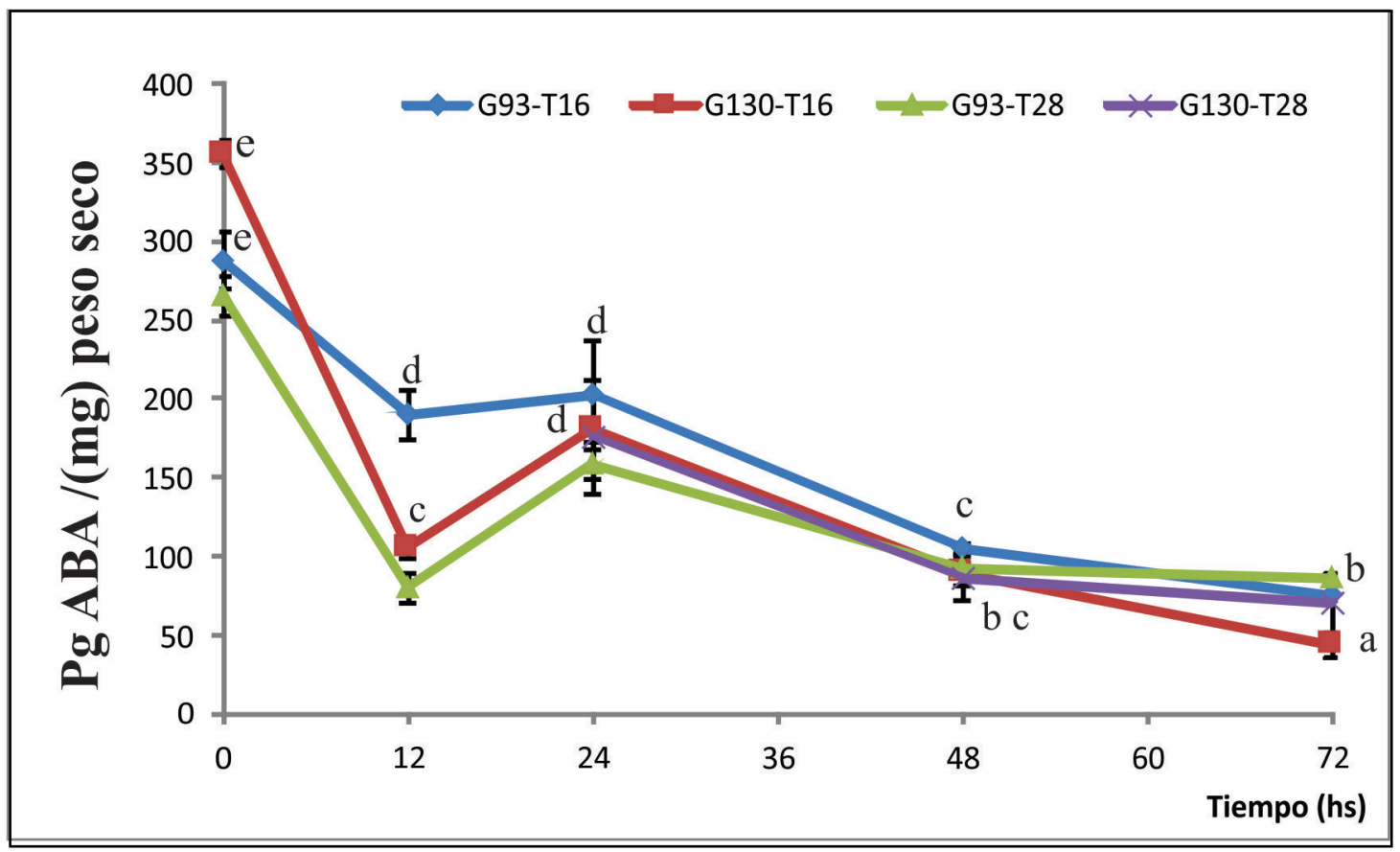

FIGURA 14: cuantificación del contenido de ABA en semillas de accesiones silvestre (130) y domesticada (93) a lo largo del tiempo (hs) a 16 y $28^{\circ}$ C. Las letras por encima de las línea azul indica la significancia para el genotipo 93 a $16^{\circ}$ y por debajo de éstas las significancia para el genotipo 130 a $16^{\circ}$. A $28^{\circ} \mathrm{C}$, no hay diferencias significativas entre los genotipos (ANOVA, Tukey $\alpha \leq 0,05$ ). Las barras de error corresponden al desvío estándar.

\section{Contenido de ABA en embriones}

El ABA contenido en los embriones es mayor en la formas silvestres que en las formas domesticadas aunque esta diferencia no es de la magnitud que presentan las testas. El 
genotipo 93 presenta una cinética de concentración de ABA irregular entre las 0 y $72 \mathrm{hs}$ de germinación. En cambio en la forma silvestre la cinética es más homogénea presentando una leve declinación significativa en sus niveles (Fig. 15).

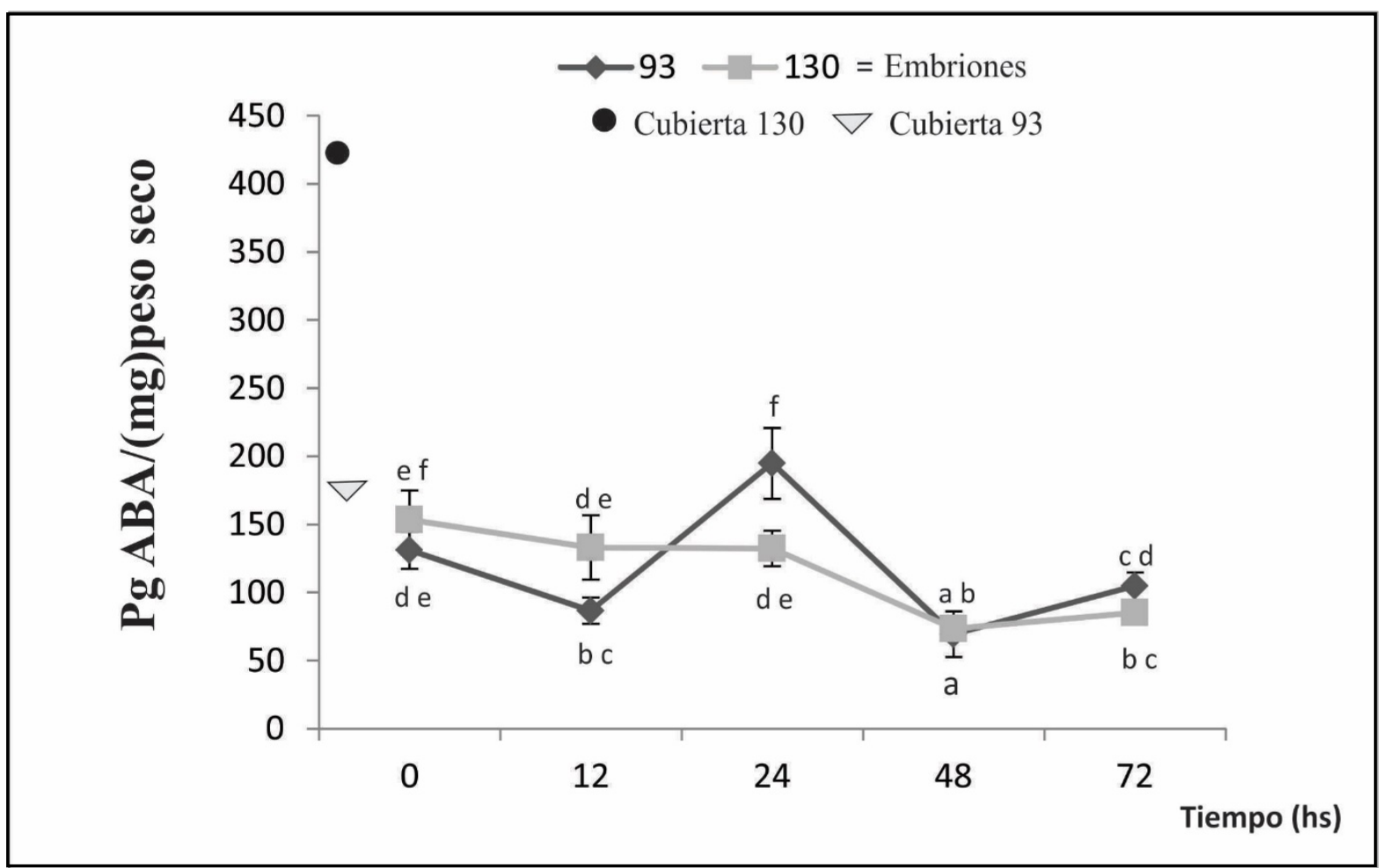

FIGURA 15: cuantificación del contenido ABA en embriones parentales -silvestre (130) y domesticado (93)- incubados a $28^{\circ} \mathrm{C}$ durante las primeras 72 hs. Los símbolos sin líneas indican el contenido de ABA inicial de las cubiertas seminales -previo a la imbibición- (406,3 pg ABA/mg peso seco para el genotipo 130 y $155 \mathrm{pg} \mathrm{ABA} / \mathrm{mg}$ peso seco para genotipo 93). Los genotipos con mismas letras no presentan diferencias significativas (ANOVA, Tukey $\alpha \leq \mathbf{0 , 0 5}$ ). Las barras de error corresponden al desvío estándar.

\section{$\underline{\text { Participación de las GAs }}$}

Se observó que el tratamiento con GAs rompe la dormición de las semillas del genotipo silvestre 130 (Fig. 16).

El tratamiento con paclobutazol, un inhibidor de la síntesis de giberelinas, inhibió totalmente la germinación de embriones del genotipo 130, el cual fue revertido por el tratamiento 
combinado con giberelinas. La germinación de los embriones del genotipo domesticado fue inhibida sólo en un $40 \%$ por el paclobutrazol pero no fue revertida por el agregado exógeno de la hormona (Fig. 17).

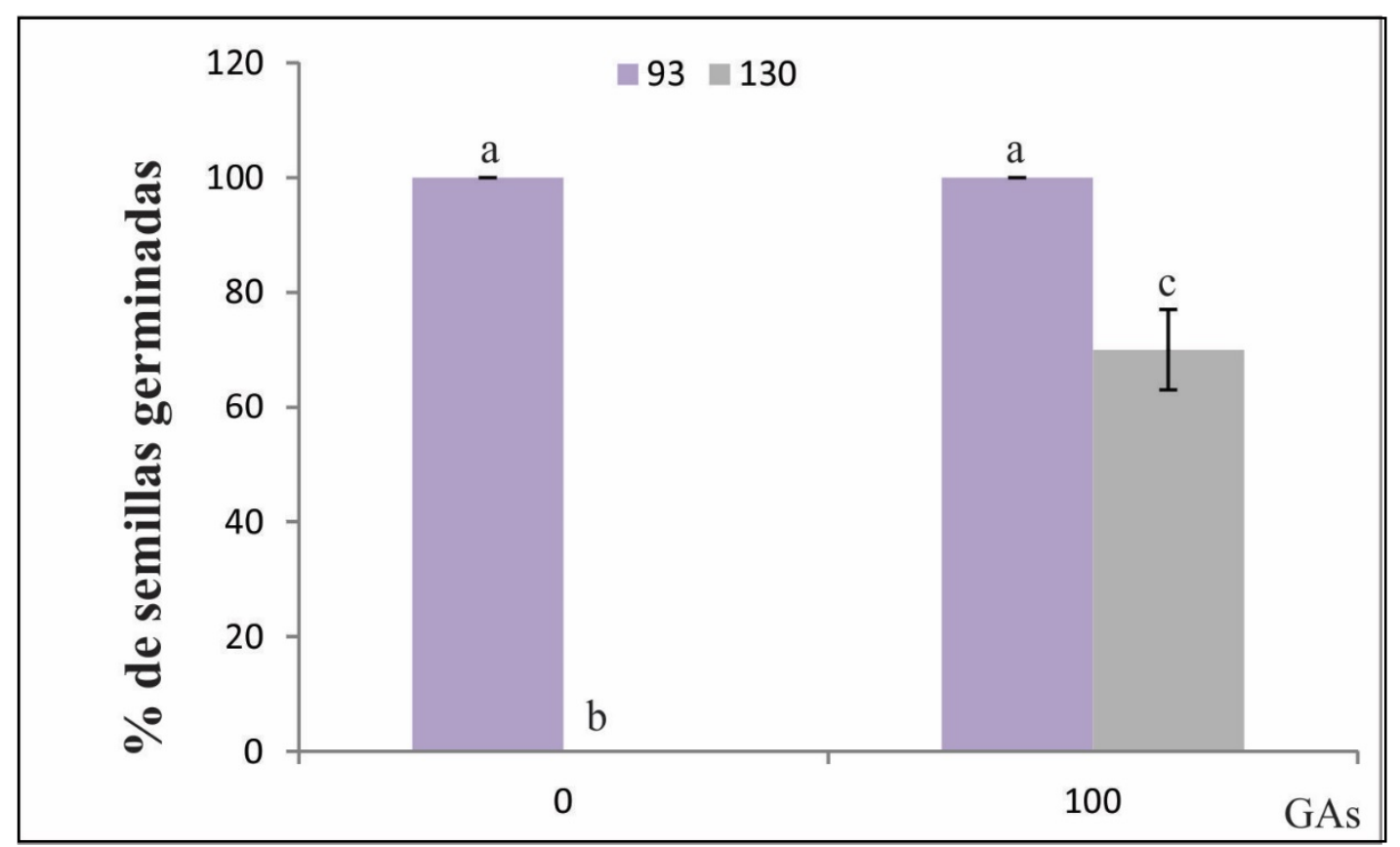

FIGURA 16: germinación de semillas parentales -silvestre (130) y domesticado (93)incubadas a $28^{\circ} \mathrm{C}$ con 0 o $100 \mu \mathrm{M}$ GAs. Los genotipos con mismas letras no presentan diferencias significativas (ANOVA, Tukey $\alpha \leq 0,05$ ). Las barras de error corresponden al desvío estándar. 


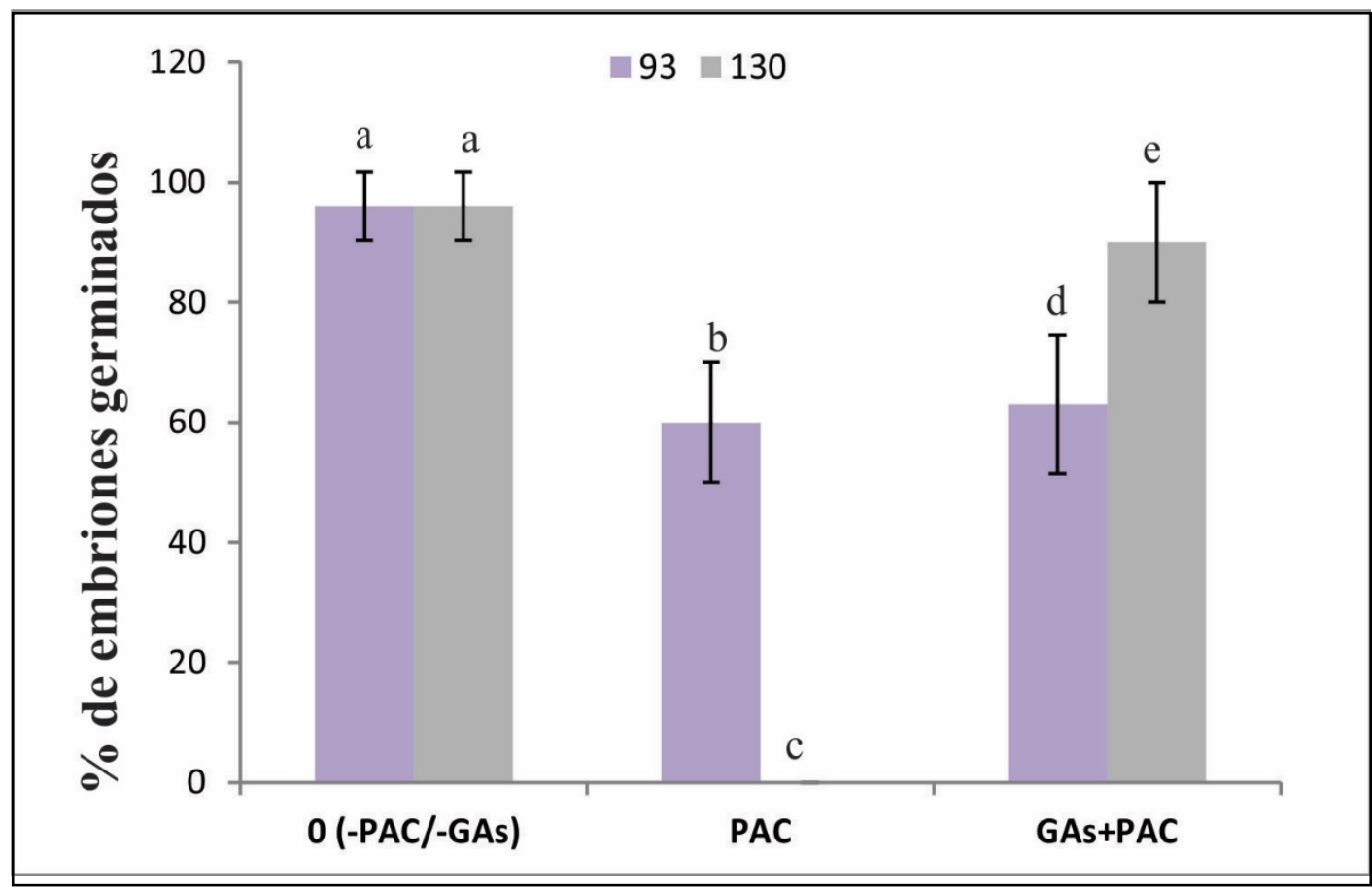

FIGURA 17: germinación de embriones parentales, silvestre (130) y domesticado (93),

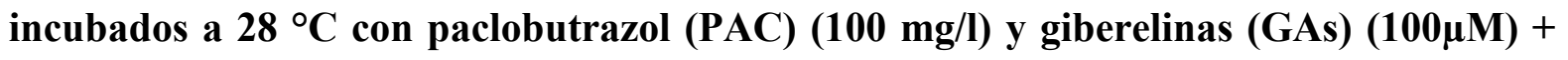
PAC (100 mg/l). Los genotipos con mismas letras no presentan diferencias significativas (ANOVA, Tukey $\alpha \leq 0,05$ ). Las barras de error corresponden al desvío estándar.

\section{DISCUSIÓN Y CONCLUSIONES GENERALES DEL CAPÍTULO}

Cucurbita maxima con sus dos subespecies C. maxima subsp. maxima y su posible antecesor C. maxima subsp. andreana presentan un comportamiento fisiológico diferencial en relación a las condiciones de germinación y por ende de dormancia. Por un lado se determinó que las semillas recién cosechadas de la subsp. maxima germinan inmediatamente a las distintas temperaturas seleccionadas, aunque a $28^{\circ} \mathrm{C}$ se observó el mayor porcentaje de germinación. El genotipo 93 nunca presentó dificultades para la germinación, de manera que se lo puede indicar como con muy baja dormición y por ello definirlo como aquél que posee "el carácter fisiológico domesticado". Las accesiones de la subsp. andreana presentaron varias diferencias no sólo entre ellas, sino también respecto del genotipo domesticado: la accesión 130 no germinó en ninguna de las condiciones de temperatura y humedad, pudiendo entonces decirse que posee "el carácter fisiológico silvestre" propiamente dicho por poseer una dormición prolongada (más de cinco meses de latencia tras la cosecha). La accesión 140, 
en cambio, presentó altos niveles de germinación a $28^{\circ} \mathrm{C}(80 \%$ de germinación), pero presentó dormición a temperaturas más bajas, de manera que se puede establecer que esta forma presentó una dormición relativa, es decir que sólo presenta dormición ante determinadas condiciones ambientales, ésta condición permite considerar a la accesión 140 como poseyendo "carácter fisiológico espontáneo" (considerando que su comportamiento germinativo se deba a algún grado de cruzamiento con la forma domesticada). A diferencia de las anteriores, la accesión 160 mantuvo un porcentaje de germinación muy bajo (10\%) en todos los ensayos incubados a $22^{\circ}$ y $28{ }^{\circ} \mathrm{C}$ y no germinó a $16^{\circ} \mathrm{C}$, de manera que a esta accesión la podemos definimos también como "silvestre" y con dormición.

En el caso de las accesiones pertenecientes a los genotipos F1, pudo observarse que el patrón de germinación y crecimiento se asemeja principalmente al del parental pistilado (femenino) ya sea éste de carácter silvestre, espontáneo o domesticado y en el caso de las accesiones pertenecientes a los cruces F2, presentaron un variado porcentaje de germinación, adquiriendo la tendencia de las formas domesticadas.

El preacondicionamiento a bajas temperaturas favoreció la germinación de al menos la accesión silvestre (160) y espontánea (140), mejoró el porcentaje de germinación de los híbridos F1 y F2, pero no fue capaz de romper la dormición de la forma silvestre (130).

En relación a la difusión de agua no se observó dificultad para su ingreso hasta llegar al embrión, ambas subespecies incrementaron su peso tras la imbibición (sobre todo alrededor de las 24 hs) demostrando que este proceso no limita la germinación y que la difusión de agua no está involucrada en la expresión de la dormición de las semillas. Sin embargo a través del ensayo de tinción se demostró que en la subespecie andreana, el contacto del agua con el embrión se da alrededor de las 48 hs, mientras que en la forma domesticada esto se logró a las 24 hs de comenzada la imbibición. Se puede sugerir también que la micrópila es un posible lugar de entrada de agua en la semilla, pero no el único, dado que su bloqueo no modificó el peso de la semilla de manera sustancial, permitiendo considerar que la difusión se produce a través de toda la cubierta seminal. El bloqueo de la micrópila afectó más la germinación en la forma domesticada 93 que en la silvestre, puede considerarse entonces que esta diferencia podría involucrar la adquisición/modificación de algún carácter que acelere la difusión de agua para la germinación en las domesticadas.

Respecto del régimen lumínico, es bien conocido que el control de la germinación puede ser mediado por la calidad de la luz. La acción de los fitocromos y la reversibilidad de acuerdo a 
las condiciones ambientales reduce el período de dormición de varias especies (Casal y Sanchez, 1998). Sin embargo para el caso aquí analizado, la luz no sería un factor que esté relacionado con la dormición en la subsp. andreana, ya que la accesión silvestre no germinó ni en presencia ni en ausencia de este factor.

Hormonalmente se comprobó que el contenido de ABA de las cubiertas seminales de las dos subespecies es diferencial: $406 \mathrm{Pg} \mathrm{ABA} /(\mathrm{mg})$ peso seco para las cubiertas de la forma silvestre frente a $155 \mathrm{Pg} \mathrm{ABA} /(\mathrm{mg})$ peso seco para la cubierta de la forma domesticada, indicando que no sólo la alta concentración de esta hormona, sino también la elevada sensibilidad mostrada por sus embriones es lo que evita la germinación (Finch-Savage y Leubner-Metzger, 2006). Este efecto también fue reconocido en granos de cebada en donde la latencia se encontró reducida por la disminución del contenido de ABA en el embrión y su sensibilidad a la hormona (Benech-Arnold et al., 1999). A su vez es importante destacar que el ABA tuvo mayor efecto a bajas temperaturas y sobre el genotipo silvestre más que sobre el resto, observándose que al aumentar la temperatura el efecto de la concentración de ABA sobre todos los genotipos fue menor. En el caso de los híbridos F1 su respuesta fue intermedia no sólo por las características de la testa (de origen materno), sino también por la condición de híbrido del embrión. En cuanto al efecto de las concentraciones, es marcada la diferencia entre el silvestre y domesticado, en la forma silvestre se reduce su porcentaje de germinación al aplicarse una mínima concentración de $\mathrm{ABA}$ a $28^{\circ} \mathrm{C}$, mientras que para la forma domesticada no hay efecto alguno, lo mismo sucede para las otras temperaturas. Este resultado nos permite inferir que a lo largo de la domesticación la sensibilidad al ABA se ha reducido, así como también que se ha perdido una dependencia para la germinación a temperaturas mayores. A diferencia de las semillas, en los embriones no hay diferencia marcada de la concentración de este regulador, de manera que el contenido de ABA en las cubiertas seminales de las semillas del genotipo silvestre (medido antes de la imbibición) contribuiría al establecimiento de la latencia.

La aplicación exógena de GAs en semillas silvestres incubadas a $28^{\circ} \mathrm{C}$ fue positiva para modificar el balance hormonal en el genotipo silvestre y así romper su dormición. Ello sugiere que en el balance ABA/GAs del genotipo silvestre la proporción entre las hormonas provoca la dormición. Contrariamente esta proporción en el domesticado estimula la germinación. Fue previamente observado que la inhibición de la síntesis de GAs imita el control ejercido por el ABA en la maduración de embriones de maíz (White y Rivin, 2000). 
En este sentido, se estableció una inhibición total de la germinación tras el tratamiento con paclobutrazol lo que demostró que se necesitan GAs recién sintetizadas para la germinación de embriones silvestres. El genotipo domesticado mostró una inhibición parcial tras la adición del inhibidor, lo que indica que el nivel de GAs es suficientemente alto para permitir su crecimiento.

Tras la remoción de las cubiertas de las semillas se demostró que la germinación de embriones fue viable en todos los casos sin restricciones e igual para todos los genotipos. Sin embargo, comparando la germinación de los embriones a distintas temperaturas, se observó que ante el descenso de ésta el crecimiento se redujo más acentuadamente en el genotipo silvestre indicando mayor sensibilidad a este factor ambiental. Podemos plantear entonces que la cubierta seminal funcionaría como una barrera protectora para el embrión según el rango de temperaturas en que se desarrolle tal como lo describieron autores como Boeswwinkel y Bouman (1995), Bewley (1997).

En base a todos estos factores evaluados y a los resultados obtenidos (en terminos generales) se propone asociar el comportamiento de los genotipos y generar grupos funcionales en base a la presencia o no de germinación:

Grupo 1-Semillas con dormición prolongada (fisiológicamente de tipo silvestre). En este grupo se incluye a los genotipos que mostraron entre 0 y $10 \%$ de germinación: (130), 130 (93x130), 160.

Grupo 2-Semillas con dormición relativa (germina en determinadas condiciones de $\mathrm{T}^{\circ}$, fisiológicamente de tipo espontánea). Se observó sólo entre un 20 y 60 \% de germinación (160x93) 160, 160 (93x160), (93x130)130, (130x93) 130.

Grupo 3-Semillas con una germinación aproximadamente entre un 60 y $80 \%$ (fisiológicamente de tipo intermedio): 93(160x93), 160(160x93), (93x130)93, (130x93) (130x93), (140x93) (140x93), (160x93) (160x93), (130x93), (160x93), (93x130) (93x 130). Grupo 4-Semillas con muy baja dormición se inhiben a bajas temperaturas (fisiológicamente de tipo domesticada): 93, 140, (93x130), (93x140), (93x160), (160x93)93, (130x93)93,

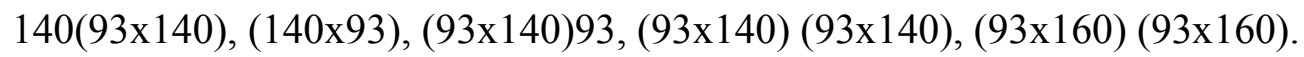




\section{CAPÍTULO 4}

\section{ARQUEOLOGÍA Y MORFOLOGÍA}

En este capítulo se presentaran -en una primera sección- las investigaciones ligadas al estudio de los caracteres morfológicos biométricos en frutos, pedúnculos y semillas de los ejemplares obtenidos en los cruces experimentales (ver cap. 2), de referencia y de los macrorrestos arqueobotánicos seleccionados para su estudio. En una segunda sección se presentan los estudios realizados a nivel anatómico en las cubiertas seminales de ejemplares actuales y arqueológicos. En cada sección se presentan primeramente los antecedentes del tema, materiales y método, resultados y una breve discusión que será luego articulada en una discusión y conclusión general del capítulo.

\section{HIPÓTESIS DE TRABAJO}

"Es posible evaluar el tipo de dormición en el pasado a través del estudio de correlatos morfológicos de caracteres fisiológicos tanto en $C$. maxima subsp. maxima como en $C$. maxima subsp. andreana, sus híbridos respectivos y diversos cruzamientos".

\section{OBJETIVO PARTICULAR DE ESTE CAPÍTULO}

El objetivo de este capítulo es identificar caracteres biométricos (morfológicos y anatómicos) que permitan diferenciar: C. maxima subsp. maxima, C. maxima subsp. andreana, cruces entre ambas subespecies (F1 y F2) y retrocruzas, al igual que los distintos grupos funcionales (ver cap. 3), que sean aplicables a restos arqueobotánicos desecados.

Este objetivo se llevó a cabo mediante tres aproximaciones:

-estudios sobre tamaño y forma en semillas 
-estudios biométricos macroscópicos en pedúnculos y pericarpios

-estudios anatómicos biométricos en cubiertas seminales

\section{ARQUEOBOTÁNICA Y DOMESTICACIÓN}

\section{INVESTIGACIONES EN EL NOROESTE DE ARGENTINA}

A lo largo de la historia de las investigaciones arqueológicas en el Noroeste de Argentina (NOA) se han interpretado los restos vegetales recuperados en los sitios de manera diferencial. A comienzos de la década del cincuenta la importancia de éstos era de escasa a nula. En general el arqueólogo determinaba las semillas, las mazorcas o cual fuera el material vegetal "in situ" que sus ojos pudieran ver, sin que esto aportara mayormente a las interpretaciones sobre los modos de vida pasados (Capparelli et al., 2010). Hacía los años sesenta y setenta se hace más frecuente la presencia de especialistas, botánicos u agrónomos, para la determinación de restos vegetales, sobre todo a partir del interés de ciertos grupos de investigadores en reconstruir los procesos de domesticación vegetal en la zona y los inicios de las prácticas agrícolas (el llamado "proceso de agriculturización"); un interés marcado por la polaridad silvestre/domesticado y cazador-recolector/agricultor-pastor (Yacobacio y Korstanje, 2007, Lema, 2008).

A comienzos de la década del noventa, con el surgimiento y afianzamiento de la arqueobotánica y/o paleoetnobotánica (Archila et al., 2008), tiene lugar un estudio más sistemático de los restos vegetales, incorporando técnicas de recuperación en campo, más adecuadas ( $v g$. flotación) y nuevas metodologías de análisis (vg. microscopía) (Pochetino y Scatolín, 1991, Capparelli 1997, Pochettino et al., 1998, Rodríguez, 1999). Desde ese momento a esta parte, la disciplina ha ido creciendo, incorporando el análisis de microrrestos (vg. almidones, fitolitos), incorporando nuevas metodologías de campo y laboratorio (Pochettino y Cortella 1999, Babot 2003, 2004, 2006) y abarcando una serie cada vez mayor de sitios, áreas y problemáticas. Entre éstas últimas la domesticación vegetal y el establecimiento de modos de vida agrícolas en el NOA cobraron un nuevo impulso, contando con una gama mayor de evidencias para su interpretación y con marcos conceptuales distintos. Entre éstos últimos podemos mencionar los que procuran superar las dicotomías 
antes mencionadas, las investigaciones sistemáticas en áreas específicas que permiten reconstruir la diversidad de situaciones que se dieron en el pasado y una integración mayor de la evidencia arqueobotánica a otros indicadores arqueológicos ( $v g$. cambios en la tecnología lítica, en los patrones de asentamiento o en las fuentes de aprovisionamiento de diversas materias líticas). Todo lo cual abreva en un panorama general donde la domesticación de especies vegetales comenzaría ca. 4000 AP y se afianzaría en un modo de vida agropastoril aldeano $c a$. 2000 AP (ver bibliografía específica y estado actual de las investigaciones en Lema, 2014).

\section{ARQUEOBOTÁNICA Y DOMESTICACIÓN DE CUCURBITAS}

Con una extensión desde el Sur de Estados Unidos hasta el norte y centro de Argentina las Cucurbitas han sido consideradas desde hace tiempo entre las primeras en ser incorporadas en los procesos de domesticación en América (Cutler, 1961). Las evidencias más tempranas de domesticación datan de 9.000 -10.000 AP para el sudoeste de Mesoamérica (Kistler et al., 2015, Lira Saade et al., 2016) para C. pepo, C. argyrosperma y taxa relacionados, proponiéndose la domesticación de C. pepo subsp. pepo en el actual territorio mexicano y de la subsp. ovifera posteriormente en el territorio comprendido actualmente en el este de EE. UU. En el caso de Sudamérica, también se cuenta con restos de igual antigüedad (10.000 AP) para el caso de C. moschata y C. ecuadorensis en la costa norte de Perú y la costa sur de Ecuador (Dillehay et al., 2007, Stothert et al., 2003, Piperno et al., 2000,2002, Piperno y Stothert, 2008, Lira Saade et al., 2016). Los principales avances en los estudios de domesticación en Cucurbita se han hecho principalmente en los taxa antes mencionados (Decker y Wilson, 1986, Cowan y Smith, 1993, Cowan, 1997, Hart, 2004, Smith, 1997, 2006a, Piperno y Stothert, 2008, Kistler et al., 2015), en tanto la historia de manejo y cultivo de la ampliamente distribuida C. ficifolia aún se desconoce (Lira Saade et al., 2016). A pesar de ser igualmente importantes en la historia de la domesticación americana, los miembros más australes del género han recibido menor atención y estudio. Uno de los registros más tempranos se ubica en territorio uruguayo, donde se recuperaron silicofitolitos de Cucurbita sp. en montículos concheros asociados al Río Santa Lucía con fechas cercanas a los 48004200 años AP (Beovide y Campos, 2014, Iriarte et al., 2001). Los fitolitos de los frutos de 
Cucurbita son depósitos de células pétreas que sirven para protección de los frutos frente al ataque de herbívoros y patógenos -puede haber miles por $\mathrm{cm}^{2}$ - y a nivel arqueológico resisten la degradación del paso del tiempo (Piperno, 2008). En cuanto al reconocimiento de las especies, los fitolitos de las formas silvestres de Cucurbita tienen un largo aproximado que va desde los 64 a $120 \mu \mathrm{m}$ y un ancho de 28 a $64 \mu \mathrm{m}$. En tanto que en las formas domesticadas su valor varía entre 56 a $134 \mu \mathrm{m}$ de largo y 56 a $136 \mu \mathrm{m}$ de ancho (Piperno y Stothert, 2008), de manera que las formas silvestres adquieren una forma alargada y plana y las domesticadas son más isodiamétricos (Piperno et al., 2002). Lamentablemente en el caso del registro de Uruguay no contamos con más precisión taxonómica para su análisis en la vinculación con procesos de domesticación.

En lo que refiere a C. maxima subsp. maxima y subsp. andreana los macrorrestos más tempranos fueron mencionados para Pampa de La Ventanilla en la costa central de Perú, donde Lanning en 1967 (en Whitaker y Cutler, 1968) reporta el hallazgo de semillas, pedúnculos y pericarpios de la subsp. andreana. Posteriormente Whitaker y Cutler (1968) indican que se trataría de Cucurbita ecuadorensis, y desde entonces no se ha reportado la presencia de dicha subespecie en sitios arqueológicos peruanos.

En territorio argentino los testimonios más tempranos parecen ser los de la Gruta del Indio (Atuel, Mendoza) donde se encontraron semillas de C. maxima con una antigüedad de 3800 años AP en un contexto funerario, junto a otros restos de plantas domesticadas, cuyos fechados oscilan entre los 2200 y 1900 años AP (Lagiglia, 1980, 2001). Otras menciones sobre vestigios de uso y consumo de $C$. maxima se reportan para los sitios Los Morrillos (San Juan, 0 a 375 DC con restos de frutos y semillas de C. moschata y C. maxima, Gambier 1977), Agua Amarga (Mendoza) (ca. 600-450 años AP) (Ots et al., 2011), La Poma (Salta) (ca. 650-500 DC) (Pochetino 1985), entre otros (ver listado en Lema 2009a). Los restos de Antofagasta de La Sierra (Catamarca) identificados por Babot sobre la base de silicofitolitos en artefactos de molienda datan del período Arcaico (ca. 3680 +/-50 AP, sitio Peñas Chicas; Hocsman, 2006). En este caso, al igual que en el de Uruguay antes mencionado de similar antigüedad, no se pudo llegar a una determinación específica por lo cual no podemos evaluar cabalmente si se trata de formas silvestres, domesticadas o intermedias.

Finalmente cabe mencionar la presencia de restos de C. moschata en el Noroeste y Centro oeste del país (Lema, 2009a), al igual que restos de C. ficifolia en el sitio Los Amarillos (Jujuy) que corresponden a una edad de 1200-1420 DC (Würschmidt, 2003). 


\section{RESTOS ARQUEOBOTÁNICOS Y SITIOS ANALIZADOS EN ESTA TESIS}

Los macrorrestos analizados corresponden a semillas, pedúnculos y pericarpios de $C$. maxima en estado seco, recuperados por distintos investigadores tras excavaciones arqueológicas llevadas a cabo en distintas provincias de Argentina y regiones del territorio peruano. A este conjunto también se suman otros restos tardíos (Ratto et al., 2014) y tempranos (Pampa de los Perros). Se tendrá en cuenta las identificaciones taxonómicas realizadas por Lema en los trabajos citados (en estos últimos se encuentra información más detallada sobre los sitios y contextos arqueológicos a analizar, a continuación presentaremos un breve panorama de cada uno).

\section{Localización de los sitios arqueológicos (Fig. 1).}

En total se contó con material arqueobotánico proveniente de nueve sitios arqueológicos, los correspondientes al período Arcaico (ca. 3000-2000 años AP) son Bandurria, Cerro Lampay y Pampa de los Perros, todos del centro-sur de Perú. Los correspondientes al período Formativo (ca. 2000-1200 AP) son Los Viscos de la provincia de Catamarca, SSalLap 20 o Puente del Diablo y Pampa Grande de la provincia de Salta, los del período Tardío o de Desarrollos Regionales (ca. 1200-800 AP) son los sitios Las Champas, Bebé de La Troya y Lorohuasi, todos ubicados en territorio catamarqueño 

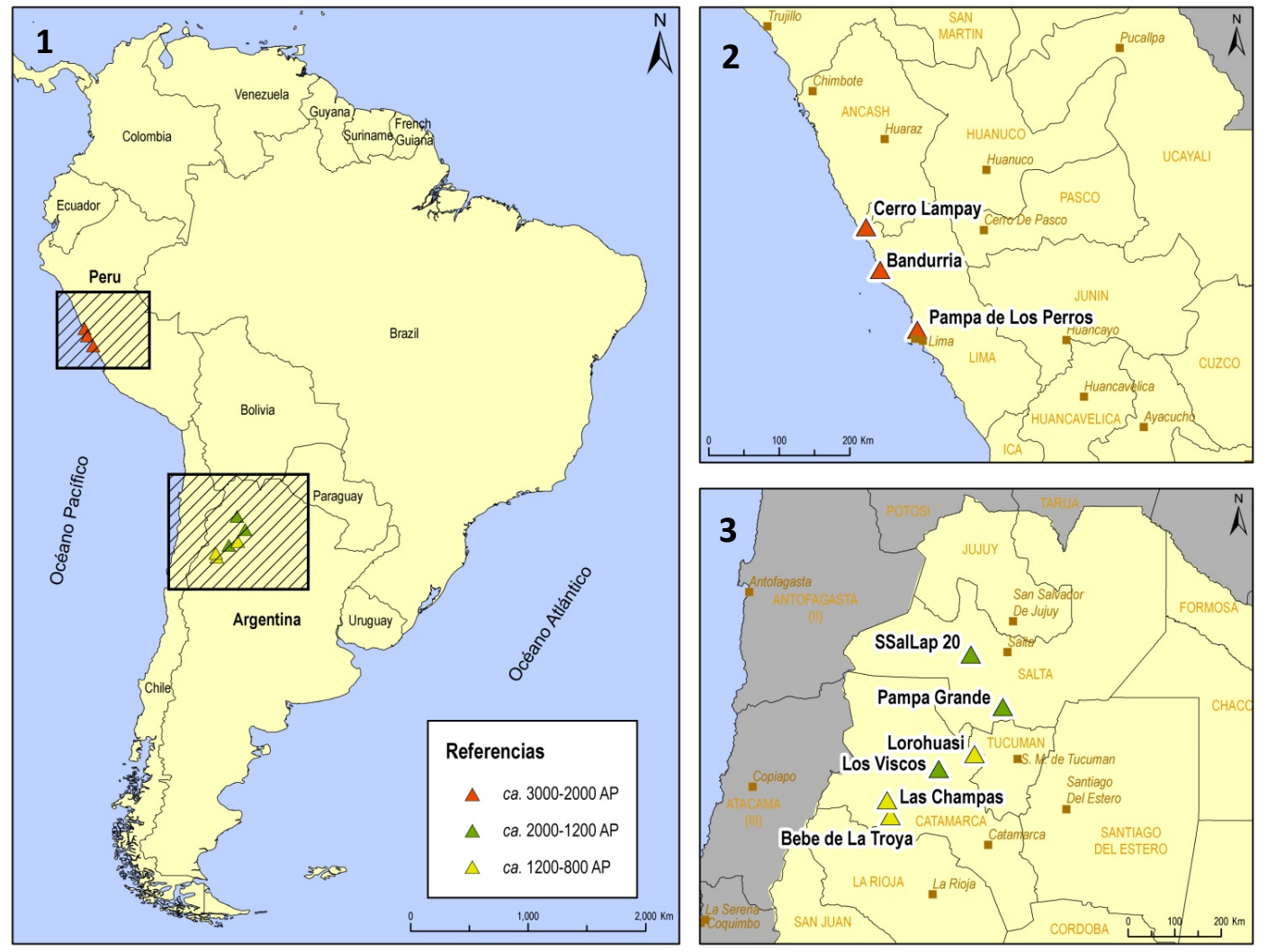

FIGURA 1 Mapa 1: ubicación de los sitios arqueológicos del centro de Perú y Noroeste Argentino. Mapa 2: detalle de los sitios peruanos (Bandurria, Cerro Lampay, Pampa de Los Perros). Mapa 3: detalle de los sitios del NOA (Ssallap 20, Los Viscos, Pampa Grande, Las Champas, Bebé de La Troya, Lorohuasi).

\section{Sitios del Área Andina Central y Meridional de Perú (Fig. 1, mapa 2)}

Bandurria: Ubicado en la provincia de Huacho (Departamento de Lima), este sitio a cielo abierto se encuentra en las cercanías de la costa y fue excavado por la Dra. Fung en la década del setenta. El sitio abarca unas 54 hectáreas y presenta dos ocupaciones con distinta cronología (4.530-3.740 AP/ 3.300-1.700 AP). El hallazgo consta de un montículo ceremonial rodeado por 250 unidades residenciales. Entre los restos vegetales recuperados se ha identificado Gossypium barbadense, Capsicum sp, Arachis hipogaea, Cucurbita sp., Psidium guajaba, Lucuma bifera y Lagenaria siceraria (Vega-Centeno Sara-Lafosse, 2005, Haas y Creamer, 2006). Los restos de semillas de C. maxima subsp. maxima analizados en esta tesis corresponden a los de momento Arcaico y se consignan en la Tabla 1. 
Cerro Lampay: ubicado en el Valle de Fortaleza a $220 \mathrm{Km}$ al norte de Lima, es un sitio con arquitectura pública a cielo abierto; su cronología data del período Intermedio tardío (9001400 DC) y del período Precerámico final o Arcaico tardío (3000-1500 AC); entre los restos vegetales se han identificado también frutos de Prosopis pallida, Phaseolus vulgaris, Gossypium barbadense, pericarpios de Lagenaria siceraria, semillas de Capsicum sp, Sapinus saponaria y marlos de maíz, entre otros (Vega -Centeno Sara-Lafosse,2005), Los restos de semillas de $C$. maxima subsp. maxima analizados en esta tesis corresponden a los de momento Arcaico y se detallan en la Tabla1.

Pampa de Los Perros: ubicado en el valle bajo del río Chillón, sobre su margen derecha, aproximadamente a 2,35 $\mathrm{km}$ del océano Pacífico y a una altitud promedio de $47 \mathrm{msnm}$. Este sitio posee evidencias arqueológicas de distintos momentos, siendo la principal secuencia constructiva y ocupacional la más temprana, correspondiente al Precerámico Final (2,500 1,800 AC), al igual que el sitio El Paraíso, ubicado exactamente en la otra margen del río (Cornejo Maya, 2013). Pampa de los Perros ocupa un área de 1.5 ha y está formado por cinco sectores: pirámide, recintos al sur de la pirámide, plaza circular, recintos al norte de la pirámide y plataforma cuya conformación fue variando a lo largo del tiempo. Las semillas analizadas en esta tesis fueron recuperadas de niveles de relleno del Precerámico Final e identificadas por Lema como correspondientes a C. maxima aff. subsp. maxima (Tabla 1).

\section{Sitios del Noroeste Argentino (Fig. 1, mapa 3)}

Los Viscos: ubicado en el valle del Bolsón, departamento de Belén, Catamarca, corresponde a un alero de unos $380 \mathrm{~m}^{2}$ con construcciones de piedra cuadrangulares excavado por la Dra Korstanje y equipo. Este abrigo tiene evidencias de distintos momentos de ocupación: Formativo, Desarrollos regionales y contacto colonial (Korstanje y Würschmidt, 1999). Maloberti y Zapatiel (2003) analizaron primeramente los restos vegetales, identificando restos de pedúnculos y pericarpios de C. moschata y C. maxima, además de restos de maíz y de Lagenaria siceraria. Los trabajos realizados por Lema (2009) indican que el diámetro basal de los pedúnculos identificados como C. maxima subsp. maxima varían entre 10 y 19 mm, ubicándose los mismos en una posición intermedia entre las medidas registradas en ejemplares actuales de dicha subespecie y de C. maxima subsp. andrena. Lamentablemente no se pudo precisar la cronología de estos restos. La autora antes citada analizó dos semillas 
posiblemente correspondientes al período Aguada, determinando que una de ellas es afín a $C$. moschata y la otra es afín a C. maxima subsp. maxima. Esta última es analizada en esta tesis (Tabla 1).

Puente del Diablo (SSalLap 20): Ubicado a $4 \mathrm{Km}$ al sur de la Localidad de La Poma, Salta, y a $3.000 \mathrm{msnm}$, el sitio es una cueva de $7 \mathrm{~m}$ de profundidad, 4,5 de ancho máximo y 1,8 $\mathrm{m}$ de alto. Fue excavada en la década del setenta por personal del Museo de Arqueología "Pio Pablo Díaz" de la localidad de Cachi, con la colaboración de la Lic. M. D. Arenas. Los enterratorios y niveles de ocupación excavados se consideraron de momentos arcaicos transicionales hacia la agricultura (Nuñez Regueiro, 1974, Tarragó 1980, Castro y Tarragó, 1992, Lema, 2009a). Estudios posteriores sobre este sitio indicaron la presencia de dos momentos de ocupación, uno del arcaico temprano ( $c a .10 .000$ AP) y otro del Formativo ( $c a$. $2000 \mathrm{AP}$ ); en este último caso se trata de ocupaciones efímeras con restos de cerámica monócroma gris temprana y consumo de frutos de Prosopis sp. y cactáceas (Lema 2009a, 2012, Lema et al., 2012). De este último período proceden los restos analizados en esta tesis identificados por la autora antes citada como C. maxima aff. subsp. maxima con caracteres posiblemente intermedios (Lema, 2009, 2012) (Tabla 1).

Pampa Grande: ubicado en el Departamento de Guachipas, en la Serranía de Las Pirguas, Salta, esta localidad arqueológica está conformada por siete cuevas ubicadas entre 2.500 y $3.000 \mathrm{msnm}$. A los trabajos que inicialmente realizó Ambrosetti en el área a principios del siglo XX, seguidos por los de Aparicio en la década del '40 se suma la exploración de las cuevas Los Aparejos, El Litro y Caverna I a la V a cargo de A. Rex González a inicios de la década del '70 (González, 1972, Baldini et al., 1998, 2003), de donde procede el material aquí analizado. Los restos vegetales de estas cuevas fueron determinados por diversos investigadores (Whitaker, Ms, 1983, Pochetino, 1985, Lema, 2009a). A continuación se describen los abrigos rocosos de donde se obtuvieron restos de C. maxima de acuerdo con las investigaciones de Lema (2009a).

a) Cueva Los Aparejos: ubicada en el Cerro Pirgua Chica, en una quebrada afluente al Río Grande de La Pampa, a $80 \mathrm{~m}$ de su cauce, tiene unos $60 \mathrm{~m}$ de largo. En esta gran cueva se han identificado sectores de ocupación y funerarios (González, 1972, Baldini et al., 1998, 2003, Lema 2009a). 
b) Cueva El Litro: ubicada sobre el faldeo del Cerro El Rodeo, en la Quebrada Las Cuevitas, es un gran abrigo de entrada pequeña, cuenta con una zona de ocupación temporaria y otra de entierros (González, 1972, Baldini et al., 1998, 2003, Lema 2009a).

c) Caverna II: ubicada en la cercanía de El Litro (a $12 \mathrm{~m}$ por encima), tiene malas condiciones de habitabilidad, por lo que se considera que ésta habría sido de uso exclusivamente funerario (González, 1972, Baldini et al., 1998, 2003, Lema 2009a).

d) Caverna IV: ubicada en el margen derecho de la Quebrada Lampazar es un abrigo rocoso con una entrada principal y varías secundarias, propuesta como de uso funerario (González, 1972, Baldini et al., 1998, 2003, Lema 2009a)

De este sitio se recuperaron gran número de restos de zapallo, tanto de frutos como de pedúnculos y semillas junto a una gran riqueza de taxa vegetales, entre los que se cuentan restos de P. vulgaris var vulgaris y aborigineus, L. siceraria, Arachis sp., Zea mays, Prospis sp., entre otros (Pochettino, 1985, Lema, 2009a).

La presencia de restos de pericarpios de C. maxima subsp. andreana, en esta localidad arqueológica fue sugerida por Whitaker, a quien González envió en su momento todos los restos de Cucurbitáceas (González, 1972, Whitaker, Ms). Y confirmada posteriormente por Lema (2009a) mediante análisis anatómicos de restos hallados en Los Aparejos, los cuales fueron fechados por AMS y arrojaron una antigüedad de 1720 +-50 AP (AA82783) correspondiente a una edad calibrada (1 sigma) de 259-433 DC. AP. El alto de los pericarpios de la subsp. andreana era de 0,95 y $2,08 \mu \mathrm{m}$, todos lisos y de color amarillo o castaño, algunos se encontraban enrollados sobre sí mismos. De acuerdo con Lema (2009) algunos fragmentos de pericarpio presentaron valores de solapamiento entre la subespecie andreana y maxima, correspondientes a frutos sin verrugas, con lóbulos o totalmente lisos y algunos moderadamente lignificados (Lema, 2009a). Esta autora también identificó pericarpios de C. maxima subsp. maxima (entre 2,38 y 6,64 $\mu \mathrm{m}$ de alto) con caracteres diversos: frutos lobulados, con verrugas, lisos, lignificados o no, pasando del amarillo al ocre, castaño, castaño-rojizo y ceniciento-grisáceo. Esto coincide con lo observado también por Whitaker (1983) acerca de la presencia de diversos cultivares de la subsp. maxima en esta localidad arqueológica. Según su informe en la cueva Los Aparejos se halló un fruto turbaniforme entero con 10 lóbulos (8 mayores y 2 menores) de 8,2 $\mathrm{cm}$ de alto y en el área de la corola de 9,3 cm de diámetro. Whitaker (Ms.) señala también que el pericarpio posee 5 mm de grosor máximo y que, en sección transversal, posee células de apariencia circular. 
También el autor menciona restos de pericarpios de un fruto el cual, según su estimación, habría tenido aproximadamente $28 \mathrm{~cm}$. de largo y $8 \mathrm{~mm}$ de grosor, asemejándose a los frutos del cultivar "banana" actual (Whitaker, 1983). Según Lema (2009a) esta gran diversidad respondería a diversas líneas de selección dentro de estas poblaciones de zapallos; la autora halló en algunos restos de pericarpios de la subsp. maxima orificios en sus bordes con restos de cordelería para la suspensión de los frutos, al igual que algunos de ellos tiznados o con restos de sustancias colorantes. En este sentido, su propuesta es que habría frutos de pericarpio delgado y no lignificado para ser consumidos y otros frutos -cuyos pericarpios superan los $3 \mathrm{~mm}$ de espesor, lignificados y rígidos- que habrían sido usados como recipientes, además de haber sido posiblemente consumidos. El análisis que Lema (2009a) realizó de los pedúnculos y semillas de esta localidad arqueológica le permitió además identificar ejemplares con caracteres intermedios junto a otros con rangos métricos de diámetro propio de formas domesticadas entre los primeros; y caracteres morfológicos y anatómicos de las segundas propios o afines a la subsp. maxima.

Los mismos restos de pericarpios, pedúnculos y semillas que analizó Lema (2009a) serán re estudiados en esta tesis (Tabla1).

Las Champas y Bebé de La Troya: ubicados al oeste de Tinogasta, en la provincia de Catamarca, ambos sitios corresponden a enterratorios bajo condiciones distintas. Las Champas se ubica en barrancas fluviales a $1.862 \mathrm{msnm}$. El sitio corresponde a un entierro de adulto en tierra, que ha sido re-intervenido debido al saqueo de piezas, y posee una antigüedad de ca. 1400 años AP (Ratto et al., 2010, 2014). Los restos vegetales asociados corresponden a semillas identificadas como $C$. aff. maxima subsp. maxima o moschata junto a granos de Ch. quinoa var melanospermum ("ajara", maleza de la quínoa con relevancia en el culto a los cerros y a los antepasados, (ver Villagrán y Castro 2003). Los análisis llevados a cabo indicaron que los granos de ajara habrían pasado por un procesamiento que involucró remojo en agua, en tanto las semillas de zapallos no habrían sido procesadas de manera previa a ser depositadas (Ratto et al., 2014). Las semillas de C. maxima aff. subsp. maxima son las que se analizarán en esta tesis (Tabla 1).

Bebé de La Troya es un barreal que se encuentra a $1.395 \mathrm{msnm}$. El hallazgo se dio a conocer tras la realización de una obra vial que dio como resultado la presencia de un entierro de un infante en una gran urna junto a varios pucos y restos vegetales (Ratto et al., 2007, 2014). 
Acompañando a las semillas de $C$. aff. maxima subsp. maxima o moschata se recuperaron restos de Chenopodium quinoa, Zea mays y endocarpos de Prosopis sp. (Ratto et al., 2014). La datación indicó una edad de 1.330-1.428 años AP y los estudios anatómicos sobre algunas semillas afines a la subsp. maxima indicaron la posibilidad de la presencia de formas intermedias o hibridas. Estas semillas de C. maxima aff. subsp. maxima son las que se analizan en esta tesis (Tabla 1).

Lorohuasi: ubicado sobre una antigua terraza fluvial de un río tributario al Guanchin, en el Departamento de Santa María, Catamarca, a $2000 \mathrm{msnm}$ este sitio se caracteriza por ser un canchón en damero regular de unos $7000 \mathrm{~m}^{2}$, a $2.142 \mathrm{msnm}$. Este campo agrícola se encuentra en la proximidad de tres enterratorios que tienen una datación de $400+/-70$ y 440 \pm 50 AP (Ratto et al., 2010). Los autores señalan la presencia junto a los cuerpos, de macrorrestos de maíz y algarroba como parte de los acompañamientos funerarios junto a textiles, cerámica y cestería; los contextos se ubicarían temporalmente entre finales del Período Tardío -preinka- y comienzos del Hispánico. Los restos fueron determinados por Lema como afines a C. maxima subsp. maxima (Tabla 1).

\begin{tabular}{|c|c|c|c|c|c|c|c|c|c|}
\hline & \multicolumn{3}{|c|}{ Perú } & \multicolumn{5}{c|}{ Argentina } \\
\hline & Bandurria & $\begin{array}{c}\text { Cerro } \\
\text { Lampay }\end{array}$ & $\begin{array}{c}\text { Pampa } \\
\text { de los } \\
\text { Perros }\end{array}$ & $\begin{array}{c}\text { Los } \\
\text { Viscos }\end{array}$ & $\begin{array}{c}\text { SSalLap } \\
20\end{array}$ & $\begin{array}{c}\text { Pampa } \\
\text { Grande }\end{array}$ & $\begin{array}{c}\text { Las } \\
\text { Champas }\end{array}$ & $\begin{array}{c}\text { Bebé de } \\
\text { La } \\
\text { Troya }\end{array}$ & Lorohuasi \\
\hline Semillas & 1 & 3 & 3 & 1 & 3 & 9 & 6 & 100 & 6 \\
\hline Pedúnculos & - & - & - & - & - & 9 & - & - & - \\
\hline Pericarpios & - & - & - & - & - & 60 & - & - & - \\
\hline
\end{tabular}

TABLA 1: material arqueobotánico analizado en este capítulo.

\section{MORFOLOGÍA Y DOMESTICACIÓN}

Los estudios abocados a conocer los cambios ocurridos en las plantas durante el proceso de domesticación están orientados a determinar, entre otros aspectos, los cambios que se sucedieron en la morfología de frutos y semillas. Así como también los cambios asociados a 
la morfología de órganos y tejidos involucrados en la dispersión, ya que esto indicaría grados de dependencia con respecto a poblaciones humanas. Los antecedentes en el tema evidencian que la selección artificial produce cambios en la morfología tanto en especies domesticadas, como en aquellas manejadas y no domesticadas (Casas et al., 1999, Casas, 2001). Podemos establecer entonces que la morfología (como expresión del genotipo en interacción con su medio) no sólo es sensible a presiones selectivas ambientales, sino también antrópicas (GrosBalthazard et al., 2016). En este escenario de estudio de la morfología los trabajos realizados en cereales euroasiáticos (trigo y cebada) atienden principalmente a los cambios generados en cuanto a la rigidez del raquis y de las glumas, al tamaño del grano y la uniformidad en la dispersión de los mismos (Hillman y Davis, 1990). En el caso de las leguminosas, se ha atendido a cambios en la dehiscencia de sus vainas y consecuentes mecanismos de dispersión de las semillas (por ejemplo en Vigna sp. y Phaseolus sp., Butler, 2002; Lema, 2009a, 2015, entre otros).

Para el cambio en frutos, semillas y granos se cuenta con antecedentes a partir de trabajos etno y arqueobotánicos americanos (Gremillión, 1993, Cowan, 1997, Casas et al., 1999, Casas, 2001). El tamaño de las semillas es considerado de gran valor evolutivo por ser estos órganos poco afectados por presiones externas (Decker y Wilson, 1986), siendo incluso más ajustado aún el estudio de su forma antes que de su tamaño (Mangafa y Kotsakis, 1996, Kay et al., 1980). Si bien gracias a estos cambios de forma/tamaño resulta factible discriminar entre ejemplares de poblaciones silvestres y domesticadas en el registro arqueobotánico (Buxó y Piqué, 2008). Lo complejo es identificar formas transicionales entre ambas. Cuando en el registro arqueológico aparecen medidas intermedias entre las formas silvestres y domesticadas, o bien cuando el rango de medidas de ejemplares arqueológicos se establece entre el de ambas poblaciones actuales, se interpreta que se está ante formas malezoides (resultado de la posible hibridación entre poblaciones silvestres y domesticadas) (Gremillion, 1993). O bien ante formas transicionales en un continuum de transformaciones (Pearsall, 1989, Hillman \& Davies, 1990)

En el caso de los cereales euroasiáticos se ha propuesto, a partir de modelados matemáticos, que el proceso no habría superado los 200 o 300 años, por lo cual sería arqueológicamente invisible (Hillman y Davies, 1990). Investigaciones arqueológicas posteriores llevaron a constatar que este escenario ideal no estuvo presente en el pasado y que diversas situaciones (principalmente flujo génico entre formas domesticadas y parientes silvestres) habría llevado 
a tasas de cambio menos veloces que lo supuesto (Füller, 2012). Un caso distinto es el de los taxa considerados "semi-domesticados" que suelen caracterizarse por prosperar bajo cultivo, pero que no son plenamente dependientes de sociedades humanas para subsistir, lo que conlleva a que tengan muchos más índices de cruzamiento y de flujo génico. Y que ciertos rasgos característicos del cultivo sostenido en el tiempo, -como el aumento de tamaño en frutos y semillas o el cambio en los mecanismos de dispersión/propagación, no sean fijados por todas las poblaciones de la especie- generando una situación de marcado mosaicismo (Clement, 1999). Un aspecto importante a tener en cuenta en este tipo de estudios es considerar que las características que se atribuyen a las formas domesticadas -salvo que surjan por mutación- deberían estar presentes en las formas silvestres, aunque sea en baja frecuencia; la domesticación "tradicional" actúa a nivel de selección y no de generación de variabilidad (Parodi, 1938, León, 1968).

La evaluación de caracteres morfológicos y biométricos debe considerarse de manera contextual en relación al conjunto de restos arqueobotánicos. En este sentido, un contexto donde abundan las formas silvestres y se detectan algunos ejemplares con caracteres que se alejan, cualitativa o cuantitativamente, de los rasgos de estas formas, puede llevar a considerar que se está ante ejemplares transicionales hacia formas domesticadas. Si éstos últimos, en cambio, se presentan junto a formas domesticadas de manera exclusiva o con algunos pocos ejemplares silvestres, se estaría presente ante formas intermedias no transicionales resultado probablemente de cruzamientos entre poblaciones con distinto grado de asociación Hombre-planta (Gremillion, 1993, Newsom et al., 1993, Clement 1999, Lema, 2009a). En términos generales puede decirse que una etapa inicial de la domesticación estaría caracterizada por una tendencia en la disminución del coeficiente de variación $(\mathrm{CV})$ respecto del registrado en poblaciones silvestres, luego hay una tendencia a aumentar su valor por la coexistencia de formas silvestres y otras que exhiben rasgos novedosos, malezoides y/o híbridos, disminuyendo nuevamente con el paso del tiempo debido a la presencia exclusiva de formas domesticadas. La generación de diversos cultivares hace que la diversidad aumente, aunque esos cultivares que serán uniformes en sus características hacen que la variabilidad intrínseca de los mismos sea baja (Gremillion, 1993, Lema, 2009a). Para estos y otros autores (Gremillion, 1993, Newsom et al., 1993) estos valores bajos de CV indican una homogeneidad morfológica. Con la domesticación estos valores aumentarán por la presencia de más de un tipo de fruto y/o semilla resultado de la hibridación, cultivo y cría selectiva 
(Newsom et al., 1993). Un valor alto de CV en una secuencia arqueológica señala, además de variedad de frutos, que ciertas prácticas tales como el aislamiento reproductivo y el cultivo o cuidado selectivo estaban limitados en frecuencia o grado (Gremillion, 1993).

Los análisis morfométricos realizados en poblaciones actuales de diversas especies, demuestran que las aproximaciones que tengan en cuanta tamaño y forma resultan ser apropiadas para determinar patrones de similitud o de variación morfológica en frutos y semillas procedentes de poblaciones sujetas a diversas prácticas de manejo (Colunga García, 1984, Casas y Caballero, 1996, Casas et al., 1999, Casas, 2001, Aguirre-Dugua et al., 2012, 2013, Rodríguez Morales et al., 2013).

\section{MORFOLOGÍA Y BIOMETRÍA DE SEMILLAS, PEDÚNCULOS Y PERICARPIOS}

\section{ANTECEDENTES}

En relación a las Cucurbitas y sus tendencias evolutivas, los trabajos han estado orientados a identificar el cambio en semillas, frutos y pedúnculos. En las contribuciones realizadas para las especies C. pepo, C. argyrosperma y C. moschata de América del Norte y noroeste de América del Sur, se utilizan medidas lineales del largo de semillas y sus coeficientes de variación, junto con el espesor de pericarpios y los diámetros basales de los pedúnculos, como principales indicadores que permiten diferenciar formas silvestres de domesticadas (Decker y Wilson, 1986, Cowan y Smith, 1993, Newsom, et al., 1993, Cowan 1997, Smith 2000, 2006b, Piperno y Stothert 2008, Kistler et al., 2015). En el caso de C. pepo se considera que el aumento en el largo de las semillas podría ser el resultado de la selección cultural dirigida para obtener ejemplares mayores para el consumo (Decker y Wilson, 1986). O bien para obtener frutos más grandes (Bisognin, 2002) ya que las semillas más grandes devienen de frutos más grandes, además de que el aumento del tamaño de las semillas resulta ser una ventaja adaptativa para la germinación y establecimiento de las plántulas dentro de una población (Baloch et al., 2001), siendo parte del llamado "síndrome adaptativo de la domesticación" (Smith 2006a). La domesticación de otras Cucurbitaceae tales como Cucumis indica que la selección y el manejo estuvo dirigida a obtener frutos menos 
espinosos y menos amargos (Bisognin, 2002). En lo que respecta al coeficiente de variación (CV) (Newsom et al., 1993, Gremillion, 1993) (el cual expresa la variabilidad en porcentaje comparando muestras que difieren en el número de ejemplares) Cowan \& Smith (1993) verifican que el CV aumenta cuando se consideran diversos cultivares actuales de morfología muy diferente, desprendiéndose de ello que un aumento en el CV o un CV alto en conjuntos arqueológicos puede indicar la presencia de variedades con frutos de morfología muy diferente.

Los trabajos realizados sobre pedúnculos de Cucurbita pepo dan cuenta del valor de éstas estructuras como indicadores de domesticación (además de ser diagnóstico para diferenciar a las especies del género) (Cutler y Whitaker, 1961, Cowan, 1997, Cowan y Smith, 1993, Smith, 1997, 2000, Lema, 2010, Loy, 2012). Se ha constatado que en los ejemplares domesticados el diámetro basal supera los $10 \mathrm{~mm}$ en la zona de inserción al fruto (Smith, 1997, 2000). El pedúnculo es una prolongación del tallo, que sostiene a la flor y con posterioridad al fruto. En las formas silvestres el pedúnculo es de tipo herbáceo, fibroso y caduco a la madurez y en estado seco permite la dispersión del fruto al producirse la separación de la conexión entre ambos (Millán, 1945, Lira Saade, 1995). Es así que los frutos se dispersan rodando o flotando en los cursos de agua, el mesocarpio a la madurez se reabsorbe $\mathrm{y}$ el fruto se rompe haciendo que las semillas se liberen; la cucurbitacina (triterpenos de sabor amargo) presente en los frutos evita parcialmente la herbívora durante la madurez de los frutos, ayudando a que el proceso se complete (Ashworth, 1997, Decker Walters y Walters, 2000, Lema, 2009a, Schaefer y Renner, 2011, Kistler et al., 2015). En las formas domesticadas el pedúnculo es de tipo corchoso y persistente, no caduco, el fruto es de sabor dulce y pesado, el mesocarpio carnoso se pudre después de un tiempo de conservación quedando las semillas inmersas en él (Millán, 1945, 1968, Lira Saade, 1995).

En cuanto a los frutos y su pared o pericarpio es importante mencionar que el fruto deriva del gineceo y de las demás partes florales que puedan asociarse con él (Essau, 1977). Si bien el incremento del alto del pericarpio ha sido utilizado como indicador de domesticación (Smith, 2000), en opinión de Piperno (2008) durante la domesticación de Cucurbita la selección humana habría estado dirigida a favor de obtener frutos de pericarpios más suaves, no lignificados y sin fitolitos. Sin embargo en la actualidad existen también cultivares de pericarpios duros, los cuales podrían estar representando la selección de determinados de frutos a favor de la durabilidad o para su función contenedora (Lema, 2009a). 
Los frutos de C. maxima subsp. andreana son particularmente diversos en forma, pudiendo ser ovoides, oblongos, globosos, piriformes, esféricos o deprimidos, incluso una misma planta puede dar frutos ovoides y globosos (Ashworth, 1997). El color varía desde el verde hasta el amarillo y pueden poseer estrías longitudinales generalmente más claras (Millán, 1945; Martínez Crovetto en Burkart 1974, Lira Saade, 1995; Ashworth y Galetto, 2001). Generalmente son lisos, hay una única referencia de frutos con lóbulos y es reportada por Millán (1945) en ejemplares procedentes de Cruz del Eje, provincia de Córdoba, Argentina. Estudios posteriores consideran que son ejemplares producto de la cruza de poblaciones de C. maxima subsp. andreana con otras de C. maxima subsp. maxima (Lira Saade, 1995); si bien esto es probable, y considerando lo comentado supra en esta sección, no estamos aún en condiciones de asegurar que la presencia de lóbulos este totalmente ausente en frutos de la subsp. andreana sin un mayor número de estudios genéticos, por lo cual la posibilidad de producir frutos lobulados podría haber estado presente en la constitución genética de la forma silvestre para luego ser seleccionada y fijada por selección cultural (Lema, 2009a). En este carácter como en otros (color, presencia de verrugas, entre otros) ésta posibilidad, o que su presencia haya sido el resultado de una mutación genética, requiere de mayor cantidad de estudios a futuro; por el momento se optó por considerar que estos son caracteres propios de las formas domesticadas.

Ashworth (1997) estableció, tras el análisis de varios ejemplares, que los frutos de la subsp. andreana poseen en promedio 71,63 +/-2,86 $\mathrm{mm}$. de longitud y 67,80 +/- 2,27 $\mathrm{mm}$. de ancho, aunque otros autores registran entre 6 y $21,5 \mathrm{~cm}$. de longitud y entre 5 y $9,5 \mathrm{~cm}$. de diámetro (Millán, 1945, Martinez Crovetto en Burkart 1974). Los frutos varían de peso de acuerdo con el estado de los mismos, ya que a la madurez el mesocarpio se reabsorbe y, por lo tanto, el peso del fruto fresco en promedio sería de $160 \mathrm{~g}$ (un 7,2\% correspondiente a las semillas) y seco disminuiría a $20 \mathrm{mg}$ (un $32 \%$ correspondiente a las semillas) (Ashworth y Galetto, 2001). Respecto a la subsp. maxima la misma posee frutos de variadas formas, tamaños y colores, salvo la forma "turbante", "turbaniforme" o "cabeza de turco" exclusivo de C. maxima subsp. maxima que se produce cuando el ovario sale por fuera del receptáculo (Lira Saade, 1995).

En cuanto al registro arqueológico de restos de pericarpios y pedúnculos en el NOA, además de los mencionados previamente y que serán objeto de estudio en esta tesis, podemos mencionar otros hallazgos de interés. En primer lugar mencionamos un fragmento de 
pericarpio identificado como $C$. maxima subsp. andreana recuperado por la Dra. N. Oliszewski en el sitio Cueva de los Corrales 1, ubicado en el valle de El Infiernillo (Tucumán) a 3.000 msnm, con una antigüedad estimada en 2000 AP (Oliszewski et al., 2008, Lema, 2012). Este resto se encontró junto a otros taxa domesticados, indicando una situación similar a la registrada en la localidad arqueológica de Pampa Grande para momentos cronológicamente cercanos. En la provincia de Salta se recuperó también un conjunto de restos arqueobotánicos carbonizados constituido casi exclusivamente por fragmentos de frutos, pedúnculos y semillas de C. maxima aff. subsp. maxima carbonizados, hallados junto a carbón de leño. Este conjunto fue recuperado por la Dra. M. C. Rivolta en estructuras residenciales del sitio Salvatierra, ubicado a $2 \mathrm{~km}$ al noroeste de la localidad de Cachi, sobre terrazas del río Calchaqui, próximo a un área de enterratorios. De los eventos que tuvieron lugar en dicha estructura se obtuvo un fechado sobre carbón de $2540 \pm 70$ AP y otro de una

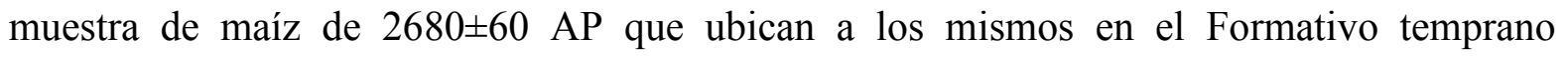
(Rodríguez y Rivolta, 2010). El conjunto se halló como una unidad discreta de restos carbonizados depositados en una oquedad del suelo, sin restos de cenizas, ni evidencias de rubefacción de la tierra circundante. El análisis de estos ejemplares carbonizados de zapallo, indica que se trata de frutos de pericarpio delgado, que posiblemente fueron trozados (en porciones que incluyen pericarpio, mesocarpio y semillas) y desecados antes de su carbonización, indicando una estrategia de conservación y almacenamiento de esta clase de frutos (Lema, 2012). Resultaron además numerosas las semillas que pertenecerían a ejemplares inmaduros, sugiriendo la presencia prehispánica en el NOA de un morfotipo similar al actual cultivar zapallito de C. maxima subsp. maxima, originario del norte Argentino (Lema, 2009a).

\section{MATERIALES y MÉTODOS}

\section{Semillas}

Para el análisis de semillas se conformaron tres grupos básicos. El primero de ellos corresponde a los ejemplares obtenidos tras los cruces experimentales (ver capítulo 2), el segundo a otros ejemplares modernos de referencia y el tercero a las semillas arqueológicas.

1) Colección semillas experimentales: corresponde a C. maxima subsp. maxima, C. maxima subsp. andreana y los cruces entre ambas (generaciones F1 y F2 obtenidas durante los años 2012, 2013, 2014, 2015). Se emplearon las tres accesiones de andreana (130,140 y 160) y 
las tres de maxima $(56,93,153)$ (ver Tabla 1 cap. 2) (Fig. 1) y generaciones F1 (Fig. 1) y F2 (ver tabla 2 cap. 2) (Fig. 2).

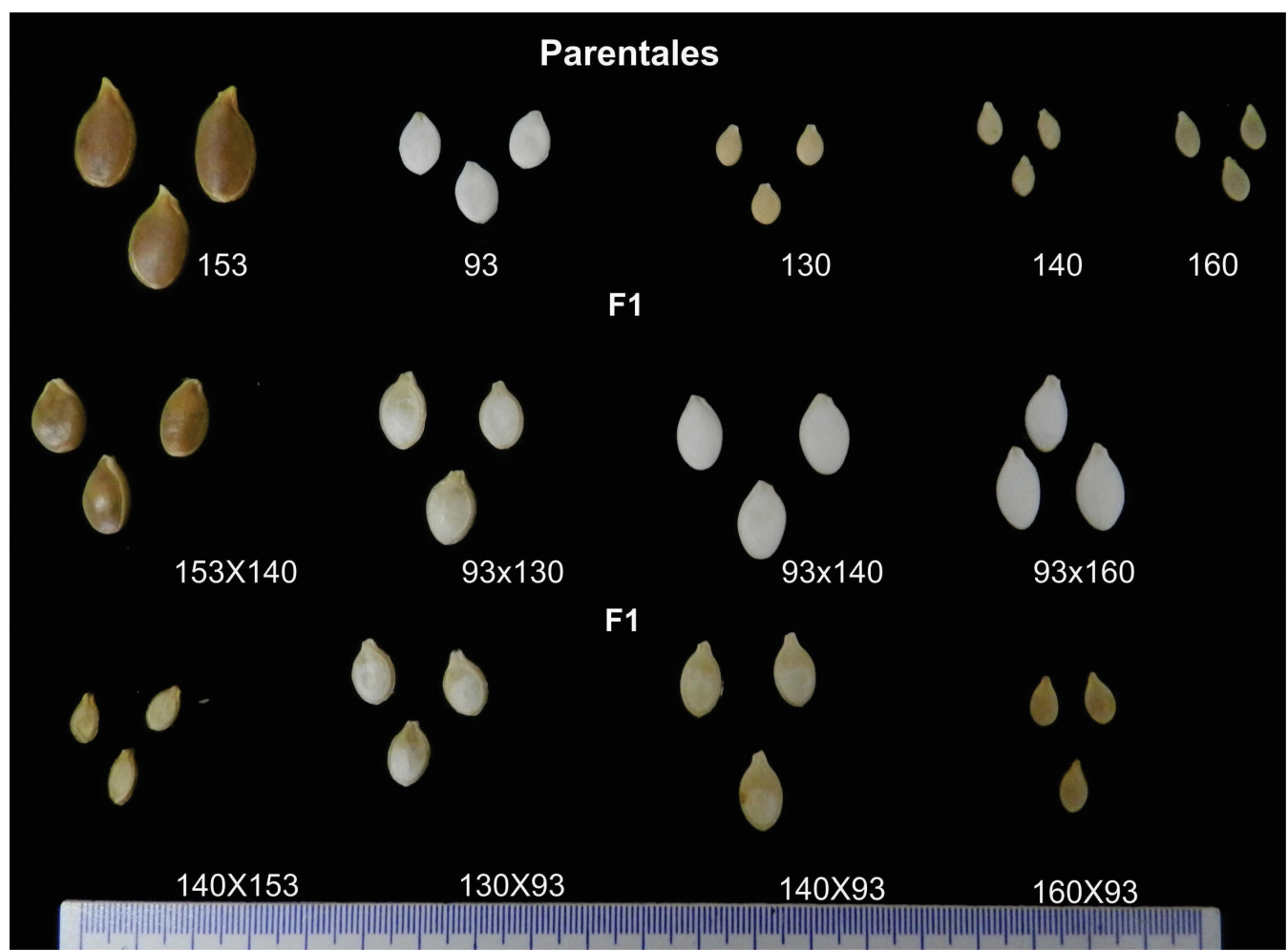

FIGURA 1: distintas morfologías de semillas parentales e híbridos de la primera generación o F1. La primera fila está representada por las formas parentales domesticadas $(153,93)$ y las silvestres $(130,140,160)$. Segunda fila representa cruces híbridos maxima-andreana (Hma) y tercer fila híbridos andreana-maxima (Ham).

2) Colección semillas de referencia: la subespecie maxima se encuentra representada por tres cultivares comerciales (Inglés, Criollo y Hubbard) cedidos por la Cátedra de Horticultura (Facultad de Ciencias Agrarias, Universidad Nacional de La Plata) y cinco cultivares locales obtenidos durante trabajo de campo en el NOA por Lema (2009 a, 2011): zapallito, boliviano, tronquero y dos provenientes de los Valles de Salta. Para la subespecie andreana se utilizaron también ejemplares cedidos por la investigadora L. Ashworth a la Dra. Lema para el desarrollo de su tesis doctoral correspondientes a tres poblaciones obtenidas por polinización cruzada, autogama y libre en el centro de Argentina (Tabla 2). 


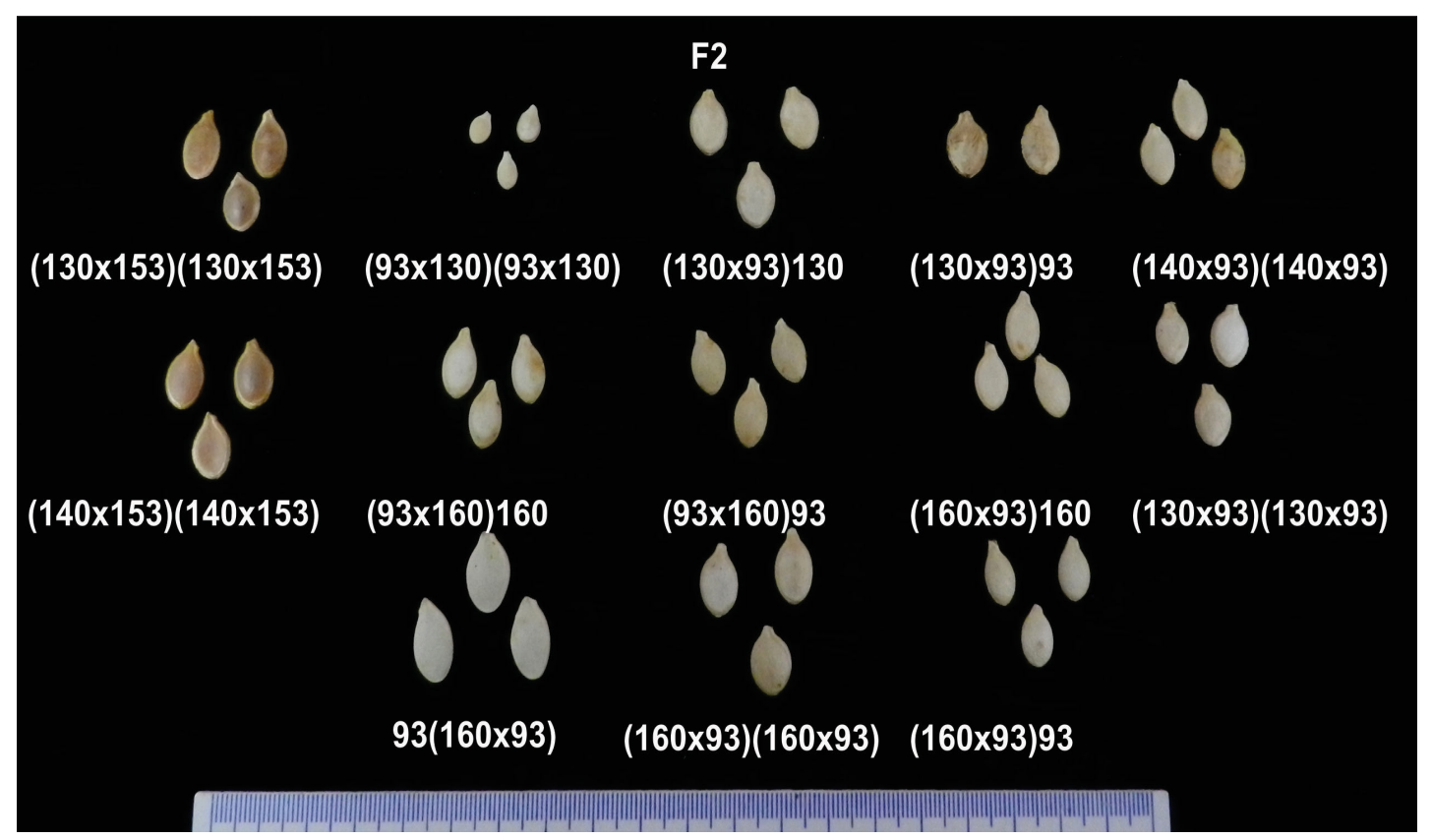

FIGURA 2: distintas morfologías de semillas de la segunda generación o F2.

\begin{tabular}{|c|c|c|c|c|c|}
\hline \multirow{2}{*}{ Subespecies } & \multirow{2}{*}{ Código/Cultivar } & \multirow{2}{*}{$\begin{array}{c}\text { Procedencia } \\
\text { (Provincia/Ciudad) }\end{array}$} & \multicolumn{3}{|c|}{$\mathbf{N}^{\circ}$ Individuos medidos } \\
\hline & & & Pedúnculos & Pericarpios & Semillas \\
\hline \multirow{8}{*}{$\begin{array}{l}\text { C maxima } \\
\text { subsp. } \\
\text { andreana }\end{array}$} & MC1 MC2 MC3 & $\begin{array}{c}\text { Mones Cazón (Bs } \\
\text { As) }\end{array}$ & 3 & 3 & - \\
\hline & LEBA & -- & 1 & 1 & - \\
\hline & G & $\begin{array}{c}\text { M B Gonnet (Bs. } \\
\text { As.) }\end{array}$ & - & 1 & - \\
\hline & $\mathrm{LT}$ & Los Toldos (Bs As) & 1 & 1 & - \\
\hline & SLD & $\begin{array}{l}\text { Orillas del Río } \\
\text { Salado (Bs As) }\end{array}$ & 2 & - & - \\
\hline & Autogama (26) & San Luis & - & - & 20 \\
\hline & Libre (63) & San Luis & - & - & 20 \\
\hline & Cruzada (27) & San Luis & - & - & 20 \\
\hline \multirow{4}{*}{$\begin{array}{l}\text { C maxima } \\
\text { subsp. } \\
\text { maxima }\end{array}$} & cv. zipinka & $\begin{array}{c}\text { El Shincal } \\
\text { (Catamarca) }\end{array}$ & 1 & - & - \\
\hline & cv. silpingo & $\begin{array}{c}\text { El Shincal } \\
\text { (Catamarca) }\end{array}$ & 1 & 1 & - \\
\hline & cv. zapallito & $\begin{array}{c}\text { El Shincal } \\
\text { (Catamarca) }\end{array}$ & 2 & - & - \\
\hline & indeterminado & El Shincal & 1 & - & - \\
\hline
\end{tabular}




\begin{tabular}{|c|c|c|c|c|}
\hline & (Catamarca) & & & \\
\hline LQ & La Quiaca (Jujuy) & 1 & -- & - \\
\hline Hubbard & La Plata (Bs. As.)* & 1 & 1 & - \\
\hline Turbaniforme & La Plata (Bs. As.)* & 2 & 2 & - \\
\hline Inglés & $\begin{array}{c}\text { Catedra de } \\
\text { Horticultura } \\
(\mathrm{FCAyF})\end{array}$ & - & - & 21 \\
\hline Criollo & $\begin{array}{c}\text { Cátedra de } \\
\text { Horticultura } \\
(\mathrm{FCAyF})\end{array}$ & - & - & 5 \\
\hline Hubbard & $\begin{array}{c}\text { Cátedra de } \\
\text { Horticultura } \\
(\mathrm{FCAyF})\end{array}$ & - & - & 41 \\
\hline Zapallito & $\begin{array}{c}\text { Cátedra de } \\
\text { Horticultura } \\
(\text { FCAyF) }\end{array}$ & - & - & 28 \\
\hline $\begin{array}{l}\text { Bolivianos } \\
\text { (Criollo) }\end{array}$ & La Quiaca* & - & - & 57 \\
\hline $\begin{array}{l}\text { Tronquero } \\
\text { (zapallito) }\end{array}$ & $\begin{array}{c}\text { Santa Victoria Oeste } \\
\text { (Salta) }\end{array}$ & - & - & 104 \\
\hline $\begin{array}{c}\text { De los valles de } \\
\text { Salta }\end{array}$ & La Quiaca* & - & - & 33 \\
\hline
\end{tabular}

\section{TABLA 2: material actual de referencia empleado en este capítulo}

3) Colección semillas arqueológicas: el material vegetal arqueológico corresponde a semillas maduras desecadas procedentes de sitios arqueológicos del NOA y del centro-sur de Perú. Entre los primeros se contó con ejemplares de los períodos Formativo o Temprano (ca. 20001200 AP; sitios: SSalLap 20, Pampa Grande y Los Viscos) y Tardío (ca. 1200-800 AP; sitios: Bebé de la Troya, Las Champas y Lorohuasi). Para los sitios del centro-sur de Perú se contó con ejemplares de los sitios Bandurria, Cerro Lampay y Pampa de los Perros que corresponden al período Arcaico (ca. 3000-2000 AP) (Tabla 1, Fig.3) 

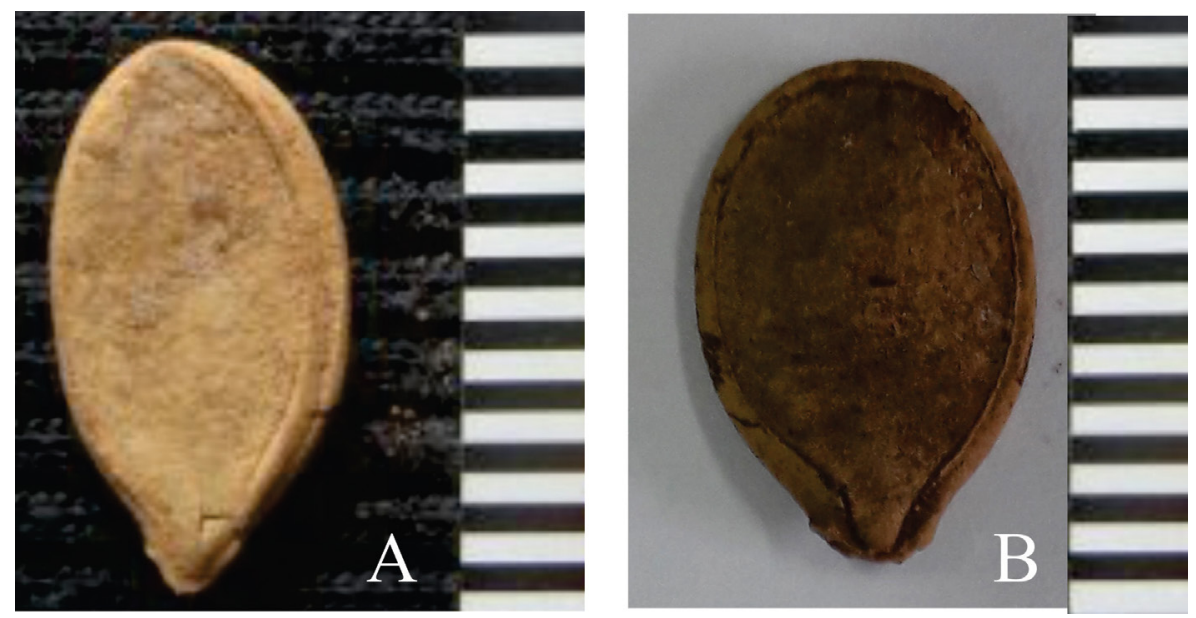

FIGURA 3: semillas arqueológicas en estado seco A) Pampa Grande (ca. 2000-1200) AP. B) Las Champas (ca. 1200-800 AP). (Foto A tomada de Lema, 2009a).

Para la caracterización morfológicamente se midieron con calibre digital TESA el largo, ancho y espesor de cada una de las semillas llegando a un total de 1374 mediciones. Para el grupo experimental se midieron $\mathrm{N}=893$ (ver detalle en tablas 1 y 2 del Cap. 2), mientras que para las muestras de referencia el total fue de $\mathrm{N}=349$ (tabla 2), y para las arqueológicas el número fue de $\mathrm{N}=132$ (Tabla 1). Para poder caracterizar la muestra en base a estas tres variables los datos fueron analizados a través del método de Componentes Principales (CP). La variación total del conjunto de datos fue particionada en un componente de tamaño y otro de forma. Utilizando estas tres variables se estimó el "tamaño" de cada semilla como la media geométrica (media aritmética de las variables originales en escala logarítmica del largo, ancho y espesor; Jungers et al., 1995). El otro componente "forma" se estimó mediante el índice largo/ancho (Corruccini, 1995, Jungers et al., 1995). Debido a que el análisis de las variables indicó que el alto no aportaba información considerable a los $\mathrm{CP}$, dentro de las muestras actuales (ver más adelante) y dado que este rasgo no se puede medir de manera precisa en los restos arqueológicos, debido a que en casi todos ellos ocurre la degradación de los cotiledones, esta medida no fue utilizada en los análisis de forma. Por último también se utilizó el Coeficiente de Variación (CV) como parámetro para indicar el grado de variación.

\section{Pedúnculos y pericarpios}

1) Colección pedúnculos y pericarpios experimentales: se utilizaron las mismas tres accesiones de parentales que para las semillas, (ver tablas 1 y 2 Cap. 2). La generación F1 
sólo fue utilizada para el caso de pedúnculos y la generación F2 fue utilizada para las mediciones de ambos órganos (Fig. 4).

En el caso de los pedúnculos se contó con un total de 66 ejemplares diferenciados en: 13 parentales, 19 pedúnculos de la primera generación ó F1, 34 de la segunda generación ó F2. En el caso de los pericarpios el número de muestras ascendió a 57 diferenciadas en: 22 parentales y 35 correspondientes a la segunda generación (ver tablas 1 y 2 Cap. 2).

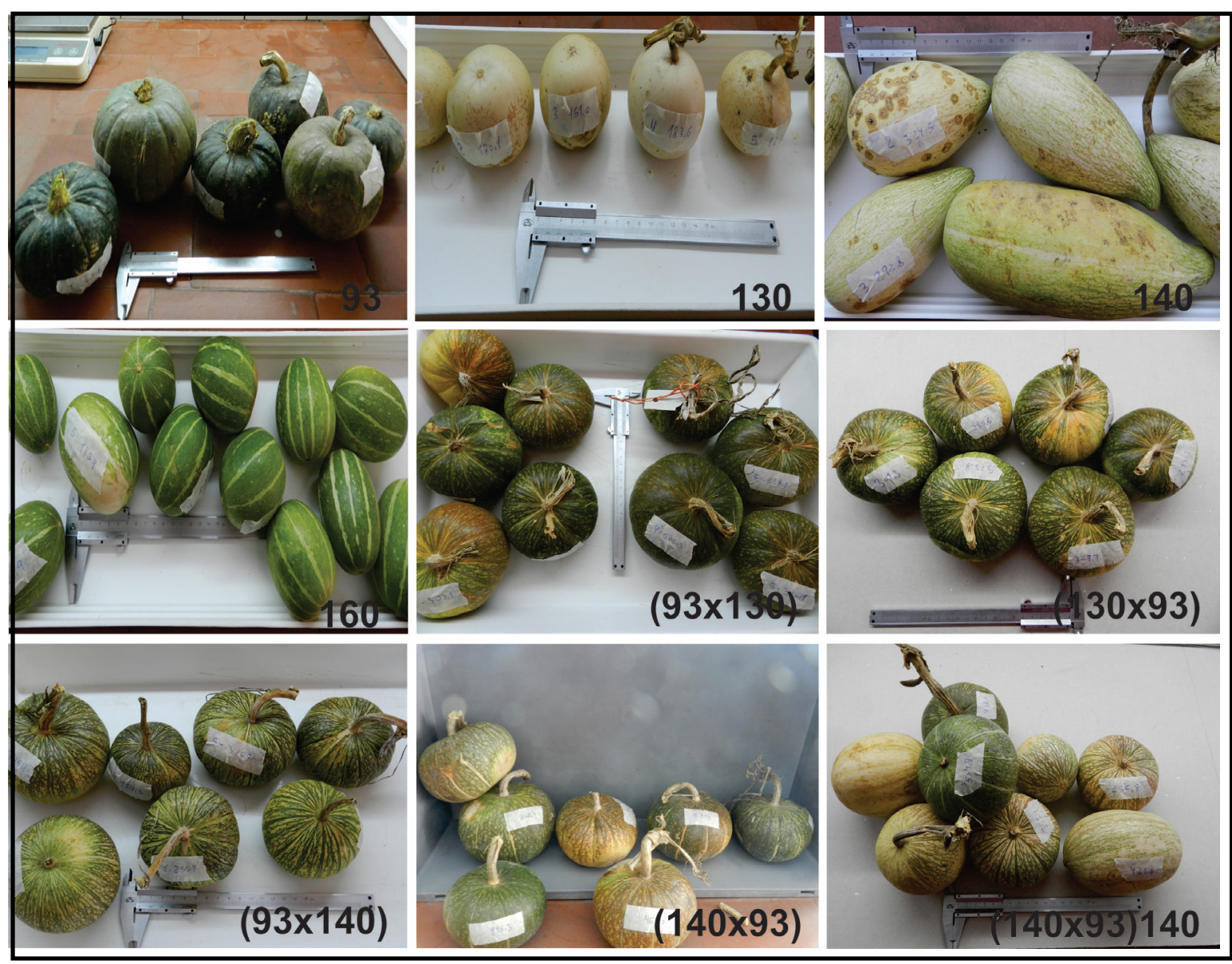

FIGURA 4: algunas de las morfologías de los frutos de la dos subespecies parentales: subsp. maxima (93), subsp. andreana (130, 140, 160). F1 (93x130), (130x93), (93x140), (140x93) y F2 (140x93)140.

2) Colección pedúnculos y pericarpios de referencia: para la subespecie andreana se contó con material proveniente de la provincia de Buenos Aires (Mones Cason-MC1, MC2, MC3-, Los Toldos -LT-, Manuel B Gonnet, Orilllas del Salado-SLD) colectados por Lema.y los pertenecientes al Laboratorio de Etnobotánica y Botánica Aplicada (LEBA) de la FCNyMUNLP. Los ejemplares domesticados provienen de la provincia de Catamarca (El Shincal), 
de la provincia de Jujuy (comprados en el mercado de La Quiaca), y también del circuito comercial platense (colectas de A. Capparelli y V. Lema). En total se midieron 16 pedúnculos y 10 fragmentos de pericarpios (Tabla 2, Fig.5).

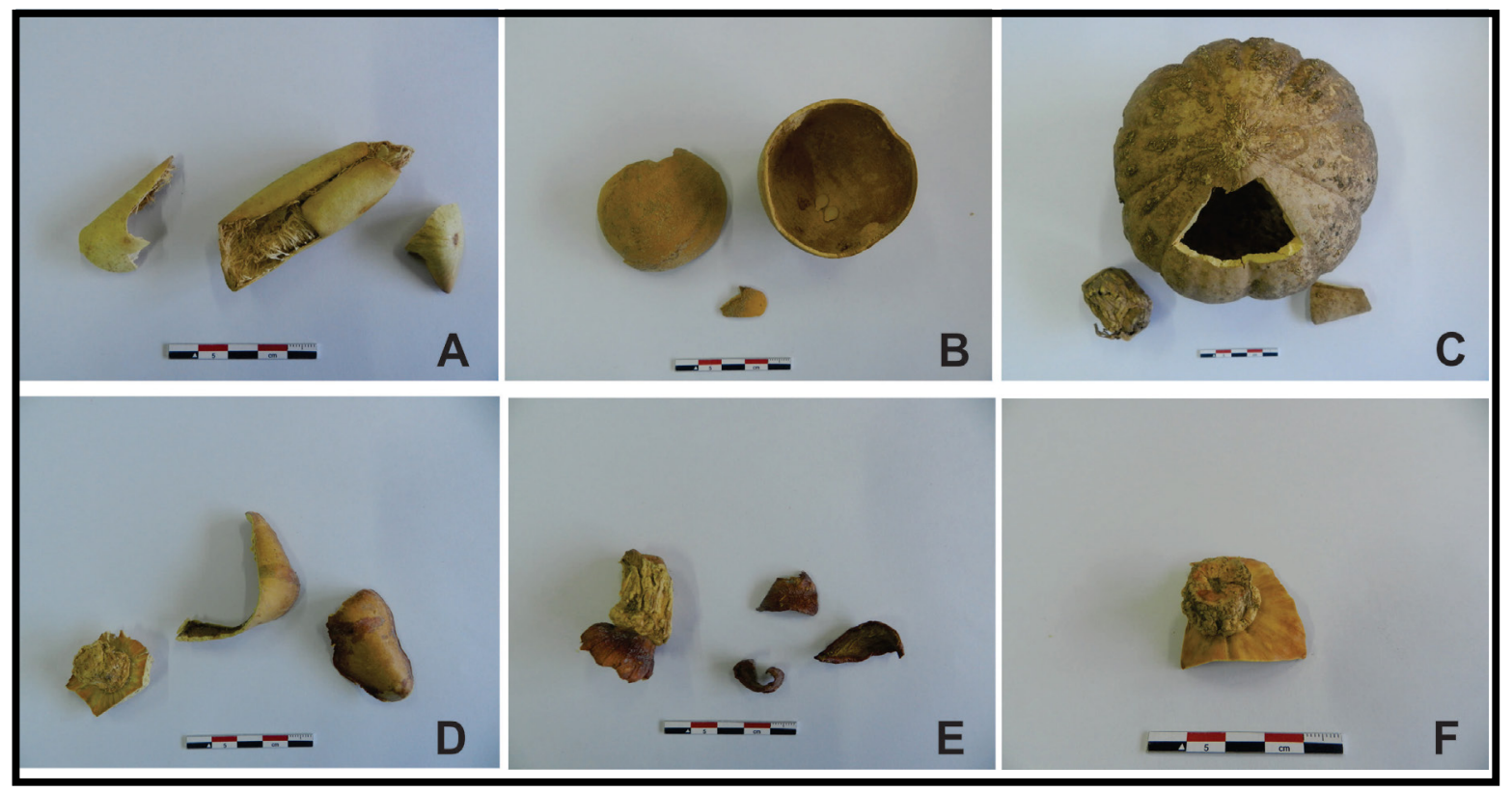

FIGURA 5: pericarpios y pedúnculos de referencia: A y $\mathrm{B}$ pericarpios que pertenecen a la subsp. andreana (Prov de Buenos Aires). C-F pericarpios y pedúnculos que pertenecen a la subsp. maxima. (C) colectados en El Shincal (Catamarca). (D-F) pericarpios y pedúnculos que pertenecen al circuito comercial (Buenos Aires).

3) Colección arqueológica pedúnculos y pericarpios de la localidad arqueológica de Pampa Grande: los restos vegetales aquí analizados provienen de Los Aparejos, El Litro, Caverna II y Caverna IV. En total fueron nueve pedúnculos medidos, discriminados en 5 de cueva Los Aparejos, dos de El Litro, uno de Caverna II y uno de Caverna IV. En el caso de los pericarpios, 42 se recuperaron en Los Aparejos, 7 en el Litro, 9 sin cueva de procedencia y 2 en la Caverna II (Fig. 6) (Tabla 1 sección Arqueobotánica y Domesticación). 

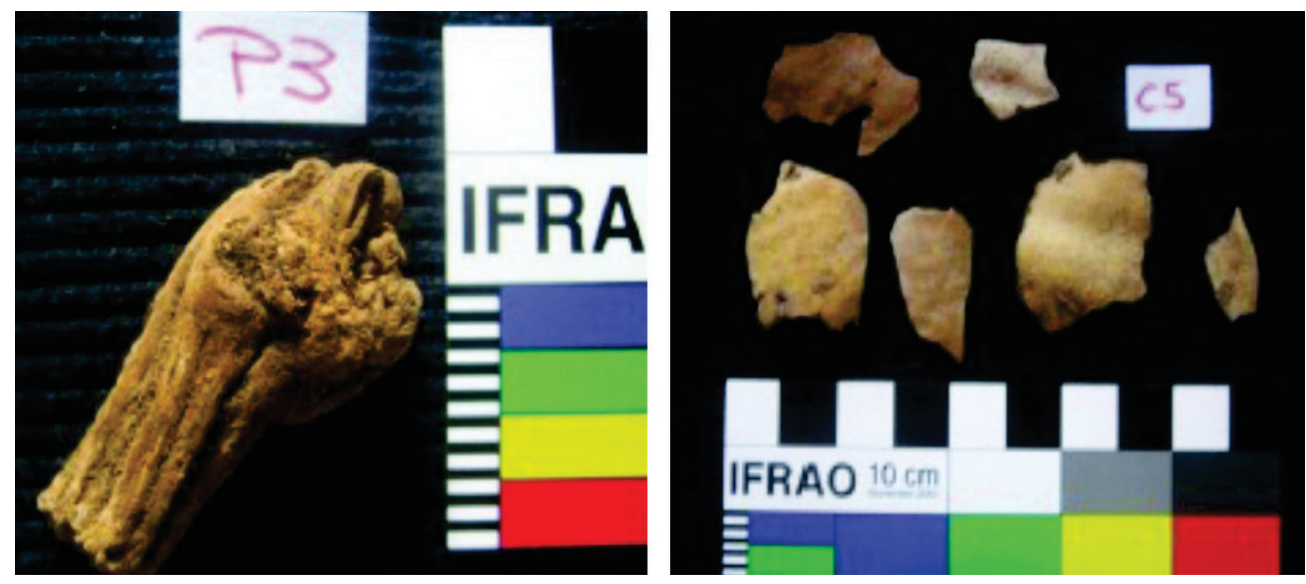

FIGURA 6: pedúnculo y pericarpios de Pampa Grande (Foto tomada de Lema, 2009a).

Para el caso de los pedúnculos se tomaron dos medidas del diámetro basal de cada individuo obteniendo a partir de ello un valor promedio. Para el caso de los pericarpios se registró el espesor (alto) tomando en consideración los indicadores propuestos por Cowan y Smith (1993) para el estudio de caracteres de frutos arqueológicos a partir de frutos actuales de referencia. En la medida de lo posible el espesor del pericarpio fue medido en distintos puntos del fruto (en la zona de inserción del pedúnculo y dos a los lados de la misma; en la zona de la corola y dos a ambos lados de la misma y a nivel del ecuador) a fin de que las medidas no variaran por haber sido tomadas en distintos puntos del fruto (Cowan y Smith, 1993, Lema 2009a). En algunos casos el estado de preservación de las muestras no permitió obtener datos para todos los parámetros mencionados. En el caso de los especímenes arqueológicos, al tratarse de fragmentos cuya correspondencia respecto de su parte en el fruto era difícil de precisar, se tomaron varias medidas en cada uno (entre 3 y 5 , dependiendo del tamaño del fragmento). Dada la naturaleza esponjosa de los pericarpios el tomar varías medidas de un mismo ejemplar también coadyuvó a reducir el error que se pudiera generar al aplicar una presión diferencial en la utilización del calibre. Una vez obtenidas todas las medidas se consideró un valor promedio de espesor del pericarpio de cada fragmento.

En los tres casos (semillas, pedúnculos y pericarpios) se utilizó calibre digital de precisión TESA y las medidas fueron registradas en mm en planillas Excel. Una vez realizada la toma de datos, éstos fueron tratados con el software estadístico R.3.3.0 (R-Development Core Team). 


\section{RESULTADOS}

\section{Tamaño de semillas}

La media geométrica del tamaño (Fig.7, izquierda), resultó ser útil para diferenciar poblaciones silvestres y domesticadas. Las semillas pertenecientes a la generación F1 y F2 ocuparían un rango de variación intermedio entre las anteriores, principalmente F2. El material arqueobotánico de los períodos Arcaico y Formativo tiene un rango de distribución coincidente con F2 (híbridos), F1 y con la forma domesticada, en tanto los ejemplares del período Tardío coinciden mayormente con la forma domesticada y en menor medida con F1 y F2. Resultado que también se corrobora con el análisis estadístico que muestra claras semejanzas entre las formas arqueológicas y las formas actuales (Anexo Fig.1).

Las semillas de los sitios arqueológicos (Fig. 7 derecha) muestran una tendencia hacía el aumento de tamaño a lo largo del tiempo. Sin embargo, el tamaño de las semillas del sitio Las Champas, es notablemente menor al de los sitios precedentes y contemporáneos. Asimismo Lorohuasi es el sitio que presenta un tamaño que sobrepasa los valores característicos para este período.

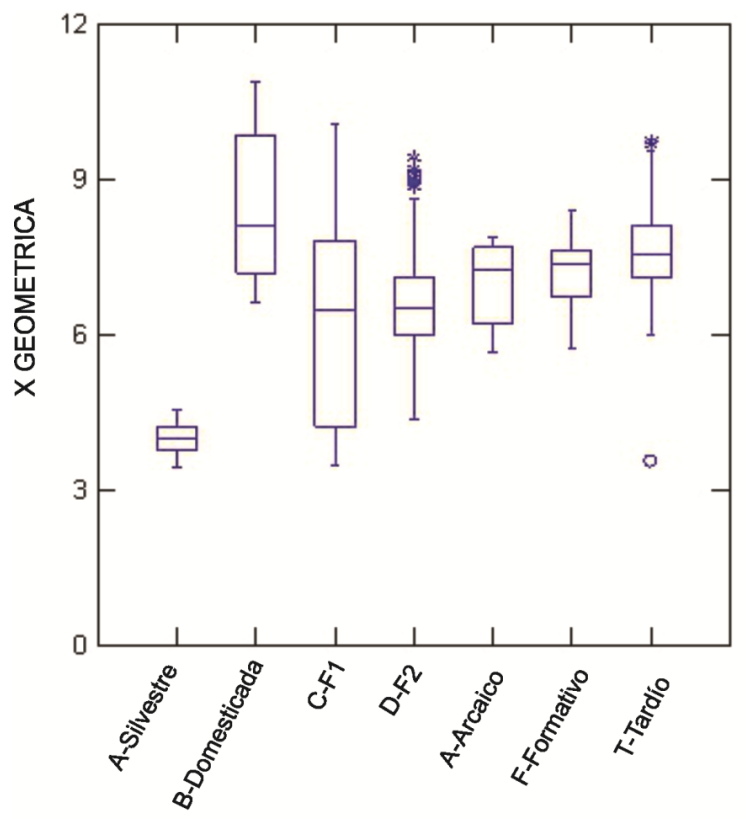

GENOTIPOS

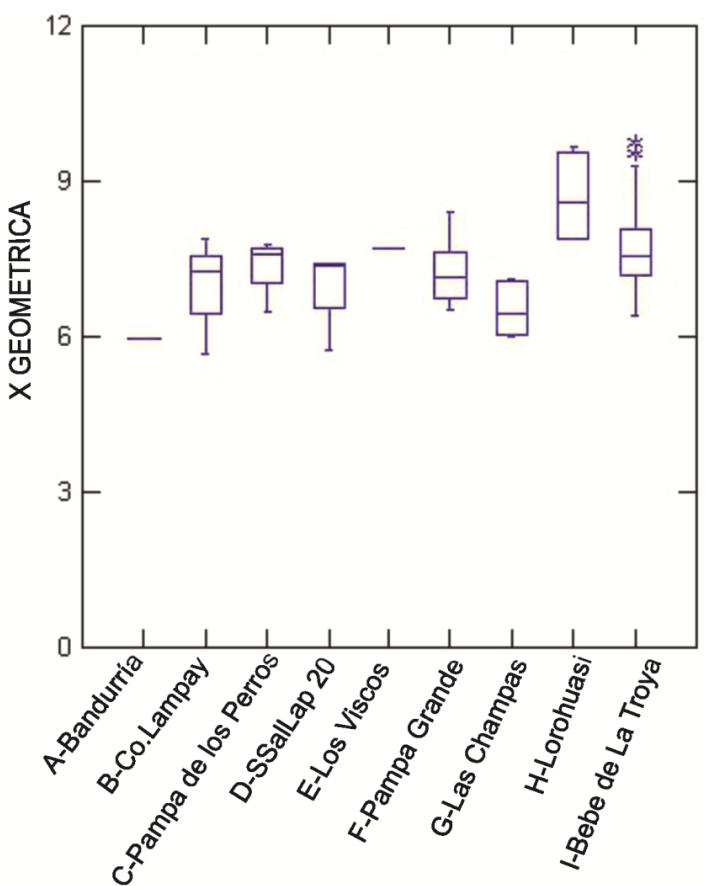

SITIOS

FIGURA 7: media geométrica. Izquierda:los genotipos silvestres y domesticados (A y B) incluyen colección de referencia más parentales de cruzamientos experimentales, 


\section{híbridos F1 y F2 (C y D), los restos arqueobotánicos se agruparon y ordenaron temporalmente. Derecha: semillas arqueológicas desde sitios tempranos a más tardíos.}

El CV permitió identificar que en la mayoría de las semillas medidas, éstas muestran valores de CV de la media geométrica entre 10 y 15 (Fig. 8). Teniendo en cuenta este indicador, la variabilidad encontrada durante el Arcaico, es mayor a la del resto de los genotipos y a la del resto de los conjuntos arqueológicos, salvo el registrado para las formas domesticadas actuales (D) que exhibe una gran variabilidad debido a que la muestra se conformó con once cultivares diferentes. Los períodos Formativo y Tardío tienen una variabilidad menor y similar a los valores registrados para F2. En el grafico se representan también valores extremos para la formas domesticadas: el cultivar de menor CV (cultivar comercial InglésE) y el de mayor CV (cultivar local Valles de Salta-F), para verificar si los arqueológicos podían acercarse en su valor, a alguno de ellos. A través de este coeficiente se constató que hubo una tendencia a la disminución de la variabilidad de tamaños a lo largo del tiempo (Fig. 8).

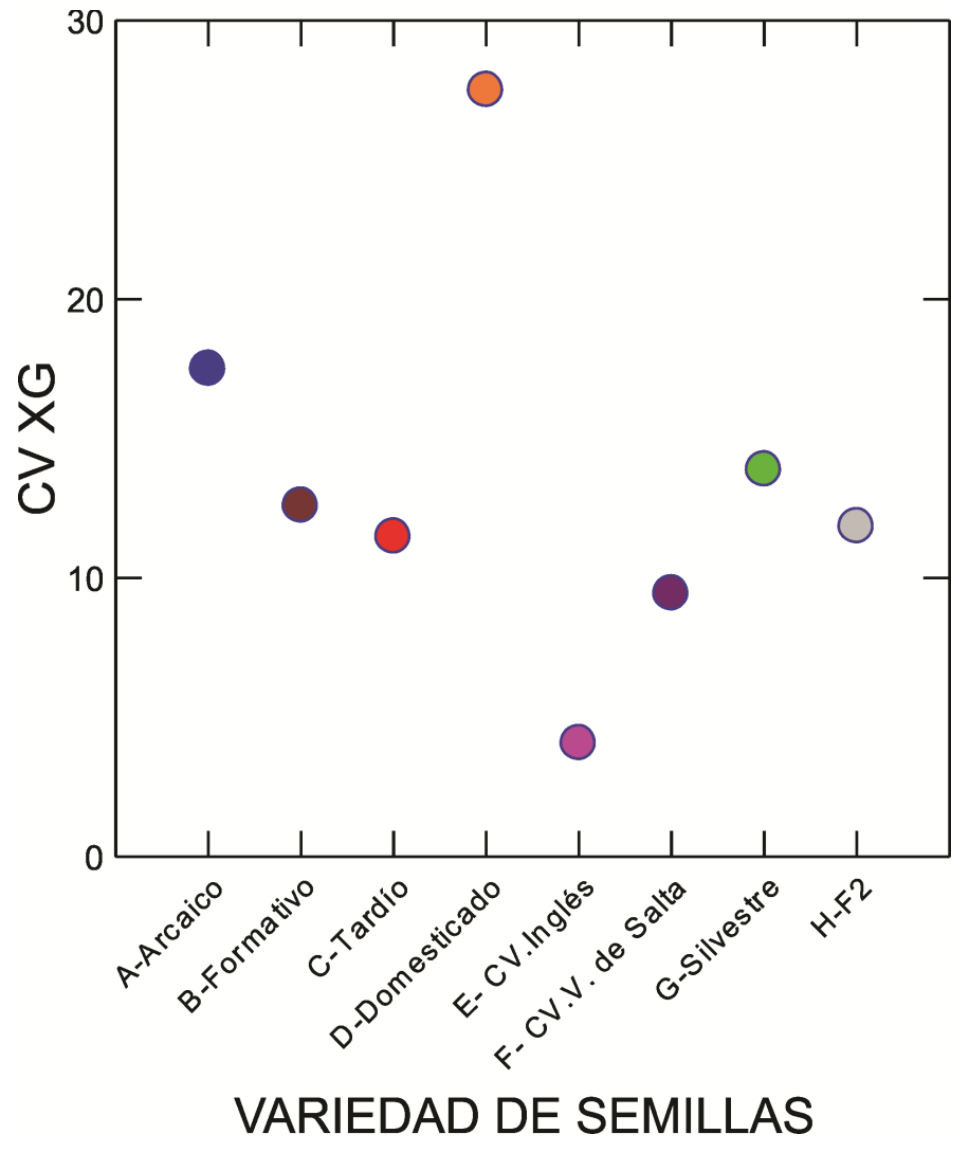


FIGURA 8: coeficiente de variación de la media geométrica de las semillas a lo largo del tiempo (A-C), también se indica la variación de la forma domesticada (D) con los dos cultivares que mostraron valores extremos (E-F), la forma silvestre (G) y los ejemplares de la segunda generación (H).

\section{Forma de semillas}

El análisis de componentes principales mostró que la variable alto es la que menos información aporta, razón por la cual se excluyó del análisis (Anexo Fig. 2). El índice largo/ancho no resultó útil para distinguir a los genotipos actuales, pero sí para diferenciar los conjuntos arqueológicos (Fig. 9 Izquierda). El Arcaico muestra una gran variabilidad de formas, variabilidad que va disminuyendo hacía el Formativo y Tardío. Discriminando este resultado sitio por sitio (Fig. 9 Derecha) se puede determinar que durante el Formativo habría habido formas de semillas donde predomina el largo, exclusivas de este momento, mientras que para el Tardío la relación largo/ancho decae nuevamente coincidiendo con la variabilidad comprendida dentro de las registradas para el Arcaico y Formativo.

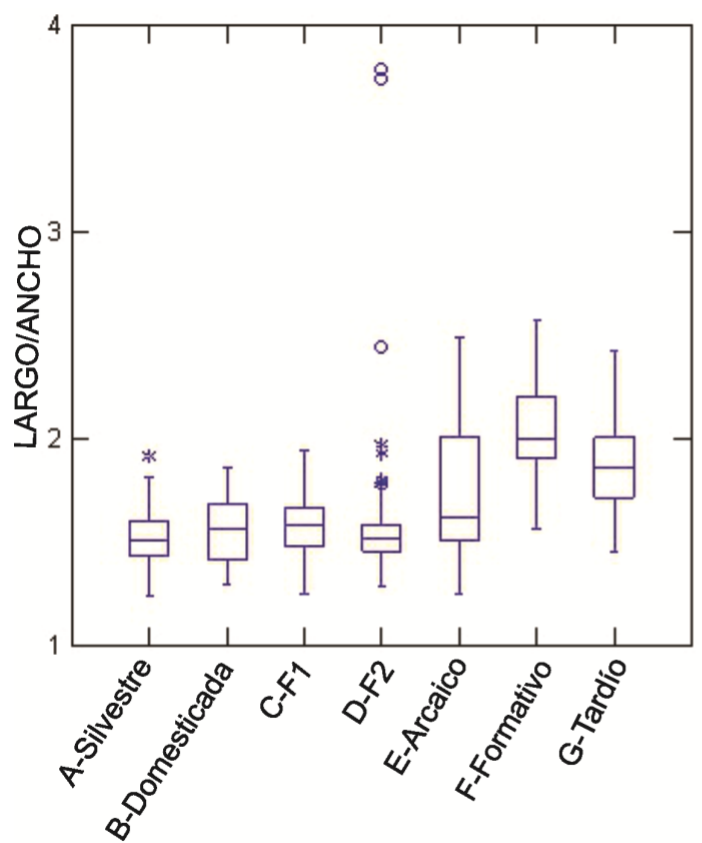

GENOTIPOS

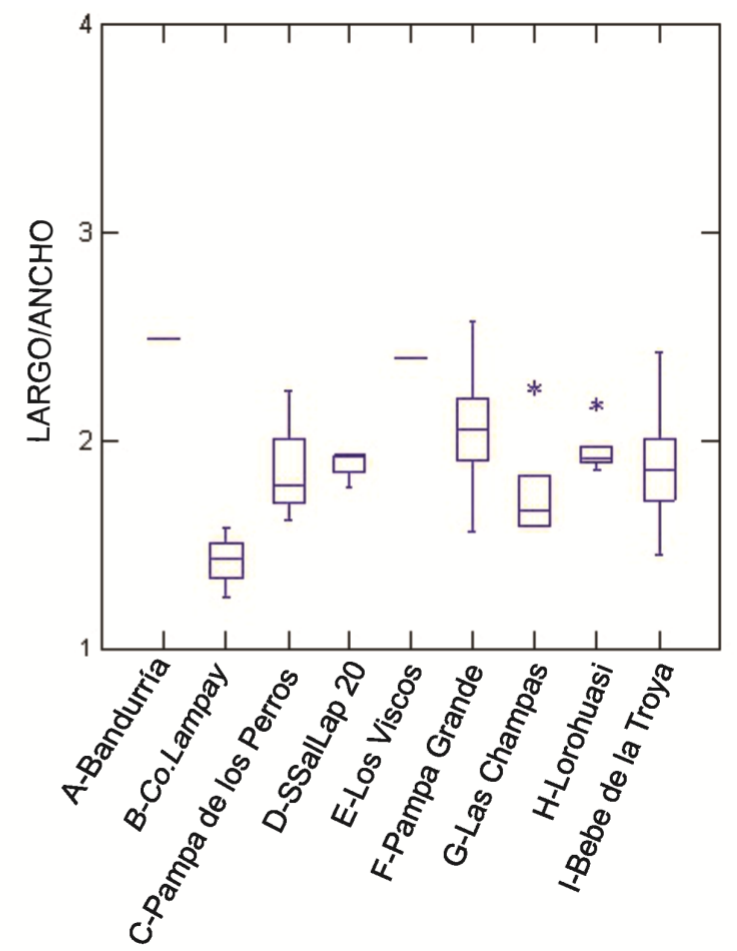

SITIOS 
FIGURA 9: indice Largo/Ancho. Izquierda: los genotipos silvestres y domesticados (A y B) incluyen colección de referencia más parentales de cruzamientos experimentales, híbridos F1 y F2 (C y D), los restos arqueobotánicos se ordenan temporalmente. Derecha: semillas arqueológicas ordenadas por sitio desde más tempranos a más tardíos.

El CV de la forma (Fig. 10) indica que las semillas del arcaico presentan un valor mucho mayor respecto de todos los otros valores registrados (en semillas actuales y arqueológicas). Hacia momentos posteriores el CV cae drásticamente y se recupera levemente en el Tardío. La variabilidad de las semillas del período Formativo se aproximan a las F2 y las del Tardío a las domesticadas actuales.

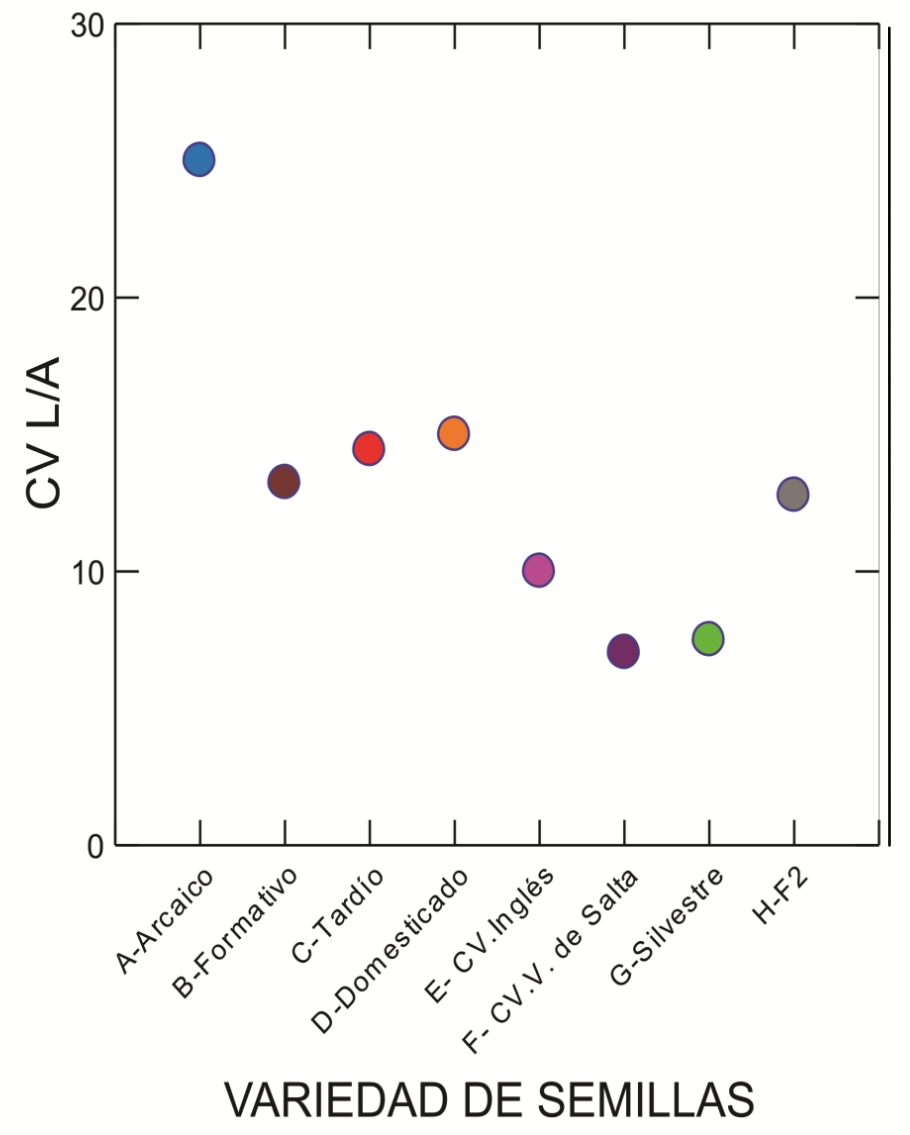

FIGURA 10: coeficiente de variación del índice Largo/Ancho de las semillas a lo largo del tiempo (A-C), se indica también la variación de la forma domesticada (D) con sus dos extremos (E-F), la forma silvestre (G) y los ejemplares de la segunda generación (H). 


\section{Pedúnculos}

El diámetro basal de los pedúnculos permitió diferenciar claramente la subsp. andreana de la subsp. maxima (Fig. 11), asimismo los ejemplares F1 se agruparon de acuerdo al parental pistilado, lo cual es coherente considerando que no se trata de pedúnculos híbridos, aunque parte de los F1-Hma poseen en parte una posición intermedia entre ambos parentales. En este sentido, los ejemplares F2 que sí son híbridos, se distribuyeron mayormente en un rango intermedio entre ambas subespecies con algunos casos de solapamiento. Los restos arqueológicos de Pampa Grande coincidieron con los F2, en parte con F1 (Hma) y con las formas domesticadas, la coincidencia con ejemplares de andreana es mínima (Anexo Fig. 3).

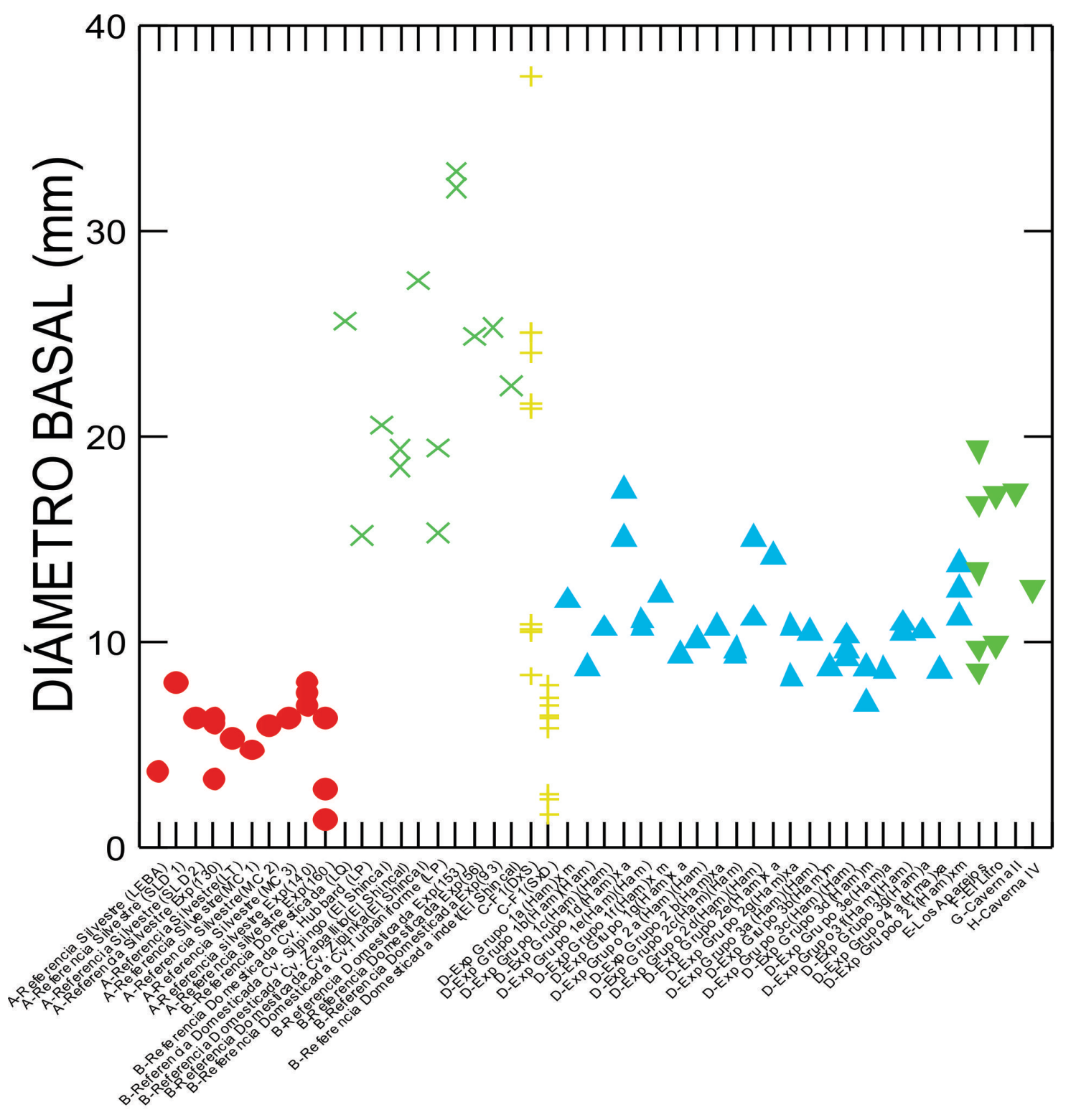


FIGURA 11: dispersión del diámetro basal de pedúnculos en ejemplares de referencia y arqueológicos. Ejemplares silvestres (círculos rojos), ejemplares domesticados (x verdes), ejemplares F1 (cruz amarilla), ejemplares F2 (triángulo azul), arqueológicos de Pampa Grande (triángulo invertido verde).

\section{Pericarpios}

El análisis de los pericarpios (Fig.12) no mostró agrupamientos marcados ni distintivos para ambas subespecies, sin embargo hay un área de valores intermedios cuyo rango no es ocupado ni por ejemplares de andreana ni de maxima y sí por ejemplares (tanto cruces de F1 consigo mismo, como retrocruzas con parentales andreana o maxima, que involucraron todos los genotipos salvo el 56) del grupo experimental F2, que representan valores intermedios. Los pericarpios arqueológicos poseen una clara distribución a lo largo de todo el gradiente de medidas, aunque cabe aclarar que ejemplares de las cuevas Los Aparejos y El Litro se encuentran en el rango de medidas exclusivo de algunos ejemplares F2 (Anexo Fig. 4). 


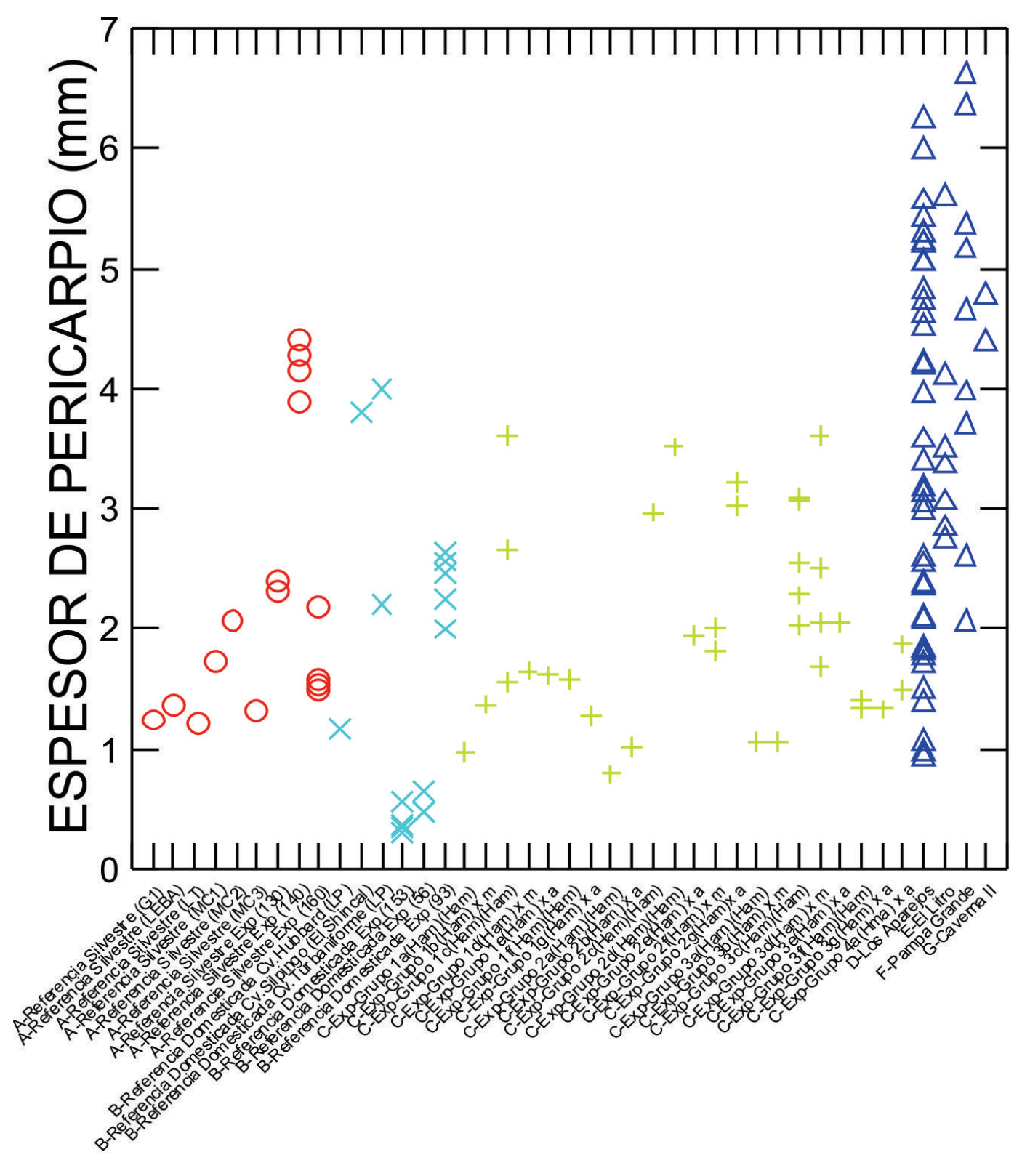

FIGURA 12: dispersión del espesor de pericarpios en ejemplares de referencia y arqueológicos. Ejemplares silvestres (círculos rojos), ejemplares domesticados (x celestes), ejemplares F2 (cruz amarilla), arqueológicos de Pampa Grande (triángulo azul).

\section{DISCUSIÓN}


A diferencia del indice largo/ancho, la media geométrica de semillas resultó ser un indicador útil para diferenciar poblaciones silvestres, domesticadas, F1 y F2. Su aplicación a restos arqueobotánicos indica que durante momentos arcaicos y formativos habría tamaños que coinciden con formas híbridas, a diferencia del momento tardío, donde mayormente coinciden con formas domesticadas (salvo para los restos del sitio Las Champas). Esto quizá es el motivo por el cual los conjuntos de semillas de ambos períodos tempranos poseen un $\mathrm{CV}$ de tamaño mayor. En cuanto a las forma (índice largo/ancho) los conjuntos arqueológicos -salvo parte del Arcaico- no coinciden con las registradas en ejemplares actuales.

A lo largo del tiempo, puede verse que entre el período Arcaico y Formativo no hay cambios notables de tamaño, pero sí de forma, siendo las semillas más largas en este último período. Durante el Tardío hay semillas de tamaño mayor, junto a otras de tamaño y forma igual a las de momentos previos, así como también otras algo más anchas. El hecho de que las semillas de Lorohuasi sean atípicas para el conjunto tardío puede explicarse ya que este sitio es posterior en el tiempo respecto de Bebé de la Troya y Las Champas. Lo que es importante destacar es que en el Tardío no se registraron formas nuevas pero sí tamaños, por lo cual no habría reemplazo, sino posiblemente continuidad de formas seleccionándose semillas/frutos más grandes.

En cuanto a variabilidad de los conjuntos arqueobotánicos, ésta es mayor en tamaño y forma durante el Arcaico, luego disminuye para ambos rasgos durante el Formativo y para el Tardío, aunque en este último período aumenta levemente la variabilidad de formas al incluir la registrada en ambos momentos cronológicos previos.

El análisis de tamaño y forma en semillas sugiere que la tendencia general luego de haberse domesticado C. maxima subsp. maxima fue, primero, la generación de nuevas formas, manteniéndose poblaciones híbridas, lo cual no aportó mayor variabilidad de forma o tamaño ya que la misma se vio reducida durante el Formativo. En momentos posteriores, continuó la reducción de la variabilidad, se mantuvieron las mismas formas y tamaños, a la vez que se optó por sumar a los conjuntos tamaños mayores y se redujo -si bien no completamente- la presencia de formas híbridas.

El análisis de pedúnculos permitió corroborar la presencia de formas domesticadas e intermedias entre los ejemplares arqueológicos de Pampa Grande. El análisis de pericarpios, por el contrario, no presentó valores diagnósticos para distinguir formas hibridas, de 
silvestres y domesticadas en el registro arqueológico, mostrando un continum de valores salvo para algunos ejemplares de las cuevas Los Aparejos y El Litro que presentaron rangos de medidas exclusivos de algunos ejemplares de F2. En cambio, la conjunción de caracteres anatómicos y rangos de medidas al interior de los conjuntos arqueológicos permitió identificar en Pampa Grande a la subsp. andreana (confirmando lo propuesto por Whitaker para esta localidad), así como también variedad de grosores en formas domesticadas, lo cual se propuso como resultado de la presencia de frutos empleados como contenedores y otros empleados solo para consumo (Lema, 2009a). Asimismo la detección previa de pericarpios de esta localidad con caracteres intermedios (Lema, 2009a) podría representar formas híbridas (F2) en el caso de El Litro y Los Aparejos. Que los pericarpios arqueológicos posean una clara distribución a lo largo de todo el gradiente de medidas, reafirma además la propuesta de la utilización y el manejo de una gran variedad de formas de frutos (Whitaker, 1983, Lema, 2009a).

Finalmente, podemos decir que, en conjunto, la morfología y biometría de semillas, pedúnculos y pericarpios analizadas en esta tesis, en relación con análisis previos, nos confirma la ausencia en el registro arqueológico de restos de la subsp. andreana sin su contraparte domesticada, la coexistencia de formas domesticadas, silvestres e híbridas durante el Formativo, donde muy posiblemente se manejó una gran diversidad de poblaciones y formas de zapallos; la persistencia de algunas de estas formas durante el Tardío, momento donde la selección apuntó a incrementar los tamaños, presentándose situaciones diversas de acuerdo a los sitios analizados, sin que se pueda descartar para este momento la presencia de formas híbridas.

\section{ANATOMÍA Y BIOMETRÍA DE CUBIERTAS SEMINALES}

\section{ANTECEDENTES GENERALES}

El análisis anatómico de órganos vegetales ha sido utilizado por diversos autores como medio para identificar modificaciones en los restos vegetales que sean producto de la selección y prácticas de manejo por parte de sociedades pasadas (Smith, 1985, Gremillion 1993, Buther, 1989, Bruno y Whitehead, 2003, Bruno, 2006, Lema et al., 2008, 2009a). En esta sección se analizará la anatomía de la cubierta seminal, la cual constituye la capa externa que rodea a las semillas espermatófitas. La capa más externa se denomina testa y deriva del 
tegumento externo del óvulo (Jeffrey, 1980), mientras que la interna o tegmen deriva del tegumento interno del óvulo y/o de la nucela. Su consistencia, generalmente dura, le confiere cierto grado de impermeabilidad al agua y a los gases (Bewley y Black, 1978, Edwards, 1973) y protege al embrión de diversas condiciones que le pueden resultar adversas.

En el trabajo realizado por Bruno (2006) sobre granos del género Chenopodium se evidencia que el grosor del episperma o cubierta seminal se fue reduciendo durante la domesticación en el caso de Ch. quinoa var. quinoa, lo cual estaría ligado -según la autora- con cambios en la dormición. En el caso de la domesticación de Phaseolus vulgaris var. vulgaris diversos autores han propuesto que las cubiertas de las semillas se volvieron más permeables y delgadas por reducción de la dormancia y crecimiento más rápido, carácter que estaría ligado a los cambios en las fibras de las vainas vinculadas a los mecanismos de dehiscencia en esta especie (ver citas en Lema 2009a). Tomando de base estos antecedentes y considerando que todo cambio anatómico en estos tejidos trae aparejado cambios a nivel físico químico y/o fisiológico en las semillas, particularmente ligados a la dormición (Murray 1984, Smith 2006a,b, Pickersgill 2007, De Wet y Harlan 1975, entre otros) es que se optó por analizar biométricamente la anatomía de los tejidos de las cubiertas.

\section{ANTECEDENTES PARA CUCURBITA}

Las semillas de las Cucurbitas varían en cuanto a forma, tamaño y características de los márgenes. Generalmente son achatadas, anatropas y elípticas, el embrión consiste de largos cotiledones y margen festoneado (Winton y Winton, 1935). Singh y Dathan (1972) indican que se pueden diferenciar cinco capas en las cubiertas seminales (desde el exterior al interior): epidermis, hipodermis, capa o tejido esclerenquimático, aerénquima y una zona interna. Según estos autores esta zona puede ser clorenquimática con células ensanchadas y de paredes delgadas en las especies mesofíticas y cultivadas, o bien de células anchas y sin cloroplastos en las xerofíticas. Análisis anatómicos previos en ejemplares arqueológicos indican que esta capa no se conserva generalmente (Lema et al., 2008, Lema, 2009 a). A continuación se describen las diferentes capas que constituyen la cubierta seminal de las Cucurbitas (Fig. 12 izquierda) detallando los rasgos propios de las subespecies maxima y andreana (Fig. 12 derecha). 
Epidermis: está formada por células elongadas, poligonales, en empalizada, de paredes delgadas o gruesas, pero no lignificadas (Winton y Winton, 1935, Essau, 1977). Dependiendo del sector de la semilla, estas células varían en el largo pudiendo ser más largas alrededor de los abultamientos próximos al margen en algunas especies (Sigh y Dathan, 1972, Teppner, 2004, Lema et al., 2008)

Hipodermis: este tejido está formado por una o más capas de células que varían en tamaño y grosor (Winton y Winton, 1935), generalmente son de tamaño pequeño, de paredes engrosadas (Esaau, 1977) y compactas. Según Singh y Dathan (1972), el número de capas de células varía de acuerdo a cada especie y tiende a aumentar en los márgenes de las especies mesofíticas y domesticadas.

Generalmente en la subsp. andreana el número de capas de células varía entre dos o tres en las caras mayores y en los márgenes varía de cinco a siete, teniendo el tejido un alto total en promedio de 34,3 $\mu \mathrm{m}$ (Lema et al., 2008, Lema, 2009a). En la subsp. maxima existe una gran diversidad de tamaños, variando de tres a cinco capas de células en las caras mayores y de siete a ocho en los márgenes, teniendo el tejido un alto total promedio de $44 \mu \mathrm{m}$ aproximadamente (Lema et al., 2008; Lema, 2009a).

Esclerénquima: tejido conformado por esclereidas de paredes sinuosas y extremadamente gruesas, pudiendo ser isodiamétricas, elongadas longitudinalmente o radialmente y ramificadas (Winton y Winton, 1935). Hayward (1953) indica que las paredes de las esclereidas tienen pliegues que se superponen. En las caras mayores de la semilla el tejido está formado por una sola capa de células regulares, pero en los extremos puede haber dos o tres capas de células con aspecto más irregular (Hayward 1953). Si las esclereidas en CT tienen un valor de alto mayor a los $91 \mu \mathrm{m}$ y un ancho de casi $70 \mu \mathrm{m}$ pertenece a la subsp. maxima, mientras que si el valor ronda las 60 a $80 \mu \mathrm{m}$ aproximadamente, pertenece a la subsp. andreana (Lema et al., 2008, Lema, 2009a).

Aerénquima: esta capa de células es considerada por algunos autores como parénquima (Wynton y Wynton, 1935). Singh y Dathan la definen como una capa de células estrelladas con engrosamientos lignificados reticulados o en espiral y con grandes espacios aéreos (Singh y Dathan, 1972). Las formas silvestres poseen una o dos capas de células a lo largo de las caras mayores y son de tamaño pequeño, a diferencia de las domesticadas que poseen 
varias capas de células (más de dos) y de tamaño mayor (Sing y Dathan, 1972; Lema et al., 2008, Lema, 2009a).

Capa Interna: Formada por una capa simple de células parenquimáticas o colenquimáticas
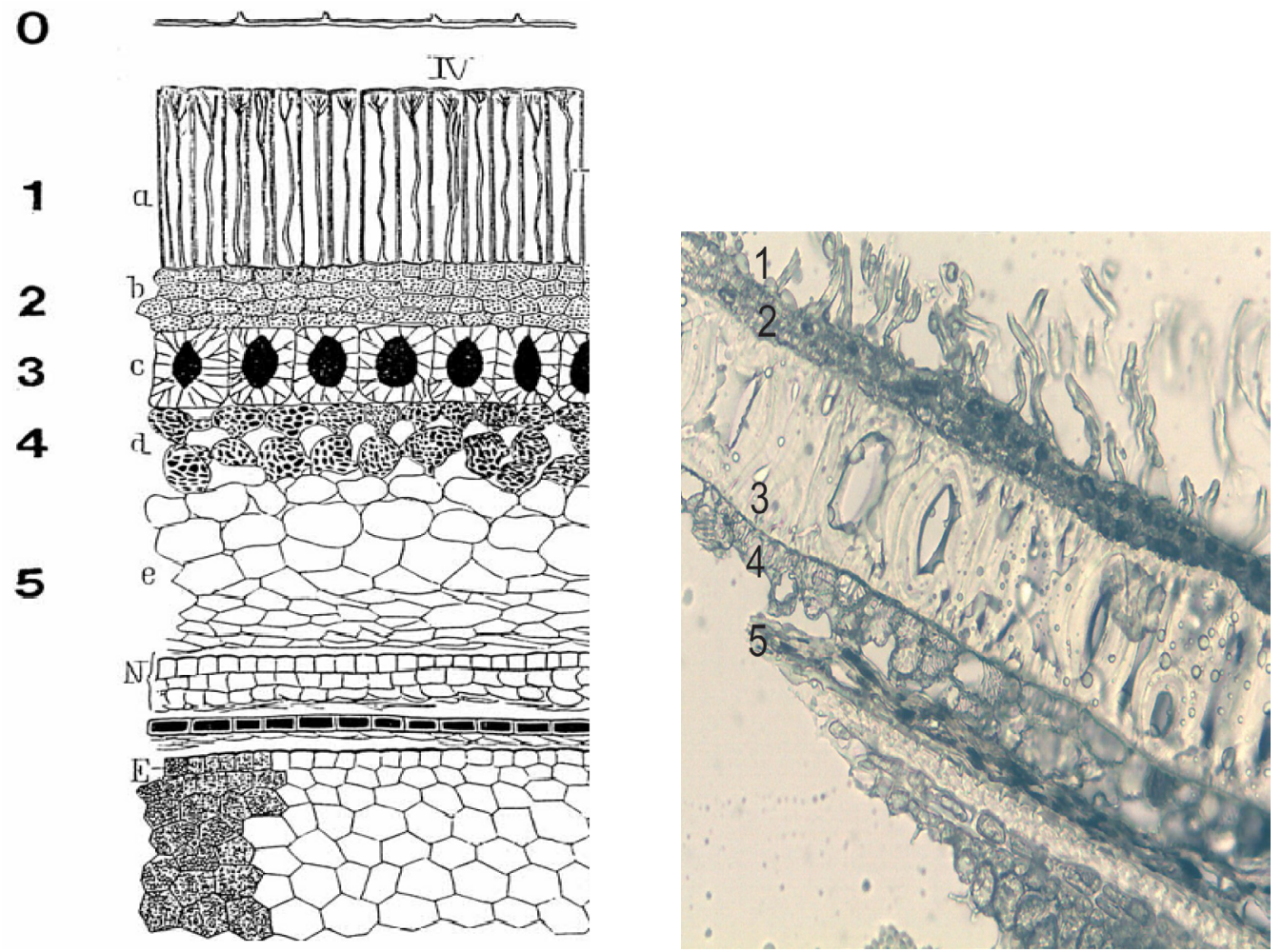

Figura 12 Izquierda: dibujo de corte transversal de la estructura interna de una semilla de Cucurbita 1-Epidermis, 2-Hipodermis, 3-Capa de Esclereidas, 4-Aerénquima, 5 Zona interna o parénquima (Tomado de Teppner, 2004). Derecha: fotografía de corte transversal de una semilla de Cucurbita maxima ssp. andreana (genotipo 130) en la que se observan los tejidos mencionados en 12 A.

El análisis de las distintas capas que conforman la cubierta seminal entre distintas especies sudamericanas del género permitió contar con caracteres diagnósticos que permitieron la identificación de semillas arqueológicas a nivel específico, muchas de las cuales son las analizadas en esta tesis (Lema 2009a).

\section{MATERIALES Y MÉTODOS}

A fin de caracterizar las cubiertas seminales se analizaron rasgos biométricos de cada una de las capas tisulares que conforman a las mismas, en los genotipos obtenidos de los cruces 
experimentales. Para ello se realizaron cortes transversales a mano alzada a nivel de la zona ecuatorial de las semillas (ya que en ella hay menos deformación de las células respecto de los márgenes, ver sección de antecedentes), se observaron con microscopio óptico, y se registraron las medidas a través de una cámara Motican 1000 1.3 MPX que se adicionó al microscopio y su software Motic Image Plus 2.0. Esta caracterización se realizó sobre la base de la colección de referencia de las semillas obtenidas experimentalmente de los tipos silvestres/espontaneo $(130,140,160)$, domesticada (93) y sobre los híbridos F1 y F2 (Tabla 3 cap.2). Teniendo en cuenta los resultados de los análisis fisiológicos efectuados y la conformación de los Grupos Funcionales (GF) (de acuerdo al tipo de dormición), es que se conformaron las muestras para su análisis anatómico.

\section{Conformación de la muestra de ejemplares actuales}

Siguiendo a Hillman (1993) (para armar una colección de referencia heterogénea) se tomaron al azar 15 semillas de cada uno de los genotipos parentales y 5 semillas para los genotipos F1 y F2, en total fueron 26 genotipos divididos en cuatro grupos funcionales. Para cada una de las semillas parentales se tomaron diez medidas, ascendiendo así el $\mathrm{N}$ a 600 mediciones -150 medidas por cada genotipo- y 30 medidas para el caso de los híbridos - seis medidas por cada semilla- $\mathrm{N}=660$ mediciones. Esta diferencia en el número de muestra se debe a que no existía variación significativa al aumentar el número de muestras ya que los valores eran bastantes homogéneos dentro de cada genotipo y considerando que un $\mathrm{N}$ de 30 observaciones aporta información útil, se prefirió reducir el número de mediciones y priorizar analizar la totalidad de ejemplares híbridos que se obtuvieron de los cruces a campo (ver Tabla 3 capítulo. 2).

En un principio se midió también el alto y el ancho de las células epidérmicas. El ancho se midió en la base de estas células que es donde sufren menor distorsión por el corte. A pesar de los cuidados tenidos al cortar las semillas, estas células de paredes delgadas -sobre todo en los ejemplares silvestres- se deformaban. Teniendo esto en cuenta y sobre todo que la epidermis es un tejido que no suele conservarse en las semillas arqueológicas (Lema 2009a) no se lo continuaron registrando sus medidas. Mediante el análisis estadístico se comprobó en general que el alto de la epidermis es la variable que menos aporta al análisis de $\mathrm{CP}$.

(Anexo Fig. 5) (Ver apartado siguiente). 


\section{Semillas arqueológicas}

Las semillas analizadas a nivel anatómico fueron de los siguientes sitios: Bandurria $(\mathrm{N}=1)$, Cerro Lampay $(\mathrm{N}=3)$, Pampa Grande $(\mathrm{N}=9)$, SSalLap $(\mathrm{N}=3)$, Las Champas $(\mathrm{N}=6)$ y Bebé de la Troya $(\mathrm{N}=5)$. En este caso debido a que no siempre se contó con la misma cantidad de semillas, se trató de unificar el número de medidas en un mínimo de 30 (Tabla 3). Las observaciones de los tejidos se realizaron con microscopio óptico de luz incidente.

\begin{tabular}{|c|c|c|c|c|c|c|}
\hline & \multicolumn{2}{|c|}{ Perú } & \multicolumn{4}{c|}{ Argentina } \\
\hline & Bandurria & $\begin{array}{c}\text { Cerro } \\
\text { Lampay }\end{array}$ & SSalLap & $\begin{array}{c}\text { Pampa } \\
\text { Grande }\end{array}$ & $\begin{array}{c}\text { Las } \\
\text { Champas }\end{array}$ & $\begin{array}{c}\text { Bebé de La } \\
\text { Troya }\end{array}$ \\
\hline Alto SCL & 62 & 40 & 75 & 100 & 30 & 30 \\
\hline Ancho SCL & 44 & 38 & 31 & 90 & 30 & 30 \\
\hline Alto Hipodermis & 59 & 34 & 76 & 90 & 15 & 15 \\
\hline Alto Aerénquima & & & 16 & & & \\
\hline
\end{tabular}

TABLA 3: número de medidas tomadas para los tejidos de material arqueobotánico correspondientes a alto y ancho de esclereidas, alto de hipodermis y alto de aerénquima.

\section{RESULTADOS}

El análisis anatómico permitió diferenciar a los grupos actuales y arqueológicos de acuerdo a determinados tejidos. Comenzando desde los tejidos más externos a los más internos de la cubierta seminal, podemos ver que el alto de la hipodermis sirvió para diferenciar a los parentales silvestres, de los domesticados y F2 (híbridos), en tanto los F1 se comportan -al igual que en otros casos- como su parental pistilado (Fig. 13 derecha). En el caso de los restos arqueobotánicos, también se observa un incremento del grosor de la hipodermis desde el arcaico al formativo, mientras que las semillas de los sitios tardíos no se adhieren a esta tendencia, mostrando valores intermedios entre estos dos grupos. Bandurria y Cerro Lampay comparten rango con F2, Pampa Grande y SSalLap 20 con parental subsp. maxima y F1 Hma y Las Champas y Bebé de la Troya con F2 y F1 (Ham), sugiriendo formas híbridas. 

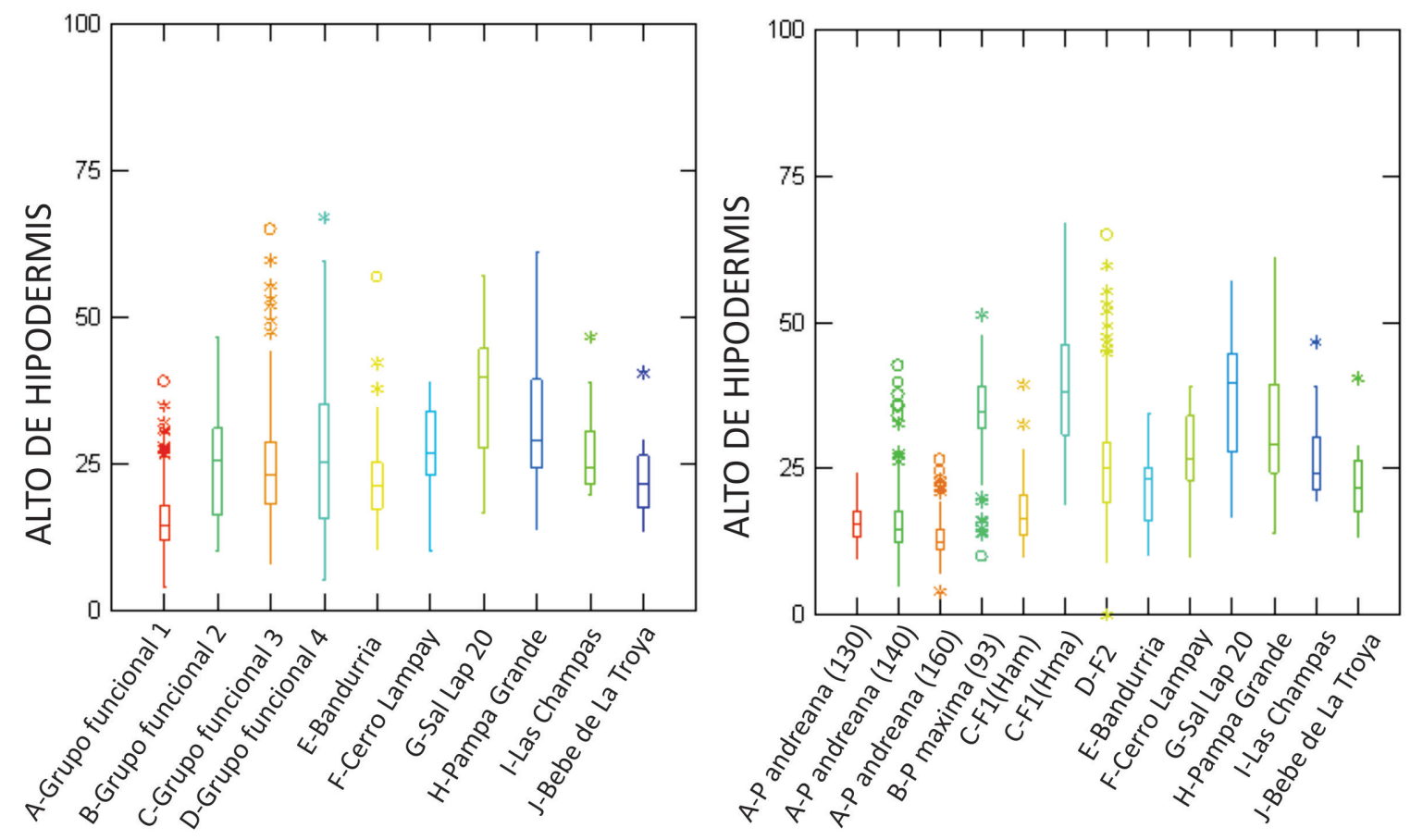

FIGURA 13 Izquierda: alto de la hipodermis $(\mu \mathrm{m})$ de los GF 1-4 (A-D) y restos arqueobotánicos (E-J). Derecha: alto de la hipodermis de los genotipos parentales (AB), F1(C), F2 (D) y restos arqueobotánicos (E-J).

El diámetro de las células hipodérmicas no resulto útil para discriminar GF si bien se vio una tendencia hacia una mayor diversidad desde el GF 1 al GF 4 (Fig.14). 


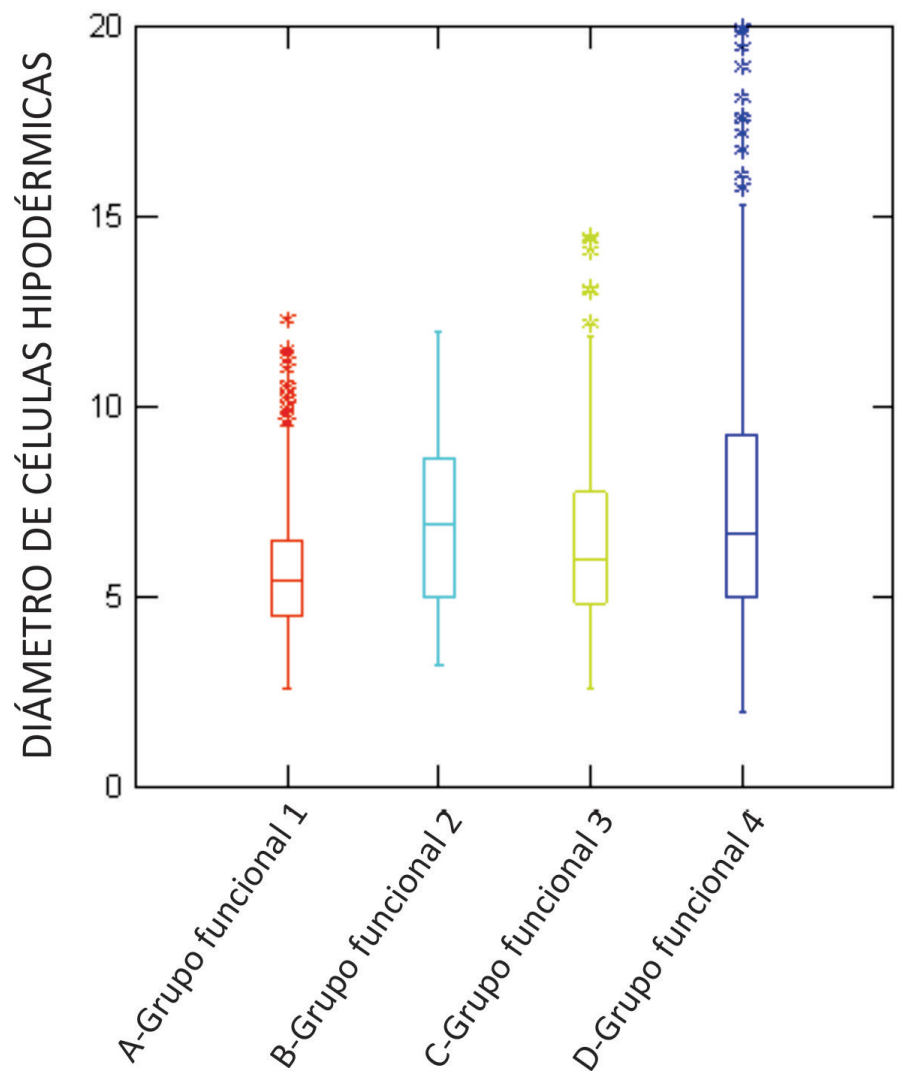

FIGURA 14: diámetro de las células hipodérmicas en los Grupos funcionales.

Las esclereidas (tanto en alto como en ancho) fueron las que mejor se conservaron en los restos arqueológicos y con límites bien diferenciados y precisos. El análisis del alto (Fig. 15 izquierda) mostró un leve agrupamiento entre el GF 1 y 2, por un lado, y el GF 3 y 4 por otro. Lo más llamativo fue que los valores de las semillas de sitios arcaicos y formativos fueron en gran parte menores a lo registrado en los cuatro GF; en el caso de los sitios tardíos coincidió mayormente con los GF 3 y 4. En cuanto a los genotipos parentales, F1 y F2, (Fig. 15, derecha), el alto de las esclereidas tampoco sirvió para distinguir a los mismos, salvo -y relativamente- a los F2; igual que en el caso anterior, Bandurria, Cerro Lampay en parte y SSalLap 20 poseen escleriedas de menor alto que las registradas actualmente. Como diferencia respecto a la comparación con GF Pampa Grande coincide con F2, F1 Ham y el parental maxima; los sitios tardíos con F1 Ham, parental maxima y parental andreana 140. 

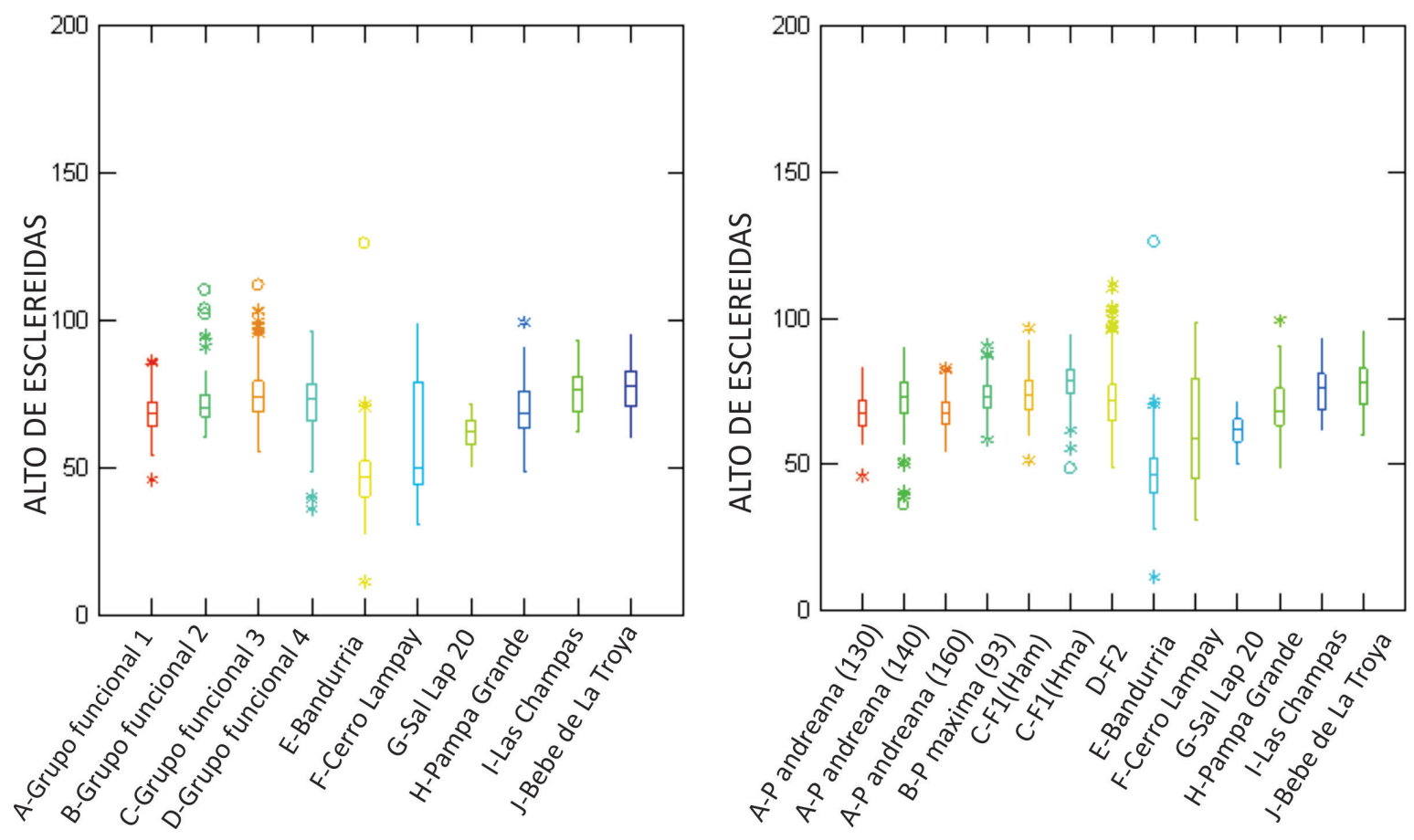

FIGURA 15 Izquierda: alto de esclereidas $(\mu \mathrm{m})$ de los grupos funcionales 1-4 (A-D) y

de los restos arqueobotánicos (E-J). Derecha: alto de esclereidas de los genotipos parentales (A-B), F1(C), F2 (D) y restos arqueobotánicos (E-J).

El ancho de las esclereidas tampoco mostró diferencias claras por GF, y un leve agrupamiento de los GF 2, 3 y 4, por un lado y el 1 por otro (Fig. 16 izquierda), nuevamente los ejemplares arqueológicos arcaicos y formativos poseen medidas menores a las actuales y en el caso de Las Champas y Bebé de la Troya sus rangos son comparables con los GF 2, 3 y 4. En el caso de grupos parentales F1 y F2, el ancho de las esclereidas no permitió diferenciar entre unos y otros (Fig. 16 derecha); los registros de semillas arcaicas y formativas son notablemente menores y las tardías coinciden con una amplia gama de genotipos actuales. 

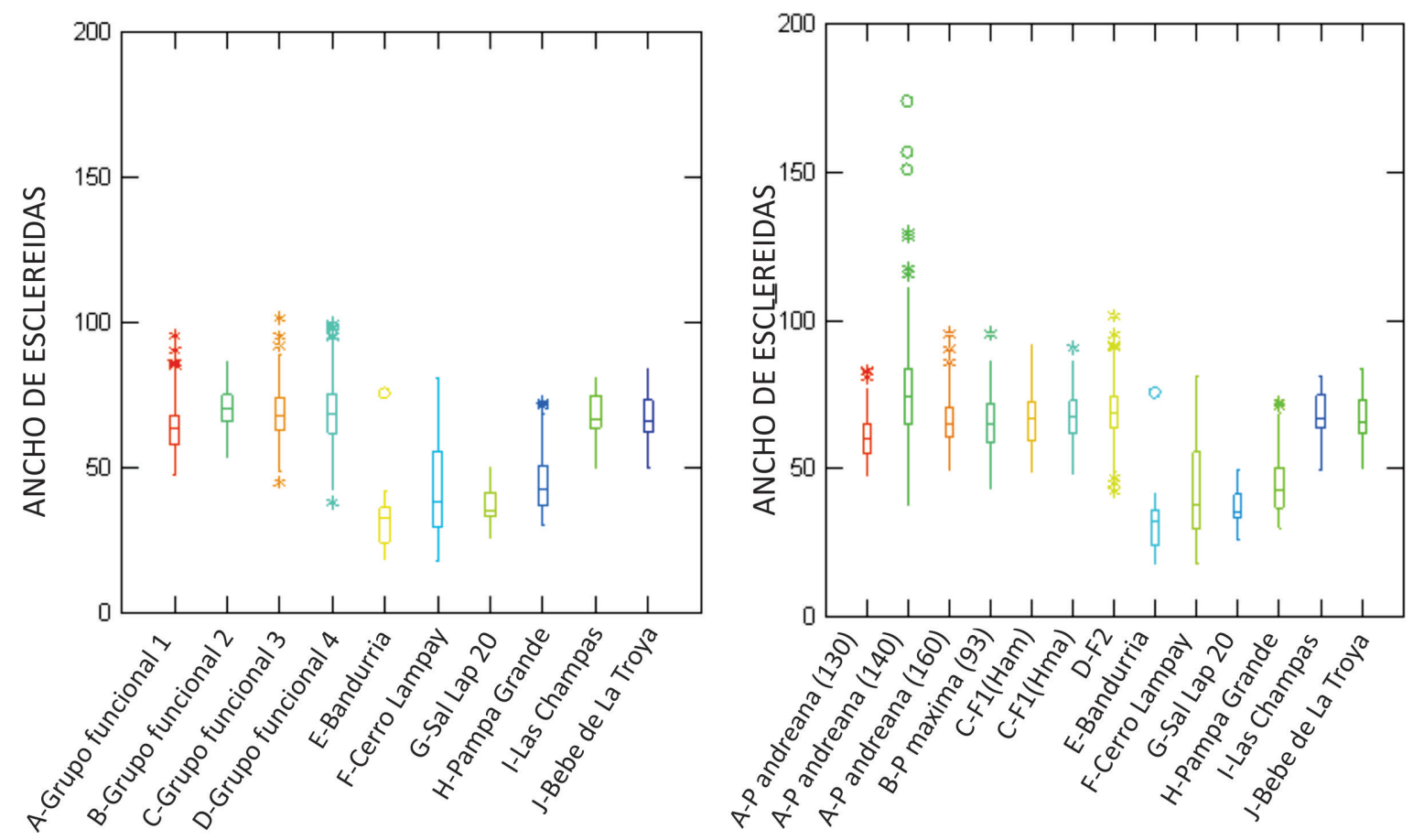

FIGURA 16 Izquierda: ancho de esclereidas $(\mu \mathrm{m})$ de los grupos funcionales (A-D) y de los restos arqueobotánicos (E-J). Derecha: ancho de esclereidas de los genotipos parentales (A-B), F1 (C), F2 (D) y restos arqueobotánicos (E-J).

El alto del aerénquima, fue difícil de medir debido a que sus células son muy lábiles y fáciles de romper al realizar el corte transversal, sólo fue medido en las formas actuales. En las formas arqueológicas no se pudieron determinar bien sus límites, excepto en las semillas del sitio SSalLap 20. En este caso (Fig. 18 izquierda) al igual que en el alto de la hipodermis, el GF 1 se diferenció de los GF 2, 3 y 4 los cuales se solapan entre sí teniendo el GF 4 un rango de medidas mucho mayor, extendiéndose desde los 20 a los casi $100 \mu \mathrm{m}$, mientras que el GF 1 -donde se encuentra las accesiones silvestres- presenta menor variabilidad con un valor promedio de menos de $50 \mu \mathrm{m}$. Las semillas del sitio formativo SSalLap 20 poseen un alto de aerénquima similar al registrado en el GF 1, y en particular a la accesión 160 de la subsp. andreana (Fig. 17 derecha). En esta última figura puede verse que el alto de aerénquima separa bien a las accesiones de andreana de las de maxima, al igual que F1 se comporta según su parental pistilado -como en otros casos- y F2 posee una posición intermedia. 

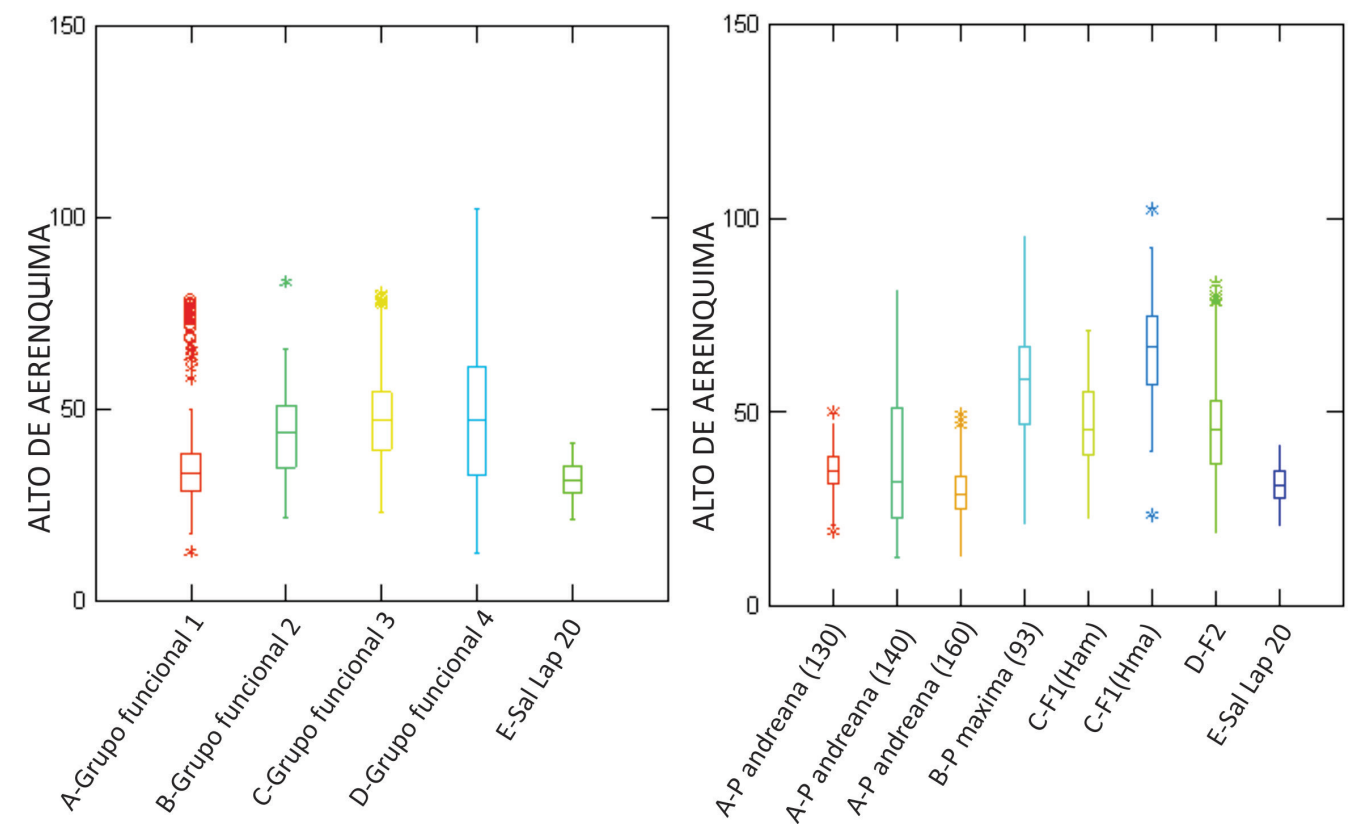

FIGURA 17 Izquierda: alto del aerénquima $(\mu \mathrm{m})$ de los grupos funcionales (A-D) y resto arqueobotánico del sitio SalLap 20 (E). Derecha: alto del aerénquima de los genotipos parentales (A-B), F1(C), F2 (D) y del sitio SalLap 20 (E).

En cuanto a las células del aerénquima, las únicas accesiones que se caracterizaron por tener un tejido aerenquimático formado por distintos tipos de células fueron las accesiones 93 y 140. Estos genotipos se diferenciaron por tener una primera capa de células bien definidas y de tamaño homogéneo, mientras que la segunda capa de células mostraba una naturaleza de forma globosa y de gran tamaño, en la mayoría de los casos se observaban como aisladas de los demás tejidos. Este rasgo no mostró diferenciación entre grupos funcionales (Fig.18) (Anexo Fig. 6). 

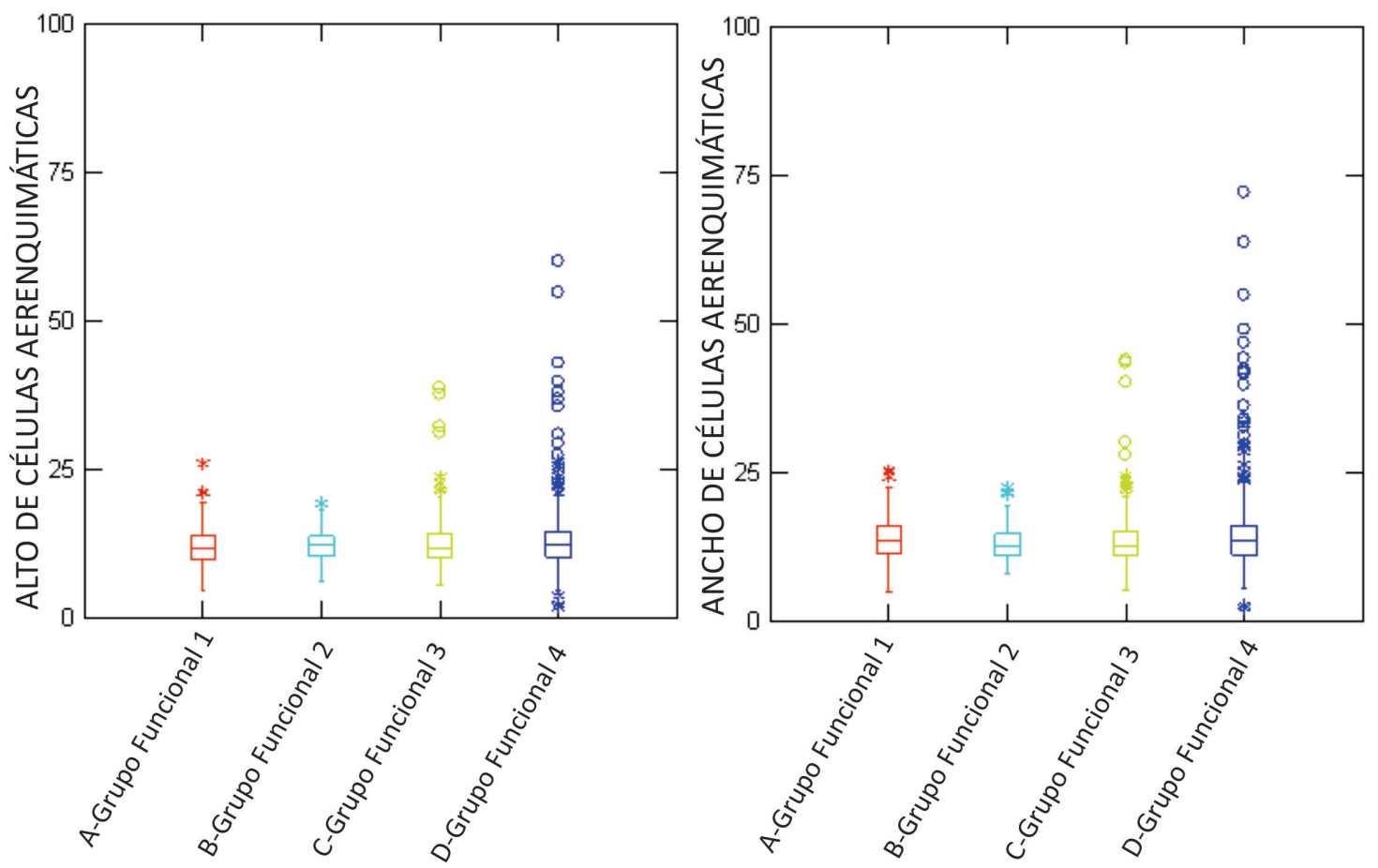

FIGURA 18: Izquierda: alto de células aerenquimáticas para los grupos funcionales. Derecha: ancho de células aerenquimáticas para los grupos funcionales.

En la Fig 6 del Anexo puede verse, a modo de ejemplo, cortes transversales de genotipos parentales $(130,93) \mathrm{F} 1(93 \mathrm{X} 130)$ y F2 (130x93)93.

Finalmente si agrupamos los caracteres observados en cada tejido en los ejemplares arqueológicos y los comparamos con los de referencia (Tabla 4) vemos que, salvo en SSalLap 20, en ningún caso hay coincidencia con el GF 1 de dormición prolongada. En los casos en que hay coincidencia con formas silvestres/espontánea se trata de las accesiones 140 у 160 . 


\begin{tabular}{|c|c|c|c|c|c|c|}
\hline & \multicolumn{2}{|c|}{ Sitios arcaicos } & \multicolumn{2}{|c|}{ Sitios formativos } & \multicolumn{2}{|c|}{ Sitios tardíos } \\
\hline & Bandurria & $\begin{array}{c}\text { Cerro } \\
\text { Lampay }\end{array}$ & SSalLap 20 & $\begin{array}{l}\text { Pampa } \\
\text { Grande }\end{array}$ & $\begin{array}{c}\text { Las } \\
\text { Champas }\end{array}$ & $\begin{array}{c}\text { Bebé de La } \\
\text { Troya }\end{array}$ \\
\hline $\begin{array}{l}\text { Parental } \\
\text { andreana }\end{array}$ & & & $\begin{array}{c}\text { Alto AER } \\
(160)\end{array}$ & & $\begin{array}{c}\text { Alto SCL } \\
\text { (140) }\end{array}$ & $\begin{array}{c}\text { Alto SCL } \\
(140)\end{array}$ \\
\hline $\begin{array}{l}\text { Parental } \\
\text { maxima }\end{array}$ & & & Alto HIP & $\begin{array}{l}\text { Alto HIP, } \\
\text { Alto SCL }\end{array}$ & Alto SCL & Alto SCL \\
\hline F1 Hma & & & Alto HIP & Alto HIP & & \\
\hline F1 Ham & & & & Alto SCL & Alto HIP & Alto HIP \\
\hline F2 & Alto HIP & Alto HIP & & Alto SCL & $\begin{array}{l}\text { Alto HIP } \\
\text { Alto SCL }\end{array}$ & $\begin{array}{l}\text { Alto HIP, } \\
\text { Alto SCL }\end{array}$ \\
\hline GF 1 & & & Alto AER & & & \\
\hline GF 2 & Alto HIP & Alto HIP & Alto HIP & Alto HIP & $\begin{array}{c}\text { Alto HIP, } \\
\text { Ancho SCL }\end{array}$ & $\begin{array}{c}\text { Alto HIP, } \\
\text { Ancho SCL }\end{array}$ \\
\hline GF 3 & Alto HIP & Alto HIP & Alto HIP & Alto HIP & $\begin{array}{l}\text { Alto HIP, } \\
\text { Alto SCL }\end{array}$ & $\begin{array}{l}\text { Alto HIP, } \\
\text { Alto SCL }\end{array}$ \\
\hline GF 4 & Alto HIP & Alto HIP & Alto HIP & Alto HIP & $\begin{array}{c}\text { Alto HIP, } \\
\text { Alto SCL } \\
\text { Ancho SCL }\end{array}$ & $\begin{array}{c}\text { Alto HIP, } \\
\text { Alto SCL } \\
\text { Ancho SCL }\end{array}$ \\
\hline
\end{tabular}

TABLA 4: se muestra la correspondencia de tejidos entre formas actuales $y$ arqueológicas.

En el caso de los sitios arcaicos los mismos mostraron coincidencias con los híbridos F2 y los grupos funcionales de dormición relativa hasta muy baja; el hecho de que sus esclereidas fueran menores a las registradas actualmente nos alerta acerca de la posibilidad de que se trate de formas actualmente no registradas o bien transicionales antes que intermedias o hibridas. Algo semejante ocurre respecto a este último carácter en las semillas de sitios formativos, si bien éstas ya poseen caracteres más próximos a las formas domesticadas y a los $\mathrm{F} 1$, sin que se pudieran adscribir a un grupo funcional. En el caso de los sitios tardíos se vio una situación interesante dado que poseen una combinación de rasgos entre F2, F1, andreana y maxima y afinidad mayormente con los GF 3 y 4 de dormición intermedia y baja dormición. 


\section{DISCUSIÓN}

El análisis anatómico de los distintos tejidos que conforman la cubierta seminal a-excepción de la epidermis cuyo aporte no resultaba significativo de acuerdo con los análisis de CP realizados- nos aporta datos de relevancia. En cuanto al análisis al interior de los ejemplares obtenidos por cruzamiento a campo, vemos que el alto del aerénquima y de la hipodermis son los rasgos que mejor distinguieron a la subsp. andreana, de maxima de los hibridos F2, en tanto los tamaños de las células que componen estos tejidos al igual que las esclereidas no resultaron de utilidad. Tomando entonces los dos primeros rasgos mencionados, vemos que las semillas de sitios arcaicos se asemejan a los hibridos F2, las de sitios formativos a las subsp. maxima y en menor medida andreana (160) y a los cruces $\mathrm{F} 1$, mientras que las de sitios tardíos a F1 y F2. Cuando consideramos los GF establecidos en el capítulo previo y evaluamos su correlato a nivel de la cubierta seminal, no encontramos correspondencias entre el agrupamiento de los genotipos por clase de dormición y las medidas de los tejidos analizados, salvo un tendencia a que se separe el GF 1 por un lado, de los GF 2, 3 y 4 por otro, principalmente en los dos rasgos destacados previamente: alto de hipodermis y de aerénquima. Cuando comparamos esto con los restos arqueológicos, vemos que ninguna de las semillas

presentó caracteres que se asociaran plenamente al GF 1, salvo las de SSalLap 20. Esto último se debe en parte a que fue sólo en esta semilla donde se conservaron restos de aerénquima. En el resto de los ejemplares arqueológicos las coincidencias se dieron con los otros tres GF, en el caso de los sitios tardíos, principalmente con los GF 3 y 4 con dormición intermedia y muy baja dormición. Finalmente, si tomamos todos estos rasgos en conjunto podemos decir que los sitios arcaicos representan semillas híbridas con dormición relativa, intermedia y/o con muy baja dormición; los formativos formas domesticadas o F1 con dormición intermedia y/o muy baja dormición y los tardíos formas hibridas y F1 de dormición intermedia.

\section{DISCUSIÓN Y CONCLUSIONES GENERALES DEL CAPÍTULO}

En este capítulo nos propusimos investigar el correlato morfológico entre distintos genotipos actuales que participaron en los cruzamientos experimentales a campo (ver cap. 2), al igual 
que entre distintos grupos funcionales con dormición diferencial (ver cap. 3). La búsqueda de estos correlatos se debía a que a través de ellos podíamos acercarnos a los cambios acaecidos a lo largo del tiempo en las poblaciones de C. maxima en el área andina centro meridional a través de restos vegetales arqueológicos y testear la hipótesis de investigación que nos propusimos a este respecto, la cual afirmaba que "es posible evaluar el tipo de dormición en el pasado a través del estudio de correlatos morfológicos de caracteres fisiológicos tanto en $C$. maxima subsp. maxima como en C. maxima subsp. andreana, sus híbridos respectivos y diversos cruzamientos". Partimos de que esta hipótesis sería mejor testeada en semillas, ya que la dormición se manifiesta en las mismas. En este sentido, un primer estudio biométrico morfológico nos indicó que la media geométrica era un buen indicador para diferenciar distintos genotipos (subsp. maxima, subsp. andreana, F1 y F2) y que el análisis de forma y los coeficientes de variación, si bien menos precisos en discriminar entre estos conjuntos, podían aportar también a su comprensión. El análisis de tamaño y forma en semillas arqueológicas, todas identificadas como $C$. maxima subsp. maxima o aff. a subsp. maxima señaló que la tendencia general luego de haberse domesticado C. maxima subsp. maxima fue, primero, la generación de nuevas formas, manteniéndose poblaciones híbridas, lo cual no aportó mayor variabilidad de forma o tamaño ya que la misma se vio reducida durante el Formativo. En momentos posteriores, continuó la reducción de la variabilidad, se mantuvieron las mismas formas y tamaños, a la vez que se optó por sumar a los conjuntos tamaños mayores y se redujo -si bien no completamente- la presencia de formas híbridas. El análisis biométrico de la anatomía de las cubiertas seminales permitió discriminar entre genotipos en el caso del alto de la hipodermis y el aerénquima, a la vez que no fue definitorio para discriminar distintos grupos funcionales salvo -y en los mismos tejidos antes mencionados- entre semillas con dormición prolongada (GF 1), respecto a las restantes con dormición relativa (GF 2), intermedia (GF 3) y muy baja dormición (GF 4). Cuando se analizaron las semillas arqueológicas, un primer rasgo llamó la atención: aquellas de sitios arcaicos y formativos mostraron esclereidas de alto y ancho menores a las registradas actualmente, incluso en formas silvestres. Descartando que esto se deba a factores de preservación diferencial y desecamiento, considerando que no se trata de semillas inmaduras o con procesamiento alguno, este rasgo nos habla de un conjunto con cierta línea de continuidad a nivel regional entre sitios del actual territorio peruano y de la provincia de Salta que se alejan de lo que hemos registrado actualmente. Esto puede relacionarse a formas pretéritas que han desaparecido actualmente (o que no se han registrado 
aún), o bien a formas con caracteres transicionales - antes que intermedios o híbridos- que no han persistido hasta la actualidad debido a los cambios propios de los procesos evolutivos y de domesticación a lo largo del gran lapso temporal que media entre dichas semillas arqueológicas y el presente. Otro aspecto a destacar es que en solo un sitio se detectó semillas que conservaban restos de aerénquima (SSalLap 20, Formativo), por lo cual su alto -de valor diagnóstico- no es posible de evaluar en gran cantidad de restos. De todas maneras resulta llamativo que en este caso el alto del aerénquima de las semillas de SSalLap 20 fue el único rasgo coincidente con lo observado en el GF 1 de dormición prolongada. Esto resultó ser coherente con otros rasgos observados en estas semillas que indicaban una afinidad con la accesión 160 de la subsp. andreana, con la subsp. maxima y con los F1 Hma. En el caso del otro sitio formativo de Salta, Pampa Grande, los rasgos se asociaron también a la forma domesticada, a F1 y F2 y a grupos funcionales con dormición desde relativa a muy baja. Estos resultados para el Formativo se condicen con lo observado a nivel morfológico donde se registraron variabilidad de formas y situaciones de hibridación lo cual podría haber implicado, aunque no podamos afirmarlo plenamente, la presencia de poblaciones con distintos tipos de dormición. En el caso de los sitios arcaicos peruanos el análisis de sus cubiertas seminales los asocia a híbridos F2. Considerando que accesiones F2 están presentes solo en los GF 3 y 4 (ver cap. 3) podemos pensar que la gran variación observada en la morfología de semillas arcaicas se correlaciona con la presencia de híbridos con dormición intermedia o muy baja. El análisis biométrico de las semillas de sitios tardíos de Catamarca arrojó resultados llamativos con mayor variación de la esperada, a pesar de la tendencia general observada de privilegiar la selección de tamaños mayores, sin que se abandonaran formas y tamaños registrados previamente e, incluso, situaciones de hibridación. El análisis de las cubiertas seminales fue coincidente también con situaciones de cruzamiento ya que los rasgos de la misma se asemejaron a lo observado en F2, F1 (Ham), subsp. maxima y la accesión espontánea 140 de la subsp. andreana, coincidiendo mayormente con los grupos con dormición intermedia (GF 3) y muy baja dormición (GF 4). Considerando todo lo antes dicho y respecto a la hipótesis original de trabajo podemos decir que la misma se ha confirmado de manera parcial, ya que si bien no ha habido un correlato preciso y exacto entre dormiciones diferenciales y rasgos biométricos (morfológicos o anatómicos), se ha podido establecer un escenario pasado donde la hibridación y el flujo génico estuvieron posiblemente presentes, mucho más de lo esperado, y que ello se vinculara a la presencia/mantenimiento/fomento de poblaciones con dormición 
diferencial. Esto será motivo de análisis en el capítulo siguiente. Finalmente, en cuanto a los resultados de los análisis de pericarpios y pedúnculos para restos de la localidad arqueológica de Pampa Grande, los mismos -sobre todo los segundos- apoyan la conclusión general de cruzamientos entre poblaciones y generación de formas hibridas. 


\section{CAPÍTULO 5}

\section{DISCUSIÓN Y CONCLUSIONES GENERALES}

En el presente trabajo de Tesis se planteó como objetivo general determinar las modificaciones fisiológicas, morfológicas y anatómicas que tuvieron lugar en semillas y frutos de Cucurbita maxima subsp. andreana y subsp. maxima, al igual que en sus diversos cultivares, a lo largo del proceso de manejo, cultivo y domesticación en el Área Andina Centro - Meridional, con particular énfasis en el Noroeste de Argentina, atendiendo principalmente a cambios en la dormición ligados a procesos naturales y culturales (entiéndase, bioculturales) de selección. Este objetivo general se acompañó de dos hipótesis, las cuales fueron contrastadas en los capítulos 3 y 4.

En este capítulo haremos, primero, un breve repaso de los resultados obtenidos, ligando principalmente los resultados de los capítulos antes mencionados en función de las indagaciones de las hipótesis de trabajo (ver capítulo 1). En segundo lugar -y a partir de la exposición de los resultados previos- presentaremos y debatiremos las interpretaciones que podemos aportar sobre los procesos generales de domesticación de los taxa involucrados, en el área de estudio. Finalmente, pero no menos importante, haremos una reflexión sobre los aportes que consideramos una metodología de trabajo interdisciplinario puede aportar al estudio de procesos de domesticación pasados, junto con algunas proyecciones a futuro.

Los resultados obtenidos nos permitieron caracterizar las modificaciones fisiológicas involucradas en la dormición de semillas de ambas subespecies y de las generaciones F1 y F2 obtenidas de su cruzamiento experimental. A continuación presentamos una breve enumeración de las conclusiones obtenidas a partir de los resultados presentados en el capítulo 3:

-La subespecie domesticada presenta baja dormición. 
-La dormición que se identificó en la subsp. andreana está impuesta por el contenido diferencial de ABA en las cubiertas de las semillas y en la diferente sensibilidad de los embriones a esta hormona.

-Los embriones maduros de todos los genotipos parentales e híbridos no poseen restricciones para germinar.

-Los genotipos F1 mostraron una dormición que se asemeja a su parental pistilado, mientras que los F2 (híbridos) mantienen la tendencia de germinación de las formas domesticadas. Estos resultados ponen en evidencia que la dormición está impuesta principalmente por tejidos provenientes del parental materno.

-La dormición de las semillas se revirtió con la aplicación exógena de ácido giberélico, mostrando que a lo largo del proceso de domesticación el balance de la relación ABA/GAs fue modificado. Además, la completa inhibición de la germinación de embriones del genotipo silvestre por paclobutrazol -y sólo parcialmente en el domesticado- indica que la síntesis de GAs necesaria para la germinación fue también modificada durante la domesticación.

-Se observó que el proceso de domesticación disminuyó la sensibilidad de los embriones a la temperatura.

-El pasaje de agua a través de la cubierta seminal no limita la germinación de las semillas.

Estos resultados permitieron, no sólo caracterizar cada genotipo, sino también crear grupos funcionales con dormición absoluta, intermedia o baja a partir de agrupaciones de los mismos. Las mediciones y los ensayos experimentales fueron útiles para caracterizar la condición de germinación y de dormición de la especie y de sus híbridos, mediante estas aproximaciones se pudo determinar que los factores ambientales desarrollaron un rol preponderante en la evolución de las Cucurbitas. Coincidiendo con autores como Boeswwinkel y Bouman (1995) o Bewley (1997) podemos considerar que las cubiertas seminales actuarían como aislantes para la protección del embrión según el rango de temperatura en que se desarrolle. Sin embargo al procurarse el reflejo morfológico de los grupos funcionales con diversos tipos de dormición en las cubiertas seminales de las semillas que formaban parte de cada uno de esos grupos (capítulo 4), no se halló una correspondencia plena, salvo en un par de rasgos, uno de los cuales (que involucra al aerénquima) es de difícil conservación en el registro arqueológico. Por lo tanto, si bien la cubierta seminal se encuentra en parte involucrada en la dormición, aún no estamos en condiciones de asociar 
directamente los rasgos anatómicos biométricos de las cubiertas de semillas con dormición diferencial, esto es: a distinta dormición no hay un conjunto robusto de caracteres anatómicos que sean reflejo de dicha condición en las cubiertas, tan sólo tendencias generales en dos tejidos. A pesar de esto, el análisis biométrico morfológico de las semillas (tamaño y forma), en conjunción con el análisis de pedúnculos y pericarpios, nos permitió proponer la presencia temprana -durante el Arcaico en el actual territorio peruano- de formas hibridas semejantes a F2. Asimismo el Formativo del NOA se caracterizó por la presencia de ejemplares similares a F2, junto a formas domesticadas y otras semejantes a F1, sumado a la detección de la subsp. andreana -por parte de otros investigadores- en la localidad de Pampa Grande. Los análisis realizados nos permitieron asimismo, proponer la presencia, si bien en menor medida, de formas híbridas en el Tardío del NOA junto a una tendencia en las formas domesticadas, ya no de generación de nuevas formas como en el Formativo, sino de tamaños mayores. Estos rasgos, sumados a los análisis de las cubiertas seminales (vinculados principalmente al tejido hipodérmico) nos llevan a considerar la posibilidad de que los híbridos arqueológicos hayan tenido mecanismos de dormición intermedios.

Esta tesis no aborda los primeros momentos de transición de la forma silvestre a la domesticada en C. maxima, lo cual constituye en el estado actual de conocimiento arqueológico y arqueobotánico de la región, un aspecto que no se ha podido profundizar puesto que carecemos de evidencias que nos permitan abordar estos momentos iniciales en el registro arqueológico del Área Andina Centro Meridional y del NOA en particular para este taxón. Por lo tanto, los resultados nos indican que estamos abordando momentos donde ya se habría domesticado esta especie, puesto que las semillas arcaicas se asemejan a los grupos F2, verdaderos híbridos.

Estudios arqueobotánicos previos detectaron la coexistencia de ambas subespecies de $C$. maxima junto a morfotipos con caracteres intermedios, lo cual llevó a proponer la hipótesis de que estas formas intermedias podrían corresponder a poblaciones híbridas entre ambas subespecies como parte de un complejo silvestre-maleza-domesticado en C. maxima (Lema, 2009a, 2015) con flujo génico, hibridación y/o introgresión. Tales mecanismos favorecieron la generación de formas nuevas, mejor adaptadas a los ambientes modificados por actividad humana y que tras la domesticación se propagaron localmente presentando diferencias respecto de los progenitores silvestres. Consideramos entonces que esta tesis ha aportado a contrastar esta hipótesis, brindando elementos que apoyan la propuesta de que los restos con 
caracteres intermedios son híbridos y que tras la domesticación de la subsp. maxima, actuaron la hibridación y el flujo génico como mecanismos importantes en la selección y domesticación de nuevos cultivares o variedades. La diversificación e introgresión resultan entonces agentes de selección importantes junto a la deriva y flujo génico. Deseamos destacar que este último mecanismo tiene correlatos actuales con procesos de selección conscientes y dirigidos que permiten el flujo génico entre formas malezoides, silvestres y domesticadas, como también con procesos no controlados por los campesinos locales quienes pueden presentar dificultad para reconocer ejemplares de distinta progenie, tal como sucede con otras especies del genero (Montes Hernández y Eguiarte, 2002). Siempre y cuando los F1 sean fértiles, lo cual ha sido constatado para el complejo C. maxima subsp. andreana - subsp maxima y ante panoramas como éstos, donde el flujo génico está presente en varias especies y subespecies de Cucurbita, el aislamiento reproductivo se torna un mecanismo esencial en la fijación de caracteres de domesticación (Kistler et al., 2015, Lira Saade et al., 2016). En el caso de C. maxima es probable que dicho aislamiento haya sido geográfico -permitiendo luego el cruzamiento y la obtención de híbridos fértiles cuando ambas subespecies son simpátricas- y que el origen de la subespecie domesticada deba buscarse en sitios mucho más tempranos que los aquí tratados, o bien, en otras regiones. En el caso de la localidad arqueológica de Pampa Grande la alta diversidad de formas que sugieren los restos arqueológicos de la subespecie domesticada, nos hace pensar que el cruzamiento e intercambio génico dentro de los complejos silvestre-maleza-domesticado fue una estrategia para generar diversidad tanto en la línea de selección de frutos usados como recipientes como de aquellos usados sólo para consumo (Lema 2009a, 2015). Esto nos 1leva, a su vez, a proponer que las formas híbridas no estarían siendo objeto de prácticas de erradicación sino de cultivo, o a una combinación de ambas, y que el flujo génico habría sido deseado y controlado con miras a aumentar la heterogeneidad de los zapallos y las opciones que esa diversidad ofrecía para los cultivadores de hace dos mil años en la región. El resultado del cruce de los análisis fisiológicos, con los biométricos y los arqueológicos nos llevan a proponer a modo de hipótesis a explorar a futuro, que dentro de las prácticas de manejo de estas poblaciones, contar con ejemplares con dormición diferencial sería una estrategia para reducir los potenciales riesgos de contar con maduraciones homogéneas. Asimismo dicha estrategia pudo ser también una fuente de generación de diversidad para seleccionar y aprovechar poblaciones con adaptaciones a condiciones ambientales diversas 
tal como sucede actualmente en la zona andina. Los resultados alcanzados en esta tesis nos llevan a considerar situaciones diferentes a la homogeneidad en germinaciones más rápidas y uniformes como un rasgo del síndrome adaptativo de la domesticación en Cucurbita (Smith, 2006 a), lo cual llevaría -entre otros aspectos- a una pérdida en la capacidad adaptativa ante factores (como lluvias) de patrón azaroso (Lira Saade et al., 2016). Todo lo antes dicho nos lleva a considerar que la procura de cruzamientos y flujo génico entre poblaciones es una estrategia que tuvo vigencia a lo largo del tiempo como modo no sólo de generar diversidad a partir de la cual luego seleccionar, sino como la base de poblaciones heterogéneas que prosperasen ante situaciones ambientales no solo diversas, sino también cambiantes.

Podemos complementar lo antes dicho indicando que a partir de los objetivos fisiológicos y morfo-anatómicos desarrollados en los distintos capítulos, se han contrastado las hipótesis de trabajo de la siguiente manera. Con respecto a la primera, se ha podido establecer una importante reducción en la expresión de la dormición como consecuencia de modificaciones fisiológicas. Sabemos que el ABA y la temperatura tuvieron injerencia en esta reducción, y que, a nivel morfo-anatómico, la cubierta seminal también participa de la misma. Aún resta confirmar con trabajos futuros qué procesos intervienen en los cambios de los niveles de ABA de la cubierta seminal y si éstos tienen relación con las diferencias micromorfológicas observadas en la misma. Con respecto a la segunda hipótesis de trabajo, si bien se ha determinado que la cubierta seminal interviene en la expresión de la dormición y que existen diferencias micromorfológicas de dicha cubierta entre las subespecies y sus híbridos, aún resta saber a que correlatos fisiológicos específicos corresponden estas diferencias.

Finalmente, nos gustaría mencionar algunas consideraciones sobre los aportes que una metodología de trabajo interdisciplinario puede brindar al estudio de procesos de domesticación pasados. En primer lugar destacamos la importancia que tuvo realizar cruzamientos experimentales a campo no sólo para comprender algunos procesos, sino también para enriquecer nuestras colecciones de referencia arqueobotánicas. En este sentido, cuando se trabaja en el registro arqueológico con restos vegetales posiblemente transicionales entre una forma y otra o considerados potenciales híbridos (como fue el caso de los materiales analizados previamente en esta tesis, ver Lema 2009a), contar con material actual sobre el cual podamos estar seguros sobre su status relacional (generaciones de las que procede) además de taxonómico, resulta esencial. Los cruces controlados a campo y particularmente las retrocruzas, permiten generar formas más cercanas a las formas 
antecesoras silvestres. Esto es particularmente importante en el caso de los taxa analizados en esta tesis ya que como vimos, el flujo génico ha sido y es un factor importante en la configuración que van adoptando las poblaciones de C. maxima. Si bien partimos el trabajo con tres accesiones de la subsp. andreana procedentes de tres localidades distintas (ver capítulo 2), los análisis fisiológicos posteriores (ver capítulo 3) demostraron que sólo dos eran de tipo puras o silvestres, siendo la otra de tipo espontáneo, posiblemente con algún grado de cruzamiento con la forma domesticada. Si bien su morfología es totalmente equiparable a la subsp. andreana y, por ende, clasificada taxonómicamente como tal. Esta dificultad la enfrentan hoy por hoy los taxónomos (lo cual ha llevado, en la tarea de caracterizar a la subespecie, a descartar poblaciones diversas por considerarlas escapes de cultivo, ver capítulo 4), fue probablemente lo que en el pasado, al igual que en la actualidad, influye en la toma de decisiones de los cultivadores sobre qué erradicar, tolerar y/o sembrar. En segundo lugar, el trabajo fisiológico llevado a cabo con el producto de las cosechas también resultó esencial, las plantas manejadas, en tanto artefactos bioculturales (Ford, 1979, 1985, Baleé, 1989, Lema, 2009a), resultan ser elementos complejos que difícilmente sean caracterizados y/o entendidos si son abordados desde un solo conjunto de rasgos. Como vimos previamente, los análisis fisiológicos nos pueden llevar a entender que representantes de tres poblaciones que son equiparables desde lo taxonómico difieren desde lo fisiológico, como las accesiones de la subsp. andrena. Sumado a lo anterior, los ensayos fisiológicos permitieron caracterizar y comprender los mecanismos de dormición en los miembros de $C$. maxima, lo cual no había sido hecho hasta el momento, su congregación en grupos funcionales y su proyección en el análisis de restos arqueobotánicos, permitiéndonos entender a los conjuntos vegetales no sólo desde lo taxonómico y fisiológico, sino también desde lo evolutivo. Las formas biológicas son resultado de múltiples factores relacionados entre sí, a la vez que resultan de la trayectoria de transformaciones de esa misma relación en el tiempo, lo cual, en el caso de la domesticación, es producto de criterios y condiciones biológicas, culturales, ecológicas y sociales en atravesamiento continuo y entre sí (Lema 2012, 2015). Por lo tanto, creemos que considerar grupos funcionales que agrupan genotipos diversos (ver capítulo 3) a la vez que genotipos y grupos taxonómicos para comparar sus caracteres morfológicos y anatómicos con restos arqueobotánicos (ver capítulo 4) es un aporte de interés en los modos de trazar vínculos entre lo actual y lo pasado en la reconstrucción de trayectorias evolutivas bajo domesticación. 
Además de los recientes avances en el campo de la genética, los estudios sobre domesticación en restos vegetales arqueológicos se realizan principalmente mediante estudios morfológicos. Como ya hemos visto (capítulos 1 y 4) estos estudios son de diverso tipo y poseen diferente grado de resolución en aspectos ligados a los cambios bajo manejo, cultivo y domesticación por parte de poblaciones humanas.

En esta tesis hemos querido aportar a entender el reflejo anatómico de un rasgo como la dormición, los estudios originales aquí realizados lograron determinar la participación de las cubiertas seminales en la misma y si bien su estudio anatómico no ha arrojado correspondencias vis a vis con los grupos funcionales, abre una puerta metodológica en la que creemos es importante seguir trabajando a futuro. Los cambios en las cubiertas seminales a nivel cualitativo y cuantitativo se han considerado en distintos casos como indicadores de cambios bajo domesticación y cultivo, particularmente ligados a cambios en la dormición (capítulo 1 y 4). En particular en el caso de las Cucurbitaceas, cuyas semillas son ingeridas, este rasgo ha sido seleccionado en función de los modos de ingesta de las mismas, ya sea eliminando completamente la testa en el caso de algunas variedades de $C$. pepo (Lema, 2009a), o manteniendo las mismas y quitándolas previo al consumo (capítulo 4) (Wasylikowa y van der Veen, 2004). Análisis a futuro que indaguen posibles procesamientos de semillas para su consumo en el caso de C. maxima pueden resultar una vía interesante para analizar los criterios de selección que operaron sobre las cubiertas. La constitución anatómica de este tejido posee roles adaptativos complejos, en donde no sólo regula la expresión de la dormición, sino que también protege al embrión frente a factores tales como la desecación y la temperatura. Si tomamos en cuenta la hipótesis antes mencionada que establece que el mantenimiento de formas híbridas a lo largo del tiempo pudo ser un mecanismo de diversificación para contar con poblaciones adaptadas a distintas condiciones ambientales, y le sumamos los resultados fisiológicos que indican que los embriones domesticados poseen una menor sensibilidad a las bajas temperaturas, creemos que explorar a futuro el rol de las cubiertas y su anatomía a este respecto puede aportar al entendimiento de la adaptación de poblaciones de C. maxima a pisos altitudinales elevados como en el área andina donde las temperaturas bajas y la menor humedad son factores claves. Esto último se articula también con estrategias de cultivo que se han detectado a nivel arqueológico en dicha zona y a lo largo del tiempo, implementadas con el fin de modular ambas variables (riego, cultivo en quebradas protegidas, parcelas de cultivo con paredes elevadas, entre otras) 
(Korstanje y Quesada, 2010, Capparelli et al., 2011). Esto nos lleva a considerar en términos más generales las diferencias que existen entre cambios en las adaptaciones vinculadas a la dormición y los cambios en las técnicas de cultivo entre sistemas agrícolas extra americanos donde la introducción del uso de arado fue relevante (Jones, 2009, Fuller, 2012). En nuestra zona de estudio el vínculo entre ambos aspectos se encuentra escasamente explorado considerando las tecnologías propias del área. Otro aspecto que sería interesante analizar a futuro es si existen relaciones alométricas entre las cubiertas seminales y las semillas, como ocurre entre las semillas y los frutos (Cowan y Smith, 1993, Fuller, 2012) y si existe una relación entre el espesor de las mismas y rasgos genéticos, como ocurre en otras cucurbitáceas del género Citrullus (Grange et al., 2003, Peng et al., 2010, Ahmad et al., 2013).

Esta tesis procuró realizar aportes que se basaran en el trabajo interdisciplinario y en la exploración de nuevas vías que dicha clase de trabajo de investigación habilita en una problemática como es la domesticación vegetal, la cual requiere de múltiples líneas de evidencia para su entendimiento. Consideramos que un fenómeno biocultural como el que esta tesis ha abordado requiere reunir ámbitos científicos que la historia académica ha escindido, lo cual es una tarea tan desafiante como prometedora. Esperamos que a futuro podamos estrechar más los vínculos entre las disciplinas de los ámbitos de las ciencias sociales y naturales a fin de superar miradas dicotómicas y enriquecer nuestro entendimiento de procesos complejos como la domesticación de especies vegetales. 


\section{BIBLIOGRAFÍA}

Aguirre, M.G.2012. Recursos vegetales: uso, consume y producción en la puna meridional Argentina (5000-1500 AP). Tesis doctoral inédita. La Plata. Universidad Nacional de La Plata.

Aguirre-Dugua, X., Eguiarte, L., González-Rodríguez, A., Casas, A. 2012 Round and large: morphological and genetic consequences of artificial selection on the gourd tree Crescentia cujete by the Maya of the Yucatan Peninsula,México. Annals of Botany 109:1297-1306. Aguirre-Dugua, X., Pérez Negrón, E.,Casas, A. 2013. Phenotypic differentiation between wild and domesticated varieties of Crescentia cujete L. and culturally relevant uses of their fruits as bowls in the Yucatan Peninsula, Mexico. Journal Etnobiology and Etnomedicine 9 (1): 76-90.

Aguirre-Dugua, X., González-Rodríguez, A. 2016. Phylogeographical approaches to the study of plant domestication, with special emphasison perennial plants. En Ethnobotany of Mexico, editado por Lira Saade R, Casas A, Blancas J. Springer, New York, pp. 319-366.

Ahmad, I., Hussain, T., Nafees, M., Moazam Jamil, M., Ashraf, I., Fakhar-u-Zaman Akhtar, M., Iqbal, M., Rafay, M., Ruby, T., Ali, L. 2013 Morphological Dissimilarity Between Tetrapoloid and Diploid Watermelon (Citrullus lanatus Thunb.) World Applied Sciences Journal 21 (6): 858-861

Ali-Rachedi, S., Bouinot, D., Wagner, M.H., Bonnet, M., Sotta, B., Grappin, P. y Jullien, M. 2004. Changes in endogenous abscisic acid levels during dormancy release and maintenance of mature seeds: studies with the Cape Verde Island ecotype, the dormant model of Arabidopsis thaliana. Planta 219: 479-488.

Allaby, R., Kitchen, J., Fuller, D. 2016. Surprisingly low limits of selection in plant domestication. Evol Bioinform 11(S2):41-51.

Anderson, P.1999. Prehistory of Agriculture. New Experimental and Etnographic Approaches, editado por Anderson P. University of California. 
Archila, S., Giovanneti, M., Lema, V. 2008. Arqueobotánica y teoría arqueológica. Discusiones desde Suramérica. Bogotá, UNIANDESCESO.

Arriola, P.E. 2005. Gene flow, hybridization and introgression: definitions and explanations. En Issues on gene flow and germplasm management, editado por Carmen de Vicente. M. IPGRI. Italia pp. 1-5.

Ashworth, L.1997. Estudios sobre la biología reproductiva del zapalllo amargo (Cucurbita andreana, Cucurbitaceae). Tesina de Licenciatura. F.C.E.F y N. U.N.N.

Ashworth, L. y Galetto, L. 1999. Morfoanatomia cuantitativa de las flores estaminadas y pistiladas de Cucurbita maxima subsp. andreana (Cucurbitaceae). Darwiniana 37(3-4):187198.

Ashworth, L. y Galetto, L. 2001. Pollinators and reproductive success of the wild cucurbit Cucurbita maxima ssp. andreana. Plant Biology 3: 398-404.

Babot, M. P. 2003. Starch grain damage as an indicator of food processing. En Phytolith and Starch Research in the Australiane Pacifice Asian Regions: The State of the Art, editado por Hart, D.M., Wallis, L.A. Pandanus Books. The Australian National University. Canberra pp. 69-81.

Babot, M. P. 2004. Tecnología y utilización de artefactos de molienda en el Noroeste prehispánico. Tesis Doctoral inédita, Facultad de Ciencias Naturales e Instituto Miguel Lillo, Universidad Nacional de Tucumán.

Babot, M. P. 2006. Damage on starch from processing Andean food plants. En Ancient starch research, editado por R. Torrence y H. Barton, Left Coast Press. California pp. 66-67, 71, 31-32.

Babot, M. P. 2011. Cazadores recolectores de los Andes centro-sur y procesamiento vegetal. Una discusión desde la puna meridional Argentina (ca. 7000-3200 años AP). Chungara 43 (1) 423-432.

Baldini, M., Baffi, E. y Togo, J. 1998. Abrigos y cavernas que hacen historia: los hallazgos de Las Pirguas (Pampa Grande, Salta). Homenaje a Alberto Rex Gonzalez. FADA-FFyL. UBA pp. 343-353.

Baldini, M., Baffi, E., Salaberry, M. y Torres, M. 2003. Candelaria: una aproximación desde un conjunto de sitios localizados entre los cerros de Las Pirguas y El Alto del Rodeo (Dto. Guachitas, Salta, Argentina). En La mitad verde del mundo andino. Investigaciones 
arqueológicas en la vertiente oriental de los Andes y las tierras bajas de Bolivia y Argentina, editado por Ortiz, G. y Ventura, B. FHyCS-UNJU pp.131-151

Balée, W.1998. Advances in Historical Ecology. Columbia University Press, New York. USA.

Baloch, H., DiTommaso, A., Watson, A. 2001. Intrapopulation variation in Abutilon theophrasti seed mass and its relationship to seed germinability. Seed Science Research 11: 333-345.

Baskin, J. y Baskin, C. 2004. A classification system for seed dormancy. Seed Science Research 14:1-16.

Batlla, D., Kruk, B.C. y Benech-Arnold, R.L. 2004. Modeling changes in dormancy in weed soil banks: implications for the prediction of weed emergence. En Handbook of Seed Physiology Applications to Agriculture, editado por Benech-Arnold R.L. y Sánchez, R.A., Haworth Press, New York pp. 245-270.

Batlla, D, Benech-Arnold, R. 2005. Predicting changes in dormancy level in weed seed soil banks: Implications for weed management. Crop Protection 26: 189-197

Batlla, D. y Benech-Arnold, R. 2006. The role of fluctuation in soil water content on the regulation of dormancy changes in buried seeds of Polygonum aviculare L. Seed Science Research 16:47-59.

Beal, W.J. 1880. Indian corn. Mich. State Board Agr. Ann. Rpt., 19: 279-289.

Benech-Arnold, R.L., Ghersa, C.M., Sánchez, R.A. y Insausti, P. 1990. A mathematical model to predict Sorghum halepense (L.) Pers. seedling emergence in relation to soil temperature. Weed Research 30: 91-99.

Benech-Arnold, R.L., Giallorenzi, M.C., Frank, J. y Rodriguez, V. 1999. Termination of hull-imposed dormancy in barley is correlated with changes in embryonic ABA content and sensitivity. Seed Science Research 9: 39-47.

Benech-Arnold, R.L., Sánchez, R.A., Forcella, F., Kruk, B.C. y Ghersa, C.M. 2000. Environmental control of dormancy in weed seed banks in soil. Field Crops Research 67:105-122.

Beovide, L. y Campos, S. 2014. Interacciones entre las sociedades y las plantas durante el Holoceno medio y tardío en el área septentrional del Río de La Plata (Uruguay). Revista Española de Antropología Americana 44 (2): 575-601.

Bewley, J. D. 1997. Seed germination and dormancy. Plant Cell 9: 1055-1066. 
Bewley, J. D. y Black, M. 1978. Physiology and Biochemistry of seeds in relation to germination.Vol 1. Editado por Springer-Verlag.Berlin Heidelberg.

Bewley, J.D. y Black, M.1994. Seeds Physiology of Development and Germination. Segunda Edición. Springer Science Business Media, New York.

Bisognin, D. 2002.Origin and evolution of cultivated Cucurbits. Ciencia Rural 35 (5):715723.

Boesewinkel, D. y Bouman, F. 1995. The seed: Structure and function. En Seed Development and germination, editado por Kigel, J, Galili, G. y Marcel Dekker. New York, pp. 1-24.

Bradford, K.J. 2005. Threshold models applied to seed germination ecology. New Phytologist 165: 338-341.

Bruno, M.C. 2005. ¿Domesticado o silvestres? Resultados de la investigación de semillas de Chenopodium chiripa, Bolivia (1500-100 A.C.). Revista Textos Antropológicos 15 (2):39-50. Bruno, M. C. 2006. A morphological approach to documenting the domestication of Chenopodium in the Andes. En Documenting domestication: new genetic and archaeological paradigms, editado por Zeder, M., Emshwiller, E., Bradley, D. y Smith, B., University of California Press, Berkeley, pp. 32-45.

Bruno, M. C. y Whitehead, W. 2003. Chenopodium cultivation and formative period agriculture at Chiripa, Bolivia. Latin American Antiquity 14 (3): 339-355.

Burkart, A. 1974. Flora ilustrada de la provincia de Entre Ríos. Colección Ci. Instituto Nacional de Tecnología Agropecuaria.

Butler, A. 1989. Cryptic anatomical characters as evidence of early cultivation in the grain legumes (pulses). En Foraging and Farming. The evolution of plant explotation, editado por Harris, D. y G. Hillman.Unwin Hyman. London, pp. 390-407.

Butler, A. 2002. Investigations of pod characters in the Vicieae. Vegetation History and Archaeobotany 11: 127-132.

Buxó, R. y Piqué, R. 2008. Arqueobotánica. Los usos de las plantas en la Península Ibérica. Ariel Barcelona.

Cadman, C., Toorop, P., Hilhorst, H., Finch-Savage,W. 2006. Gene expression profiles of Arabidopsis Cvi seeds during dormancy cycling indicate a common underlying dormancy control mechanism. Plant Journal 46: 805-22.

Cantoro, R., Fernandez, L., Rodriguez, V., Gieco, J., Puebla, A., Paniego, N., Heinz, R. y Benech Arnold, R. 2010. Caracterización fenotípica y genotípica de una población de mapeo 
de F2:F3 de Sorghum bicolor para el carácter dormición de semillas. En Actas XXVIII Reunión Argentina de Fisiología Vegetal. La Plata pp. 209.

Capparelli, A. 1997. Reconstrucción ambiental de la instalación arqueológica Inka El Shincal. Tesis Doctoral Inédita. Facultad de Ciencias Naturales y Museo. Universidad Nacional de La Plata.

Capparelli, A., Oliszewski, N. y Pochettino. M.L. 2010. Historia y estado actual de las investigaciones arqueobotánicas en Argentina. Arqueología Argentina en los inicios de un nuevo siglo. En Tomo III Publicación del XIV Congreso Nacional de Arqueología Argentina, compilado por Fernando Oliva, Nélida de Grandis y Jorge Rodriguez pp. 701-715.

Capparelli A., Hilgert N., Ladio A., Lema V., Llano C., Molares S., Pochettino M.L. y Stampella P. 2011. Paisajes culturales de Argentina: pasado y presente desde las perspectivas etnobotánica y paleoetnobotánica. Revista de la Asociación Argentina de Ecología de Paisajes 2(2): 67-79. Volumen Especial IIIJAEP: "Hacia la sustentabilidad ecológica en un planeta que cambia rápidamente.

Cardoso, M.L., Alonso, S.I., Clausen, A.M. y Castaño, J. 2007. Dormición y germinación de semillas de agropiro alargado recientemente cosechadas. Revista Argentina de Producción Animal 27(3): 159-167.

Casal, J.J. y Sánchez, R.A. 1998. Phytochromes and seed germination. Seed Science Research 8: 317-329.

Casas, A. 2001. Silvicultura y domesticación de plantas en Mesoamérica. Plantas, cultura y sociedad. Estudio sobre la relación entre seres humanos y plantas en los albores del siglo $X X I$, editado por Aguilar, B; Domínguez S.; Caballero Nieto J. y Martínez Alfaro M. UAMS.M.A.R.N.yP.- México pp.123-157.

Casas, A y Caballero, J. 1996.Tradicional management and morphological variation in Leucaena esculenta (Moc.et sessé ex A.DC.) Benth. (Leguminosae:Mimosoideae) in the Mixtec región of Guerrero,México. Economic Botany 50:167-181.

Casas, A.; Caballero, J., Valiente Banuet, A.; Soriano, A. y Davilas, P. 1999. Morphological Variation and process of Domestication of Stenocereus stellatus (Cactaceae) in Central Mexico. American Journal of Botany 86(4): 522-533.

Casas, A., Blancas, J., Otero-Arnaiz, A., Cruse- Sanders, J., Lira Saade, R., Avendaño, A., Parra, F., Guillén, S., Figueredo, C., Torres, I. y Rangel-Landa, S. 2016. Evolutionary 
ethnobotanical studies of incipient domestication of plants in Mesoamerica. En Ethnobotany of Mexico, editado por Lira, R., Casas, A. y Blancas, J. Springer, New York, pp. 257-286

Castro,V. y Tarrago, M. 1992. Los inicios de la producción de alimentos en el Cono sur de América. Revista de Arqueología Americana 6:91-124.

Clement, Ch. 1999. 1492 and the loss of Amazonian crop genetic resources.I. The relation between domestication and human population decline. Economic Botany 53:188-202.

Clement, Ch., Denevan, W., Heckenberger, M., Braga Junqueira, A., Neves,E., Teixeira,W. Y Woods, W. 2015.The domestication of Amazonia before European conquest Proc.R.Soc.B 282:20150813.

Colunga-García, P. 1984. Variación morfológica, manejo agrícola y grados de domesticación de Opuntia ssp. en El Bajío guanajuatense. Tesis de Maestría en Ciencias Agrícolas con especialidad en Botánica, Colegio de Posgraduados, Chapingo, Estado de México.

Contardi, D. 1939. Estudios genéticos en Cucurbita y consideraciones agronómicas. Phycis $18: 331-347$.

Contrera Ramirez, P. 2010. Efecto de la alternancia de temperaturas en la germinación de cinco especies de interés forrajero de la pradera anual mediterránea. Memoria para optar al Título Profesional de Ingeniero Agrónomo. Mención Fitotecnia. Chile

Cornejo Maya, C. 2013. Arquitectura precerámica monumental en la costa central: la tradición El Paraíso. Investigaciones sociales 30: 105-129.

Corruccini, R.S.1995. Of ratios and rationality. Am J Phys Anthropol 96:189-191.

Cowan, C.W. 1997. Evolutionary changes associated with the domestication of Cucurbita pepo En: People, plants and landscapes. Studies in Paleoethnobotany, editado por K. Gremillion. University of Alabama Press. pp. 63-85.

Cowan, C.W. y Smith, B.D. 1993. New perspectives on a wild gourd in Eastern North America. Jounal of Ethnobiology 13(1):17-54.

Cutler, H. y Whitaker, T. 1961. History and distribution of the cultivated cucurbits in the Americas. American Antiquity 26(4): 469-485.

Chantre, G. 2010. Ecología del Banco de semillas de Lithospermum arvense L.Modelado de la Dormición y Germinación. Tesis de doctorado en Agronomía. Universidad Nacional del Sur. Bahía Blanca. 
Debeaujon, I. y Koornneef, M. 2000. Gibberellin requirement for Arabidopsis seed germination is determined both by testa characteristics and embryonic abscisic acid. Plant Physiology 122: 415-424.

Decker-Walters, D. y Wilson, H. 1986. Numerical analysis of seed morphology in Cucurbita pepo. Systematic Botany 11 (4): 595-607.

Decker-Walters, D. y Walters, T. 2000. Squash. The Cambridge World History of food Vol.1, editado por K.F. Kiple y K.C. Ornelas. Cambridge University Press.

De la Cuadra, C., 1993. Germinación, latencia y dormición de las semillas. Dormición en las avenas locas N³/28 HD. Ministerio de Agricultura Pesca y Alimentación, Secretaria General de Estructuras Agrarias.

De Wet, J.M. y Harlan, J. 1975. Weeds and domesticates: evolution in the man-made habitat. Economic Botany 29: 99-107.

Dillehay, T., Rossen, J., Andres, T. \& Williams, D. 2007. Preceramic adoption of peanuts, squash and cotton in Northern Peru. Science 316: 1890-1893.

Doebley, J.2004. The genetics of maize evolution. Annua Review of Genetics 38:37-59.

Duarte -Vera, A., Batlla, D., Ghersa, C. y Ferraro, D.2015.Cuando la clave es integrar:

Introducción al desarrollo de grupos de comportamiento de dormición de malezas en cultivos agrícolas. Agronomía y ambiente. Revista de la Facultad de Agronomía 35(2): 153-169.

Ellstrand, N. Prentice, H. y Hancock, J. 1999. Gene Flow and Introgression from Domesticated Plants into Their Wild Relatives. Annual Review of Ecology and Systematics 30: $539-563$.

Essau, K.1976. Anatomía de las plantas con semilla. Tercera edición. Ed. Omega. España. Essau, K.1977.Anatomía Vegetal. Ed. Omega. Barcelona.

FAO. 1991. Guía para la manipulación de semillas forestales 20/2. Editado por Willand,R. DANIDA. www.fao.org [Último acceso]: 24/11/2016.

Fernández, G. y Johnston, M.1986. Fisiología Vegetal Experimental. Libro y Materiales educativos $\mathrm{N}^{\circ}$ 58.IICA.Instituto Interamericano de Cooperación para la agricultura. Costa Rica.

Finch-Savage, W.E. y Leubner-Metzger, G. 2006. Seed dormancy and the control of germination. New Phytologist 171: 501-523.

Finkelstein, R., Reeves, W., Ariizumi, T. y Steber, C. 2008. Molecular aspects of seed dormancy. Annual Review of Plant Biology 59: 387-415. 
Ford,R.1979.Paleoethnobotany in American Archaeology.En Advances in archaeological method and theory. Schiffer (Ed). Academic Press.New York .Vol (2):285-336.

Ford,R.1985. The processes of plant food production in prehistoric north America Anthropological papers 75:1-18.

Fuller, D. 2012. New archaeobotanical information on plant domestication from macro remains: tracking the evolution of domestication syndrome traits. En Biodiversity in agriculture: domestication, evolution, and sustainability, editado por Gepts P, Famula TR, Bettinger RL, Brush SB, Damania AB, McGuire PE, Qualset CO. Cambridge University Press, London. pp. 110-135.

Galussi, A., Argüello, J., Cerana, M., Maximino, M. 2010.Morfofisiología de dormición física de semillas de alfalfa (Medicago sativa L.) cv Baralfa 85. En Actas de la XXVIII Reunión Argentina de Fisiología Vegetal, pp. 212.

Gambier, M. 1977. La cultura Ansilta. Instituto de Investigaciones arqueológicas y Museo. F.F.H y A. U.N.S.J. San Juan.

González, A. R. 1972. Descubrimientos arqueológicos en las Serranías de Las Pirguas, Pcia. de Salta. Revista de la Universidad Nacional de La Plata 24: 388-392.

Grange S., Leskovar D., Pike L., Cobb B. 2003. Seedcoat structure and oxygen.enhanced envirinments affect germination of triploid watermelon J. American Society of Horticultural Sciencie 128 (2): 253-259.

Gremillion, K. 1993. The evolution of seed morphology in domesticated Chenopodium: an archaeological case study. Journal of Ethnobiology 13(21): 149-169.

Griffiths, A., Gelbart, W., Miller, J., Lewontin, R. 2000. Genética Moderna, editado por Mc Graw Hill.

Gros-Balthazard, M., Newton, C., Ivorra, S., Pierre, M., Pintaud, J. y Terral, J. F. 2016. The Domestication Syndrome in Phoenix dactylifera Seeds: Toward the Identification of Wild Date Palm Populations. http://journals.plos.org/plosone/article? id=10.1371/journal.pone.0152394.

Guillén, F. 2010. El proceso de domesticación en las plantas. Revista Casa del Tiempo.UAM. 3 EPOCA 4 (28): 66-70.

Hallam, S.J. 1989. Plant usage and management in southwest Australian aboriginal societies. En Foraging and Farming, the evolution of plant explotation, editado por D. Harris y G. Hillman. Unwin Hyman, London. 
Harlan, J. 1992. Crops and man. 2da Ed American Society of Agronomy.

Harlan, J.R., y Martini, M.L.1937. Problems and results in barley breeding. Washington:

USDA. pp. 303-306.

Hart, J. 2004. Can Cucurbita pepo gourd seeds be made edible? Journal Archaeology Science 31: 1631-1633.

Hass, J. y Creamer, W. 2006. Crucible of Andean civilization. The peruvian coast from 3000 to 1800 BC. Current Anthropology 47(5): 745-775.

Hayward, H. 1953. Estructura de las plantas útiles. ACME. Buenos Aires.

Heeden, P y Phillips, A.2000.Gibberellin metabolism: new insights revealed by the genes. Trends in plant science.523-530.

Hernandez-Leal, E., Lobato-Ortiz, R., Garcia-Zavala, J., Reyes-López D., Mendez-López, A., Bonilla-Barrientos, O. y Hernandez-Bautista, A. 2013.Comportamiento agronómico de poblaciones F2 de híbridos de tomate (Solanum lycopersicum L.).

Hilhorst, H.W.K. 1995. A critical update on seed dormancy I. Primary dormancy. Seed Science Research 5: 61-73.

Hilhorst, H. W. M. 2007. Definitions and hypotheses of seed dormancy. En Seed Development, Dormancy and Germination, editado por Bradford KJ, Nonogaki y H.Oxford. Blackwell, pp. 50-71.

Hilhorst, H.W.M., Finch-Savage, W.E., Buitink, J., Bolingue, W. y Leubner-Metzger, G. 2010. Dormancy in Plant Seeds. En Dormancy and resistance in harsh environments. Topics in Current Genetics 21, editado por Lubzens, E., Cerda, J., Clark, M. Springer-Verlag. Berlin. Alemania pp. 43-68.

Hillman, G y Davies, M. 1990. Measured domestication rates in wild wheats and barley under primitive cultivation, and their archaeological implications. Journal of World Prehistory 4 (2): 157-222.

Hillman, G., Wales, S., Mc Laren, F., Evans, J., Butler, A. 1993. Identifying problematic remains of ancient plant foods: a comparison of the role of chemical, historical and morphological criteria. Wold Archaeology 25(1):94-121.

Hocsman, S. 2006.Producción lítica, variabilidad y cambio en Antofagasta de la Sierra ca.5500-1500 AP. Tesis doctoral inédita. Facultad de Ciencias Naturales, Universidad Nacional de La Plata. 
Holdsworth, M., Bentsink, L. y Soppe, W.2008. Molecular networks regulating Arabidopsis seed maturation,after-ripening,dormancy and germination. Tansley review. pp 33-54.

Huarte, H. 2013. Mecanismos fisiológicos y moleculares involucrados en la terminación de la dormición de semillas expuestas a las temperaturas alternadas. Tesis doctoral. Facultad de Ciencias Agrarias. UBA.

Hufford, M., Xu, X., Van Heerwaarden. J., Pyhäjärvi, T., Chia, J., Cartwright, R., Elshire, R., 2012. Comparative population genomics of maize domestication and improvement. Nature Genetics 44(7): 808-118.

Iriarte, J., Holst, I., López, J. y Cabrera, L. 2001. Subtropical wetland adaptations in Uruguay during the mid-Holocene: an archaeobotanical perspective. En Enduring Records: the Environmental and Cultural Heritage of Wetlands, editado por B. Purdy, Oxbow Books, Oxford. Holoceno medio-tardío en el área septentrional del Río de la Plata. Uruguay pp. 6170 .

Jeffrey, C. 1980. A review of the Cucurbitaceae. Botanical Journal of the Linnean society 81: 233-247.

Jones, G. 1992. Weed phytosociology and crop husbundry: identifying a contrast between ancient and modern practice. Review of Palaeobotany and Palynology 73:133-43.

Jones, M. 2009. Dormancy and the plough: Weed seed biology as an indicator of agrarian change in the first millenium AD. En From Forages to Farmers. Paper in Honour of Gordon Hillman, editado por Fairbairn, A. y Weiss, E.. USA pp. 58-63.

Jordán, M. y Casaretto, J. 2006. Hormonas y Reguladores del Crecimiento: Etileno, Ácido Abscísico,Brasinoesteroides, Poliaminas, Ácido Salicílico y Ácido Jasmónico. En Fisiología Vegetal, editado por Squeo y Cardemil. Ediciones Universidad de La Serena, La Serena. Chile pp. 1-28.

Jungers, W.L., Falsetti, A. y Wall, C.E. 1995. Shape, relative size and size-adjustments in morphometrics. American Journal of Physical Anthropology 38:137-161.

Karsen, C., Brinkhorst-van der Swan, D., Breekland, A. y Koorneef, M. 1983. Induction of dormancy during seed development by endogenous absicic acid: studies on absicic aciddeficient genotypes of Arabidopsis thaliana (L.) Hynh. Planta 157: 158-165.

Kay, S; King, A, y Robinson, M. 1980. Study of archaeobotanical seeds. American Antiquity 35:26-39. 
Killian, S. 2012. Técnicas de germinación de Prosopis chilensis Moll Stuntz. Biología en agronomía (2) 2: 97-107.

Kistler, L.; Newsom, L.; Ryan, T; Clarke, A; Smith, B. y Perry, G. 2015. Gourds and squashes (Cucurbita spp.) adapted to megafaunal extinction and ecological anachronism through domestication. Proceedings of the National Academy of Sciences 112(49): 1510715112.

Korstanje, M. y Würschmidt, A.1999. Producir y recolectar en los valles altos del NOA: Los Viscos como caso de estudio. En los tres reinos: prácticas de recolección en el cono sur de América. Instituto de Arqueología y Museo FCN e IML-UNT, pp:151-160.

Korstanje, M. y Quesada, M. 2010. Arqueología de la agricultura. Casos de estudio en la región andina argentina. Tucumán: Magna.

Kruk, B., Insausti, P., Razul, A. y Benech-Arnold, R. 2006. Light and thermal environments as modified by a wheat crop: effects on weed seed germination. Journal of Applied Ecology 43: $227-236$.

Kucera, B., Cohn, M., y Leubner-Metzger, G. 2005. Plant hormone interactions during seed dormancy release and germination. Seed Science Research 15: 281-307. DOI: 10.1079/SSR2005218.

Lagiglia, H. 1980. El proceso de agriculturización del Sur de Cuyo. La cultura del Atuel II. En Actas del V Congreso Nacional de Arqueología Argentina I, pp. 231-252.

Lagiglia, H. 2001. Los orígenes de la agricultura en la Argentina. En Historia Argentina Prehispánica, editado por Berberián, E. y Nielsen, A. Editorial Brujas. Córdoba. Tomo I, pp. 41-81.

Lema, V. 2008. De qué hablamos cuando hablamos de domesticación vegetal en el NOA? Revisión de antiguas propuestas bajo nuevas perspectivas teóricas. En Arqueobotánica y Teoría Arqueológica. Discusiones desde Suramérica, compilado por Archila, M. Giovannetti y V. Lema. UNIANDESCESO. Bogotá pp.97-126.

Lema V, 2009a. Domesticación vegetal y grados de dependencia ser humano-planta en el desarrollo cultural prehispánico del noroeste argentino. Tesis doctoral inédita. Facultad de Ciencias Naturales y Museo, UNLP.

Lema, V. 2009b. Criterios de selección en los procesos de manipulación vegetal: el potencial de la información etnobotánica en la interpretación de restos arqueobotánicos de Cucurbita sp. Darwiniana 47 (1): 35-55. 
Lema, V. 2010. Procesos de domesticación vegetal en el pasado prehispánico del Noroeste argentino: estudio de las prácticas más allá de los orígenes. Relaciones de la Sociedad Argentina de Antropología 32: 121-142.

Lema, V. 2011. Lo micro en lo macro: el tratamiento microscópico de macrorrestos vegetales para la identificación de prácticas y modos de relación con el entorno vegetal en el estudio arqueológico de la domesticación vegetal. Arqueología 17: 57-79.

Lema, V. 2012. Nuevas ideas sobre la domesticación ¿nuevas ideas sobre el Formativo? aportes para una relectura crítica. En Precirculados del Taller Arqueología del periodo Formativo en Argentina: un encuentro para integrar áreas y sub-disciplinas, revisar significados y potenciar el impacto de las investigaciones en curso, Tafí del Valle, Tucumán, abril de 2012. Inédito.

Lema, V. 2014. Boceto para un esquema: domesticación y agricultura temprana en el Noroeste argentino. Revista española de antropología americana 44 (2): 465-494.

Lema, V. 2015 Al toro ¿por las astas? Reflexiones sobre aproximaciones teóricas y metodológicas a la temática de la domesticación en el Área Andina Meridional. En Domesticación y Agricultura en el Nuevo Mundo: historias y perspectivas del manejo de recursos genéticos, editado por Alejandro Casas Fernández, Juan Torres Guevara y Fabiola Parra Rondinel. Universidad Nacional Agraria la Molina, Universidad Nacional Autónoma de México. En prensa.

Lema, V., Capparelli, A., Pochettino, M. L. 2008. Taxonomic identification of Cucurbita species through seed coat micromorphology: implications for dry and carbonized archaeobotanical remains. Vegetation History and archaeobotany 17: 277-286.

Lema, V., Capparelli, A. y Martínez, A. 2012. Las vías del algarrobo: Antiguas preparaciones culinarias en el Noroeste Argentino. Jornadas de la Alimentación, Córdoba. En Las manos en la masa. Arqueologías y antropologías de la alimentación en Suramérica, editado por Babot, M. P., Pazzarelli, F. y Marschoff, M. Córdoba pp. 639-665.

León J. 1968. Botanica de los cultivos tropicales. Instituto Interamericano de cooperación para la agricultura. San José. Costa Rica.

Lira Saade, R. 1995. Estudios taxonómicos y ecogeográficos de las Cucurbitaceae latinoamericanas de importancia económica. Instituto de Biología, UNAM, México. 
Lira Saade, R., Eguiarte, F.,Montes Hernandez,S.2009. Proyecto Recopilación y análisis de la información existente de las especies de los géneros Cucurbita y Sechium que crecen y /o se cultivan en México.

Lira Saade, R., Eguiarte, L., Montes, S., Zizumbo-Villarreal, D., Colunga-García Marín, P. y Quesada, M. 2016. Homo sapiens-Cucurbita interaction in Mesoamerica: domestication, dissemination and diversification. En Ethnobotany of Mexico, editado por Lira, R., Casas, A., Blancas, J. Springer, New York pp. 389-402.

Loy, B. 2012. Breeding Squash and Pumpkin. En Genetics, Genomics and Breeding of Cucurbits, editado por Yi-Hong Wang, TK Behera, C Kole. CRC Press. St. Helier, Jersey Enfield, N.H., Boca Raton, FL. pp. 93-139.

Maloberti, M. y Zapatiel, J. 2003.Cucurbitacea. Informe para la cátedra Práctica de campo IV.U.N.C. Inédito.

Mangafa, M. y Kotsakis, K. 1996. A new method for the identification of wild and cultivated charred grape seeds. Journal of archaeological science 23: 409-418.

Mapes, C. y Basurto, F. Biodiversity and edible plants. En Etnobotany of México: Interactions of people and plants in Mesoamerica, editado por Lira Saade, R., Casas, A., Blancas, J. Springer. New York.

Martínez, A., Lema, V., Perez, S. y López Anido F. 2016. Pedúnculos y pericarpios de Cucurbita maxima Duch.: Un aporte para la reconstrucción del proceso de domesticación del zapallo criollo en el Noroeste Argentino. Enviado julio de 2016 a Revista de Etnobiología México.

Martínez Croveto, R. Cucurbitaceae.1974. En Flora ilustrada de la provincia de Entre Ríos, editado por A. Burkart. Colección Científica Instituto Nacional de Tecnología Agropecuaria 4:63-94.

Matilla, A. 2000. Germinación y dormición de las semillas. En Fundamentos de Fisiología vegetal, editado por Azcon Bieto, J. y Talón, M. Mc Graw-Hill-Interamericana pp. 435-449 Matsuoka Y, Vigouroux Y, Goodman M, Sanchez J, Buckler E, Doebley J (2002) A single domestication for maize shown by multilocus microsatellite genotyping. PNAS 99(9): 60806084 .

Millán, R. 1945. Variaciones del zapallito amargo Cucurbita andreana y el origen de Cucurbita máxima. Revista Argentina de Agronomía 12: 86-93. 
Millán, R. 1968. Observaciones sobre cinco Cucurbitáceas cultivadas o indígenas en la Argentina. Darwiniana 14: 664-660.

Montechiarini, N., Gosparini, C., Morandi, E. 2010. Rol del tegumento en la germinación de semillas inmaduras de soja. En Actas de la XXVIII Reunión Argentina de Fisiología Vegetal pp. 196.

Montes- Hernández, S. y Eguiarte, L. 2002. Genetic structure and indirect estimates of gene flow in three taxa of Cucurbita (Cucurbitaceae) in Western Mexico American. Journal of Botany 89(7): 1156-1163.

Murray, D. 1984. Seed physiology I. Academic Press., Sydney.

Nambara, E., Okamoto, M., Tatematsu, K., Yano, R., Seo, M. y Kamiya, Y. 2010. Abscisic acid and the control of seed dormancy and germination. Seed Science Research 20: 55-67.

Nee, M. 1990.The domestication of Cucurbita (Cucurbitaceae). En Economic Botany 44 (3) Supplement: New perspectives on the origin and evolution of New World Domesticated plants, editado por Bretting 56-68.

Newsom, L. A., Webb, S.D., y Dunbar, J.S. 1993. History and geographic distribution of Cucurbita pepo gourds in Florida. Journal of Ethnobiology 13(1): 75-98.

Nuñez Regueiro, V. 1974.Conceptos instrumentales y marco teórico en relación al análisis del desarrollo cultural del noroeste Argentino. Revista del Instituto de Antropología 5:169190.

Oliszeswski, N., Martínez, J y Caria, M. 2008 Ocupaciones prehispánicas de altura: el caso de Cueva de Los Corrales 1 (El Infiernillo, Tafí del Valle, Tucumán). Relaciones de la Sociedad Argentina de Antropología XXXIII: 209-221.

Ots, M. J, Oliszewski, N. y García Llorca, J. 2011.Estrategias alimentarias y de subsistencia prehispánica en el Centro-Oeste de Mendoza: consumo y descarte en el sitio arqueológico Agua Amarga. Revista del Museo de Antropología 4: 65-80.

Parodi, L. 1938. El proceso biológico de la domesticación vegetal. Revista Argentina de Agronomía 5(1):1-24.

Parodi, L. 1988. Enciclopedia Argentina de Agricultura y Jardinería. Tomo I. Vol II. Descripción de Plantas Cultivadas. ACME pp. 1011-1017.

Pastor, S. y Gil, A. 2014. Dossier Procesos de domesticación y dispersión de la agricultura en el sur de Sudamérica. Revista Española de Antropología Americana 44(2): 453-464.

Pearsall, D. 1989. Paleoethnobotany, a handbook of procedures. Academic Press. 
Peng, L., Wengge, L., Shengjie, Z., Zhihong, Y., Nan, H., Xuqiang, L. 2010. Comparison of seed coat structure between different ploidy watermelons Journal of Changjiang Vegetable (13): $22-31$.

Pickersgill, B. 2007. Domestication of plants in the Americas: insights from Mendelian and molecular genetics. Annals of Botany 100: 925-940.

Piperno, D. y Pearsall, D.1998. The origins of agriculture in lowland tropics Academic Press, San Diego.

Piperno, D.R. 2008. Identifying crop plants with phytolits (and starch grains) in Central and South America: a review and an update of the evidence. Quaternary International DOI: 10.1016/j. quaint. 2007.11.011.

Piperno, D., Andres, T., Stothert, K. 2000. Phytolits in Cucurbita and others Neotropical Cucurbitaceae and their occurrence in early archaeological sites from the lowland American tropics. Journal of archaeological science 27:193-208.

Piperno, D., Holst, I., Wessel Beaver, L., Andres, T. 2002. Evidence for the control of phytolith formation in Cucurbita fruits by the hard rind (Hr) genetic locus: archaeological and ecological implications. Proceeding of the National Academy of Science (USA) 99: 10923-10928.

Piperno, D. y Stothert, K. 2008. Phytolith evidence for early Holocene Cucurbita domestication in Southwest Ecuador. Science 299:1054-1057.

Pochettino, M.L. 1985. Disemínulos utilizados por los aborígenes del noroeste de la República Argentina. Tesis para optar al grado de Doctor en Ciencias Naturales. FCNyM. Universidad Nacional de La Plata. Buenos Aires, Argentina. Inédito.

Pochettino, M.L. y Scattolin, M. 1991. Identificación y significado de frutos y semillas carbonizados de sitios arqueológicos formativos de la ladera occidental del Aconquija (Catamarca, Argentina). Revista del Museo de La Plata, Antropología 71: 169-177.

Pochetino, M. L., Cortella, A., Capparelli, A. 1998. Identificación de macrorrrestos vegetales: el microscopio, un aliado indispensable Revista del Museo de Historia Natural de San Rafael. En Actas y memorias del XI C.N.A.A Revista del Museo de Historia Natural de San Rafael: 19-32.

Pochettino, M.L. y Cortella, A.1999. Hallucinogenic snuff from Northwestern Argentina: Microscopical Identification of Anadenanthera colubrina var. cebil (Fabaceae) in Powered Archaeological material. Economic Botany 53(2):127-132. 
Pozner, R. Cucurbitaceae Flora del Valle de Lerma.2012.Aportes Botánicos de Salta-Ser Flora.Herbario MCNS.Facultad de Ciencias Naturales.Universidad Nacional de Salta.Vol 9 (8).

Puricelli, E., Orioli, G., Sabbatini, M. 2005. Efecto de la temperatura sobre la germinación de Anoda cristata. Revista de Investigaciones de la Facultad de Ciencias Agrarias 7 25-31.

Ratto, N., Feely, A. y Basile, M. 2007. Coexistencia De Diseños Tecno-Estilísticos En El Período Tardío Preincaico: El Caso del Entierro en Urna del Bebé de La Troya (Tinogasta, Catamarca, Argentina). Intersecciones en Antropología 8: 69-86.

Ratto, N., Rodríguez M.F. y Hershey, D. 2010. Explotación y uso de recursos vegetales en sitios arqueológicos del área cordillerana y del valle mesotérmico (Depto. Tinogasta, Catamarca, Argentina). En Actas del XVII Congreso Nacional de Arqueología Chilena, pp. 1267-1278.

Ratto, N., Lema V.S. y López, M.L. 2014. Entierros y ofrendas: prácticas mortuorias, agrícolas y culinarias en los siglos XIII y XIV en Tinogasta (Catamarca, Argentina). Darwiniana 2(1): 125-143.

Rivolta, M.C. y Rodríguez, J. 2012. La problemática de la temporalidad y perduración del Formativo en sitios del valle Calchaquí norte a partir de la alfarería doméstica y funeraria. En precirculados del simposio-taller arqueología del período Formativo en Argentina: un encuentro para integrar áreas y subdisciplinas, revisar significados y potenciar el impacto de las investigaciones en curso, Instituto de Arqueología Museo, UNT, organizado por Korstanje, A. y Lazzari, M. Tucumán pp. 11-13

Roberts, E. y Ellis, R. 1988. Water and seed survival. Annals of Botany: 39-51.

Rodríguez, M.F. 1999. Arqueobotánica de Quebrada Seca 3 (Puna meridional Argentina): especies vegetales utilizadas en la conferencia de artefactos durante el arcaico. Relaciones de la Sociedad Argentina de Antropología 24: 159-186.

Rodríguez Morales, J., Guillén Rodríguez, S., Casas, A. 2013. Consecuencias de la domesticación de Stenocereus stellatus en el tamaño de las semillas y en la germinación en un gradiente de estrés hídrico. Botanical Sciense.Vol 91 (4).

Sanjur, O., Piperno, D., Andres, T. y Sel-Beaver, L. 2002. Phylogenetic relationships among domesticated and wild species of Cucurbita (Cucurbitaceae) inferred from a mitochondrial gene: Implications for crop plant evolution and areas of origin. PNAS 99: 535-540. 
Schaefer, H. y Renner, S.S. 2011. Cucurbitaceae. Families and Genera of Vascular Plants vol. 10, editado por K. Kubitzki. Springer Verlag, Berlin pp. 112-174.

Singh, D. y Dathan, A. 1972. Structure and development of seed coat in cucurbitaceace IV.Seeds o Cucurbita. Phytomorphology 22 (1):29-45

Smith, B. 1985. The role of Chenopodium as a domesticate in pre-maize garden systems of Eastern United Stated. Southeastern archaeology 41 (1):51-72.

Smith, B. 1997. The initial domestication of Cucurbita pepo in the Americas 10.000 years ago. Science 276: 865-996.

Smith, B. 2000. Guila Naquitz .Revisited. Agricultural origins in Oaxaca, México. En Cultural evolution: contemporary viewpoints, editado por Feinman G. y Manzanilla L. Kluwer Academic/Plenum Publishers New York, Cap. 2, pp.:15-60.

Smith, B. 2006a. Documenting domestication in plants in the archaeological record. En Documenting domestication: new genetic and archaeological paradigms, editado por Zeder M., Emshwiller E., Bradley D, Smith B. University of California Press. Berkeley.pp 15-24 Smith, B. 2006b. Seed size increase as a marker of plant domestication in Squash. En Documenting domestication: new genetic and archaeological paradigms, editado por Zeder, M., Emshwiller, E., Bradley, D., Smith, B. University of California Press, Berkeley.pp 2531.

Srb, A., Owen, R., Edgar, R.1971.2007.Genética general. Ed Omega S.A

Staller, J. 2006. Etnobotanic, Interdisciplinary and Multidisciplinary Methodologies. In Maize cobs and cultures: History of Zea Mays L.

Stothert, K., Piperno, D. y Andres, T. 2003. Terminal Pleistocene/Early Holocene human adaptation in coastal Ecuador: the Las Vegas evidence. Quaternary International 109-110: 23-43.

Tapia, A.M., Romero, A., Luque, V., Gervasoni, P., Allolio, P. y Gómez, I. 2013. Ruptura de dormición en semillas de Acacia caven aplicando diferentes métodos de escarificación Biología en Agronomía 3(2): 48-54.

Tarrago, M. 1980. El proceso de agriculturización en el noroeste argentino, zona valliserrana. En Actas del V Congreso Nacional de Arqueología Argentina, Tomo I. Universidad Nacional de San Juan, San Juan pp. 181-217.

Teppner, H. 2004. Notes on Lagenaria and Cucurbita (Cucurbitaceae). Review and new contributions. Phyton 44 (2):245-308. 
Vega-Centeno Sara Lafosse, R. 2005. Ritual and architecture in a context a emergent complexity: A perspective from Cerro Lampaya late archaic site in the Central Andes. Disertación enviada al departamento de antropología para optar al grado de Doctor en Filosofía. Universidad de Arizona.

Vibrans, H. 2016. Ethnobotany of Mexican weeds. En Ethnobotany of Mexico, editado por Lira Saade, R., Casas, A. y Blancas, J. Springer, New York pp. 287-318.

Vigliocco, A., Andrade, A., Kovasevich, N., Alemano, S., Alvarez, D. y Abdala, G. 2010. Hormonas involucradas en la dormición de semillas de dos líneas endocriadas de girasol (Helianthus annuus L). En Actas de la XXVIII Reunión Argentina de Fisiología Vegetal pp. 183.

Villagran, C. y Castro, V. 2003.Ciencia indígena de los Andes del Norte de Santiago de Chile. Edición Universitaria S.A.

Wang, M., Heimovaara-Dijkstra, S. y Van Duijn, B. 1995. Modulation of germination of embryos isolated from dormant and nondormant barley grains by manipulation of endogenous abscisic acid. Planta. 195:586-592.

Wasylikowa, K.y van der Veen, M. 2004. An archaeobotanical contribution to the history of watermelon, Citrullus lanatus (Thunb.) Matsum. \& Nakai (syn. C. vulgaris Schrad.) Vegetation History and Archaeobotany 13:213-217.

Whitaker, T. 1974. Cucurbitales Enciclopedia británica 15². Ed. Helen Hemingway Benton Publisher U.S.A.

Whitaker, T. 1983. Cucurbits in Andean prehistory. American Antiquity 48(3): 576-585.

Whitaker, T. y Bemis,W.1964. Evolution in the genus Cucurbita. Evolution 18 (4):553-559.

Whitaker, T. W. Manuscrito sin fecha. Cucurbitaceae Pampa Grande. Inédito.

Whitaker, T. y Cutler, H. 1968. A new species of Cucurbita from Ecuador. Annals of the Missouri Botanical Garden 55 (3):392-396.

White, C. N., Proebsting, W. M., Hedden, P. y Rivin, C. J. 2000. Gibberellins and seed development in Maize. L. Evidence that gibberellins/abscisic acid balance governs germination versus maturation pathways. Plant Physiology 122:1081-1088.

Willcox, G.1999. Archaeobotanical Significance of Growing Near Eastern Progenitors of Domestic Plants at Jalés, France. En Prehistory of Agriculture. New Experimental and Ethnographic Approaches, editado por Anderson pp.118-144. 
Wilson, H., Lira Saade, R., y Rodríguez, I. 1994. Cop/weed gene flow: Cucurbita argyrosperma Hubelt and C. fraterna L. H. Bailey (Cucurbitaceae). Economic Botany 8(3): 293-300.

Winton, A. y Winton, K. 1935. The structure and composition of foods. Vegetable, legumes, fruits. Vol II. pp. 429-459.

Würschmidt, A. 2003. Evidencias prehispánicas de Cucurbitaceas en un sitio arqueológico de la provincia de Jujuy (Argentina). Relaciones de la Sociedad Argentina de Antropología 28: $253-255$.

Yacobaccio, H. y Korstanje, M. 2007. Los procesos de domesticación vegetal y animal. Un aporte a la discusión Argentina en los últimos 70 años. Relaciones de la Sociedad Argentina de Antropología 32: 191-215.

Zizumbo-Villarreal, D., Colunga- García Marín, Payró de la Cruz, E., Delgado-Valerio, P. y P., Gepts. 2005. Population Structure and Evolutionary Dynamics of Wild-Weedy Domesticated Complexes of Common Bean in a Mesoamerican Region. Crop Science 45:1073-1083.

www.Agrobanco.com.pe.UNLM/AGROBANCO, 2014. Mejoramiento Genetico y Biotecnologico de Plantas. 


\section{ANEXO}

$\underline{\text { Tablas correspondientes a los análisis estadísticos utilizados. Software estadístico } \mathbf{R}}$

\section{$\underline{\text { 3.3.0 (R-Development Core Team,2016) }}$}

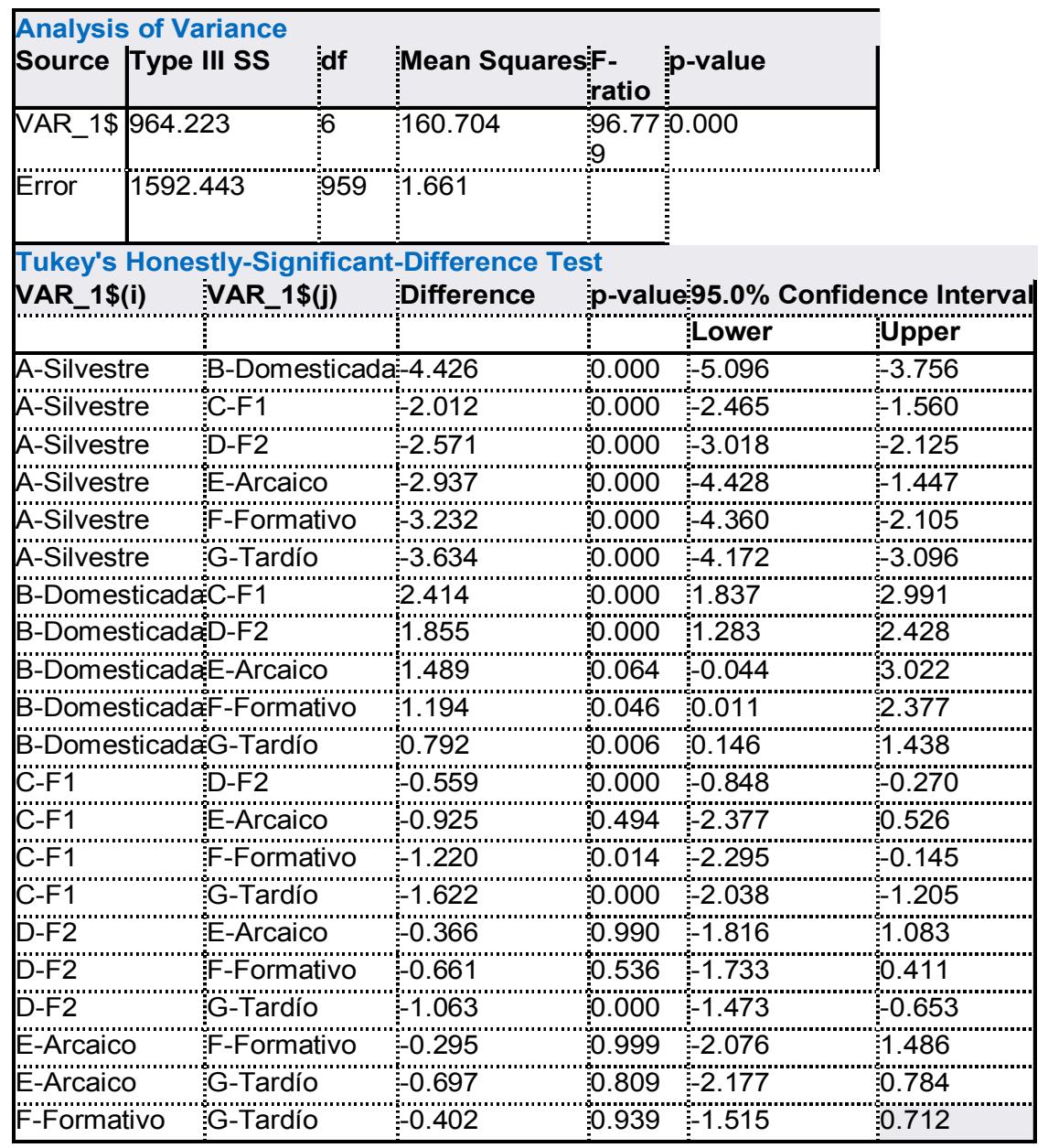

GURA 1: análisis de la varianza y Tukey entre formas silvestres, domesticadas, F1 y F2 para morfología de semillas. 
Component Loadings

123

LARGO $3.555-0.2630 .054$

ANCHO $2.0600 .417 \quad 0.091$

ALTO $1.087 \quad 0.068-0.350$

FIGURA 2: valores del análisis de CP para el largo, ancho y alto de semillas.

\begin{tabular}{|c|c|c|c|}
\hline $\begin{array}{l}\text { Tukey's Hone } \\
\text { Referencia }\end{array}$ & $\begin{array}{c}\text { stly-Significan } \\
\text { Referencia }\end{array}$ & $\begin{array}{l}\text { Difference Test } \\
\text { Diferencia }\end{array}$ & $\begin{array}{c}\mathrm{F}=19.71 \mathrm{Df}(4) \\
\text { p-value }\end{array}$ \\
\hline Silvestre & Domesticada & $-17,457^{\prime}$ & 0.000 \\
\hline Silvestre & F1 & $-7,188^{\prime}$ & 0.002 \\
\hline Silvestre & F2 & $-5,349^{\prime}$ & 0.013 \\
\hline Silvestre & Arqueológica & $-8,187^{\prime}$ & 0.004 \\
\hline Domesticada & F1 & $10,269^{\prime}$ & 0.000 \\
\hline Domesticada & $\mathrm{F} 2$ & $12,108^{\prime}$ & 0.000 \\
\hline Domesticada & Arqueológica & $9,270^{\prime}$ & 0.001 \\
\hline F1 & $\mathrm{F} 2$ & $1,839^{\prime}$ & 0.759 \\
\hline F1 & Arqueológica & $-0.999^{\prime}$ & 0.991 \\
\hline $\mathrm{F} 2$ & Arqueológica & $-2,838^{\prime}$ & 0.630 \\
\hline
\end{tabular}

FIGURA 3: análisis a Posteriori (Tukey) de Pedúnculos: Grupos silvestre, domesticados, F1 y F2

\begin{tabular}{|c|c|c|c|}
\hline \multicolumn{3}{|c|}{ Tukey's Honestly-Significant-Difference Test } & \multirow{2}{*}{$\begin{array}{c}\mathrm{F}=19.153 \mathrm{Df}(3) \\
\text { p-value }\end{array}$} \\
\hline Referencia & Referencia & Diferencia & \\
\hline Silvestre & Domesticada & $1,075^{\prime}$ & 0.131 \\
\hline Silvestre & $\mathrm{F} 2$ & $0.402^{\top}$ & 0.757 \\
\hline Silvestre & Arqueológicas & $-1,312^{\top}$ & 0.002 \\
\hline Domesticada & $\mathrm{F} 2$ & $-0.673^{\top}$ & 0.438 \\
\hline Domesticada & Arqueológicas & $-2,387^{\prime}$ & 0.000 \\
\hline $\mathrm{F} 2$ & Arqueológicas & $-1,714^{\prime}$ & 0.000 \\
\hline
\end{tabular}

FIGURA 4: análisis a Posteriori (Tukey) de Pericarpios: Grupos silvestre, domesticado y F2. 


\begin{tabular}{|c|c|c|c|c|c|}
\hline & 1 & 2 & 3 & 4 & 5 \\
\hline Alto AER & 0.837 & 0.245 & 0.313 & 0.054 & 0.009 \\
\hline D̈iam C AER (ALTO) & 0.376 & 0.233 & 0.718 & 0.049 & 0.494 \\
\hline Diam C AER (ANCHO) & 0.321 & 0.226 & 0.772 & 0.186 & 0.435 \\
\hline Älto HIP & 0.869 & 0.178 & 0.148 & 0.070 & $=0.268$ \\
\hline Diam C HIP & 0.721 & 0.144 & 0.095 & 0.352 & 0.087 \\
\hline Alito SCL & 0.348 & 0.646 & 0.374 & 0.472 & 0.184 \\
\hline Ancho SCL & -0.176 & 0.821 & 0.159 & $=0.424$ & 0.086 \\
\hline A'lto EPI" & -0.296 & 0.147 & 0.083 & 0.421 & 0.075 \\
\hline Ancho EPI & 0.033 & 0.786 & 0.061 & 0.190 & 0.026 \\
\hline
\end{tabular}

\begin{tabular}{|c|c|c|c|c|}
\hline & 6 & 7 & 8 & 9 \\
\hline Alto AER & 0.261 & 0.324 & 0.172 & 0.222 \\
\hline Diam C AER (ALTO) & 0.165 & 0.109 & 0.034 & -0.048 \\
\hline Diam C AER (ANCHO) & -0.102 & 0.013 & 0.076 & 0.102 \\
\hline Âlto HIP & 0.252 & 0.006 & 0.009 & -0.225 \\
\hline Diam C HIP & -0.555 & 0.095 & 0.037 & $=0.016$ \\
\hline Alto SCL & -0.058 & $=0.068$ & 0.235 & 0.035 \\
\hline Ancho SCL & -0.051 & 0.097 & 0.264 & -0.003 \\
\hline Alito EPI & 0.119 & 0.043 & 0.020 & 0.017 \\
\hline Ancho EPI & 0.109 & 0.344 & 0.045 & 0.069 \\
\hline
\end{tabular}

FIGURA 5: variables utilizadas para el análisis de Componentes Principales de los GF.
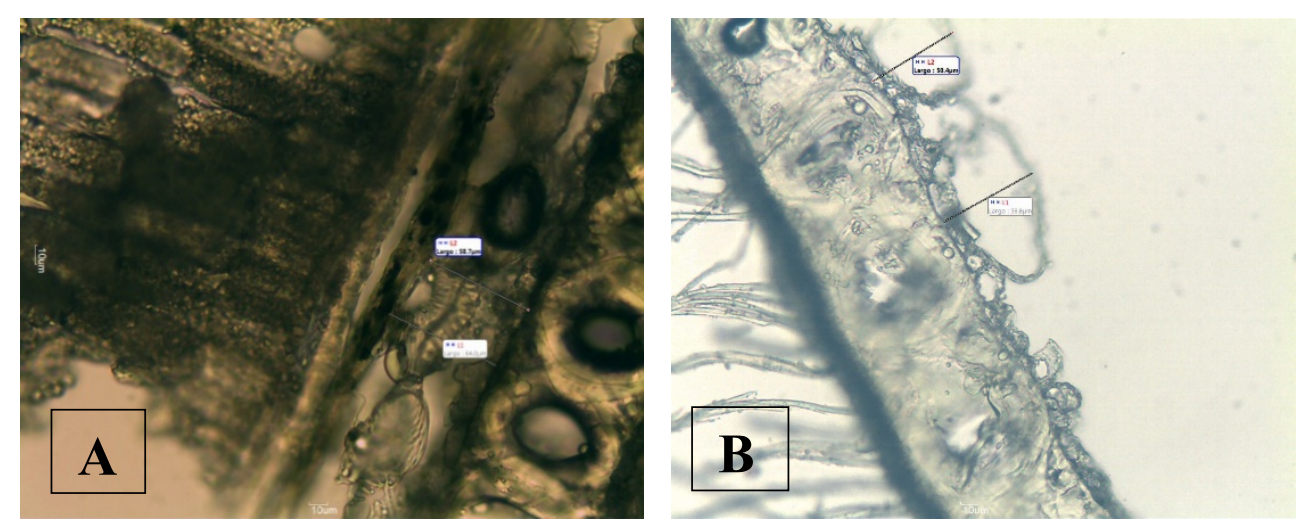

FIGURA 6: corte transversal de las accesiones A) 93, B) 140 que muestran las células globosas aerenquimáticas que constituyen a ese tejido a partir de la segunda capa de células. 200x. Escala: reglilla en A $10 \mu \mathrm{m}$. 

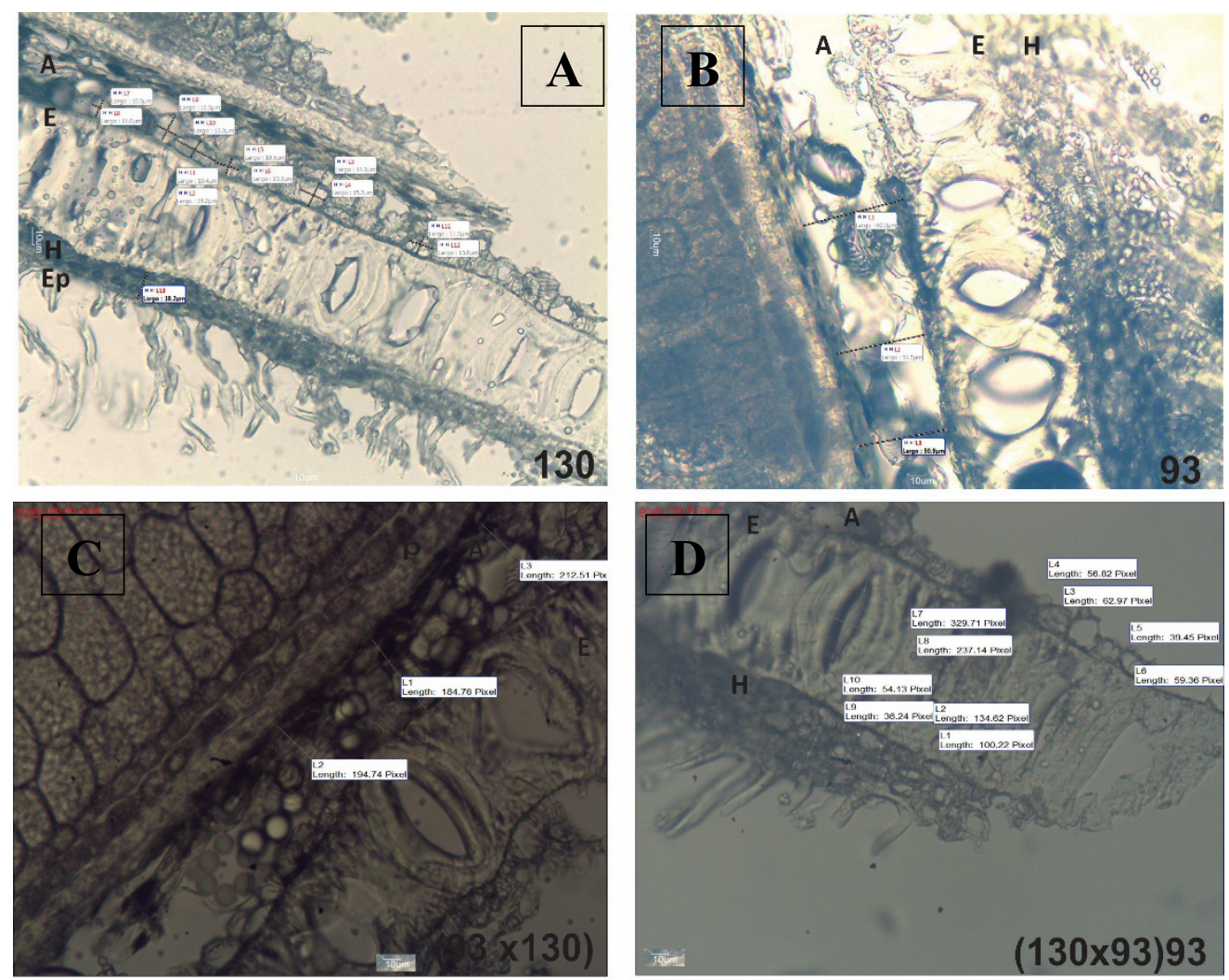

FIGURA 7: algunos de los cortes transversales realizados en las semillas. Medición de los tejidos que componen la cubierta seminal (ver Fig. 12). A (Genotipo 130), B (Genotipo 93), C (Genotipo 93x130),D (Genotipo 130x93)93. 200x. Escala: $10 \mu \mathrm{m}$. 